\title{
Interactions between teachers and students in four co -taught, inclusive, middle school classrooms
}

\author{
Nancy G. Burton \\ West Virginia University
}

Follow this and additional works at: https://researchrepository.wvu.edu/etd

\section{Recommended Citation}

Burton, Nancy G., "Interactions between teachers and students in four co -taught, inclusive, middle school classrooms" (2008). Graduate Theses, Dissertations, and Problem Reports. 2858.

https://researchrepository.wvu.edu/etd/2858

This Dissertation is protected by copyright and/or related rights. It has been brought to you by the The Research Repository @ WVU with permission from the rights-holder(s). You are free to use this Dissertation in any way that is permitted by the copyright and related rights legislation that applies to your use. For other uses you must obtain permission from the rights-holder(s) directly, unless additional rights are indicated by a Creative Commons license in the record and/ or on the work itself. This Dissertation has been accepted for inclusion in WVU Graduate Theses, Dissertations, and Problem Reports collection by an authorized administrator of The Research Repository @ WVU.

For more information, please contact researchrepository@mail.wvu.edu. 
Interactions Between Teachers and Students in Four Co-Taught, Inclusive, Middle School Classrooms

Nancy G. Burton

\author{
Dissertation submitted to the \\ College of Human Resources and Education \\ at West Virginia University \\ in partial fulfillment of the requirements \\ for the degree of \\ Doctor of Education \\ in \\ Curriculum and Instruction \\ Randall Wiesenmayer, Ph. D., Chair \\ Barbara Ludlow, Ed. D. \\ Jaci Webb-Dempsey, Ph. D. \\ Patricia Obenauf, Ed. D \\ Hugh Campbell, Ed. D. \\ Department of Curriculum and Instruction
}

Morgantown, West Virginia

2008

Keywords: Co-teaching, Middle School Inclusion, Teacher-Student Interactions Copyright 2008 Nancy G. Burton 


\begin{abstract}
Interactions Between Teachers and Students in Four Co-Taught, Inclusive, Middle School Classrooms
\end{abstract}

Nancy G. Burton

Co-teaching in inclusive, content classrooms is becoming increasingly more popular as schools work toward the inclusion of significantly more students with special learning needs in the general education environment. Inherent in every classroom environment is the expectation of teacher-student interactions. It is often the relationship between the teacher and the student that provides opportunities for student achievement and success. The daily interactions that occur between teachers and their students set the tone for the successes and failures that may be realized as a result. The purpose of this study, therefore, is to explore and identify both the context and frequency of interactions that occur between teachers and their students in inclusive, co-taught classrooms in four middle schools in southern West Virginia.

Case study design was used for the study. Both within-case and cross-case analysis were constructed from data that was collected from interviews of co-teacher pairs (both individual and in pairs), observations of co-taught classes, and frequency tabulations of the observed interactions between teachers and their students during instruction. Transcripts from each interview and field notes were prepared and coded for the case studies that were written. In-case and cross-case analysis revealed multiple findings specific to both the current and future practice of co-teaching as a means of delivering instruction to students with special learning needs in inclusive, content classrooms. Additionally, recommendations for future research are suggested. 


\section{Dedication}

I dedicate this work to the memory of my father whose dreams for me have become my reality. This one's for you, Dad! 


\section{Acknowledgements}

There have been so many who have had a hand in this accomplishment...so many that space does not allow for each to be named. But there are those few who have supported me throughout the entire process. To those individuals, I have something to say.

To the members of my committee:

Dr. Randall Wiesenmayer - I've lost count of the times your encouragement has helped me to believe in myself. You saw in me something I was reluctant to acknowledge. Without your kindness and understanding that SOMETIMES the M.A.T. shouldn't hold a person back, I may never have gotten beyond those first few classes. All of your help, your willingness to take my calls, respond to my emails, and your patient kindness will never be forgotten.

Dr. Barbara Ludlow - My respect and admiration for your knowledge, expertise, and teaching are deeper than words can express. I am always amazed at how you managed to be there when I needed you. Your guidance, direction, and advice have never failed me. I am grateful to be able to share the field of special education with you and to count you as one of my mentors.

Dr. Jacqueline Webb-Dempsey - You have guided me through this writing process to create something of which I can be proud. I especially appreciate your encouragement and support during the final stages of this process. Thanks for reminding me to breathe!

Dr. Patricia Obenauf - The night I stepped into your class in South Charleston several years ago marked my first steps in this journey. It was then that my mind was awakened to new thoughts and perspectives I had never considered. I have since come to understand that emerging from "the box"...taking the "quantum" leap...is something I should have done much sooner in life.

Dr. Hugh Campbell - Well, I didn't spit out secrets of the Universe... but I can tell you this... It's MORE than just a union card... it is now something I am proud to say, you had a part of. I couldn't have done it without your badgering when I procrastinated, your kindness when I panicked, and the time you spent reading... and re-reading....and rereading. Thanks for watching my back!

And the others:

Dr. Linda Spatig - I vowed I'd never do a qualitative study...then you walked into class and convinced me that I could. Well, the "elusive butterfly" sits in my hand and this "reluctant doc" is no more. Thanks for believing in me. 
To my colleagues at Concord - When I became a part of the Concord family, I did not fully understand just what that afforded me. I do now. Thank you all.

Mom and Janet Lynn - Thanks for your unwavering faith in me. It gives me the strength I need to accomplish the things that many can only dream about. I love you both.

Ariel - I realize that there have been times that all you saw of me was either at a desk buried in thought or at the computer lost in cyberspace. I am so glad that I took time to be a part of your childhood. All this would be meaningless and empty if I had forfeited you in the process.

Diane - My entire world would have collapsed if you had not been there to carry my load along with your own. This is a reality for me because of your dedication to ensuring that my dream could be achieved. I look forward to no more missed Sunday dinners at Annie's, long and relaxing visits on the porch, the completion of projects put on hold, and time to just enjoy life without a deadline. I hope l've made you proud. 
Table of Contents

Dedication

Acknowledgements

iv

List of Tables

$x$

Chapter I: Introduction

Purpose of the Study

$\begin{array}{lr}\text { Research Questions } & 8\end{array}$

$\begin{array}{ll}\text { Design of the Study } & 9\end{array}$

$\begin{array}{ll}\text { Definitions } & 10\end{array}$

$\begin{array}{ll}\text { Purposeful Sampling } & 11\end{array}$

$\begin{array}{ll}\text { Data Collection } & 11\end{array}$

$\begin{array}{ll}\text { Data Analysis } & 12\end{array}$

$\begin{array}{ll}\text { Limitations } & 12\end{array}$

$\begin{array}{ll}\text { Chapter II: Literature Review } & 14\end{array}$

$\begin{array}{ll}\text { Highly Qualified Status for Teachers } & 16\end{array}$

$\begin{array}{lc}\text { Justification and Benefits of Co-teaching } & 18\end{array}$

$\begin{array}{ll}\text { Co-Teaching Models } & 21\end{array}$

Roles and Responsibilities of Co-teachers $\quad 22$

Interactions Between Co-teachers and Their Students 23

$\begin{array}{ll}\text { Chapter III: Method } & 26\end{array}$

$\begin{array}{ll}\text { Setting and Participants } & 27\end{array}$

$\begin{array}{ll}\text { Procedures and Data Collection } & 33\end{array}$

$\begin{array}{ll}\text { Data Analysis } & 39\end{array}$ 
$\begin{array}{ll}\text { Coding } & 40\end{array}$

$\begin{array}{ll}\text { Case Analysis } & 41\end{array}$

$\begin{array}{ll}\text { Cross-case Analysis } & 41\end{array}$

Issues of Reliability and Validity 42

Chapter IV: Case Studies $\quad 44$

$\begin{array}{ll}\text { Chicory Middle School } & 48\end{array}$

$\begin{array}{ll}\text { Caryn and Micah } & 49\end{array}$

Co-teaching Partnership/Roles and Responsibilities 54

Use and Impact of Technology 57

Interactions with Students $\quad 59$

$\begin{array}{ll}\text { Frequency Data } & 65\end{array}$

$\begin{array}{ll}\text { Coalton Middle School } & 79\end{array}$

$\begin{array}{ll}\text { Linda and Betty } & 80\end{array}$

$\begin{array}{ll}\text { Co-teaching Partnership/Roles and Responsibilities } & 87\end{array}$

Use and Impact of Technology $\quad 89$

$\begin{array}{ll}\text { Interactions with Students } & 91\end{array}$

$\begin{array}{ll}\text { Frequency Data } & 95\end{array}$

$\begin{array}{ll}\text { Great Falls Middle School } & 110\end{array}$

$\begin{array}{ll}\text { Naomi and Mary } & 111\end{array}$

Co-teaching Partnership/Roles and Responsibilities $\quad 115$

$\begin{array}{ll}\text { Use and Impact of Technology } & 117\end{array}$

$\begin{array}{ll}\text { Interactions with Students } & 120\end{array}$

$\begin{array}{ll}\text { Frequency Data } & 125\end{array}$ 
$\begin{array}{ll}\text { Wright Middle School } & 139\end{array}$

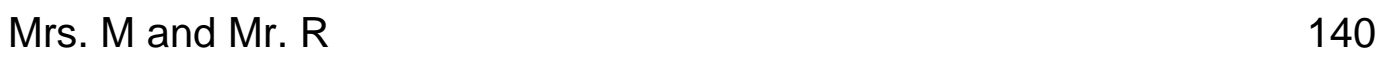

Co-teaching Partnership/Roles and Responsibilities 146

Use and Impact of Technology 149

Interactions with Students 152

$\begin{array}{ll}\text { Frequency Data } & 155\end{array}$

$\begin{array}{ll}\text { Cross-Case Analysis } & 169\end{array}$

Participants' Perspectives - Research Question $1 \quad 169$

$\begin{array}{lr}\text { Caryn and Micah } & 169\end{array}$

$\begin{array}{ll}\text { Linda and Betty } & 171\end{array}$

$\begin{array}{ll}\text { Naomi and Mary } & 173\end{array}$

$\begin{array}{ll}\text { Mrs. M and Mr. R } & 174\end{array}$

Cross-Case Summary - Research Question $1 \quad 175$

Types, Frequencies and Patterns of Interactions Research Question $2 \quad 178$

$\begin{array}{ll}\text { Caryn and Micah } & 178\end{array}$

$\begin{array}{lr}\text { Linda and Betty } & 179\end{array}$

$\begin{array}{ll}\text { Naomi and Mary } & 180\end{array}$

$\begin{array}{ll}\text { Mrs. M and Mr. R } & 181\end{array}$

Cross-Case Summary - Research Question $2 \quad 182$

$\begin{array}{ll}\text { Chapter V: Results } & 184\end{array}$

$\begin{array}{ll}\text { Research Questions } & 184\end{array}$

$\begin{array}{ll}\text { Implications for the Field } & 190\end{array}$

$\begin{array}{ll}\text { Future Research } & 192\end{array}$ 
Conclusion

References

195

Appendices

A Graphic Representations of Procedures 204

B Statistical Comparison of Race, Low SES, and Special Education Distribution

205

C Teacher Interview Protocol - Interview 1

206

D Seating Chart - Chicory Middle School

209

E Seating Chart - Coalton Middle School

210

F $\quad$ Seating Chart - Great Falls Middle School

211

G Seating Chart - Wright Middle School

212

H Teacher Interview Protocol - Interview 2

213

I Interactions Between General Education Teacher and Students Chicory Middle School

J Interactions Between Special Education Teachers and Students Chicory Middle School

K Interactions Between General Education Teacher and Students Coalton Middle School

L Interactions Between Special Education Teacher and Students Coalton Middle School

M Interactions Between General Education Teacher and Students Great Falls Middle School

N Interactions Between Special Education Teachers and Students Great Falls Middle School

O Interactions Between General Education Teacher and Students Wright Middle School

P Interactions Between Special Education Teachers and Students Wright Middle School 
List of Tables

1 Summary of School Locations and Enrollment 46

2 Statistical Comparison of Race/SES/Special Education Enrollment/AYP Results FY 2007-2008

3 Observation 1 - Frequency Data - Chicory Middle School SPED Teacher

4 Observation 2 - Frequency Data - Chicory Middle School SPED Teacher

5 Observation 3 - Frequency Data - Chicory Middle School SPED Teacher

6 Observation 4 - Frequency Data - Chicory Middle School SPED Teacher

7 Observation 5 - Frequency Data - Chicory Middle School SPED Teacher

8 Observation 1 - Frequency Data - Chicory Middle School GENED Teacher

9 Observation 2 - Frequency Data - Chicory Middle School GENED Teacher

10 Observation 3 - Frequency Data - Chicory Middle School GENED Teacher

11 Observation 4 - Frequency Data - Chicory Middle School GENED Teacher

12 Observation 5 - Frequency Data - Chicory Middle School GENED Teacher

13 Number of Interactions Observed - Chicory Middle School

14 Comparison of SPED to GENED Teachers' Interaction Chicory Middle School

15 Observation 1 - Frequency Data - Coalton Middle School SPED Teacher 
16 Observation 2 - Frequency Data - Coalton Middle School SPED Teacher

17 Observation 3 - Frequency Data - Coalton Middle School SPED Teacher

18 Observation 4 - Frequency Data - Coalton Middle School SPED Teacher

19 Observation 5 - Frequency Data - Coalton Middle School SPED Teacher

20 Observation 1 - Frequency Data - Coalton Middle School GENED Teacher

21 Observation 2 - Frequency Data - Coalton Middle School GENED Teacher

22 Observation 3 - Frequency Data - Coalton Middle School GENED Teacher

23 Observation 4 - Frequency Data - Coalton Middle School GENED Teacher

24 Observation 5 - Frequency Data - Coalton Middle School GENED Teacher

25 Number of Interactions Observed - Coalton Middle School

108

26 Comparison of SPED to GENED Teachers' Interaction8 Coalton Middle School

27 Observation 1 - Frequency Data - Great Falls Middle School SPED Teacher

28 Observation 2 - Frequency Data - Great Falls Middle School SPED Teacher

29 Observation 3 - Frequency Data - Great Falls Middle School SPED Teacher

30 Observation 4 - Frequency Data - Great Falls Middle School SPED Teacher

31 Observation 5 - Frequency Data - Great Falls Middle School SPED Teacher 
32 Observation 1 - Frequency Data - Great Falls Middle School GENED Teacher

33 Observation 2 - Frequency Data - Great Falls Middle School GENED Teacher

34 Observation 3 - Frequency Data - Great Falls Middle School GENED Teacher

35 Observation 4 - Frequency Data - Great Falls Middle School GENED Teacher

36 Observation 5 - Frequency Data - Great Falls Middle School GEED Teacher

$37 \quad$ Number of Interactions Observed - Great Falls Middle School

38 Comparison of SPED to GENED Teachers' Interactions Great Falls Middle School

39 Observation 1 - Frequency Data - Wright Middle School SPED Teacher

40 Observation 2 - Frequency Data - Wright Middle School SPED Teacher

41 Observation 3 - Frequency Data - Wright Middle School SPED Teacher

42 Observation 4 - Frequency Data - Wright Middle School SPED Teacher

43 Observation 5 - Frequency Data - Wright Middle School SPED Teacher

44 Observation 1 - Frequency Data - Wright Middle School GENED Teacher

45 Observation 2 - Frequency Data - Wright Middle School GENED Teacher

46 Observation 3 - Frequency Data - Wright Middle School GENED Teacher

47 Observation 4 - Frequency Data - Wright Middle School GENED Teacher 
48 Observation 5 - Frequency Data - Wright Middle School GENED Teacher

49 Number of Interactions Observed - Wright Middle School

168

50 Comparison of SPED to GENED Teachers' Interactions

Wright Middle School 


\section{Chapter 1}

Introduction

"The difference between a lady and a flower girl is not how she behaves, but how she's treated. I shall always be a flower girl to Professor Higgins, because he always treats me as a flower girl, and always will; but I know I can be a lady to you, because you always treat me as a lady, and always will."

Eliza Doolittle, Pygmalion George Bernard Shaw

It's about perception... and how one person perceives another; it's about relationships... and how individuals relate to one another; and it's about interactions... and how individuals interact with each other...how they treat each other. Nothing could be any more relevant to collaborative instruction or co-teaching in an inclusive classroom environment. Collaborative teaching, or co-teaching, refers to a method of instruction which is based on the ongoing partnership of a general educator and a special educator who function as a team to plan, instruct, and evaluate heterogeneous groups of students in the general education environment (WaltherThomas, Korinek, McLaughlin, and Williams 2000). The concept of co-teaching, however, is neither a new concept nor is it exclusive to a general education-special education partnership. It was, in fact, a popular method of instructional delivery during the late 1960s and early 1970s prior to federal special education legislation in 1975. During that time, "open plan" schools were the trend. Designed to foster "learning communities" within the schoolhouse, classrooms became "doorless", open rooms where teachers and students teamed to enhance learning experiences and opportunities (Cohen, 1973). However, without appropriate professional development designed to foster collaborative relationships and a lack of planning time allocated to teaching pairs, the popularity of co-teaching diminished. 
When the Education of All Handicapped Children Act of 1975, (EHA or PL 94142), became law, co-teaching was revived and touted as an effective model of instruction in "mainstreamed" classrooms. Although the EHA mandated that qualified students receive a "free, appropriate, public education" (FAPE) in the "least restrictive environment" (LRE), co-teaching's revival was short lived because it had little impact on the delivery of instruction in the general education classroom (Garvar \& Papanla, 1982). Co-teaching, therefore, gave way to pull out programs, and students with special learning needs (SLN) received most of their instruction in environments separate from their nondisabled peers (Weiss \& Lloyd, 2002). It was not until several years later when significantly more emphasis was placed on the inclusion of students with special learning needs in the general education environment that co-teaching re-emerged as a popular model of instruction. As pull out programs became less popular, co-teaching once again - became a favored means of both facilitating professional collaboration and providing students and their teachers with direct classroom support (Bauwens \& Hourcade, 1995; Friend \& Cook, 1996; Walther-Thomas, Bryant, \& Land, 1996). This shift in perspective gave impetus to the concept of inclusion and altered the manner in which LRE requirements were addressed.

Implicit in the definition of LRE is the notion that students with special needs are best served when they are included with their non-disabled peers. At issue, however, are at least two significant considerations. First, placing students with special learning needs in general education environments still requires that special education and related services be provided. Ensuring that the services are made available in an appropriate manner is essential. Second, content teachers, although often considered 
highly qualified in their individual fields, are frequently ill-prepared to address the learning needs of students who have disabilities. In a 2002 report issued by the United States Department of Education's National Center for Education Statistics, only 32\% of the content teachers surveyed (English, mathematics, social studies, foreign language and science) felt prepared to address the needs of students with disabilities. Of particular significance is the fact that general educators' confidence in serving students with special learning needs was found to be dependent upon the general educators' relationships with special education teachers (Boyer \& Mainzer, 2003).

Because their individual and collective areas of expertise are so important to the successes of all students, co-teaching partnerships have proven to be an effective means of delivering content in inclusive classroom environments. "It is recognized that all teachers are specialists who bring their areas of expertise to the table when planning and making decisions about students. Classroom teachers are specialists in curriculum; special education teachers, including related service personnel, are specialists in the unique learning and behavior needs of students. Each specialist learns skills from the others with all students being the ultimate beneficiaries" (Beckman, 2001, 2). The National Center on Educational Restructuring and Inclusion Study (1995) reported that co-teaching had, at that time, become the most frequently cited staffing model for the implementation of inclusion. More than a decade later, coteaching is still among the preferred models for the implementation of inclusion at all programmatic levels.

Designing and delivering appropriate instruction are the keys to student success; determining how to deliver instruction and who will deliver the instruction are equally 
important. The underlying assumption regarding the specialized instruction of special education has often been that students with SLN could not be successful in the general education or content environment (Wills, 1986). Research indicates, however, that with appropriate supports and services, students with SLN are indeed successful in the general education environment. In fact, because students with SLN historically had limited access to the core curriculum, it became increasingly apparent that they were not mastering required content standards and objectives.

The reauthorization of PL 94-142 in 1990 (re-titled The Individuals with Disabilities Education Act, IDEA) brought about a significant emphasis on including students with SLN in the general education environment. Subsequent reauthorizations of IDEA in 1997 and 2004 emphasized the necessity of providing opportunities for students with SLN to access the general education curriculum (Hoover \& Patton, 2004; Pugach \& Warger, 2001; Thurlow, 2000). Additionally, legislation mandated that students with SLN be included in mandatory state and district formal assessments designed to measure student progress within the standards-based curriculum.

The No Child Left Behind Act of 2001 (NCLB) included multiple stipulations regarding programs and services ensuring the progress of all students - including students with SLN. Three stipulations had an immediate and direct impact on the delivery of instruction to students with special learning needs. First was the stipulation that all students have access to the core content curriculum to the maximum extent possible - a stipulation that both re-emphasized and strengthened the LRE provisions of IDEA 1997. Second, NCLB stipulated that all students have access to and participate in state and district testing. Third, NCLB legislation stipulated that all 
students were to receive instruction from "highly qualified" teachers. Ensuring the stipulations of NCLB not only requires the commitment of teachers to improving their teaching skills, but it also necessitates the effective delivery of content by individuals prepared to address the learning needs of all students. Understanding this, therefore, requires that appropriate opportunities be provided for teachers to acquire the skills required of co-teaching pairs and to develop the relationships conducive to the implementation of co-teaching as an effective method of instructional delivery in inclusive general education classrooms.

There are multiple approaches to co-teaching; however, those most commonly cited in the literature are: the "Interactive" model in which teachers interact with each other and alternate roles during instruction in an effort to share the responsibilities of content delivery; the "One Teach, One Observe" model where one teacher leads instruction while his partner observes academic behaviors of students so that appropriate instructional decisions can be made; the "One Teach, One Assist" or "Teach and Monitor" model which, when successfully implemented, provides opportunities for both teachers to participate in content delivery and student assistance; "Station Teaching" where instructional activities take place as students move from learning station to learning station during the instructional period; the "Parallel" model where both teachers plan lessons, but the class is split and each teacher teaches the same lesson to his group; and the "Alternative" model where one teacher works with a large group while his partner works with a much smaller, select group of students for remediation, pre-teaching, or enrichment (Dettmer, Thurston, Dyck, 2005; Friend \& Bursuck, 2006; Walther-Thomas, Korinek, McLaughlin, Williams, 2000). 
Regardless of the approach implemented, the potential for problems exists. Coteaching at the secondary levels can be especially problematic because of the increased emphasis on content, the pace of instruction, scheduling constraints, teacher expectations of student independence, and high-stakes testing (Mastropieri \& Scruggs, 2001). Additionally, challenges for co-teaching pairs can include inadequate budgetary issues, insufficient planning time, a lack of cooperation, personality conflicts, and increased teacher workloads (Murray, 2004; Weiss \& Lloyd, 2002). Although it is essential that both the general educator and special educator understand their roles and responsibilities regardless of which model of co-teaching they implement, there is another powerful dynamic at work in the co-taught classroom. The very act of teaching requires multiple interactions between and among teachers and their students. It is no different in the co-taught classroom. In fact, the effective instruction of students in a cotaught environment requires that both teachers work to recognize, understand, and address the specific learning needs of all students. Recognizing, understanding, and addressing the specific learning needs of all students can not and will not become a reality if appropriate interactions between teachers and their students do not occur. Simply put, effective instruction requires effective interactions.

\section{THE STUDY}

As a classroom teacher at the middle school level, I came to understand that much of my success and effectiveness was a direct result of the rapport and types of interactions I had with my students on a daily basis. During my personal experiences with working with a co-teacher, although admittedly limited, I had the opportunity to learn, firsthand, a great deal about the dynamics of the co-taught classroom. One of the 
most significant observations I made during my co-teaching experience was that the effectiveness of both me and my partner was somehow linked to the interactions we each had with our students. While there are many characteristics that define effective teachers, ultimately, teaching is about relationships that are developed in the classroom.

It is often the relationship between the teacher and student that provides opportunities for student achievement and success. The daily interactions that occur between teachers and their students set the tone for the successes or failures that may be realized as a result. It has long been my belief that the rapport, relationship, and ultimately, the interactions between teachers and their students have a significant impact on students' opportunities to succeed. Current literature focusing on co-teaching is limited. Because there is a lack of empirical data that focuses on co-teaching and the interactions that occur during co-taught classes, this study focused primarily on the interactions between teachers and their students during instructional time.

\section{Purpose of the Study}

This study examined both the types and frequencies of interactions that occurred between teachers and students during co-taught, inclusive classes. Each classroom identified for the study included both students with special learning needs and their nondisabled peers. Given that there are often extenuating circumstances that require that some teachers are teaching by virtue of a permit, instruction was delivered by both a content certified teacher and an appropriately certified special educator as they were 
available in the sites selected for this study. The teacher pairs used one or more of the previously identified co-teaching models.

The main purpose of this study, therefore, was to explore and identify both the context of the interactions that occurred between teachers and their students in inclusive, co-taught classrooms at the middle school level and the frequency of each type of interaction identified. Additionally, through observation, this study examined and documented what actually occurred during teacher-student interactions, and, through interview and observation, documented the co-teaching perspectives of teacher participants. Through analysis and interpretation of data collected, the study explored possible patterns of interactions that appeared to exist between teachers and students in co-taught classrooms. Finally, the perspectives of the teacher participants were given voice.

\section{Research Questions}

My research was guided by two broad questions.

1. What are the perspectives of co-teaching that teachers identify from their experiences, and

2. What types of interactions can be observed during co-taught, inclusive classrooms? With what frequency does each type occur? Are there identifiable patterns of interactions that occur? 


\section{Design of the Study}

Case study is a design particularly suited to situations in which it is impossible to separate the phenomenon's variables from their context (Yin, 1994; Merriam, 1998, p. 29). Therefore, the research design selected for this qualitative study was a multi-case study that included within-case and cross-case analysis of the interactions that occurred in four co-taught, inclusive classrooms at the middle school level. "This type of study involves collecting and analyzing data from several cases and can be distinguished from the single case study that may have subunits or subcases embedded within" (Merriam, 1998, p. 40). I envisioned this case study much like a compilation of a photo album. While the album itself represents the framework of inclusive middle school environments, it is from each individual classroom, each case - the "photographs" inside the album - that themes, voice, and meaning can emerge.

In this study I examined teacher-student interactions as they occurred within individual classrooms during instruction, examined the similarities and differences of teacher-student interactions among the individual classrooms to determine possible patterns of interactive behaviors that emerged, and identified characteristics of observed interactions common across cases. Finally, I examined teacher interviews and observed actions to identify their respective perspectives.

While I anticipated that my participation and role in the proposed study was to be a nonparticipant observer, I also understood that "the extent of participation is a continuum that varies from complete immersion in the setting as full participant to complete separation from the setting as spectator, with a great deal of variation along 
the continuum between the two end points" (Patton, 2002). Realistically, I was aware that he potential for the extent of my participation to change during the data collection period was always a possibility. It was extremely important to my study, however, that I was as nonintrusive as possible. It was not my intent to interact with either teachers or students during my observations of co-taught instruction.

The study was conducted in a manner that not only provided opportunities to observe teacher-student interactions during instructional delivery, but also gave voice to the teacher participants in each case. Because their perspectives were individually and collectively significant to both their interactions with their students and their implementation of co-teaching, it was essential that I attempted to understand the processes from each teacher's perspective. This was achieved through interviews conducted with each teacher individually, an interview with each co-teaching pair, and classroom observations. All interviews occurred outside of classroom instructional time.

\section{Definitions}

A complete understanding of any phenomenon begins with a common language. Therefore, it is essential that several key concepts and terms be identified and defined. First, because there are multiple ideas about how co-teaching should be defined, it is essential that one definition be used throughout this study. Co-teaching, for the purposes of this study, referred to a method of instruction which is based on the ongoing partnership of a general educator and a special educator who function as a team to plan, instruct, and evaluate heterogeneous groups of students in the general education environment (Walther-Thomas, et al, 2000). Since the study focused 
specifically on the interactions that occurred during instruction in inclusive classrooms, it should be noted that the types of interactions examined included only those that occurred between teachers and students and did not include interactions between the co-teachers.

\section{Purposeful Sampling}

"Purposeful sampling is based on the assumption that the investigator wants to discover, understand, and gain insight and therefore must select a sample from which the most can be learned" (Merriam, 1998, p. 61). In this study, I have identified specific criteria for the initial selection of schools within the local Regional Education Service Agency (RESA). This step was taken to narrow the number of sites to a manageable number. Additional criteria for the selection of co-teaching pairs were established. According to LeCompte and Preissle (1993), this criterion-based selection allows the researcher to create a list of the attributes essential to the study and then to proceed to find a site that matches the list. It would serve little purpose to deny the influence of convenience as a part of the sampling process. In some ways, the selection of schools and co-teaching pairs in the local RESA was based on travel, finances, and time. I do not, however, believe that this had a significant impact on my study.

\section{Data collection}

Patton (2002) stipulates that "Qualitative data grows out of three kinds of data collection... Interviews yield direct quotations from people about their experiences, opinions, feelings, and knowledge. The data from observations consist of detailed descriptions of people's activities, behaviors, actions and the full range of interpersonal 
interactions... Document analysis includes "studying excerpts, quotations, or entire passages extracted from a variety of types of documents" ( $p$ 4). Data collection for my study was conducted through observations, frequency tabulation, detailed field notes from observations, and interviews. Transcripts of field notes and interviews were prepared and coded for data analysis and interpretation.

Data analysis

Determining the exact point when data analysis actually begins is elusive at best. In fact, in qualitative research, analysis quite possibly begins before the formal collection of data has begun (Stake, 1995). In this study, data analysis began early since I included observer comments to transcripts from both observations and interviews. As data collection was completed with each individual co-teaching pair, I examined it to identify what, if any, patterns of interactions had emerged. Additionally, I used the data to determine why and how frequently co-teachers interacted with their students. After data collection was completed at all sites, within case and across case analysis was completed.

\section{Limitations}

Case study research is not an exact science. It is, by its very design, limiting. It is representative of only a portion of an entire phenomenon. It is but one "picture" of a particular place at a particular moment in time, yet it is not all inclusive, for beyond the frame of the photograph, beyond the picture's edges, other subjects are emerging other cases are unfolding. As context changes, so too, do events. A significant limitation of this study was in the form of scheduling conflicts which eliminated the 
participation of some schools. Time constraints also limited the amount of time available to conduct interviews during the school day.

No qualitative study can be completed without the recognition of the effect and limitations presented by researcher biases. My passion in life is teaching; therefore, I have very strong convictions about what effective teaching is. While those convictions have served me well in my profession, I must acknowledge them as biases that may have presented potential limitations to what I noted during observations and the interpretations of the data I collected. Finally, while I anticipated that each of the four co-taught inclusive classrooms was somewhat representative of what co-teaching "looks like", the data I collected, analyzed and interpreted was not for the purpose of making generalizations among all co-taught classrooms. 


\section{Chapter 2}

\section{Literature Review}

Collaborative teaching, or co-teaching, emerged as a method of instructional delivery in general education classrooms during the late 1960s when the concept of "open" classrooms was popular. In practice, co-teaching is an instructional delivery model in which both a general education teacher and a special education teacher are responsible for the instruction in inclusive classroom settings (Bauwens, Hourcade, \& Friend, 1989). It was not until the late 1980s that co-teaching was introduced as a method of collaboration between general education and special education to implement mainstreaming (Garvar \& Papanla, 1982; Bauwens, Hourcade, \& Friend, 1989). Since that time, the use of co-teaching has often been more a matter of choice than one of expectation. Special education legislation from PL94-142 (1975) until IDEA in 1990 stipulated that students with special learning needs (SLN) be placed in their least restrictive environment (LRE). Frequently that has meant that students with SLN could be placed at any point along a continuum ranging from home/hospital to the general education environment. Yet, historically, students with SLN who had typically been placed in self-contained, special education environments, or who had been placed in pull-out programs, often received neither equal nor adequate instruction designed to prepare them to successfully master the general education curriculum. In fact, those same students were often not included in state- and district-wide assessments. Prior to IDEA 1997, accepted practice was to either exclude many students from state- and district-wide testing entirely, or to remove their scores from the aggregate thereby skewing the overall test scores of both individual schools and their districts. 
Consequently, a significant measure of progress was, in effect, denied to many students with SLN (Thurlow \& Yesseldyke, 1997).

It was the reauthorizations of IDEA in 1990 and 1997 that actually initiated a major shift in the least restrictive environment (LRE) practices by requiring that students with special learning needs (SLN) have access to the general education curriculum including state and district assessments to the maximum extent possible (Polloway, Patton, \& Serna, 2005). In an effort to comply with special education mandates, some increase in the inclusion of students with SLN in the general education environment occurred. Since the passage of the No Child Left Behind Act (NCLB) in 2001 and the reauthorization of the Individuals with Disabilities in Education Improvement Act (IDEA 2004), the numbers of included students with SLN once again increased. Making this increase even more significant was the NCLB 2001 requirement that "95\% of students with disabilities" must participate in the state and district assessment. Therefore, it would appear that NCLB mandates created a greater impetus than did IDEA '97 to link more students' IEP goals with the content standards of the general education curriculum" (Council for Exceptional Children, 2003).

Renewed interest in the implementation of co-teaching models finds its basis in the two aforementioned legislations. Ultimately, however, it was the introduction of the "annual yearly progress" stipulations of NCLB 2001 and the increased emphasis on the LRE requirements of IDEA that gave rise to the implementation of co-teaching as a way to comply with NCLB and IDEA mandates (IDEA 2004; Murawski \& Dieker, 2004; Mandlawitz, 2006). As a result, more students with SLN were placed in general education, core content classes. In an effort to ensure that all students received 
appropriate instruction of the core curriculum, NCLB stipulations required that all teachers, both general and special education, must be "highly qualified" in the content they teach.

"Highly Qualified" Status for Teachers

First, since both NCLB 2001 and IDEA 2004 require that all students be taught by "highly qualified" teachers, understanding what makes a teacher so is essential. To be deemed "highly qualified", core content teachers (English, mathematics, social studies, or science) must have a minimum of:

a. A bachelor's degree,

b. Full state certification or licensure, and

c. Prove that they know each subject they teach (i.e., passing an appropriate PRAXIS exam in the content field taught) (U.S. Department of Education Fact Sheet, 2004).

"Highly qualified" stipulations for special education teachers are different from those of their general education colleagues, however. "The highly qualified requirements apply only to teachers providing direct instruction in core academic subjects. Special educators who do not directly instruct students in core academic subjects or who provide only consultation to highly qualified teachers in adapting curricula, using behavioral supports and interventions or selecting appropriate accommodations, do not need to demonstrate subject-matter competency in those subjects" (U. S. Department of Education Fact Sheet, 2004, np). 
Requiring that all students receive instruction from "highly qualified" teachers is not without justification. Since all students, including students with SLN, must have access to the general curriculum and to state and district assessments, it is only logical to expect that all students receive appropriate instruction from appropriately credentialed teachers. In enacting NCLB, Congress indicated its recognition that states were not doing enough to ensure that all students were performing adequately in school (Rosenberg, Westling, \& McLeskey, 2008). Additionally, IDEA 2004 has significantly strengthened the concept of a continuum of services by stipulating that a) students must be placed in an educational environment that is appropriate to each individual's needs, b) students with SLN should be separated from their nondisabled peers to the least extent possible, and c) students should not be removed from the general education environment unless the severity of the disability is such that education in that setting with the use of supplementary aids and services cannot be achieved successfully (Taylor, Smiley, \& Richards, 2008; Rosenberg, Westling, \& McLeskey, 2008). LRE requirements, therefore, have never had more impact on the field of education than they do at this time. NCLB 2001 and IDEA 2004 have become the catalysts for including students with SLN in the general education content classroom. Significant changes in both teacher expectations and in student placements have resulted in higher standards for education in general. For example, as stated, the "highly qualified" status requires that all general education teachers be fully certified in the field in which they teach. Additionally, all special education teachers, regardless of their special education certification status, must also have certification or endorsement in any and all content fields they teach (i.e., Elementary K-6, or 5-Adult in secondary content fields in the state 
of West Virginia). In spite of the different defining characteristics of "highly qualified" for general educators and special educators, the expectation is actually the same - all students are to receive instruction from "highly qualified" teachers.

\section{Justification and Benefits of Co-teaching}

"The purpose of co-teaching is to provide access to the general education teacher and general education curriculum for students with disabilities while providing the accommodations from the student's individualized education program (IEP)" (Magiera, Smith, Zigmond, \& Gebauer, 2005, p. 21). Emphasis on the appropriate instruction of all students by "highly qualified" teachers, increased emphasis on student achievement and stronger, more meaningful LRE requirements have significantly increased current interest in the implementation of co-teaching models. Additional rationales for co-teaching include access to the general education curriculum, increased instructional options, and more flexibility (Bauwens \& Hourcade, 1997; Cook \& Friend, 1995; Dieker, 2001; Murawski, 2002).

Recent studies report both the effectiveness and benefits of co-teaching in a variety of instructional circumstances including English language learners (Mahoney, 1997), students with hearing impairments (Compton et al., 1998; Luckner, 1999); students with learning disabilities (Rice \& Zigmond, 1999; Trent, 1998; Welch, 2000); high-risk students in a social studies class (Dieker, 1998) and in a language remediation class (Miller, Valasky, \& Molloy, 1998). In a three-year study of co-taught, inclusive elementary classrooms, Walther-Thomas et al. (1996) found that both low achieving students and students with special learning needs (SLN) not only improved in their 
social skills but also developed a deeper sense of appreciation for their own skills and accomplishments. In a later study, Walther-Thomas (1997) investigated both the benefits and problems associated with co-teaching at both the elementary and middle school levels. Results of the study included the identification of benefits for students with SLN, their nondisabled peers, and both special and general education teachers. Of significance is the fact that the students in inclusive, co-taught environments improved academically and socially. Problems identified in the study indicated concerns with administrative issues rather than classroom issues.

Assuming that both teachers in a co-teaching pair are fully certified in their respective fields (one content and one special education), the belief is that both students with SLN and their non-disabled peers will benefit from both areas of expertise. The literature prior to NCLB and IDEA 2004 appears to support that belief. Boyer (1996) evaluated the teaching practices of regular and special education teachers and the academic achievement of their students. Results of the study indicated that students with and without learning disabilities (LD) made academic progress. Additionally, the study showed a significant level of shared philosophy between the coteacher pairs. Choate (1997) investigated, through surveys, the perceptions of both regular and special education teachers as well as the perceptions of administrators. Survey responses indicated an overwhelming consensus among all groups that both special education and general education students benefitted from co-teaching. Similar results were found by Gerber \& Popp (1999) when they interviewed both students with and without learning disabilities and their parents. Miller and Valasky (1998) described how co-teaching teams blended whole-class and small-group instruction, peer teaching, 
and small cooperative learning groups to provide language remediation activities within the general education curriculum. Their findings indicated that these methods also resulted in increased achievement for the students involved.

More recent studies also support the use of co-teaching models as effective methods of instruction in inclusive classrooms. In their meta-analysis of co-teaching research, Murawski and Swanson (2001) reviewed 89 articles pertaining to co-teaching. Six of the articles provided enough quantitative data to calculate an effect size. Their calculations produced an effect size of 0.40 which would suggest that co-teaching is a moderately effective model of instruction.

Hardy (2001) examined the instructional behaviors of teachers in both selfcontained classrooms and in an inclusive, co-taught secondary biology class. Findings indicated that the presence of the special educator in the co-taught classroom contributed to: the creation of a new learning environment, notable changes in instructional behaviors of general education teachers, specialized instruction for students with SLN, and the success of some included students. In spite of increased uses of co-teaching models, some school systems continue to use pull-out programs to serve students with SLN. Research has indicated, however, that students with SLN served in co-taught, content classrooms earn higher grades in core content subjects and achieve higher standard scores in language and math than do students in pull-out programs (Marston, 1996; Rea, McLaughlin, \& Walther-Thomas, 2002; Scruggs, Mastropieri, \& McDuffie, 2007). 
Co-teaching models

The manner in which co-teachers implement their instruction varies among six frequently identified co-teaching models found in current literature. The most commonly identified models found in the literature include:

- the "Interactive" model in which teachers interact with each other and alternate roles during instruction in an effort to share the responsibilities of content delivery;

- the "One Teach, One Observe" model where one teacher leads instruction while his partner observes academic behaviors of students so that appropriate instructional decisions can be made;

- the "One Teach, One Assist" or "Teach and Monitor" model which, when successfully implemented, provides opportunities for both teachers to participate in content delivery and student assistance;

- "Station Teaching" where instructional activities take place as students move from learning station to learning station during the instructional period;

- the "Parallel" model where both teachers plan lessons, but the class is split and each teacher teaches the same lesson to his group; and

- the "Alternative" model where one teacher works with a large group while his partner works with a much smaller, select group of students for remediation, preteaching, or enrichment (Dettmer, Thurston, Dyck, 2005; Friend \& Bursuck, 2006; Walther-Thomas, Korinek, McLaughlin, Williams, 2000). 
Roles and Responsibilities of Co-Teachers

While multiple models of co-teaching have been identified, the roles and responsibilities of co-teachers are often not as definitive. In her investigation of the collaborative efforts of teachers in two $8^{\text {th }}$ grade United States history classes, Bouck (2007) identified eight different roles co-teachers must negotiate as partners. Her findings also indicated that communication between co-teachers as they negotiate their roles is essential. Characteristics essential to the success of any co-teaching model include: common planning time, teachers' willingness to engage in co-teaching models, co-teaching partners volunteer to co-teach and are not assigned administratively, and there is a balanced, heterogeneous group of students (Walther-Thomas, Bryant, \& Land, 1996).

Weiss and Lloyd (2002) examined the roles and instructional actions of special education teachers in both co-taught, general education environments and in special education environments. Their observations indicated that the special educators had assumed a variety of roles including: a) a non-instruction, support role; b) instructor for pullout sessions, c) small group instructor of different content within the same classroom; and d) participant in team teaching opportunities. Of significance is their conclusion that special education teachers often served in subordinate roles while content teachers typically took the lead or primary role in the co-taught classroom. Weiss and Brigham (2002) conducted a review of both qualitative and quantitative studies of co-teaching. The studies took place at both the elementary and secondary grade levels. Their findings indicated that the special education teachers were responsible for preparing content modification, monitoring student progress, and 
discipline. The general education teachers were found to be responsible for delivering content instruction. Morocco and Aguilar (2002) identified three essential roles of special education teachers in co-teaching environments. First, the special education teachers must be present in the classroom. Second, the special educator must understand the learning strengths and weaknesses of their students. And, finally, special educators must model for content teachers ways to make complex content accessible to all students - especially to those with SLN.

Interactions Between Co-teachers and Their Students

All but absent from the literature are studies that focus on the interactions that occur between co-teachers and their students during instruction. Typically, research indicates that interactions during co-taught classes occur are limited to whole group instruction with few opportunities for teacher interactions with individual students (Mastropieri, Scruggs, Graetz, Norland, Gardizi, \& McDuffie, 2005; Scruggs, Mastropieri, \& McDuffie, 2007). One study in particular focused on the actions of coteachers during instruction. Harbort, Gunter, Hull, Brown, Venn, Wiley, \& Wiley (2007) sought to examine the roles and actions of co-teachers in secondary public schools. Each team consisted of a special education teacher and a content specific regular education teacher. Observational data using momentary time sampling procedures was collected during 15 class sessions. Each session was videotaped so scoring could be completed. All co-teachers used the "one teach, one assist" model.

Their findings indicated the following: a) the regular education teacher presented the majority of the instruction to the whole group with very little instruction presented to 
small groups or by the special education teacher; and b) the special education teacher responded to students (both individually and in large groups) more frequently than did the general education teacher. It was concluded, therefore, that the special education teachers' expertise was not utilized to its fullest potential since the special education teachers functioned more in a monitoring role than in an instructional role. The types of interactions and their frequency were not stipulated.

Although the Harbort, et al (2007) study is the only study I found that specifically focused on the interactions that occur between co-teachers and their students, other studies incorporate findings related to such interactions. Other studies, in fact, include teacher-student interactions but use different terminology such as "teacher actions" or "teacher roles", when teacher-student interactions are discussed. For example, Weiss and Lloyd (2002) examined the roles and actions of six secondary teachers in both cotaught and special education settings. Actions identified among the teachers included instructing, explaining, questioning, giving help, and giving feedback.

Teacher interactions are not always identified specifically in the literature; however, they may be implicit with a study. Vaughn, Elbaum, Schumm, and Hughes (1998) reported that special education teachers in general education classrooms provided a range of services including whole- and small-group instruction in co-taught classrooms. Based on the observations of co-taught classes, Morocco and Aguilar (2002) identified several roles assumed by both special and general educators in cotaught classrooms. Embedded within those roles are such teacher-student interactions as explaining, clarifying, instructing, giving praise, providing feedback, and managing behavior. Results of the study indicated that, while the content teachers provided more 
instruction, the special education teachers provided more individualized assistance to enhance students' learning. Additionally, both the content and special education teachers assumed a variety of instructional roles or interactions. Bouck (2007) identified teacher roles as instruction, disciplinarian, classroom gatekeeper, and confidant. It should be noted, perhaps, that not all roles occur exclusively during an instructional period; however, they each require interactions between teachers and students nonetheless.

Implied interactions can be identified in the literature as ranging from observing and monitoring student progress to making immediate and appropriate adaptations to instruction (Mastropieri \& Scruggs, 2001); elaborating on content during instruction to enhance comprehension (Mastropieri, Scruggs, Graetz, Norland, Gardizi, \& McDuffie, 2005); setting and maintaining high expectations, creating positive learning environments, evaluating student progress and actively engaging students (Dieker, 2001); and providing assistance and modifications to individual students who are struggling (Scruggs, Mastropieri, \& McDuffie, 2001).

That interactions between teachers and their students in co-taught classrooms occur is a given assumption. The types of interactions, their frequencies and their impact on student learning cannot be assumed and must, therefore, continue to be studied. 


\section{Chapter 3}

Method

This qualitative study was a case study of the interactions that occurred in four co-taught, inclusive classrooms in four separate middle schools in southern West Virginia. Because there is such diversity in the interpretation of what case study is, (a method for conducting research or a method of reporting research), stipulating a single definition is difficult. Yin (2003) defines case study as "an empirical inquiry that investigates a contemporary phenomenon within its real-life context, especially when the boundaries between phenomenon and context are not clearly evident" (p. 13). Case study is, therefore, a research strategy that emphasizes contextual conditions believed to be significant to the phenomenon under study (Yin, 2003). As such, the case study is a methodological approach that incorporates a variety of data-gathering measures (Hamel, Dufour, and Fortin, 1993; Merriam, 2001). Stake (1995) describes case study as "the study of the particularity and complexity of a single case, coming to understand its activity within important circumstances" (p. xi). Denzin and Lincoln (2003), however, describe case study in terms of a choice of what to study. Case study from this perspective becomes a form of reporting rather than a methodology or strategy for conducting research (Wolcott, 2001).

In this study, case study was used as a methodological framework. I utilized the data-gathering tools common to qualitative case study research. Interviews, observation, and subsequent field notes yielded data that "aims to uncover the manifest interaction or significant factors characteristic of the phenomenon" of study (Berg, 2004, 
p. 251). Within the framework of case study, there were multiple cases or units identified for study. This multi-case approach provided opportunity for cross-case comparisons for a deeper understanding of the phenomenon - the interactions between teachers and students in co-taught, inclusive environments - at the heart of this study.

\section{Setting and Participants}

Selecting appropriate settings for any study is often a tedious task at best. Because of time constraints and my own teaching requirements, I used a combination of criterion sampling and convenience sampling as strategies for selecting classrooms appropriate to my study. The setting of this study was stipulated as inclusive, co-taught classrooms in four middle schools (grades 6-8) located in southern West Virginia. Participants were the co-teachers in each of the stipulated classroom.

Using a multi-case design can easily become unmanageable. To avoid this, I determined the units of study according to the funnel analogy described by Bogdan and Biklen (2007). Additionally, I used a flow chart as a graphic representation of the procedures I followed throughout this study (Appendix A). I began by exploring potential participant pools in southern West Virginia. Counties in the state of West Virginia are divided into six regions. Because of personal time constraints and limited resources for extensive travel throughout the state, I selected RESA I (Regional Education Service Agency) as my initial pool of possible units of study - what Bogdan and Biklen (2007) would identify as the wide part of the funnel. As I narrowed the pool to a manageable number of sites, I developed specific criteria that each school had to meet. Ultimately, four middle schools that met the identified criteria emerged from the 
RESA-1 pool. One co-teaching pair from each middle school was identified as the participants in this study.

Purposeful sampling. As the term implies, purposeful sampling must serve a purpose. "Purposeful sampling is based on the assumption that the investigator wants to discover, understand, and gain insight and therefore must select a sample from which the most can be learned" (Merriam, 2001, p. 61). There are several strategies for purposefully selecting cases for study. Each has its own particular focus which allows the researcher considerable flexibility. "Purposeful sampling focuses on selecting information-rich cases whose study will illuminate the questions under study" (Patton, 2002, p. 230). Since co-teaching models are used in schools all across the state of West Virginia, conducting a study of all cases in the state is neither practical nor feasible. Therefore, I used both criterion and convenience sampling to identify information-rich cases for my study. The first criterion for selection was that the schools for study must be included in RESA I. A second criterion was that the schools must be middle schools (grades $6-8$ ).

As the "funnel" continued to narrow and the middle schools were identified, additional criteria were stipulated. For example,

- Each middle school functioned as a 'true' middle school modelmeaning that each grade level (grades 6-8) was represented by a core group of teachers who participated in regularly scheduled grade level team meetings and planning sessions. 
- Students with special learning needs were included in core curriculum classes (i.e., English, reading, mathematics, social studies, and science.)

- At least one of the inclusive core classes was taught by a highly qualified content teacher and a fully certified special education teacher.

- The co-teaching model used was one of the models identified in the literature as a recognized model of co-teaching.

Selection of sites and co-teacher pairs. Middle school sites for this study were selected from the pool of middle schools identified in a six county region in southern West Virginia (one region of eight Regional Educational Service Agencies in West Virginia). Initial preparatory research identified a total of twenty-six schools in the six county region that house the following programmatic configurations including middle school grades either 5-8 or 6-8: thirteen schools were identified as K-8 schools; nine schools represented "true" middle school configurations of grades 6-8; and four schools housed grades 5-8. The criterion for narrowing the pool to a more manageable number was simply to select only those schools that represented a "true" middle school configuration. Since nine schools, representing four of the six counties, met that stipulation, additional criteria were developed to further narrow the pool to a more manageable number. In my efforts to approach this study in a practical and realistic manner, the following circumstances were considered as additional criteria for site selection:

- Travel time required to and from each site, 
- Scheduling limitations of both the public school schedules and my personal schedule,

- Pre-existing, personal relationships with co-teachers at each site, and

- The implementation of at least one co-teaching model in a content field (limited to English/Language Arts, Mathematics, Science, or Social Studies).

Once the above criteria were applied to the initially narrowed pool of nine schools, the number of schools in the pool was reduced to seven. One school was removed from the pool because of pre-existing, personal and professional relationships I had developed from working extensively with the co-teaching pairs in the school. The risk of tainting the data with my own personal biases was too great. The second school was removed for two reasons. First, travel to the school would have involved a two-hour drive one way; and second, since there was only one class that was being cotaught (a $7^{\text {th }}$ grade science class), unresolvable scheduling conflicts were quickly identified. The remaining seven schools represented two counties in the six-county region. In all seven of the remaining schools, co-teaching occurred at each grade level. Additionally, at least one "inclusion" class was co-taught in both English/Language Arts and mathematics at each grade level. Only one of the seven remaining schools uses co-teaching in the science or social studies classes.

Given the scheduling issues of the two counties (a week for spring break and a two-week window for state/district formal assessments), a total of seven schools was not manageable within a five week time frame for data collection. Therefore the 
following criteria were used to attempt to narrow the number of sties to four. First, since one of the two remaining counties (County A) had only two middle schools, I decided to research the five schools in County B to identify two schools with demographics similar to the two schools in County A (Appendix B). Statistical data for each of the seven schools was collected (WVEIS Data on Demand). In an effort to identify two schools in County B with comparable demographics to the two schools in County A, the data collected was compared and the following observations were made:

- School 1 in County A (A1) was similar to two schools in County B (B1\& B3) in racial distributions. With regard to total enrollment, low SES and special education populations, School A1 was most similar to School B1.

- School 2 in County A (A2) was very similar to the three remaining schools in County B (B2, B4, \& B5). In fact, all four schools (A2, B2, B3, \& B4) had comparable total enrollments, racial distributions, low SES, and special education populations.

Based on the conclusions drawn from the preliminary data collected, it was impractical to eliminate any of the schools in County B until more information can be collected. Therefore, I conducted site-based, informal, interviews with principals in County B to determine the selection of the two remaining sites for study. Only three prepared questions were asked. I requested that each principal: a) explain how coteaching is implemented in his/her school; b) identify the content and credentials of the co-teaching pairs at each grade level; and c) identify any other information deemed appropriate to the selection of co-teaching pairs for study. I also requested the 
following documents: a) a master schedule including times of each class; b) a specific schedule of co-taught classes school wide; and c) a schedule of the designated planning times of co-teachers. Information that was disclosed during each interview was appropriately analyzed and interpreted to allow for possible additional criteria to emerge. Schools were eliminated from the selection pool if principals were not willing to participate or were not available for face-to-face interviews.

Because co-teaching occurs in all four core content areas in each of the schools in both counties, there was the potential for multiple content specific configurations for study. In the beginning, the final selection of co-teachers and their respective content was to be determined by the following criteria:

- Teachers had to willingly agree to participate in the study,

- Each teacher was to be fully certified in his/her field - one fully certified in the content field and the other fully certified in special education,

- No pull-out occurred during allotted instructional time, and

- The scheduled co-taught classes were scheduled at a time compatible with my personal schedule.

However, once the narrowing process began, it became apparent that more flexibility was required with regard to teacher certification status. Consequently, while all content teachers were appropriately certified, special education teachers on permit were considered as potential participants. Ultimately of the five schools in County B, three were eliminated. Two were removed from the pool because principals were repeatedly 
unavailable for interview. The third was eliminated because of scheduling conflicts that would have significantly disrupted the continuity of data collection (i.e., field trips, special assemblies, etc.)

\section{Procedures and Data Collection}

In qualitative research, data collection takes many forms. Patton (2002) stipulates that findings from data grow out of three types of data collection: in-depth, open-ended interviews; direct observation; and written documents. Merriam (2001) indicates that in qualitative case studies, all three types of data collection are frequently used. Regardless of the type of data collection used, understanding the case in its totality requires both breadth and depth of data collection. Stake (1995) recommends the development of a data-gathering plan to include: "definition of case; research questions, identification of helpers; data sources, allocation of time, expenses, and intended reporting" (p. 51). Although I used all three methods of data collection, I relied on observations of the participants in their classrooms and on interviews of those participants to ensure that every effort was made to gain a deeper understanding of the essence of the interactions that occurred with their students.

Teacher Interview \# 1- Prior to Observations. Interviewing in qualitative research serves multiple purposes. "We interview people to find out from them those things we cannot directly observe" (Patton, 2002, p 340). In this study I conducted three interviews. Two of the interviews were conducted prior to any classroom observations. The first interview was an informal discussion with each of the five principals in County B for the sole purpose of narrowing the participant pool. The second interview was 
with the co-teachers prior to classroom observations. Teachers were initially interviewed separately to determine the following factual information: certifications held, number of years experience (overall and co-teaching), training in co-teaching, model(s) of co-teaching implemented, and how the partnership was formed. Additionally, I asked teachers to explain their perceptions regarding the following: 1) their current roles and responsibilities; 2) the types of interactions that occur during their respective co-teaching situations; 3) the perceived impact co-teaching has had on student learning; and 4) the impact co-teaching has had on their teaching.

To gain as much insight with each interview as is possible, it is essential that interview questions be formulated and prepared carefully. Bogdan and Biklen (2007) suggest that where interviews fall on the "structured/unstructured continuum" may vary significantly. Although the interviews in this study focused specifically on co-teaching and teacher interactions with their students, questions were predominantly openended. Examples of initial interview questions are:

- Describe the training/preparation you have had in the models of coteaching.

- How would you describe the model of co-teaching that you use in your current experiences?

- Describe what your roles and responsibilities are as a co-teacher in the inclusive classroom.

- Explain how you plan for each class that is co-taught.

- Describe the types of interactions you have with students.

- Take me through a class period where you participate in co-teaching. 
- What impact do you think co-teaching has had on student achievement or student learning?

- How has co-teaching affected you as an educator?

In addition to prepared interview questions, follow-up questions can provide opportunities for deeper understanding of participants' responses. Bogdan and Biklen (2007) offer the following probes or follow-up questions - some of which may be useful during interviews for my study:

- What do you mean?

- I'm not sure that I am following you.

- Would you explain that?

- What did you say then?

- What were you thinking at the time?

- Give me an example.

- Tell me about it.

- Take me through the experience.

Although some of the questions for this interview were designed to identify specific background information (and are, therefore considered closed), there were other open-ended questions designed to allow each teacher's perspective, or individual voice, to begin to emerge. A complete interview protocol (Appendix C) was used during each interview to ensure that all teachers had an opportunity to respond to the same questions thereby allowing for some consistency of questioning during the first interview. Each interview was digitally recorded to ensure accuracy during 
transcription. Observer comments and reflections were added to transcripts as appropriate.

Observations. Ralph Waldo Emerson once said, "[p]eople only see what they are prepared to see." The fact is research observation does not necessarily come naturally; rather, it requires training, concentration, and practice (Patton, 2002). Although each of us observes life on a daily basis - either consciously or subconsciously - observation as a formal, research tool has four characteristics: it serves a specific research purpose; it is planned deliberately; it is recorded systematically; and it is subjected to checks and controls on validity and reliability (Kidder, 1981).

Observation allows the observer to record behavior as it is happening (Merriam, 1998). According to Patton (2002), the purposes of collecting observational data are to describe the setting, the activities, the people, and the meanings of what was observed - all from the perspective of those being observed. Understanding the necessity of collecting accurate and factual data, I put aside my personal, preconceived notions about what the nature of co-teacher's interactions with their students should be and recorded only what I observed in each classroom. I collected data not as a participant, but rather as a silent onlooker - "as a researcher participant who participates in a social situation but is personally only partially involved, so that he can function as a researcher" (Gans, 1982; Merriam, 1998).

Following the initial teacher interviews, observations of co-taught classes were scheduled. A minimum of five 45-minute observations per co-teaching pair per school will be scheduled. During all observations, the types and frequency of interactions 
between teachers and their students were documented as they occurred. Because there were numerous interactions each with their own particular context, I chose not to "hold fast" to a preconceived and fully developed list of the types of and reasons why teachers interact with their students and allowed previous research to identify the following general categories of interactions from which additional categories of interactions emerged: instruction, elaboration, progress monitoring, and disciplinary/behavior management (Vaughn, et al; Morocco \& Aguilar, Mastropieri, Scruggs, et al). The context of each interaction frequently proved to be of much greater significance than the actual interactions observed. Anecdotal field notes were kept to document the activities that were observed during each class period. Field notes also provided a measure of accuracy to the sequence of activities and interactions that were observed.

Identifying the frequency of interactions that teachers had with individual students required a system of tallying those observed instances. To maintain the integrity of the natural environment, prior to observations, I discussed with the co-teachers their current seating arrangements of students in their classrooms. I requested that teachers provide a blank seating chart, and an identification number was assigned to each student by assigning a seat number to each desk. Students in School A - Chicory Middle - were identified as A1, A2, A3, etc. (See Appendix D); students in School B - Coalton Middle (See Appendix E); School C - Great Falls Middle - (See Appendix F), and School D Wright Middle - (See Appendix G) were numbered in like manner so that student numbers, therefore, corresponded to both their respective schools and their seat numbers. Teachers maintained possession of the master seating chart to ensure that, 
after all data was collected, accurate student identification of students with SLN and students without disabilities were made. Student identities were not, at any time, disclosed. Student gender, while not an identified focus of this study, was designated on each student's corresponding seat on the respective seating charts. The purpose of such action was in anticipation of possible emergent data significant to the study. Differentiation between students with SLN and their nondisabled peers was not be made until all frequency tabulations and observations were completed. At that time, each student's desk on the seating chart was labeled as either "ND" to designate students without disabilities or as "SLN" to indicate students who qualified for special education services. In this manner, at least some effort to control my own biases was addressed.

During each observation, I documented the frequency of interactions between the teachers and their students. To do so, two copies of each seating chart were used during each observation period. The charts were copied onto two different colored sheets so that I was able to differentiate between the interactions of the content teachers and those of the special education teachers. (The seating charts for the content teachers were yellow, and the charts for the special education teachers were goldenrod.) Each time a teacher interacted individually with a student, a tally mark was made in the appropriate "seat" on the seating chart. In addition to monitoring the teacher-student interactions that occurred during each observation, anecdotal notes were prepared to accompany the individual interactions as well as those that I observed during whole- or small-group instruction. 
Reality is a dynamic, ever changing concept. As each interaction occurred it was tallied, the specific context of each observed interaction was noted, and the interaction was immediately categorized as instruction, elaboration, progressmonitoring or behavior management. Since there were multiple contexts that served as catalysts for interactions, it was essential that annotated descriptions of each interaction were included in the data collection.

Teacher Interview \#2 - After Observations. The purpose of in-depth interviewing is not to get answers to questions, nor to test hypotheses, and not to "evaluate" as the term is normally used. At the root of in-depth interviewing is an interest in understanding the experience of other people and the meaning they make of that experience (Seidman, 1998). In this case study, interviews provided significant, relevant information about the participants that observations could not provide. At the root of behavior is that which an individual thinks and how he perceives his experiences. What the observer notes is only a portion of the reality of the experience (Patton, 2002). Therefore, my goal during the second interview with teachers was to add depth and dimension to the co-teaching voice - individually and collectively. Questions for this interview emerged from observations; therefore, the second set of interview protocol (Appendix $\mathrm{H}$ ) for teachers was developed as an emergent set of questions. Both interviews served as part of the triangulation process in that each provided evidence supportive of observation data.

\section{Data Analysis}

Bogdan \& Biklen (2007) define data analysis as "the process of systematically searching and arranging the interview transcripts, field notes, and other materials that 
are accumulated" (p. 159). Patton (2002) suggests that although "analysis transforms data into findings, no formula exists for that transformation" (p. 432). According to Stake (1995), "there is no particular moment when data analysis begins" ( $p$ 71), therefore, it should be an ongoing part of the research process.

\section{Coding}

Digital recordings of each interview were converted to verbatim transcripts in preparation for data analysis. Accuracy of interview transcripts was determined by reading them while listening to the corresponding digital recording. Additionally, field notes, including observer comments and reflections, were transcribed. Once all transcriptions were prepared, I examined data from each site separately. I used three levels of coding (open-coding, axial coding, and thematic coding) to analyze and code each data set. From the very onset of data coding, all codes and their descriptors were compiled in a codebook both to provide organization of codes and to avoid confusion in data interpretation.

I used open-coding to identify concepts and interactions in each of the data sets individually. I read each data set and noted the types of interactions identified. Following the open-coding of all four data sets, I examined the results in all four sets collectively to identify similarities, what Patton (2002) refers to as "recurring regularities." Thus, through axial coding I identified categories common among all data sets. The third and final level of coding, thematic coding, occurred after categories and subcategories had been identified. This level of coding allowed me to identify emergent themes to which each of the categories were related. At this level, the relationships represented by teacher-student interactions were analyzed and 
interpreted. To ensure the accuracy of data analysis, draft copies of individual case studies were given to respective teachers for their review and comment.

Case analysis

"Conveying an understanding of the case is the paramount consideration in analyzing the data" (Merriam, 193). As Stake (1995) explains, in case study, the researcher attempts to understand behaviors, issues, and contexts from the perspective of the case itself. In this multi-case study, I collected and managed data for each individual case through interviews with each co-teacher and through observations of each co-taught class identified for study. I prepared transcripts and field notes, (including observer comments), after each interview and observation. From the perspectives that emerged, I was able to develop the thick, rich description required of meaningful qualitative analysis and reporting (Patton, 2002). Data from each case was organized, coded and interpreted so that the emergence of at least four individual perspectives - the photographs from the album - occurred.

Cross-case analysis

"In a multiple case study, there are two stages of analysis - the within-case analysis and the cross-case analysis. For the within-case analysis, each case is first treated as a comprehensive case in and of itself... Once the analysis of each case is completed, cross-case analysis begins" (Merriam, 1998, pp. 195-196). Upon completion of all observations and the compilation of field notes and transcripts from interviews, I reviewed the data to determine the existence of cross-case similarities or patterns that emerged. Because there was a significant amount of data, developing an appropriate management system included coding the data in such a way as to note 
emergent categories throughout. In an effort to effectively and efficiently manage the data collected, I began the coding process after the first set of interviews and observations had been transcribed.

Issues of Reliability and Validity

No qualitative study can be complete without a discussion of the issues of reliability and validity. "Reliability is concerned with the question of the extent to which one's findings will be found again" (Merriam, 1995, p. 55). The problem this posed for my study was the fact that both the inclusive classrooms and the interactions that occurred in them were dynamic. In other words, the events that occurred during a class period could never be quite the same at another moment in time. Much like a photograph, the instant the image is captured, it changes. So, qualitative research does not necessarily intend to replicate. Rather it seeks to determine "whether the results of a study are consistent with the data collected" (Merriam, 1995, p 56) or, as described by Patton (2002), whether or not the results are trustworthy. One method of determining the reliability of findings is through triangulation - the use of multiple methods of data collection or multiple sources of data to confirm emerging findings (Merriam, 1995; Patton, 2002).

External validity refers to "the extent to which findings from an investigation can be applied to other situations is determined by the people in those situations. It is not up to the researcher to speculate how his or her findings can be applied to other settings; it is up to the consumer of the research" (Merriam, 1995, p 58). Therefore, the issues of validity and trustworthiness in this study were addressed through the collection 
of data from multiple sources including interviews, observations, and member checks of the participants in the individual case studies. 


\section{Chapter 4}

\section{Case Studies}

The purpose of this study is to examine co-teaching in inclusive middle school classrooms through the perspectives of teachers and observations of the types and frequencies of interactions between teachers and students. Two research questions provided the framework for this study.

1. What are the perspectives of co-teaching that teachers identify from their experiences?

2. What types of interactions can be observed during co-taught, inclusive classrooms? With what frequency does each type occur? Are there identifiable patterns of interactions that occur?

Based on specific sampling criteria developed prior to the beginning of the study, four co-teaching pairs in four middle schools in southern West Virginia were selected as participants in this study. Each of the eight teachers was interviewed separately prior to classroom observations. Following the interviews, each of the four co-taught classrooms was observed during five class periods. During each observation, the frequency and type of interactions were recorded. Additionally, observation fieldnotes were written so that the context of the interactions could be included in each case study. After each set of observations was complete, each co-teaching pair was interviewed a second time. During this interview, however, teachers were interviewed with their respective co-teaching partners. The interviews were transcribed verbatim. Data from 
the interviews, observation fieldnotes, and interaction frequency tabulations were analyzed to develop each case. Within-case and cross-case analyses were conducted to answer the research questions and the resulting emergent themes common to all four cases provide a framework both for identifying characteristics of current co-teaching practice and for stipulating suggestions for future practice and research.

The four middle schools that were the focus of this study are located in the RESA-I region of southern West Virginia. Two of the schools are in Coalfield County which is situated in the extreme southern region of West Virginia. It borders three Virginia counties along its southern edges, and its remaining borders are shared with the five other counties in southern West Virginia. Coalfield County has only two schools that are designated as middle schools that house grades 6, 7, and 8. Chicory Middle, so named for the chicory flower native to the area, enrolled 576 students during the 2007-08 school year. According to state statistics for 2007, Coalton Middle, located in Coalfield's county seat of Coalton, enrolled 622 students during 2007-08. The remaining two schools in this study are located in Walter County located north of Coalfield County. Although Walter County has five schools designated as middle schools with grades 6-8, only two, Great Falls and Wright Middle (both located in the county seat of Alfredton), were included in this study. 2007 state statistics report that during the 2007-08 school year, Great Falls Middle enrolled 674 students, and Wright Middle enrolled 418 students. Similar in size and configuration, all four schools use some form of coteaching in inclusive math and English/language arts classes at grades 6, 7 and 8. Consequently, one math and one English/language arts class was selected from each county for study. To ensure that grade level content requirements were comparable, all 
classes selected were $6^{\text {th }}$ grade classes. Table 1 provides a brief summary of each school's location and enrollment; however, in the spirit of confidentiality, all names are pseudonyms.

Table 1

Summary of School Location and Enrollment

\begin{tabular}{|l|l|c|}
\hline \multicolumn{1}{|c|}{ County } & \multicolumn{1}{|c|}{ School } & Enrollment \\
\hline \multirow{3}{*}{ Coalfield County } & Chicory Middle School & 576 \\
\cline { 2 - 3 } Walter County & Coalton Middle School & 622 \\
\cline { 2 - 3 } & Great Falls Middle School & 674 \\
\cline { 2 - 3 } & Wright Middle School & 418 \\
\hline
\end{tabular}

A closer examination of each school's population provided in Table 2 reveals a breakdown of each school's total enrollment. The enrollment data identifies the schools as being similar in size and population. Additionally, the most recent designation of annual yearly progress (AYP) in both Mathematics and Reading are included in the table. Information for both Table 1 and Table 2 was taken from the West Virginia Department of Education's "WVEIS on Demand" site. 
Table 2

Statistical Comparison of Race, SES, and SPED Enrollment/AYP Results FY 2007-08

\begin{tabular}{|c|c|c|c|c|c|c|c|c|c|c|}
\hline & & & & & & & $\begin{array}{r}A \\
200 \\
\end{array}$ & $\begin{array}{l}P \\
-08\end{array}$ & $\begin{array}{r}\text { SPEL } \\
200 \\
\end{array}$ & $\begin{array}{l}\text { AYP } \\
-08\end{array}$ \\
\hline & $\begin{array}{l}\text { Enrollment } \\
\text { Total }\end{array}$ & WHITE & BLACK & OTHER & SES & SPED & MATH & RDNG & MATH & RDNG \\
\hline $\begin{array}{c}\text { Coalfield } \\
\text { County }\end{array}$ & & & & & & & & & & \\
\hline $\begin{array}{l}\text { Chicory } \\
\text { Middle }\end{array}$ & 576 & $\begin{array}{l}435 \\
76 \%\end{array}$ & $\begin{array}{l}134 \\
23 \%\end{array}$ & $\begin{array}{c}* \\
7 \\
\text { Reported } \\
1 \%\end{array}$ & $\begin{array}{l}403 \\
70 \%\end{array}$ & $\begin{array}{c}97 \\
17 \%\end{array}$ & Y & $Y$ & Y & Y \\
\hline $\begin{array}{l}\text { Coalfield } \\
\text { Middle }\end{array}$ & 622 & $\begin{array}{l}572 \\
92 \%\end{array}$ & $\begin{array}{l}47 \\
7 \%\end{array}$ & $\begin{array}{c}* \\
8 \\
\text { Calculated } \\
1 \% \\
\end{array}$ & $\begin{array}{l}348 \\
56 \%\end{array}$ & $\begin{array}{c}95 \\
15 \%\end{array}$ & $Y$ & $Y$ & $\mathrm{~N}$ & $\mathrm{~N}$ \\
\hline $\begin{array}{l}\text { Walter } \\
\text { County }\end{array}$ & & & & & & & & & & \\
\hline $\begin{array}{l}\text { Great Falls } \\
\text { Middle }\end{array}$ & 674 & $\begin{array}{c}493 \\
73 \%\end{array}$ & $\begin{array}{l}165 \\
24 \%\end{array}$ & $\begin{array}{l}16 \\
2 \%\end{array}$ & $\begin{array}{l}409 \\
61 \%\end{array}$ & $\begin{array}{l}141 \\
21 \%\end{array}$ & $Y$ & $Y$ & $Y$ & $Y$ \\
\hline $\begin{array}{l}\text { Wright } \\
\text { Middle }\end{array}$ & 418 & $\begin{array}{l}399 \\
99 \%\end{array}$ & $\begin{array}{c}* \\
4 \\
\text { Reported } \\
1 \%\end{array}$ & $\mathrm{~N} / \mathrm{A}$ & $\begin{array}{l}231 \\
57 \%\end{array}$ & $\begin{array}{c}61 \\
15 \%\end{array}$ & $Y$ & $Y$ & $Y$ & $Y$ \\
\hline
\end{tabular}

*Indicates a cell with fewer than ten students. 


\section{Chicory Middle School}

Chicory Middle School was built in the late 1990s. It is located on a hill above the Chicory city park and the city's recreation center and stadium. At the base of the entrance to the school are two reminders of the city's heritage. Signifying its pioneer origins is a log cabin said to have belonged to one of the first settlers who arrived shortly after the American Revolution. A second symbol of the city's heritage, a steam locomotive of the Norfolk and Western Railway, sits just across the road at the city park. It serves as a reminder of the prosperity that both the railroad and coal brought to the region. At the top of the hill, the middle school building itself is a relatively new building in good condition, and the grounds are well kept. Yet, each time I arrived at the school, as I walked toward the building I couldn't help but notice how isolated the school seemed to be even though I knew that at the bottom of the hill were places teeming with activity... all within a few hundred yards of the school. It was as quiet and peaceful as a building would be if it were situated on a remote mountaintop with nothing for miles around to disrupt the silence. Interestingly, it was just as quiet inside.

At the entrance of the school, just inside the front doors and to the right, is a large mural of the school's mascot standing on the shore of an unknown beach. The mural consumes an entire wall. It is an excellent display of student artwork...and a lasting testament to the artistic talent within the student body. To the left, just past the stairway doors, is the office. Two desks which face each other are located just behind a large counter where sign-in/sign-out books for visitors, students, and college students are kept. The two desks in the center of the office are just outside three administrative offices. The principal's office, however, is to the right and down a hallway which opens 
into a workroom, a storage room and several more administrative offices. Along the walls of the office are more displays of student artwork.

\section{Caryn and Micah}

Caryn holds an Elementary K-8 license, but because of a change in state licensing procedures, her certification is only recognized as Elementary K-6. As such, she is not certified to teach math to students any higher than grade 6 , yet she is considered highly qualified to teach $6^{\text {th }}$ grade mathematics by virtue of her experience and extensive training in standards based mathematics. She has taught a total of 14 years -6 of which have been in a co-teaching configuration. Caryn and Micah have taught together for the past two years.

Micah holds an Elementary K-8 multisubject license. He also has special education certifications in learning disabilities, behavior disorders, and mental impairments K-Adult. As with Caryn's license, the state recognizes Micah's elementary license as only an Elementary K-6 license. Because the state requires that special education endorsements are in conjunction with a content certification, his special education endorsements are only recognized through grade 6 . Micah has been teaching a total of seven years; all of which have been in co-teaching situations. What makes Micah's experience somewhat unique is that he has co-taught from both "sides" of the partnership perspective. For three years he co-taught as a regular education teacher with a special education teacher as his co-teaching partner; the remaining four years he has served as the special education teacher in the co-teaching partnership. For the past two years he has been the special educator in a co-teaching classroom 
with Caryn. As Caryn and Micah explain, much of their preparation in the models of coteaching has come from a combination of professional development opportunities provided by their school system and their own personal experiences with co-teaching. In fact, neither has received extensive formal training in co-teaching models and techniques. When asked about their preparation for working in a co-teaching situation, both talked about co-teaching as if it were synonymous with inclusion. Throughout the course of this study, I came to understand that, in many ways, for the participants in this study it is. I began to see that, by virtue of the fact that co-teaching is a method now often used as a means of ensuring that students with special learning needs (SLN) are taught in their least restrictive environment (LRE), inclusive environments are often more effective when they are co-taught by a content specialist and a certified special education teacher. What I witnessed in Caryn and Micah's classroom was evidence of the positive results that can occur when, as Caryn says, "it works the way it was meant to work." When I asked her to elaborate, she explained:

It's supposed to be a shared teaching experience. It's not supposed to be my classroom, and he's intruding on my classroom. He's supposed to be as much of this class as I am. I don't think...I don't know that you'll ever have that ideal set up. Like the women that came and visited us the first time...they were like Siamese twins. You know, they worked 50-50 on everything. And I think, where you have anybody who's not in the content...he doesn't have the content training and the standards base that I do...I don't have the special ed training he does. So it's NEVER going to be 50-50. He's always going to be better at something I'm not... and I'm always going to be a little better at something that he's not, and it'll balance itself out somewhere. But I don't think $50-50$ is ever going to happen.

She went on to explain how the co-teaching arrangement that she had with Micah was probably the best she'd had in her experiences in a co-teaching situation: 
I think this is the first time that l've felt...since the six years that l've done it...that there's that balance there that's almost perfect...that, you know, when he's in his area where we're having a problem getting through to them, and I don't know what else to do, he knows what to do. And when they get it and we can go on, then he just kind of holds ground and we keep going and we go with the content. And that balance, I think, is where it's meant to be... where it's supposed to be. And those other years, it wasn't. It was, you know, you lean more towards that old 'they're helping me out' or, you know, something like that. In past years I felt that way, and I don't feel like that anymore.

There are two co-taught, inclusive sixth grade math classes at Chicory; one is taught in the morning, and the other is taught in the afternoon. Both are taught by Caryn and Micah who offered either class for observation. Following their interviews, I chose the morning class as the class to include in this study. The class had 18 students when all were present; six of them were students with special learning needs who were identified as individuals with either mild mental impairments or learning disabilities. There were eight girls and ten boys. One of the students, however, identified as A-S19, was not actually enrolled in the inclusive class. He usually received math instruction with four other students in a pullout classroom, but as Caryn explained during her interview prior to my observations, he needed to experience math instruction from a content teacher in preparation for the upcoming Westest:

We are going to have a student come into that classroom that has been in the pullout program all year long. He is the only in that group that doesn't have an IEP for alternate assessment. Everybody in his room is going to be alternate assessment except for him. So now, all of a sudden they've decided it would be a good idea if he got some experience in the regular classroom. So they're going to put him down here in here for the last two weeks before Westest. ... See, the instructional coach said he doesn't know how to use a calculator...that's going to alter our classroom atmosphere a little bit. I think if he were just here and soak some of it in, I think he'd be okay. 
Although her apprehension was evident, Caryn was not only willing to allow the student to be a part of the class, but she was also confident that being in the included environment would be to his benefit even if the gains were minimal. During the second interview, a joint interview with both Caryn and Micah, additional information about this situation surfaced. The information was significant in that it gave an example of the type of knowledge that both Caryn and Micah have of the students they serve. It also revealed their belief in the effectiveness of their co-teaching:

Micah: He can do some thinking. He can do some work, but the problem with him is behaviors and also his mother...or his step-mother. (to Caryn) Remember, he was with us...

Caryn: He was in my room the very beginning of the year...

Micah: First of the year...and then he went home complaining...said it was too hard. Momma stepped in and said, "We want him back in special ed classes." So they pulled him out into special ed classes. Then they got to looking at his test scores; he was so close to passing last year...really close to passing last year.

NB: How do you think the co-teaching that you two have would have benefitted him all year?

Micah: Simply because whoever is teaching in front, the other could work with him one-on-one.

The effectiveness of Caryn and Micah's co-taught classroom is not something that has come without challenges at Chicory Middle School. In the beginning when Micah first arrived at Chicory Middle, he was assigned to co-teach with six different teachers. Instead of co-teaching with one teacher in one content area, the students he served were grouped together so that he could follow them throughout each day from one class to the next. As Micah put it, "my core group of special ed kids and the other 
group, the way the rotation was set up, they all traveled from one teacher to another.

So I had like 30 preparations to do a day because I went with the kids."

Both Caryn and Micah agree that current configurations are far more acceptable and successful. In fact, the success of their partnership goes beyond opinion or personal belief as documented in the Westest math scores after their first year together as co-teachers. Caryn, obviously proud of the accomplishment, boasted that the overall $6^{\text {th }}$ grade math scores following that first year "went from $20 \%$ mastery to over $60 \%$ mastery." Micah added, "Our scores, as far as the $6^{\text {th }}$ grade, were one of the tops in the state as far as with special needs kids. And we had some difficult kids last year." Such results prompted the principal to offer them the same co-teaching set up for a second year. At the time of this study, however, the Westest had not been administered so there is no data to determine if the partnership continues to enjoy the same level of success. I should note that while Micah believed that co-teaching "had to have had" a direct impact on the increase in scores, Caryn was quick to attribute the students' increased levels of mastery to a combination of factors, one of which was co-teaching:

There would have been several things going on there. One may have been we switched to 90 minutes for just the special ed kids. That could have been part of it. Part of it was that we were co-teaching together. ...And it finally clicked and worked the way it was meant to work. ...We also are deep into the standards based math. There's a lot of research that shows that that's helping these lower kids to bring things up. So we've got that going on at the same time, so I think the combination of all those things at the same time...you know...I don't know that you can say it's one or the other.

Regardless, it was plain to see that much of the success in their classroom has come from their knowledge and understanding of the students they serve and their willingness to try to meet their individual learning needs. Equally plain to see was the 
level of involvement these teachers had with their students during instructional time.

During observations, not only were the students actively engaged throughout the entire 90 minutes of class, but both Caryn and Micah were also actively engaged. Neither sat behind a desk while students worked; both were accessible and approachable whenever a student began to struggle. They moved about the room monitoring students as they worked, offering assistance as needed, and keeping students focused and on task. The rapport they had with students was such that everyone, even the least vocal, appeared comfortable and willing to participate.

\section{Co-teaching Partnership/Roles and Responsibilities}

Understanding the interactions between teachers and their students during cotaught instruction requires an understanding of how teachers themselves have been impacted by co-teaching. Although Micah offered no specific information about the impact co-teaching has had on him, it is evident that he enjoys what he does. Caryn had this to say:

I think it makes you a better teacher as far as you see things that you wouldn't normally see....he can see things that I'm doing that I don't necessarily see... or if I'm getting frustrated with their ability where I've tried six different ways and I can't get it, he knows when to step in and say, 'You know, we need to try something different.' And if you're in a classroom by yourself, there's nobody there to do that for you. So I think it grounds me better as a person; it grounds me to be more in control of what I'm doing....I think that makes you a better teacher because you're more aware, I think, when you have somebody else in the room.

Caryn and Micah work well together despite the fact that theirs is an assigned partnership which was actually the result of previous, less effective attempts at coteaching. While both teachers are not necessarily critical of previous efforts, both are 
openly more satisfied with their assigned partnership. As I watched them work, I could sense an excitement and passion for what they did. It was obvious to me that they enjoyed their work. They appeared to have similar teaching styles and philosophies, and they exemplified the type of co-teaching partnership that is essential to successful co-teaching.

The roles and responsibilities of effective co-teaching are numerous. While both Caryn and Micah are actively engaged with students during instructional time, there is a subtle distinction between the two that clearly indicates Caryn as the lead teacher. Her confident attitude and obvious content knowledge base set her apart from Micah who, even though he knows the content, is quick to follow her lead. Beyond that distinction, both teachers have their own beliefs about the roles they fulfill in the classroom. Caryn is aware of her responsibility to appropriately serve the students she encounters. Inherent in that service is the ability to recognize that not all students who are eligible for special education services are identified as students with special learning needs. As she stated, "...there's sometimes you have a regular class that you have a special needs kid that's either identified or not.... If you have a kid that's undiagnosed or unidentified in your class, you're going to have to come up with some techniques or strategies to teach them."

Micah is also very clear about the roles and responsibilities he has. He is not only responsible for co-teaching two classes with Caryn, but he is also responsible for teaching classes of his own. He explained, "Because of the numbers in the special ed department and, of course, good 'ole fashioned cutbacks, we don't have the man power for the pull out classes. So instead of having two planning periods like everybody else, 
special ed teachers have one... because someone has to teach the pullout classes." He also has non-instructional duties which require a significant amount of his time during each day.

Key to any teacher's effectiveness is the type and quality of planning that is done. While it is essential that co-teachers have opportunities to co-plan, time and opportunity may not be readily available. Because Micah is often performing "a lot of non-instructional duties," he frequently does not have opportunity to plan with Caryn. Additionally, as Caryn explained, Micah does not attend the $6^{\text {th }}$ grade math teachers' planning sessions because of other teaching obligations. The fact that Micah is frequently called out because of other issues in the building is one reason Caryn does not believe their co-teaching relationship will ever be $50-50$. She believes she needs to prepare the lesson plans according to what level of understanding she gauges the students to have because Micah may not always know the students' current levels of understanding. Additionally, Caryn sees herself as the content specialist whose responsibility is to prepare "at least the framework of the lesson plans" because she knows the content. Then, once the framework is developed she and Micah adjust it for the students with special learning needs. Opportunities to discuss Caryn's plans do occur periodically. Micah explains:

Generally on Friday we talk about what we're going to do. Every day, Caryn goes over the homework at the beginning of the period. And then, as she's doing that, I know exactly who was absent the day before... who is struggling or whatever, and that's when I'll pull a chair and sit down beside them and then we'll go through what they need to know. Sometimes, if there is content I like to do, I'll be the lead... but usually I assist... basically sneaking life skills in... how to use a ruler...how to...the little things they need to know... and I always chime 
in every day...you know...'One of you all are going to be on a construction site... you need to know this.' Something like that...

Use and Impact of Technology

The use of technology in instruction has become increasingly more popular as more emphasis continues to be placed on $21^{\text {st }}$ century learning skills. While technology use was not a focus of this study, it emerged from the data as a regular feature of the classrooms in the study. In fact, all four schools in this study used some form of technology on a daily basis. In my experiences, I have found that the classroom use of technology is often a topic of discomfort with teachers who are either not interested in learning the skills required to be proficient in classroom technologies or who claim that they do not have the time to incorporate technology in their already crammed schedules. Caryn and Micah didn't seem to harbor either of these feelings

At Chicory Middle School, Caryn used a document camera, whiteboard, and Smartboard was an effective way to engage students both individually and as a group during whole group instruction. Although student names are hidden from view, they see their own work projected onto the whiteboard for analysis and necessary corrections and feedback. They are also familiar enough with the Smartboard that Caryn and Micah frequently call on students to come up and demonstrate their solutions to specific problems. Because technology was used daily and the students were so comfortable with it, I asked Caryn and Micah about how its use has impacted their instruction and student opportunities to learn. They responded quite enthusiastically:

Caryn: I always use it for anything that's paper because the kids do better if you can say..."look at this direction here....read it in your book." And you read this direction and I can cover it up and they can see specifically 
what I'm talking about...and I can point to it...that type of thing. So, I use the document camera any time that I would have normally just put a book on the podium and talked like that. If they're doing anything they're sharing work, I would always have them come up and show some of their work up under the document camera.

Micah: Anytime it can be used to do, like, color coding...'cause it's so easy to change the colors...You can highlight one thing in yellow and then do something else and go back and highlight the next step in orange....and then they can see how that works.

NB: So how would you describe the impact that the technology has had as far as enhancing your instruction?

Micah: It keeps them focused.

Caryn: Oh, it's fabulous! It keeps them focused; they anticipate wanting to come up and help so they pay better attention. If you notice you're losing a group, you can throw something like that in there... and they're like..."Oh, I want to, yeah...I want one, I want to go, I want to go..." and they like that.

MJ: Yeah, you pull one kid out and have them come and write on that thing....and they're ready to go. They want to do it.

Caryn: ... and they're all paying attention...they're wired all the time. It's the way they're wired themselves right now, so that's what they understand. I would not want to teach without it.

NB: That's interesting! Really? You feel that comfortable with it?

Caryn: Yes, yes. If I changed schools, that would be one of my major sticking points. I would want to have that in my room. I don't know how l'd make it going back to a... back to that. I've used on here... to make it relevant to them....we've pulled up pictures of places that have parallel lines, or... if they ask a question....now sometimes we get off task that way, but sometimes it helps to keep their interest. If we're talking about something we can get online and find something that answers a question, they'll say "well, how come that doesn't work here?" We'll just bring it up on the computer. When we were talking about pi, I just... while they were doing their assignment, I just clicked on the computer what pi looks like for real and brought it up. They're just sitting there working and all of a sudden they look up and they're "What is that" and I explain it and they were like, "Ohhhh...." Then they understood what non-terminating number is. 
It was apparent that technology is an integral part of Caryn and Michael's daily instruction.

Interactions with Students

During observations the atmosphere in the classroom is relaxed but there is no mistaking that Caryn and Micah are indeed in charge. The rapport they each have with their students is comfortable enough that they often use humor during instruction and even joke with students from time-to-time. What struck me as most significant about the atmosphere or tone of the class was that even when there were some acting-out behaviors, the atmosphere did not change. Misbehaving students were calmly redirected and eased back into what ever activity was occurring - often without any disruption to the activity or instruction. It appeared that combined with the rapport that had been established, both teachers were actively engaged with the students and were aware of their levels of participation for the duration of each 90-minute class period.

Micah and Caryn have a working relationship that appears much more comfortable and productive than one might expect from just two years together as coteachers. Although Caryn most frequently assumed the role of lead teacher, Micah was free to take the lead as appropriate, to move freely among the students to offer assistance or individual instruction as needed, or to lead the group in solutions, often alternate paths to solutions, of specific problems that seemed to cause some students significant difficulty. Additionally, Micah often interjected additional information, suggested a particular problem solving strategy, or provided visual aids to assist students in their comprehension of both the problems and their solutions. Frequently he 
offered information that may, as he explained it, "someday, be useful to a student in his or her daily life."

Caryn and Micah know their students; they understand their needs and can discuss details of many of their students' family circumstances. Their interactions with their students are often more familiar as a result. While much of the instruction that occurs in their classroom would be classified as whole group instruction, both teachers are familiar enough with the individual needs of their students that there are multiple incidents of individualized instruction or assistance provided by both throughout a class period. In fact, while Caryn is presenting content, Micah frequently sits or kneels beside struggling students to provide individual assistance to help keep them on pace.

A comfortable routine has been established with the group I observed. As students enter the classroom each day, they typically go to their assigned seats and take out their materials. Each class period begins with a warm-up problem which is projected onto the whiteboard at the front of the room. The problem is an example of the type of problems that students will be working with during the class period. On my first visit, students were working on constructed response problems in preparation for the upcoming Westest. In successive visits, students worked on such topics as surface area, setting up word problems, polygons, and the creation and interpretation of bar and pictographs. Students, for the most part, immediately begin working to find a solution to the day's problem. It is a time for students to prepare their thoughts for the day's lesson; it is also a time that both Caryn and Micah have an opportunity to identify specific issues that may need to be addressed. 
As the students work, Caryn and Micah move about the room monitoring student progress and offering assistance as needed. Once students have been given enough time to reach a solution to the problem, all papers are collected. Each paper is projected onto the whiteboard and is checked with the group. Caryn takes great pains to keep students' names concealed while their papers are projected on the screen. All responses are immediately addressed and students are provided with either praise for correct answers or with immediate, corrective feedback for incorrect responses. Since none but each paper's owner recognizes each paper, none of the students seem to mind receiving general praise or corrective feedback. To the contrary, they seem to respond very positively to the attention and acknowledgement, albeit anonymous, and often appear to feel free to discuss particular problems they may have encountered.

Homework is assigned each night. Following the warm-up activity, Caryn checks attendance and homework simultaneously. As she calls each student's name, the expected response is either a "yes" or a "no" indicating whether or not the student has completed the homework assignment. Most often students simply respond with a oneword answer, but if a student has had difficulty with an assignment, or has only completed part of the assignment, the attendance/homework check portion of class provides an opportunity for students to interact individually with Caryn. The procedure, therefore, ensures that every student who is present has some level of interaction with Caryn on a daily basis. Since every student is acknowledged at least twice during class - once during the warm-up session and once during the attendance/homework check there is little opportunity for any student to be left out or to go unnoticed. Additionally, the established routine is about more than just homework completion. Caryn and Micah 
take pride in the fact that there is more than just math taught in their classroom. In

many ways, it's about establishing skills and a work ethic that will serve the students

well as they continue to move through Chicory Middle. The routine is also about

knowing their students' patterns of behavior. Caryn and Micah explained:

Caryn: ....at the beginning of the year, I did little pink papers back there where if they didn't have it [homework] l'd give them a pink paper. And they had to fill out why they didn't have it. When they got three, I called home. And we did that until about the half way point. By that point you had a pattern...you knew...their parents knew at that point whether or not they were doing their homework or not. And if they were choosing to do something about it, they were going to do something about it. So I didn't bother beating a dead horse.

Micah: We spent the first two or three weeks of school...we'd ask "Did you do your homework?" And if they didn't give us a verbal response, they got in trouble. After that, they have to go through about a week of "yes sir" or "no ma'am".

Caryn: And if I start to get suspicious that they're lying to me, that they're telling me they have it when they don't quite, what I do is as soon as I'm finished I just mentally remember who told me they didn't have it, then I just real quick, while I'm checking I'll walk through...I do that on my homework sheet. I mark either they did it all, they didn't do it at all, they did half, they did the wrong page, they have a parent note.... and I look for patterns. And if they did half a page one day...it was a tough assignment...I'm not worrying about it. But if it's one day, then I have their "my dog ate it; I left it in my locker; I did the wrong page; I did the odds, and you said the evens;" then I start to worry about it.

Micah: You work hard! That's the way that we do the best of anything that we do... is they come in here...normally, by the end of the year, $99 \%$ of the kids understand that they have to work hard. And this year I was fortunate enough to loop with the seventh graders that we had last year, and that work ethic was basically still there. They knew they needed to do their homework. They brought it in on a daily basis. It wasn't always right...but they brought it in.

Once the attendance/homework check is complete, Caryn, positioned at the desk with the document camera, begins to go over each of the homework problems. She does this by projecting the problem on the whiteboard and then proceeds to model how 
to work the problem so that students both hear and see the solution process from start to finish. Often as Caryn is going over the homework, she calls on students to share the strategies they used to set up and complete the problems. Sometimes she has students work in pairs or small groups to share strategies they have used to solve a particular problem. Micah moves among the rows of students to assist them in checking their work. When he sees that a student has an incorrect answer or that a student is having difficulty understanding Caryn's instruction, he provides the individual instruction necessary to help the student gain a better understanding. Frequently, Micah also interjects strategies for solving problems and then models how to use the strategy he has shared. It is interesting to note that sometimes the strategies are not specific to mathematics but are more specific to test taking strategies. For example, as Caryn reads each problem aloud to the students, she emphasizes what information each problem is seeking. She stresses each item or task to be completed to ensure that students know what they need to know or what they need to do to complete the problem accurately. Micah interjects, "one strategy that is useful with multiple step problems or with problems that have a lot if information is to underline the key words in each problem." He then models underlining the key words as Caryn reads the problem aloud. The whole group has the opportunity to benefit from the strategy.

Instruction and reinforcement are provided by both teachers. Each lesson incorporates some discussion or activity that activates students' prior knowledge and ties the information to something that is presumably relevant to students' lives. On one particular occasion, students were completing problems that required the interpretation of pictographs. It was obvious that the students had been exposed to pictographs in 
earlier lessons because Caryn asked if anyone remembered what a pictograph was.

She referred to the example of a picture of a cow - an example that had evidently been used in a previous class because students understood the connection and were immediately able to explain what a pictograph is. Micah then related pictographs to social studies and used the example of how crops are indicated on maps in the social studies text to represent agricultural resources. He also used other examples of how pictographs are used across the $6^{\text {th }}$ grade curriculum.

Although Micah provides more individual instruction than does Caryn, there are still times when she pulls students aside to address their specific needs. During one observation, Caryn called some of the students into the hall to speak with them privately. I had not noticed any behaviors that would warrant such a private discussion, so after class I asked Caryn what the purpose was. She explained that she had called those particular students out of class to go over their individual progress and to get their personal commitment to do their best on the Westest. During our second interview, when I asked for more information about the incident, she provided more details. She explained:

The students have a little check sheet that tells them where they scored on the Westest last year. There's a numerical score and we call the "Westest Talks"..."Test Talks"... and we show them where mastery is an how close they were to it. And they made themselves a goal of if they were try8ing to shoot for mastery, above mastery, whatever. And then to show them...two more questions and you would have made it...two more questions and you're going to lose it... and five them a gauge so they know what their own personal goal is. And then if they have any concerns at that point...like that one little girl at the end of the day...I took her out. She doesn't do well on tests at all, and she's one of my best kids... plummets on tests...took her out and asked her, 'Is there something that's... do you need a quieter room...you need a warmer 
room...you need...?' You know, what can we do within our means to help?

She had created an opportunity to give these students individual attention and encouragement that they did not have to share with anyone else in the class.

\section{Frequency Data}

A significant part of my observations focused on both the frequency of interactions that occurred between the teachers and their students and the purposes for those interactions. Consequently, during each observation, as I made note of each interaction, I assigned a purpose for the interaction based on what I saw and heard during the exchange. As a result of the frequency tabulation and accompanying purposes, the data I collected allowed me to identify several types of interactions that occurred. Initially, one table for each teacher was developed to summarize the total number of teacher interactions and their corresponding purposes that occurred during instruction (See Appendices I through P). It became apparent, however, that although some general conclusions could be drawn base on those initial tables, the overall data lacked the context that both the daily frequency data and observation data provided. Therefore, data was re-organized and tables containing frequency data for each day, and for each teacher (the general educator and the special educator) were prepared. It should be noted that students with Special Learning Needs (SLN) are designated by the highlighted areas on each table.

Tables $3-7$ present Micah's daily interactions with his students. It is immediately evident that Micah's most frequent type of interaction is to assist students. It is interesting to note, however, that his assistance is provided to more general 
education students than to students with special learning needs. Yet this is consistent with the subtle "attitude' of inclusion depicted in the case narrative. As shown in Tables 8-12, Caryn not only provides students with assistance, but she also provides a significant amount of corrective feedback. Like Micah, most of her interactions are with the general education population. A survey of the tables reveals that of the eighteen students listed, only six are identified as students with SLN. Therefore, it would be reasonable to expect that more interactions with general education students than with students with SLN would occur. What stand out are the differences in the number of Caryn's and Micah's daily interactions. The numbers alone would seem to suggest that Micah's interactions with students are minimal. Yet, what the tables do not indicate is the amount of time Micah spends with each student he assists or for whom he provides individual instruction. In fact, often during my observations, Micah sat or kneeled beside a struggling student for several minutes at a time - something I had the presence of mind to note but failed to see the impact of such actions at the time.

As previously stated, of the eighteen students in Caryn and Micah's class, six are identified as students with SLN. The significance of this information becomes apparent when a comparison is made between the total interactions with students with SLN and the general education student. 
Table 3: Observation 1 - Frequency Data - Chicory Middle School - SPED Teacher

\begin{tabular}{|c|c|c|c|c|c|c|c|c|c|c|c|c|c|c|c|c|}
\hline $\begin{array}{c}\text { Student } \\
\text { Seat \# }\end{array}$ & $A$ & CF & $\mathrm{CO}$ & D & $E$ & EXP & $\mathrm{H}$ & $\mathrm{H} / \mathrm{J}$ & II & $P$ & PM & $\mathrm{Q}$ & $\mathrm{R}$ & $\mathrm{RA}$ & $S$ & TOTAL \\
\hline 1 & 3 & & & & & & & & & & & & & & & 3 \\
\hline 2 & & & & & & & & & & & & & & & & NONE \\
\hline 3 & 1 & & & & & & & & 2 & & & & & & & 3 \\
\hline 4 & & & & & & & & & & & & & & & & NONE \\
\hline 5 & & & & & & & & & & & & & & & & NONE \\
\hline 6 & & & & & & & & & & 1 & & & & & & 1 \\
\hline 8 & & & & & & & & & & & & & & & & NONE \\
\hline 9 & & & & & & & & & & & & & & & & NONE \\
\hline 10 & 1 & & & & & & & & & & 1 & & & & & 2 \\
\hline 11 & & & & & & & & & & & & & & & & NONE \\
\hline 12 & 1 & & & & & & & & & 1 & & & & & & 2 \\
\hline 14 & & & & & & & & & & & & & & & & NONE \\
\hline 15 & & & & & & & & & & & & & & & & NONE \\
\hline 16 & & & & & & & & & & & & & & & 1 & 1 \\
\hline 17 & 1 & & & & & & & & & & & & & & & 1 \\
\hline 19 & 1 & & & & & & & & 1 & & & & & & & 2 \\
\hline 20 & 2 & 1 & & & & & 2 & & 1 & & 1 & & & & & 7 \\
\hline 24 & & & & & & & & & & & & & & & & NONE \\
\hline TOTAL & 10 & 1 & & & & & 2 & & 4 & 2 & 2 & & & & 1 & 22 \\
\hline
\end{tabular}
$A=$ Assist
$\mathrm{CF}=$ Corrective Feedback
$\mathrm{CO}=$ Called on to answer question
$\mathrm{D}=$ Discipline
$\mathrm{E}=$ Encourage to engage

EXP = Explanation

$\mathrm{H}=$ Called into Hallway

$\mathrm{H} / \mathrm{J}=$ Humor/Joking

II = Individualized Instruction

$\mathrm{P}=$ Praise
$\mathrm{PM}=$ Progress Monitoring

$\mathrm{Q}=$ Student asked question

$\mathrm{R}=$ Teacher responds to question

$\mathrm{RA}=$ Read Aloud

$\mathrm{S}=$ Social

INDICATES STUDENT W/SLN 
Table 4: Observation 2 - Frequency Data - Chicory Middle School - SPED Teacher

\begin{tabular}{|c|c|c|c|c|c|c|c|c|c|c|c|c|c|c|c|c|}
\hline $\begin{array}{l}\text { Student } \\
\text { Seat \# }\end{array}$ & $A$ & CF & $\mathrm{CO}$ & $D$ & $E$ & EXP & $\mathrm{H}$ & $\mathrm{H} / \mathrm{J}$ & II & $P$ & $P M$ & $\mathrm{Q}$ & $\mathrm{R}$ & $\mathrm{RA}$ & $S$ & TOTAL \\
\hline 1 & & & & & & & & & & & & & & & & NONE \\
\hline 2 & & & & & & & & & & & & & & & & NONE \\
\hline 3 & 1 & & & & & & & & & & & & & & & 1 \\
\hline 4 & & & & & & & & & & & & & & & & NONE \\
\hline 5 & 1 & & & & & & & & 1 & & & & & & & 2 \\
\hline 6 & & & & & & & & & 1 & & & & & & & 1 \\
\hline 8 & & & & & & & & & & & & & & & 1 & 1 \\
\hline 9 & & & & 1 & & & & & & & & & & & & 1 \\
\hline 10 & & & & & & & & & & & & & & & & NONE \\
\hline 11 & & & & & & & & & & & & & & & & NONE \\
\hline 12 & & & & & & & & & & & & & & & & NONE \\
\hline 14 & 3 & 2 & & & & & & & & & & & & & & 5 \\
\hline 15 & & & & & & & & & & & & & & & & NONE \\
\hline 16 & 1 & & & & & & & & & & & & & & & 1 \\
\hline 17 & & & & & & & & & & & & & & & 1 & 1 \\
\hline 19 & 2 & & & & & & & & 1 & 1 & & & & & & 4 \\
\hline 20 & 1 & & & & & & 1 & & & & & 1 & & & & 3 \\
\hline 24 & 1 & & & 1 & & & & & 2 & & 1 & & & & & 5 \\
\hline TOTAL & 10 & 2 & & 2 & & & 1 & & 5 & 1 & 1 & 1 & & & 2 & 25 \\
\hline
\end{tabular}
$A=$ Assist
$\mathrm{CF}=$ Corrective Feedback
$\mathrm{CO}=$ Called on to answer question
$\mathrm{D}=$ Discipline
$\mathrm{E}$ = Encourage to engage
EXP = Explanation
$\mathrm{H}=$ Called into Hallway
$\mathrm{H} / \mathrm{J}=$ Humor/Joking
II = Individualized Instruction
$\mathrm{P}=$ Praise
$\mathrm{PM}=$ Progress Monitoring
$\mathrm{Q}=$ Student asked question
$\mathrm{R}=$ Teacher responds to question
$\mathrm{RA}=$ Read Aloud
$\mathrm{S}=$ Social

INDICATES STUDENT w/SLN 
Table 5: Observation 3 - Frequency Data - Chicory Middle School - SPED Teacher

\begin{tabular}{|c|c|c|c|c|c|c|c|c|c|c|c|c|c|c|c|c|}
\hline $\begin{array}{l}\text { Student } \\
\text { Seat \# }\end{array}$ & $A$ & CF & $\mathrm{CO}$ & $\mathrm{D}$ & $E$ & EXP & $\mathrm{H}$ & $\mathrm{H} / \mathrm{J}$ & II & $P$ & $P M$ & $\mathrm{Q}$ & $\mathrm{R}$ & $\mathrm{RA}$ & $\mathrm{S}$ & TOTAL \\
\hline 1 & & & & & & & & & & & & & & & & NONE \\
\hline 2 & & & & & & & & & & & & & & & & NONE \\
\hline 3 & & 1 & & & & & & & & & & & & & & 1 \\
\hline 4 & & & & & & & & & & & & & & & & NONE \\
\hline 5 & & & & & & & & & & 1 & & & & & & 1 \\
\hline 6 & 1 & & & & & & & & & 1 & & & & & & 2 \\
\hline 8 & & & & & & & & & & & & & & & & NONE \\
\hline 9 & & & & 1 & & & & & & & & & & & & 1 \\
\hline 10 & & & & & & & & & & & & & & & & NONE \\
\hline 11 & 1 & & & & & & & & & & & & & & & 1 \\
\hline 12 & & & & & & & & & & & & & & & & NONE \\
\hline 14 & & & & & & & & & & & & & & & & NONE \\
\hline 15 & & & & & & & & & & & & & & & & NONE \\
\hline 16 & & & & & & 1 & & & & & & & & & & 1 \\
\hline 17 & & & & & & & & & & & & & & & & NONE \\
\hline 19 & 2 & & & & & & & & & & & & & & & 2 \\
\hline 20 & & & & 1 & & & & & & & & & & & 1 & 2 \\
\hline 24 & 1 & & & 1 & & & & & 2 & & & & & & & 4 \\
\hline TOTAL & 5 & 1 & & 3 & & 1 & & & 2 & 2 & & & & & 1 & 15 \\
\hline
\end{tabular}
$A=$ Assist
$\mathrm{CF}=$ Corrective Feedback
$\mathrm{CO}=$ Called on to answer question
$\mathrm{D}=$ Discipline
$\mathrm{E}$ = Encourage to engage
EXP = Explanation
$\mathrm{H}=$ Called into Hallway
$\mathrm{H} / \mathrm{J}=$ Humor/Joking
II = Individualized Instruction
$\mathrm{P}=$ Praise

$\mathrm{PM}=$ Progress Monitoring

$\mathrm{Q}=$ Student asked question

$\mathrm{R}=$ Teacher responds to question

$\mathrm{RA}=$ Read Aloud

$\mathrm{S}=$ Social

INDICATES STUDENT w/SLN 
Table 6: Observation 4 - Frequency Data - Chicory Middle School - SPED Teacher

\begin{tabular}{|c|c|c|c|c|c|c|c|c|c|c|c|c|c|c|c|c|}
\hline $\begin{array}{l}\text { Student } \\
\text { Seat \# }\end{array}$ & $A$ & CF & $\mathrm{CO}$ & $D$ & $E$ & EXP & $\mathrm{H}$ & $\mathrm{H} / \mathrm{J}$ & II & $\mathrm{P}$ & $P M$ & $\mathrm{Q}$ & $\mathrm{R}$ & $\mathrm{RA}$ & $\mathrm{S}$ & TOTAL \\
\hline 1 & & & & & & & & & & & & & & & & NONE \\
\hline 2 & & & & & & & & & & & & 1 & & & & 1 \\
\hline 3 & & 1 & & & & & & & & & & & & & & 1 \\
\hline 4 & & & & & & & & & & & & & & & & NONE \\
\hline 5 & & & & & & & & & & & & & & & & NONE \\
\hline 6 & & & & & & & & & & & & & & & & NONE \\
\hline 8 & & & & & & & & & & & & & & & & NONE \\
\hline 9 & & & 1 & & & & & & & & & & & & & 1 \\
\hline 10 & & & & & & & & & & & & & & & & NONE \\
\hline 11 & & & & & & & & & & & & & & & & NONE \\
\hline 12 & 1 & & 1 & & & & & & & & & & & & & 2 \\
\hline 14 & & & & & & & & & & & & & & & & NONE \\
\hline 15 & & & & & & & & & & & & & & & & NONE \\
\hline 16 & & & & & & & & & 1 & & & & & & & 1 \\
\hline 17 & 1 & & & & & & & & & & & & & & & 1 \\
\hline 19 & 1 & & & & & & & 1 & & & & & & & & 2 \\
\hline 20 & & & & & & & & & & 1 & & 1 & & & & 2 \\
\hline 24 & & & & & & & & & 2 & & & & & & 1 & 3 \\
\hline TOTAL & 3 & 1 & 2 & & & & & 1 & 3 & 1 & & 2 & & & 1 & 14 \\
\hline
\end{tabular}
$A=$ Assist
$\mathrm{CF}=$ Corrective Feedback
$\mathrm{CO}=$ Called on to answer question
$\mathrm{D}=$ Discipline
$\mathrm{E}=$ Encourage to engage

EXP = Explanation

$\mathrm{H}=$ Called into Hallway

$\mathrm{H} / \mathrm{J}=$ Humor/Joking

II = Individualized Instruction

$\mathrm{P}=$ Praise

$\mathrm{PM}=$ Progress Monitoring

$\mathrm{Q}=$ Student asked question

$\mathrm{R}=$ Teacher responds to question

$\mathrm{RA}=$ Read Aloud

$\mathrm{S}=$ Social

INDICATES STUDENT w/SLN 
Table 7: Observation 5 - Frequency Data - Chicory Middle School - SPED Teacher

\begin{tabular}{|c|c|c|c|c|c|c|c|c|c|c|c|c|c|c|c|c|}
\hline $\begin{array}{l}\text { Student } \\
\text { Seat \# }\end{array}$ & $A$ & CF & $\mathrm{CO}$ & $\mathrm{D}$ & $E$ & EXP & $\mathrm{H}$ & $\mathrm{H} / \mathrm{J}$ & II & $\mathrm{P}$ & PM & $\mathrm{Q}$ & $\mathrm{R}$ & RA & $S$ & TOTAL \\
\hline 1 & & & & & & & & & & & & & & & & NONE \\
\hline 2 & & & & & & & & & & & & & & & & NONE \\
\hline 3 & & & & & & & & & & & & & & & & NONE \\
\hline 4 & & & & & & & & & & & & & & & & NONE \\
\hline 5 & 1 & & & & & & & & & & & & & & 1 & 2 \\
\hline 6 & 2 & & & & & & & & & & & & & & & 2 \\
\hline 8 & & & & & & & & & & & & & & & & NONE \\
\hline 9 & & & & & & & & & & & & & & & & NONE \\
\hline 10 & & & & & & & & & & & & & & & & NONE \\
\hline 11 & & & & & & & & & & & & & & & & NONE \\
\hline 12 & & & & & & & & & & & & & & & & NONE \\
\hline 14 & & & & & & & & & & & & & & & & NONE \\
\hline 15 & & & & & & & & & & & & & & & & NONE \\
\hline 16 & 1 & & & & & & & 1 & & & & & & & & 2 \\
\hline 17 & & & & & & & & & & & & & & & & NONE \\
\hline 19 & 1 & & & & & & & & 1 & & & & & & & 2 \\
\hline 20 & & & & & & & & & & & & & & & & NONE \\
\hline 24 & 1 & & & & & & & & 2 & & & & & & & 3 \\
\hline TOTAL & 6 & & & & & & & 1 & 3 & & & & & & 1 & 11 \\
\hline
\end{tabular}
$A=$ Assist
$\mathrm{CF}=$ Corrective Feedback
$\mathrm{CO}=$ Called on to answer question
$\mathrm{D}=$ Discipline
$\mathrm{E}=$ Encourage to engage

EXP = Explanation

$\mathrm{H}=$ Called into Hallway

$\mathrm{H} / \mathrm{J}=$ Humor/Joking

II = Individualized Instruction

$\mathrm{P}=$ Praise
$\mathrm{PM}=$ Progress Monitoring

$\mathrm{Q}=$ Student asked question

$\mathrm{R}=$ Teacher responds to question

$\mathrm{RA}=$ Read Aloud

$\mathrm{S}=$ Social

INDICATES STUDENT w/SLN 
Table 8: Observation 1 - Frequency Data - Chicory Middle School - GENED Teacher

\begin{tabular}{|c|c|c|c|c|c|c|c|c|c|c|c|c|c|c|c|c|}
\hline $\begin{array}{l}\text { Student } \\
\text { Seat \# }\end{array}$ & $A$ & CF & $\mathrm{CO}$ & $D$ & $E$ & EXP & $\mathrm{H}$ & $\mathrm{H} / \mathrm{J}$ & II & $P$ & $P M$ & $\mathrm{Q}$ & $\mathrm{R}$ & $\mathrm{RA}$ & $\mathrm{S}$ & TOTAL \\
\hline 1 & 1 & 1 & & & & & & & & 1 & & & & & & 3 \\
\hline 2 & 1 & & 1 & & & & & & & & & & & & & 2 \\
\hline 3 & & 1 & & 1 & & & & & & & 1 & & & & & 3 \\
\hline 4 & 3 & & 2 & & & & & & & 2 & & & & & & 7 \\
\hline 5 & & & & & & & & & 1 & & & & & & & 1 \\
\hline 6 & 1 & & & & & & & & & & & & & & & 1 \\
\hline 8 & & & & & & & & & & & & & 1 & & & 1 \\
\hline 9 & 3 & & 2 & & & & & & 1 & 1 & & & & & & 7 \\
\hline 10 & & & & & & & & & & & & & & & & NONE \\
\hline 11 & & 2 & 1 & & & & & & & 1 & & & & & & 4 \\
\hline 12 & & & & & & & & & & & & & & & & NONE \\
\hline 14 & & & & & & & & & & & & & & & & NONE \\
\hline 15 & 1 & 1 & 2 & & & & & & & & & & & & & 4 \\
\hline 16 & & & 3 & & & & & & & & & & & & 1 & 4 \\
\hline 17 & 1 & & & & & & & & & & 2 & & & & & 3 \\
\hline 19 & & & & & & & & & & 1 & 1 & & & & & 2 \\
\hline 20 & & & & & & & 1 & & & 1 & 1 & & & & & 3 \\
\hline 24 & & & & & & & & & & & & & & & & NONE \\
\hline TOTAL & 11 & 5 & 11 & 1 & & & 1 & & 2 & 7 & 5 & & 1 & & 1 & 45 \\
\hline
\end{tabular}
$A=$ Assist
$\mathrm{CF}=$ Corrective Feedback
$\mathrm{CO}=$ Called on to answer question
$\mathrm{D}=$ Discipline
$\mathrm{E}=$ Encourage to engage

EXP = Explanation

$\mathrm{H}=$ Called into Hallway

$\mathrm{H} / \mathrm{J}=$ Humor/Joking

II = Individualized Instruction

$\mathrm{P}=$ Praise
$\mathrm{PM}=$ Progress Monitoring

$\mathrm{Q}=$ Student asked question

$\mathrm{R}=$ Teacher responds to question

$\mathrm{RA}=$ Read Aloud

$\mathrm{S}=$ Social

INDICATES STUDENT w/SLN 
Table 9: Observation 2 - Frequency Data - Chicory Middle School - GENED Teacher

\begin{tabular}{|c|c|c|c|c|c|c|c|c|c|c|c|c|c|c|c|c|}
\hline $\begin{array}{c}\text { Student } \\
\text { Seat \# }\end{array}$ & $A$ & CF & $\mathrm{CO}$ & $D$ & $E$ & EXP & $\mathrm{H}$ & $\mathrm{H} / \mathrm{J}$ & II & $\mathrm{P}$ & PM & $\mathrm{Q}$ & $\mathrm{R}$ & RA & $S$ & TOTAL \\
\hline 1 & & & & & & & & & & & & & & & & NONE \\
\hline 2 & & & 2 & & & & & & & & & & & & & 2 \\
\hline 3 & & & & 1 & & & & & & & & & & & & 1 \\
\hline 4 & & & & & & & & & & & & & & & & NONE \\
\hline 5 & & & & & & & & & & & & & & & & NONE \\
\hline 6 & & 2 & & & & & & & & & & & & & & 2 \\
\hline 8 & & & 1 & & & & & & & & & & & & & 1 \\
\hline 9 & 1 & & & 3 & & & & & & & 1 & & & & & 5 \\
\hline 10 & 1 & 1 & & 1 & 1 & & & & & & & & & & & 4 \\
\hline 11 & 1 & & 1 & & & & & & & & 1 & & & & & 3 \\
\hline 12 & & & & & & & & & & & & & & & & NONE \\
\hline 14 & & & & & & & & & & & & & & & & NONE \\
\hline 15 & & & & & & & & & & & & & & & & NONE \\
\hline 16 & & 1 & & & & 1 & & 2 & & & & & & & & 4 \\
\hline 17 & & & 1 & & & & & & & & 1 & & & & & 2 \\
\hline 19 & 5 & & & & & & & & 2 & & & & & & & 7 \\
\hline 20 & 1 & & & 2 & & & & & & 1 & & & & & & 4 \\
\hline 24 & & & & 2 & 1 & & & & 1 & & & & & & & 4 \\
\hline TOTAL & 9 & 4 & 5 & 9 & 2 & 1 & & 2 & 3 & 1 & 3 & & & & & 39 \\
\hline
\end{tabular}
A $=$ Assist
$\mathrm{CF}=$ Corrective Feedback
$\mathrm{CO}=$ Called on to answer question
$\mathrm{D}=$ Discipline
$\mathrm{E}$ = Encourage to engage
EXP = Explanation
$\mathrm{H}=$ Called into Hallway
$\mathrm{H} / \mathrm{J}=$ Humor/Joking
II = Individualized Instruction
$\mathrm{P}=$ Praise

$\mathrm{PM}=$ Progress Monitoring

$\mathrm{Q}=$ Student asked question

$\mathrm{R}=$ Teacher responds to question

$\mathrm{RA}=$ Read Aloud

$\mathrm{S}=$ Social

INDICATES STUDENT w/SLN 
Table 10: Observation 3 - Frequency Data - Chicory Middle School - GENED Teacher

\begin{tabular}{|c|c|c|c|c|c|c|c|c|c|c|c|c|c|c|c|c|}
\hline $\begin{array}{l}\text { Student } \\
\text { Seat \# }\end{array}$ & $A$ & CF & $\mathrm{CO}$ & $D$ & $E$ & EXP & $\mathrm{H}$ & $\mathrm{H} / \mathrm{J}$ & II & $P$ & $P M$ & $\mathrm{Q}$ & $\mathrm{R}$ & $\mathrm{RA}$ & $\mathrm{S}$ & TOTAL \\
\hline 1 & & & 1 & & & & & & & & & & & & & 1 \\
\hline 2 & 1 & & 1 & & & & & & & & & & & & & 2 \\
\hline 3 & & 2 & 1 & & & & & & & & & & & & & 3 \\
\hline 4 & & & & & & & & & & & & & & & & NONE \\
\hline 5 & 1 & 1 & & & & & & & & & & & & & & 2 \\
\hline 6 & & & & 1 & & & & & & & 1 & & & & & 2 \\
\hline 8 & & & & & & & & & & & & & & & & NONE \\
\hline 9 & 2 & 1 & 1 & & & & & & & & & & & & & 4 \\
\hline 10 & & 1 & 1 & & & & & & & & 1 & & & & & 3 \\
\hline 11 & 1 & & 1 & & & & & & & & 1 & & & & & 3 \\
\hline 12 & & 2 & & & & & & & & & & & & & & 2 \\
\hline 14 & 1 & & & & 1 & & & & & & & & & & & 2 \\
\hline 15 & & 1 & 1 & & & & & & & & & & & & & 2 \\
\hline 16 & 1 & 1 & & & & & & & & & 1 & & & & & 3 \\
\hline 17 & & & & & & & & & 1 & & & & & & & 1 \\
\hline 19 & 6 & & & & & & & & 3 & 1 & & & & & & 10 \\
\hline 20 & 1 & & & & & & & & & & & & & & & 1 \\
\hline 24 & 2 & & & 2 & 1 & & & & & & 1 & & & & & 6 \\
\hline TOTAL & 16 & 9 & 7 & 3 & 2 & & & & 4 & 1 & 5 & & & & & 47 \\
\hline
\end{tabular}
$A=$ Assist
$\mathrm{CF}=$ Corrective Feedback
$\mathrm{CO}=$ Called on to answer question
$\mathrm{D}=$ Discipline
$\mathrm{E}=$ Encourage to engage

EXP = Explanation

$\mathrm{H}=$ Called into Hallway

$\mathrm{H} / \mathrm{J}=$ Humor/Joking

II = Individualized Instruction

$P=$ Praise
$\mathrm{PM}=$ Progress Monitoring

$\mathrm{Q}=$ Student asked question

$\mathrm{R}=$ Teacher responds to question

$\mathrm{RA}=$ Read Aloud

$\mathrm{S}=$ Social

INDICATES STUDENT w/SLN 
Table 11: Observation 4 - Frequency Data - Chicory Middle School -GENED Teacher

\begin{tabular}{|c|c|c|c|c|c|c|c|c|c|c|c|c|c|c|c|c|}
\hline $\begin{array}{l}\text { Student } \\
\text { Seat \# }\end{array}$ & $A$ & CF & $\mathrm{CO}$ & $D$ & $E$ & EXP & $\mathrm{H}$ & $\mathrm{H} / \mathrm{J}$ & II & $P$ & $P M$ & $\mathrm{Q}$ & $\mathrm{R}$ & $\mathrm{RA}$ & $\mathrm{S}$ & TOTAL \\
\hline 1 & 2 & 1 & & & & & 1 & & & & & & & & & 4 \\
\hline 2 & & & & & & & 1 & & & & & & 1 & & & 2 \\
\hline 3 & 1 & & 2 & & & & & & & & & & & & & 3 \\
\hline 4 & 1 & & 2 & & & & 1 & & & 1 & & & & & & 5 \\
\hline 5 & & & & & & & & & & & & & & & & NONE \\
\hline 6 & & & & & & & & & & & & & & & & NONE \\
\hline 8 & & & & & & & & & & & & & & & & NONE \\
\hline 9 & & & & 2 & & & & & & & & & & & & 2 \\
\hline 10 & & & & & & & & & & & & & & & & NONE \\
\hline 11 & & & & & & & & & & & & & & & & NONE \\
\hline 12 & & & & & & & & & & & & & & & & NONE \\
\hline 14 & & & & & & & & & & & & & & & & NONE \\
\hline 15 & 2 & & & & & & & & & & & & & & & 2 \\
\hline 16 & 1 & & & & & & & & & & & & & & & 1 \\
\hline 17 & & & & & & & & & & & & & & & & NONE \\
\hline 19 & 2 & & & & & & & & 1 & & & & & & & 3 \\
\hline 20 & & & 2 & & & & 2 & & & & & & & & & 4 \\
\hline 24 & & & & 1 & & & & & & & & & & & & 1 \\
\hline TOTAL & 9 & 1 & 6 & 3 & & & 5 & & 1 & 1 & & & 1 & & & 27 \\
\hline
\end{tabular}
$A=$ Assist
$\mathrm{CF}=$ Corrective Feedback
$\mathrm{CO}=$ Called on to answer question
$\mathrm{D}=$ Discipline
$\mathrm{E}=$ Encourage to engage

EXP = Explanation

$\mathrm{H}=$ Called into Hallway

$\mathrm{H} / \mathrm{J}=$ Humor/Joking

II = Individualized Instruction

$\mathrm{P}=$ Praise
$\mathrm{PM}=$ Progress Monitoring

$\mathrm{Q}=$ Student asked question

$\mathrm{R}=$ Teacher responds to question

$\mathrm{RA}=$ Read Aloud

$\mathrm{S}=$ Social

INDICATES STUDENT w/SLN 
Table 12: Observation 5 - Frequency Data - Chicory Middle School- GENED Teacher

\begin{tabular}{|c|c|c|c|c|c|c|c|c|c|c|c|c|c|c|c|c|}
\hline $\begin{array}{l}\text { Student } \\
\text { Seat \# }\end{array}$ & $A$ & CF & $\mathrm{CO}$ & $D$ & $E$ & EXP & $\mathrm{H}$ & $\mathrm{H} / \mathrm{J}$ & II & $P$ & $P M$ & $\mathrm{Q}$ & $\mathrm{R}$ & $\mathrm{RA}$ & $\mathrm{S}$ & TOTAL \\
\hline 1 & 2 & & 1 & & & & & & & & & & & & & 3 \\
\hline 2 & & & 2 & & & & & & & & & & & & & 2 \\
\hline 3 & 1 & & 1 & & & & & & & & & & & & & 2 \\
\hline 4 & 1 & & 1 & & & & & & & & & & & & & 2 \\
\hline 5 & & & 2 & & & & & & & & & & & & & 2 \\
\hline 6 & 1 & & & & & & & & & & & & & & & 1 \\
\hline 8 & & & & & & & & & & & & & & & & NONE \\
\hline 9 & & & 2 & & & & & & & & & & & & & 2 \\
\hline 10 & & & & & & & & & & & & & & & & NONE \\
\hline 11 & & & & & & & & & & & & & & & & NONE \\
\hline 12 & & & 1 & & 1 & & & & & & & & & & & 2 \\
\hline 14 & & & 2 & & & & & & & & & & & & & 2 \\
\hline 15 & & & 2 & & & & & & & & & & & & & 2 \\
\hline 16 & & & & & & & & & & & 1 & & & & & 1 \\
\hline 17 & & & & & & & & & & & & & & & & NONE \\
\hline 19 & 2 & & & & & & & 1 & & & & & & & & 3 \\
\hline 20 & 1 & & & 1 & & & 1 & & & & 1 & & & & & 4 \\
\hline 24 & & & & & & & 1 & & & & 1 & & & & & 2 \\
\hline TOTAL & 8 & & 14 & 1 & 1 & & 2 & 1 & & & 3 & & & & & 30 \\
\hline
\end{tabular}

$A=$ Assist

$\mathrm{CF}=$ Corrective Feedback

$\mathrm{CO}=$ Called on to answer question

$\mathrm{D}=$ Discipline

$\mathrm{E}=$ Encourage to engage

INDICATES STUDENT W/SLN
EXP = Explanation

$\mathrm{H}=$ Called into Hallway

$\mathrm{H} / \mathrm{J}=$ Humor/Joking

II = Individualized Instruction

$\mathrm{P}=$ Praise
$\mathrm{PM}=$ Progress Monitoring

$\mathrm{Q}=$ Student asked question

$\mathrm{R}=$ Teacher responds to question

$\mathrm{RA}=$ Read Aloud

$\mathrm{S}=$ Social 
As evidenced in the case study narrative, Caryn is the lead teacher and her role is verified by the data displayed in Table 13. Additionally, because Caryn frequently calls on students to participate and frequently provides corrective feedback during whole group instruction, it is logical that these types of interactions would be significantly higher for her. Again, this is supported by both the case narrative as well as data that appear in Table 13. It is interesting to note that Micah provided individual instruction more frequently than Caryn - a fact that would appear to indicate his attention to the needs of individual students rather than the group as a whole. It is also supportive of the information reported in the case narrative.

Table 13

Total Number of Interactions Observed - Chicory Middle School

\begin{tabular}{|c|c|c|c|c|c|c|c|c|c|c|c|c|c|c|c|c|}
\hline & A & CF & CO & D & E & EXP & H & H/J & II & P & PM & Q & R & RA & S & TOTAL \\
\hline $\begin{array}{c}\text { SPED } \\
\text { (Micah) }\end{array}$ & 34 & 5 & 2 & 5 & & 1 & 3 & 1 & 17 & 6 & 3 & 3 & & & 6 & $\mathbf{8 6}$ \\
\hline $\begin{array}{c}\text { GENED } \\
\text { (Caryn) }\end{array}$ & 53 & 19 & 43 & 17 & 5 & 1 & 8 & 3 & 10 & 10 & 16 & & 2 & & 1 & $\mathbf{1 8 8}$ \\
\hline COMBINED & $\mathbf{8 7}$ & $\mathbf{2 4}$ & $\mathbf{4 5}$ & $\mathbf{2 2}$ & $\mathbf{5}$ & $\mathbf{2}$ & $\mathbf{1 1}$ & $\mathbf{5}$ & $\mathbf{2 7}$ & $\mathbf{1 6}$ & $\mathbf{1 9}$ & $\mathbf{3}$ & $\mathbf{2}$ & & $\mathbf{7}$ & $\mathbf{2 7 5}$ \\
\hline
\end{tabular}
A = Assist
CF = Corrective Feedback
CO = Called on to answer question
D = Discipline
E = Encourage to engage
EXP = Explanation
$\mathbf{H}=$ Called to hall
$\mathbf{H} / \mathbf{J}=$ Humor/Joking

II = Individual Instruction

$\mathbf{P} \quad=$ Praise

PM = Progress Monitoring

$\mathbf{Q}=$ Student asked question

R = Teacher responds to question

RA = Read aloud

S = Social

Table 14 breaks down the number of teacher interactions into four categories of teacher initiated interactions: special education teacher to student with special learning needs (SPED >SLN); special education teacher to general education student (SPED > gened); general education teacher to student with special learning needs (GENED > SLN) and general education teacher to general education student (GENED > gened). 
Breaking down the interactions in this manner indicates that both teachers interacted with the general education students more frequently than either of them interacted with the students with SLN. As stipulated previously, however, only six of the 18 students in the class are identified as students with SLN.

Table 14

Comparison of SPED Teacher's Interactions to GENED Teacher's Interactions Chicory Middle School

\begin{tabular}{|c|c|c|c|c|c|c|c|c|c|c|c|c|c|c|c|c|}
\hline & A & CF & CO & D & $E$ & EXP & $\mathrm{H}$ & $\mathrm{H} / \mathrm{J}$ & II & $\mathbf{P}$ & PM & Q & $\mathbf{R}$ & RA & $\mathrm{S}$ & TOTAL \\
\hline $\begin{array}{c}\text { SPED } \\
\text { (Micah) } \\
> \\
\text { SLN }\end{array}$ & 14 & 2 & 1 & 2 & & & & 1 & 7 & 4 & & & & & 2 & 33 \\
\hline $\begin{array}{c}\text { SPED } \\
> \\
\text { gened }\end{array}$ & 20 & 3 & 1 & 3 & & 1 & 3 & 1 & 10 & 2 & 3 & 3 & & & 4 & 54 \\
\hline TOTAL & 34 & 5 & 2 & 5 & & 1 & & 5 & 18 & 4 & 3 & 3 & & & 6 & 87 \\
\hline $\begin{array}{c}\text { GENED } \\
\text { (Caryn) } \\
> \\
\text { SLN }\end{array}$ & 26 & 7 & 10 & 9 & & & & 2 & 8 & 3 & 4 & & 1 & & & 70 \\
\hline $\begin{array}{c}\text { GENED } \\
> \\
\text { gened }\end{array}$ & 27 & 12 & 30 & 9 & 5 & 1 & 8 & 2 & 2 & 7 & 12 & & 1 & & 1 & 118 \\
\hline TOTAL & 52 & 17 & 40 & 18 & 7 & 1 & 9 & 5 & 10 & 9 & 18 & & 2 & & 1 & 188 \\
\hline
\end{tabular}
A = Assist
CF = Corrective Feedback
CO = Called on to answer question
D = Discipline
E = Encourage to engage
EXP = Explanation
$\mathbf{H}=$ Called to hall
H/J = Humor/Joking
II = Individual Instruction
$\mathbf{P} \quad=$ Praise
PM = Progress Monitoring
$\mathbf{Q} \quad=$ Student asked question
$\mathbf{R}=$ Teacher responds to question
RA = Read aloud
$\mathrm{S}=$ Social




\section{Coalton Middle School}

Coalton Middle School is situated a few blocks from the county courthouse which is located in the center of the city of Coalton. The school is located directly behind one of the city's three funeral homes and is adjacent to the city's Chamber of Commerce housed in the historical McNutt House which was built in 1840.

Coalton Middle was built as Coalton High School during the early 1960s. Since that time, the school has been reconfigured twice. The first reconfiguration, which occurred when the new Coalton High School was built, resulted in the formation of Coalton Jr. High, which consisted of grades 7, 8, and 9. The second reconfiguration, in the 1990s, resulted in the current configuration of Coalton Middle School housing grades 6,7 , and 8 . The significance of the school's restructuring is deeply embedded in the philosophical differences between junior high and middle school configurations. Of greatest significance is the fact that the building itself does not lend itself to the full implementation of the middle school concept. Specifically, since the school was built conducive to the departmentalization of core subjects, it is not designed to accommodate either the core team concept of a middle school or the structural separation of $6^{\text {th }}, 7^{\text {th }}$, and $8^{\text {th }}$ grade halls or pods. Until I observed at Coalton Middle, I was ignorant of the impact the facility on the application and implementation of middle school philosophy. It became obvious to me the first day I entered the building to observe.

The main entrance opens to a foyer where there are paintings of the school mascot, a tiger cub, painted on the wall. Moving down the hall toward the office, bulletin 
boards and enclosed showcases display the most recent honor roll, newspaper articles documenting the academic and athletic accomplishments of both students and faculty, and a variety of academic awards. The main office window is on the left about midway down the hall. Across the hall is the auditorium, and at the end of the hall is the entrance to the school gymnasium. Along the hall outside the gym are trophy cases filled with evidence of championship teams from past athletic seasons of football, basketball, and volleyball. At the end of the gym hallway to the left is the staircase leading to the second floor and to Linda and Betty's classroom.

\section{Linda and Betty}

Linda has been teaching a total of seven years. She has a degree in Elementary Education $\mathrm{K}-8$, but her certification, as issued by the state, is stipulated as Elementary K-6. She does not have an English/Language Arts certification, however, by virtue of her multisubject degree, she is qualified to teach $6^{\text {th }}$ grade English/Language Arts. She is also qualified to teach several other content area subjects and has taught both science and social studies at Coalton Middle. In fact, it is because Linda taught science a few years ago that her classroom is a science lab. As Linda explains, it has had a somewhat limiting impact on her current co-teaching arrangement:

We don't use station teaching because one reason is I have a science lab. Two years ago, I taught one science class. I don't teach science now, but I'm in a science lab. I've gotten used to it. This is the third year l've had it. I've kinda gotten used to it, but I feel like the kids are too close together...there's no where to...no way to really space them out. It's easier now that the group has dwindled down throughout the year. It's easier to space them out, but you're so confined. You can't rearrange things to help the kids out. You're HERE...you're stuck... and there's so many things that distracts their attention. 
I suppose what struck me was that the gas hookups, electric outlets, and sinks positioned every two seats along the lab tables were operable. The thought occurred to me that these middle school kids were probably no less mischievous than my friends and I were at that time - and that was a sobering thought. When I asked Linda about how she kept students from using the equipment, she explained that although the gas and water were operable, a shut off valve behind her desk allowed her to keep them both turned off. Additionally, Linda describes the procedure she follows at the beginning of each school year as "it's almost like you go over science lab rules and safety for my English and social studies classes." After a brief pause, she adds:

It was actually mentioned by the central office to get me out of the science lab and put me in one of the four new rooms that were just recently built, but our administration said, "No." They wanted to keep all the sixth grade teachers together.

What is interesting, however, is that not all of the $6^{\text {th }}$ grade special education classrooms are located with the rest of the $6^{\text {th }}$ grade classrooms. In fact, as Linda explained, they are situated among the seventh and eighth grade classrooms so that during class changes "some of them are scared to death when they try to get to and from classes" from Betty's room because she is so far away. Betty added, "Their lockers are in the middle of the seventh and eighth grade hallways."

Betty, the $6^{\text {th }}$ grade special education teacher, has taught for 27 years; four of those have been in a co-teaching situation. She has an Elementary 1-6 degree and a Master's degree in Special Education with endorsements in Mental Impairments (MI) and Specific Learning Disabilities (SLD). During my first observation at Coalton, Betty approached me at my seat in the back of the room and spoke to me privately to ensure 
that I understood her qualifications for teaching the English/Language Arts class. She explained, "You have to realize that language arts is not my area, but they made me 'highly qualified' in every area." I did not question the accuracy of the statement.

Betty co-teaches English/Language Arts with Linda during two class periods. Her four other classes are all self-contained, English/Language Arts classes in which she tries "to implement everything that I do up there [indicating the co-taught classroom] down in my classroom, too." Throughout my time at Coalton Middle, it became apparent that Betty believes that some of the students with special learning needs who are being included in the general education environment would be better served in a self-contained environment. She was adamant in her discussion of this belief. As she stated:

...there's a few that I feel are out there by mistake, and I feel we're doing an injustice to those few because once they're out there, they're more or less put there to stay. There's always going to be kids that need that selfcontained....I don't feel we're meeting their needs out in inclusion..... Once I retire l'm going to go back and advocate for this!

Both teachers have had some training in models of co-teaching which has been provided through in-service or professional development opportunities provided by the central office. Linda explained their training:

We've been to several different in-services, mostly. They were all at the county level. We also had that one girl that came from California. She was a young girl who was so vibrant. Wendy Murawski...everybody really enjoyed her. And we've had several on the local level that have given us in-services.

In spite of the types of training Linda and Betty have had, it appears that they, and perhaps other co-teaching pairs at Coalton Middle, are still searching for the most 
appropriate implementation of co-teaching in the inclusive environments in their school.

Although Linda and Betty seem to have developed a productive co-teaching relationship

over the past two years, they both agree that their first few months together were

somewhat difficult, and, at times, they continue to experience difficulties with the

demands of implementing the co-teaching model. Part of that difficulty could have been

the result of their being assigned as partners. Both teachers explained their feelings:

Linda: They just told us we were going to do it.

NB: How did that make you feel?

Linda: I felt uncomfortable because I hadn't ever worked with inclusion before until last year. And I was like..."I'm going to do WHAT?" I've actually enjoyed the last two years - after we got started. The first couple of months...just trying to figure out what to do, what to expect...it was just trying to figure out the best way for us to work together. But after we got started, we discussed what we each needed to be responsible for and the way we wanted to do it. And after we tried a few different ways, we just got into the feel of it - the routine of it - in which worked best for us:

Betty's feelings were similar. However, as she explained her initial reaction to

being assigned to co-teach with Linda, she began to elaborate on a previous co-

teaching partnership that had not been a positive experience for her:

At first, because l've had a bad experience with inclusion before in the past, I was real leery of it once again, but you know, I was trying to be positive and upbeat about it. Anybody who leaves their environment and steps into someone else's environment, naturally you're out of your comfort zone. You're going to feel uncomfortable. So, I had had a very bad experience with it the year before and I was totally turned off by the idea. I look back now and some of the little remarks that were made in the other situation I was in and I think those kids knew there was bitter feelings between the two teachers:

One reason for their continuing struggle to successfully implement an effective co-teaching model could stem from the manner in which students were placed in their 
inclusive English/Language Arts classroom. Both teachers believe that the students

with special learning needs who have been placed in inclusive environments were

"dumped" into the general education classes without appropriate transitioning or

preparation for such a placement. Betty explained:

A lot of these kids had been self-contained up to this year, and they threw them out all at once into inclusion... all their classes. It upset me terribly because my sister had worked with a few at an elementary school, and she kept saying, 'They won't make it; they won't make it!' And that would just upset me to no end. And I kept telling them...'Lynne, (the assistant principal), we need to get these in self-contained. I need 'em downstairs; they don't need to be in here.' And it went on; and there wasn't going to be no changes.

The appropriate placement of students with special learning needs was not their

only concern. As Linda and Betty related, sometimes it's the placement of students who do not have an IEP or 504 plans that limits their effectiveness as co-teachers:

Linda: Sometimes I do think that some of the students that are in here that do not have an IEP or 504, sometimes I fell like we hold them back a little bit, because sometimes it takes so long to get a concept over to the IEP students that they've got it and they're just like...'Okay, well, what do I do now?'

NB: How do you handle that? What do you do with them?

Linda: I don't...they've occasionally helped other students - depending on what it is we're doing.

Betty: And I think the one that we're really thinking of here at the end she had so many issues going on at home and things that were making her fall behind, so that it worked out okay.

Linda: It did. I think we handled it okay. But... around the first of the year and into maybe the first part of second semester, I kinda felt like she could be pushed on.... She could be succeeding in a classroom that was going on and doing more things - especially in reading because with the level, we're not able to read novels on a sixth grade reading level....I think she would have benefitted from that especially so much but we couldn't offer that to her in here. 
NB: So, in essence, that inclusion class is holding some of them back? Linda: ...there is a possibility that it could.

NB: And the co-teaching does not help that, then?

Linda: I don't see - I don't think it really helps that.

Betty: No, because we had too many that was - I mean, you know, we couldn't just leave three-fourths of 'em back to, you know, to meet that one fourth neither.... I felt a little better toward the end of the year 'cause I watched all the problems going on with home life and the emotions and everything.

Given the limitations of their informal training in co-teaching, their difficult beginnings as partners, Betty's previous negative experience with co-teaching, and the struggles of the school to appropriately implement co-teaching models, it is easy to understand why both Linda and Betty expressed that they are frustrated and believe there is still a need for self-contained classrooms at Coalton Middle. As Linda explained, at the beginning of the 2007-08 school term, the class enrollment was 25 and included one student who was blind and without an aide; a student who was in a wheelchair in a room not at all accessible to him; a student with extreme behavior issues; a student with learning disabilities that was reassigned to the self-contained classroom; and several others who, for one reason or another, were removed from the classroom and placed in other environments. Even with those departures, both Linda and Betty believe there were others who should have been switched to a self-contained room, but the administration refused to allow it:

Linda: I think even with the small group like we have, some of them still need an even smaller group. And some of them don't deal well with having so many different teachers. Most of them have come up to middle school and they've had that one teacher; they haven't had eight different teachers. And they're put in inclusion here where they have eight, nine, ten different teachers, and they have a real hard time adjusting to that. 
Some of them don't adjust to it. I think they need that relationship with maybe one or two teachers and then gradually bring other teachers in because, it's almost like we've thrown them to the wolves when they come to our school. No matter how hard we try, I think there are a few that need more than what we are giving to them now.

I was curious to know what Linda meant by not being able to give students what they needed, so I asked her to describe what they needed that she and Betty were not able to give them. She replied:

We have some that are reading on a first or second grade level. We have some that are on an actual $6^{\text {th }}$ grade level. And there is such a gap between that that we can't step down to that second grade level because of the other kids in the class. But yet, these kids cannot function on a $6^{\text {th }}$ grade level. There are a few that no matter how hard we try, no matter what the different types of lessons we do, I still don't think they're getting it.

In spite of their discontent with the limited self-contained classes at Coalton and their difficulty in giving all students what they need, both Linda and Betty still believe that co-teaching can and does have a positive impact on all but a few students with special learning needs. Both agree that the structure of their classroom environment combined with the fact that there are two teachers in the classroom positively impacts student learning and achievement. Additionally, both agree that their working relationship in the classroom contributes to their ability to provide students with at least two ways of acquiring the content they need. They recognize their limitations and are comfortable relying on each other to ensure that students get what they need:

Linda: You get two different perspectives...for any child...for any assignment...you know, anything that's going on. And things that I may overlook, I know Betty will step in and say, 'Maybe we ought to try it this way, or maybe we should do this.' And I may completely have overlooked that....And also if there is something I can't get across to them or Betty can't get across to them, the other one stepped in and tried to reword it or 
to give a different example... us working off of each other I think we are able to get the point across.

Betty: It's each teacher using her own strategies and her own techniques and all because every teacher teaches differently.

From their perspective, having two teachers in the classroom also provides additional opportunities for one-on-one interactions with their students thereby giving students more of the individual attention they require.

\section{Co-teaching Partnership/Roles and Responsibilities}

Much of the impact of Linda and Betty's co-teaching comes from their shared roles and responsibilities. According to Linda, the two "share everything. We share planning; we share the grading of papers; we share discipline; we share everything." Of major significance, however, is their method of co-planning. Each day during seventh period, both Linda and Betty attend the $6^{\text {th }}$ grade team planning meetings. Seventh period on Thursdays has been designated as the time for inclusion teachers to work together with their respective content teachers. As adequate as this may sound, it isn't always enough. In fact, as Linda explains, "...we do a lot before school. Sometimes you'll see us running up and down the hall trying to catch each other... and after school, we'll stop and talk."

Because their class is split into two 45-minute class periods with a lunch period in between, Linda and Betty opted to split the planning responsibilities. Each chose the content she preferred. Linda chose the first 45 -minute period of reading because she enjoys the reading and literature portion of the content; Betty prefers writing and 
grammar content, so she selected the second 45-minute language period which follows

lunch. The process is better described in their words:

Linda: We plan together; after we talk about what we're going to do the next week in reading and English, I pretty much write up the plan for reading and she writes up the plan for English after we've discussed everything we're going to do. Instead of one person sitting down and writing both plans, we discuss it all before we sit down to write it, so we actually plan it together, but one of us just takes on reading and one on English to actually write it on a lesson plan. And we also have this section where we check off the things for each lesson that she or I will specifically help with.

Betty: Then we make copies of the plans. Like on Mondays, I always give her a copy of mine, and she gives me a copy of hers. We mark at the top who our cooperating teacher is. Then on the back of the plan it's got modifications per IEP and its got different ways that we meet IEPs. And then in my own folder that I carry with me, my inclusion plan is separate. I have all the modifications and she's got it in her lesson plan book of each individual child under a 504 or IEP.

Implementing co-teaching as an instructional model has had a significant impact

on Linda. She credits the use of the co-teaching model with making her a better

teacher. She explained that she believes co-teaching actually holds her to a higher

level of accountability by virtue of the fact that there is someone else to assist her when

students don't grasp the content. Additionally, co-teaching has provided learning

opportunities for Linda in spite of the fact that she is the content teacher in the classroom:

I've learned a lot of strategy. I've learned a lot of strategies that I had no idea about in reading and English. It even carries over into my other language arts class that doesn't have inclusion.

While the impact of co-teaching in Betty's view is not as definitive, events that occurred during my observations would seem to indicate that she, too, has had learning opportunities. In spite of the fact that Linda is actually considered the content teacher, 
Betty assumes the lead role during ELA instruction. This would seem to be a logical role for her since she develops the lesson plans for this portion of the English/Language Arts class. Yet, there are times when, if Betty is not confident in the content being presented, she seeks the assistance of Linda. On one occasion, for example, students were completing a worksheet on comma usage. Betty called on students randomly to identify where the correct location of commas should be in the sentences on the worksheet. One student responded and identified where he thought the commas should be placed. Betty seemed unsure of the student's answer and hesitated to respond. Linda, recognizing Betty's reluctance, quickly spoke up to confirm that the student had correctly placed the commas. During that same class period, when there was a question about another of the sentences, Linda called Betty over to confer about the correct placement of commas when they are used in compound sentences joined with a comma and a conjunction. The exchange between them seemed to be something that both the teachers and students were accustomed to, so it didn't seem at all awkward for Betty to turn to Linda and ask that she explain the rule to the class. Additionally, much like many teachers who have taught for several years, Betty has had to learn new technologies. As Betty states, "I like having a young mind on the technology thing because, I'm like...'you figure it out and let me know. And I'll try it after you get it figured out.' I'm still learning."

Use and Impact of Technology

Until their Smartboard was installed toward the end of my observations, the use of technology in Linda and Betty's classroom was limited to the overhead projector, a PowerPoint presentation from time to time, and occasional trips to the computer lab. 
Walking into the classroom to observe on the day that the laptop and Smartboard were dubbed "up and running" was like coming downstairs on Christmas morning to find the long awaited present just waiting to be opened and explored. Although Betty had repeatedly claimed to be reluctant to use new technologies, her demeanor in class that day revealed quite a different attitude as noted in my fieldnotes:

As with every other day, Linda greeted the students as they arrived. When Betty entered the room, she could hardly contain her excitement. She instructed students at the end of each lab table to get their row's notebooks and distribute them appropriately. [I still don't know why she had them do this.] Then, unable to hold back the news, she excitedly told the students that they would be using the Smartboard during class. Both she and Linda are visibly anxious to try it out.

While Betty explained what the students would be doing, Linda began to prepare the Smartboard. Betty had prepared an activity to be projected onto the Smartboard. So that all students could prepare their answers before going up to the Smartboard, she had provided each student with his own individual copy of the activity. The gist of the activity was for students to read the paragraph and then to put commas in the appropriate places within the sentences. After the paragraph had been read and students had an opportunity to insert commas on their papers, students were called to the Smartboard to insert the commas in the appropriate spots on the projected copy.

The students were impressed with the technology...especially with the fact that if they picked up one of the "pens", they could use their fingers to "write" on the screen. Each student who took a turn at the screen made a comment about the difference in writing and erasing on the Whiteboard as opposed to writing and erasing on the Smartboard.

Betty, too, was impressed with the technology. She had obviously spent a significant amount of time prior to class preparing the activities she covered that day. She did not miss an opportunity to model the appropriate use of the Smartboard nor did she refuse an opportunity to learn from the students when they showed her how to scroll down the screen by simply using her finger on the touch screen.

Both Betty and Linda see benefits to incorporating technology in their inclusive classrooms. In spite of their inexperience with the newly installed equipment, both are 
looking to the future. As Linda explained, "We're getting there because we're learning, too. We've already checked into getting a scanner for the writing strategies we use. We can scan all those worksheets...instead of kids trying to write on the little overhead." Betty readily acknowledged the time that she can save in preparation by using the scanner is such a manner. When asked what impact the technology might have on the students, Linda responded:

Well, I think they themselves will feel more involved with their learning....which, yeah, coming to the overhead was one thing, but because it's THE BOARD, it's just the name of it...they're just so excited about it. I think they'll feel actually more involved in it...even though they would be doing the same thing at their seat, they get up to move around, and they're in front of other people, and they like that.

I couldn't help but think that the enthusiasm for technology was something that both the students and teachers shared. It put them on common ground even to the point of allowing the students to become their teachers' instructors.

Interactions with Students

As has been noted, the classroom is a science lab. Entering the room expecting a physical environment conducive to teaching English/Language Arts classroom is a mistake. It is also confusing at first. In the room there are four rows of lab tables that extend across the width of the room except for enough space to allow for an aisle along each end of the tables and one in between each table. From the back of the room, to the right along the wall there is a counter where books are stacked in between sinks. Above the counter is a book case glass doors; it extends the length of the counter. In the corner in the back is a sink, some storage cabinets and a computer desk with a 
laptop on it. Also along the back wall are several storage cabinets. Windows line the wall to the left. Below them are storage areas and the heater which is stacked with books. One window has an air conditioner in it. A filing cabinet is in the front left corner of the room. At the front of the room, there are two white boards of the sort that has one solid board behind another board that slides either right or left in front of the solid board. The white boards are situated in the center of the wall and are obviously the focal point of the room during instruction. It is not at all conducive to small group instruction. It would require a significant amount of time and creativity to incorporate a variety of grouping strategies as part of the English/Language Arts instruction that takes place in this room. Yet both the students and the teachers appear to have accepted the limitations of the classroom and they manage to work well as a large group.

Oddly enough, when the students enter the room, it is no longer a science lab. It is as if by merely walking through the door, the atmosphere immediately becomes that of an ELA class and not a science lab at all. Every day as the students filter in from lunch, Linda is at the door to greet them. She frequently greets students by name and often adds something personal to her greeting. Her friendliness sets the tone for a comfortable environment. Once all students are in class, she begins class with some type of warm-up activity to get students ready for the day's lesson. Because Betty monitors students during their lunch period, she is typically not in the room as students arrive. Therefore, the warm-up activity conducted by Linda serves a dual purpose. It prepares students for the topic that will be covered during the day's class, and it provides Betty the time she needs to get from her monitoring station to the classroom. The routine seems to work well for them. 
Betty enters the room each day ready to assume the lead. The atmosphere in the room remains relaxed and settled as Betty begins the day's lesson. The students are obviously comfortable with this arrangement because they are ready to begin on her cue. She immediately engages students in an activity that requires their participation. Although students generally have some type of worksheet to complete, there was never any indication that the worksheets assigned were for busy work. On the contrary, each worksheet was placed on the overhead or Smartboard so that students could follow along as solutions were added to each sheet. In fact, students were frequently called to the overhead or Smartboard to share their answers with their classmates.

During Betty's instruction, Linda moves about the room offering encouragement and individual instruction to those who need it. Because most of the students are seated so that there is at least one empty seat on either side of them, Linda frequently sits beside a struggling student so that she can provide whatever instruction or assistance the student requires. Since many of the students are struggling readers, both Linda and Betty spend a lot of time reading to the students.

While neither teacher tolerates disruptions or typical middle school antics, they are both willing, on occasion, to engage students in lighthearted discussion. Yet, maintaining a disciplined environment is an expectation that both Betty and Linda adhere to with little room for negotiation. Sometimes, however, without warning, a well disciplined class of students can still be the cause of some anxious moments. Following one such incident, when both teachers had been caught off guard by their students' behaviors, Betty approached me. She and Linda were both shocked at the behaviors I had witnessed. In an effort to explain what she believed to be the reason for 
the behavior, Betty said to me, "This has got to be the hardest group. There's so many with IEPs or 504s." I remember wondering if this alone was reason enough for the behaviors. What I witnessed that day had not shocked me; it seemed normal for a group of $6^{\text {th }}$ graders who had known exactly what button to push.

At the end of each class, Linda and Betty use the final three to five minutes to answer any questions the students may have, or to review the requirements for the night's homework, or sometimes to interact with students on a more personal basis. Their brief conversations with the students are often the types of interactions that help develop the rapport the teachers need with their students so their efforts in the classroom are more effective.

It is important to note that there are occasions when the teachers' interactions with students had little to do with English/Language Arts but everything to do with making sure students' needs were being met. For instance, when Student B-S14 informed Linda that he would be absent, she took time to gather materials for him to take with him so he would not fall behind in his work. On another occasion, concerned about how well Student B-S1 would do on his microscope test, Linda took some time at the end of a class to quiz the student on the parts of a microscope. After he had responded correctly to each of her questions, she exclaimed, "Yes! Yes! Yes! You're going to make a 100 on your science test! I am so proud of you!" Student B-S1 glowed with pride.

Co-teaching in inclusive environments at Coalton Middle School is far from perfect. Both Linda and Betty agree that splitting their co-taught English/Language Arts 
class into two sections, one before lunch and one after lunch, is a mistake. Ideally, if the inclusive, co-taught classes could be taught together in the morning, both teachers believe student achievement would be greater. While their hope is that next year will be different, neither of them expect much improvement. For reasons I did not seek, the number of co-taught classes will decrease next year. In fact, after this year, while students will continue to be included in English/Language Arts, math, social studies, and science, the social studies and science classes will no longer be co-taught - something that Linda and Betty believe will set some students up for failure. Linda explained, “...if they can't make it in Language Arts in a regular ed classroom, they're not going to make it in science and social studies. I mean, it's not going to happen." Betty added, "I mean, most of them have a lower reading level and lower comprehension skills. I think it's a shame they're sending those kids out to science or social studies with no co-teaching going on. That regular ed teacher's going to have that whole class by herself. That's terrible, I can't imagine."

\section{Frequency Data}

Just under half of the students in Linda and Betty's class are identified as having special learning needs. This is significant given that, based on both the frequency data

in Tables 15-24 and the case study itself, it appears that both Linda and Betty are equally engaged with their students as presented in Table 26 . With the exception of my first observation, both teachers' interactions are nearly equal. During the first observation, however, Betty's interactions with the class were more than double those of Linda's. The numbers alone seem to indicate very little involvement on Linda's part 
on that particular day; however, after a closer review of that day's observation notes, I

found an observer comment that provides a quite different perspective:

Although Linda spent some time getting materials together for a student who was going to be absent, most of her time was spent roaming about the room monitoring student progress. She offered little, if any, direct instruction and kept her interactions to a minimum. In fact, Betty conducted the entire class. Since the content of instruction was review material, I have no way of knowing whether Linda or Betty presented the material initially. Regardless of that, it was obvious that both teachers were actively engaged with the students because neither sat down during the entire class period.

Linda and Betty both indicate that an effective partnership is one that requires each partner to carry his or her share of the load. They agree that the same is true in a co-teaching partnership. Tables $15-18$ and 20-23 provide some evidence of their belief in action, even if it is specific to the numbers of daily interactions each has with her students. It should be noted that Tables 19 and 24 do not contain data. Upon my arrival to observe on that day, our fifth session was unexpectedly cancelled. Although attempts were made to reschedule, none of us could find a suitable date, and I was left to use the data I had collected over the previous four days.

Other than the blatant difference in the numbers of interactions on the first day of observation, I find it very interesting that Linda and Betty seem to divide their time equally among their students. In fact, with few exceptions, the data would appear to indicate that the teachers make efforts to ensure that each student has been engaged at least once a class by one of them. Whether by design or coincidence, teachers and students interact frequently. 
Finally, research often leads to the discovery of something unseen or of something that has gone unnoticed - something that "was there all the time", but just not recognized. Although not necessarily a significant piece of information, the fact remains that in review and analysis of each of the daily data sheets, it became apparent that both Linda and Betty spend a great deal of time engaged in interactions that are related in some way to classroom discipline. Even though each interaction that involved discipline was noted both in field notes and on tally sheets, I did not realized how frequently students were reprimanded for what most would identify as minor, but disruptive behaviors. (See Tables 25 and 26; Column D). 
Table 15: Observation 1 - Frequency Data - Coalton Middle School - SPED Teacher

\begin{tabular}{|c|c|c|c|c|c|c|c|c|c|c|c|c|c|c|c|c|}
\hline $\begin{array}{c}\text { Student } \\
\text { Seat \# }\end{array}$ & $A$ & CF & $\mathrm{CO}$ & $\mathrm{D}$ & $E$ & EXP & $\mathrm{H}$ & $\mathrm{H} / \mathrm{J}$ & II & $P$ & PM & $\mathrm{Q}$ & $\mathrm{R}$ & $\mathrm{RA}$ & $S$ & TOTAL \\
\hline 1 & 2 & & 1 & 1 & & & & & & 1 & & & & & & 5 \\
\hline 2 & 2 & & 4 & & & & & & & 1 & & & & & & 7 \\
\hline 3 & & & & & & & & & & & & & & & & NONE \\
\hline 4 & & & 2 & & & & & & & & & & & & & 2 \\
\hline 5 & 1 & & & 1 & & & & & & & & & & & & 2 \\
\hline 6 & 3 & & & & & & & & & & & & & & & 3 \\
\hline 7 & & & 1 & & & & & & & & 1 & & & & & 2 \\
\hline 8 & & & 3 & & & & & & & & & & & & & 3 \\
\hline 10 & & & & & & & & & & & & & & & & NONE \\
\hline 11 & & & & 1 & & & & & & & 1 & & & & & 2 \\
\hline 14 & & & 1 & & & & & & & & & & & & & 1 \\
\hline 15 & 1 & & 3 & & & & & & & & & & & & & 4 \\
\hline 17 & 5 & & 4 & & & & & & & & & & & & & 9 \\
\hline 19 & 2 & & 4 & & & & & & & & & & & & & 6 \\
\hline 21 & & & & 2 & & & & & & & 1 & & & & & 3 \\
\hline 23 & & & 2 & & & & & & & & & & & & & 2 \\
\hline 25 & 1 & & 4 & 2 & 2 & & & & & & & & & & & 9 \\
\hline TOTAL & 17 & & 29 & 7 & 2 & & & & & 2 & 3 & & & & & 60 \\
\hline
\end{tabular}

$A=$ Assist

$\mathrm{CF}=$ Corrective Feedback

$\mathrm{CO}=$ Called on to answer question

$\mathrm{D}=$ Discipline

$\mathrm{E}=$ Encourage to engage

INDICATES STUDENT w/SLN

INDICATES STUDENT WISLN
EXP = Explanation

$\mathrm{H}=$ Called into Hallway

$\mathrm{H} / \mathrm{J}=$ Humor/Joking

II = Individualized Instruction

$\mathrm{P}=$ Praise
$\mathrm{PM}=$ Progress Monitoring

$\mathrm{Q}=$ Student asked question

$\mathrm{R}=$ Teacher responds to question

$\mathrm{RA}=$ Read Aloud

$S=$ Social 
Table: 16 Observation 2- Frequency Data - Coalton Middle School - SPEDTeacher

\begin{tabular}{|c|c|c|c|c|c|c|c|c|c|c|c|c|c|c|c|c|}
\hline $\begin{array}{c}\text { Student } \\
\text { Seat \# }\end{array}$ & $A$ & CF & $\mathrm{CO}$ & $D$ & $E$ & EXP & $\mathrm{H}$ & $\mathrm{H} / \mathrm{J}$ & II & $P$ & PM & $\mathrm{Q}$ & $\mathrm{R}$ & $\mathrm{RA}$ & $\mathrm{S}$ & TOTAL \\
\hline 1 & 1 & & 1 & & & & & & & & & & & & & 2 \\
\hline 2 & & & & & 1 & & & & & & & & & & & 1 \\
\hline 3 & & & 1 & & & & & & & & & & & & & 1 \\
\hline 4 & & & & & & & & & & & & & & & & NONE \\
\hline 5 & 1 & & & & & & & & & & 1 & & & & & 2 \\
\hline 6 & & & & & & & & & & & & & & & & NONE \\
\hline 7 & 4 & & & & & & & & & & & & & & & 4 \\
\hline 8 & & & & & & & & & & & & & & & & NONE \\
\hline 10 & & & & & & & & & & & & & & & & NONE \\
\hline 11 & & & 3 & & & & & & & & & & & & & 3 \\
\hline 14 & & & & & & & & & & & & & & & & NONE \\
\hline 15 & & & 1 & & & & & & & & & & & & & 1 \\
\hline 17 & 4 & & 1 & & & & & & & & 1 & & & & & 6 \\
\hline 19 & & & 4 & & & & & & & & & & & & & 4 \\
\hline 21 & & & 1 & 1 & & & & & & & & & & & & 2 \\
\hline 23 & & & 2 & & & & & & & & & & & & & 2 \\
\hline 25 & 2 & & 2 & & & & & & & & & & & & & 4 \\
\hline TOTAL & 12 & & 16 & 1 & 1 & & & & & & 2 & & & & & 32 \\
\hline
\end{tabular}

$A=$ Assist

$\mathrm{CF}=$ Corrective Feedback

$\mathrm{CO}=$ Called on to answer question

$\mathrm{D}=$ Discipline

$\mathrm{E}$ = Encourage to engage
EXP = Explanation

$\mathrm{H}=$ Called into Hallway

$\mathrm{H} / \mathrm{J}=$ Humor/Joking

II = Individualized Instruction

$\mathrm{P}=$ Praise
$\mathrm{PM}=$ Progress Monitoring

$\mathrm{Q}=$ Student asked question

$\mathrm{R}=$ Teacher responds to question

$\mathrm{RA}=$ Read Aloud

$\mathrm{S}=$ Social

INDICATES STUDENT w/SLN 
Table 17: Observation 3 - Frequency Data - Coalton Middle School - SPED Teacher

\begin{tabular}{|c|c|c|c|c|c|c|c|c|c|c|c|c|c|c|c|c|}
\hline $\begin{array}{l}\text { Student } \\
\text { Seat \# }\end{array}$ & $A$ & CF & $\mathrm{CO}$ & $\mathrm{D}$ & $E$ & EXP & $\mathrm{H}$ & $\mathrm{H} / \mathrm{J}$ & II & $\mathrm{P}$ & PM & $\mathrm{Q}$ & $\mathrm{R}$ & $\mathrm{RA}$ & $\mathrm{S}$ & TOTAL \\
\hline 1 & 1 & & 2 & & & & & & & & & & & & & 3 \\
\hline 2 & & & & 1 & & & & & & & & & & & & 1 \\
\hline 3 & & & 1 & & & & & & & 1 & & & & & & 2 \\
\hline 4 & & & 1 & & & & & & & & & 1 & & & & 2 \\
\hline 5 & & 1 & & 2 & & & & & & & 1 & 1 & & & & 5 \\
\hline 6 & & & 1 & & & & & & & & 1 & & & & & 2 \\
\hline 7 & & & 2 & & & & & & & & & & & & & 2 \\
\hline 8 & & & & & & & & & & & & & & & & NONE \\
\hline 10 & 1 & 1 & 1 & & & & & & & & & & & & & 3 \\
\hline 11 & & & & 1 & & & & & & & & & & & & 1 \\
\hline 14 & & & & & & & & & & & & & & & & NONE \\
\hline 15 & & & & & & & & & & & & 1 & & & & 1 \\
\hline 17 & & & 2 & & & & & & 3 & & & & & & & 5 \\
\hline 19 & 1 & & 1 & & & & & & & 2 & & & & & & 4 \\
\hline 21 & 1 & & & 1 & & & & & & & & & & & & 2 \\
\hline 23 & & & & & & & & & & & & & & & & NONE \\
\hline 25 & & & 2 & 1 & & & & & & & & & & & & 3 \\
\hline TOTAL & 4 & 2 & 13 & 6 & & & & & 3 & 3 & 2 & 3 & & & & 36 \\
\hline
\end{tabular}

$A=$ Assist

$\mathrm{CF}=$ Corrective Feedback

$\mathrm{CO}=$ Called on to answer question

$\mathrm{D}=$ Discipline

$\mathrm{E}$ = Encourage to engage
EXP = Explanation

$\mathrm{H}=$ Called into Hallway

$\mathrm{H} / \mathrm{J}=$ Humor/Joking

II = Individualized Instruction

$\mathrm{P}=$ Praise
$\mathrm{PM}=$ Progress Monitoring

$\mathrm{Q}=$ Student asked question

$\mathrm{R}=$ Teacher responds to question

$\mathrm{RA}=$ Read Aloud

$\mathrm{S}=$ Social

INDICATES STUDENT w/SLN 
Table 18: Observation 4 - Frequency Data - Coalton Middle School - SPED Teacher

\begin{tabular}{|c|c|c|c|c|c|c|c|c|c|c|c|c|c|c|c|c|}
\hline $\begin{array}{l}\text { Student } \\
\text { Seat \# }\end{array}$ & $A$ & CF & $\mathrm{CO}$ & $\mathrm{D}$ & $E$ & EXP & $\mathrm{H}$ & $\mathrm{H} / \mathrm{J}$ & II & $\mathrm{P}$ & $P M$ & $\mathrm{Q}$ & $\mathrm{R}$ & $\mathrm{RA}$ & $\mathrm{S}$ & TOTAL \\
\hline 1 & 1 & & & 1 & & & & & & & & & & & & 2 \\
\hline 2 & 1 & & 2 & & & & & & & & & 1 & & & & 4 \\
\hline 3 & & & 2 & & & & & & & & & & & & & 2 \\
\hline 4 & & & & & & & & & & & & & & & & NONE \\
\hline 5 & 2 & & & 1 & & & & & & & 1 & & & & & 4 \\
\hline 6 & 1 & & 2 & & & & & & & 1 & & & & & & 4 \\
\hline 7 & & & 1 & & & & & & & & & & & & & 1 \\
\hline 8 & & & 1 & & & & & & & & & & & & & 1 \\
\hline 10 & & & 1 & & & & & & & & & & & & & 1 \\
\hline 11 & & & 4 & & & & & & & & & & & & & 4 \\
\hline 14 & & & 1 & & & & & & & & & & & & & 1 \\
\hline 15 & & & & & & & & & & & & & & & & NONE \\
\hline 17 & 1 & 1 & 2 & & & & & & & 1 & & & & 1 & & 6 \\
\hline 19 & 1 & & 1 & & & & & & & & & 2 & & & 1 & 5 \\
\hline 21 & & & 2 & & & & & & & & & & & & & 2 \\
\hline 23 & & & & & & & & & & & & & & & & NONE \\
\hline 25 & & & & & & & & & & & & & & & & NONE \\
\hline TOTAL & 7 & 1 & 19 & 2 & & & & & & 2 & 1 & 3 & & 1 & 1 & 37 \\
\hline
\end{tabular}

$A=$ Assist

$\mathrm{CF}=$ Corrective Feedback

$\mathrm{CO}=$ Called on to answer question

$\mathrm{D}=$ Discipline

$\mathrm{E}$ = Encourage to engage
EXP = Explanation

$\mathrm{H}=$ Called into Hallway

$\mathrm{H} / \mathrm{J}=$ Humor/Joking

II = Individualized Instruction

$\mathrm{P}=$ Praise
$\mathrm{PM}=$ Progress Monitoring

$\mathrm{Q}=$ Student asked question

$\mathrm{R}=$ Teacher responds to question

$\mathrm{RA}=$ Read Aloud

$\mathrm{S}=$ Social

INDICATES STUDENT W/SLN 
Table 19: Observation 5 - Frequency Data - Coalton Middle School - SPED Teacher

\begin{tabular}{|c|c|c|c|c|c|c|c|c|c|c|c|c|c|c|c|c|}
\hline $\begin{array}{l}\text { Student } \\
\text { Seat \# }\end{array}$ & A & CF & $\mathrm{CO}$ & D & $E$ & EXP & $\mathrm{H}$ & $\mathrm{H} / \mathrm{J}$ & II & $P$ & $P M$ & $\mathrm{Q}$ & $\mathrm{R}$ & RA & $S$ & TOTAL \\
\hline 1 & & & & & & & & & & & & & & & & \\
\hline 2 & & & & & & & & & & & & & & & & \\
\hline 3 & & & & & & & & & & & & & & & & \\
\hline 4 & & & & & & & & & & & & & & & & \\
\hline 5 & & & & & & & & & & & & & & & & \\
\hline 6 & & & & & & & & & & & & & & & & \\
\hline 7 & & & & \multirow{4}{*}{\multicolumn{8}{|c|}{$\begin{array}{c}\text { FIFTH OBSERVATION-CANCELLED } \\
\text { UNABLE TO RESCHEDULE }\end{array}$}} & & & & & \\
\hline 8 & & & & & & & & & & & & & & & & \\
\hline 10 & & & & & & & & & & & & & & & & \\
\hline 11 & & & & & & & & & & & & & & & & \\
\hline 14 & & & & & & & & & & & & & & & & \\
\hline 15 & & & & & & & & & & & & & & & & \\
\hline 17 & & & & & & & & & & & & & & & & \\
\hline 19 & & & & & & & & & & & & & & & & \\
\hline 21 & & & & & & & & & & & & & & & & \\
\hline 23 & & & & & & & & & & & & & & & & \\
\hline 25 & & & & & & & & & & & & & & & & \\
\hline TOTAL & & & & & & & & & & & & & & & & \\
\hline
\end{tabular}

$A=$ Assist

$\mathrm{CF}=$ Corrective Feedback

$\mathrm{CO}=$ Called on to answer question

$\mathrm{D}=$ Discipline

$\mathrm{E}$ = Encourage to engage
EXP = Explanation

$\mathrm{H}=$ Called into Hallway

$\mathrm{H} / \mathrm{J}=$ Humor/Joking

II = Individualized Instruction

$\mathrm{P}=$ Praise
$\mathrm{PM}=$ Progress Monitoring

$\mathrm{Q}=$ Student asked question

$\mathrm{R}=$ Teacher responds to question

$\mathrm{RA}=$ Read Aloud

$\mathrm{S}=$ Social

\section{INDICATES STUDENT w/SLN}


Table 20 Observation 1 - Frequency Data - Coalton Middle School - GENED Teacher

\begin{tabular}{|c|c|c|c|c|c|c|c|c|c|c|c|c|c|c|c|c|}
\hline $\begin{array}{l}\text { Student } \\
\text { Seat \# }\end{array}$ & $A$ & CF & $\mathrm{CO}$ & $D$ & $E$ & EXP & $\mathrm{H}$ & $\mathrm{H} / \mathrm{J}$ & II & $\mathrm{P}$ & $P M$ & $\mathrm{Q}$ & $\mathrm{R}$ & $\mathrm{RA}$ & $S$ & TOTAL \\
\hline 1 & 1 & & & & & & & & & & & & & & 1 & 2 \\
\hline 2 & 1 & & & & & & & & & & 1 & & & & & 2 \\
\hline 3 & & & & & & & & & & & & & & & & NONE \\
\hline 4 & & & & & & & & & & & & & & & & NONE \\
\hline 5 & 1 & & & & & & & & & & & 1 & & & & 2 \\
\hline 6 & & & & & & & & & & & & & & & & NONE \\
\hline 7 & 2 & & & & & & & & & & & & & & & 2 \\
\hline 8 & & & 3 & & & & & & & & & & & & & 3 \\
\hline 10 & & & & & & & & & & & & & & & & NONE \\
\hline 11 & & & & & 1 & & & & & & & & & & & 1 \\
\hline 14 & 1 & & 1 & & & & & & & & & & & & & 2 \\
\hline 15 & 1 & & 2 & & & & & & & & & & & & & 3 \\
\hline 17 & & & 2 & & & & & & & & 1 & 1 & & & & 4 \\
\hline 19 & 3 & & 1 & & & & & & & & & 1 & & & & 5 \\
\hline 21 & & & & & & & & & & & & & & & & NONE \\
\hline 23 & & & & & & & & & & & & & & & & NONE \\
\hline 25 & 2 & & & & & & & & & & & & & 1 & & 3 \\
\hline TOTAL & 12 & & 9 & & 1 & & & & & & 2 & 3 & & 1 & 1 & 29 \\
\hline
\end{tabular}
$A=$ Assist
$\mathrm{CF}=$ Corrective Feedback
$\mathrm{CO}=$ Called on to answer question
$\mathrm{D}=$ Discipline
$\mathrm{E}=$ Encourage to engage
EXP = Explanation
$\mathrm{H}=$ Called into Hallway
$\mathrm{H} / \mathrm{J}=$ Humor/Joking
II = Individualized Instruction
$\mathrm{P}=$ Praise

\section{INDICATES STUDENT w/SLN}


Table 21 Observation 2 - Frequency Data - Coalton Middle School - GENED Teacher

\begin{tabular}{|c|c|c|c|c|c|c|c|c|c|c|c|c|c|c|c|c|}
\hline $\begin{array}{l}\text { Student } \\
\text { Seat \# }\end{array}$ & $A$ & CF & $\mathrm{CO}$ & $\mathrm{D}$ & $E$ & EXP & $\mathrm{H}$ & $\mathrm{H} / \mathrm{J}$ & II & $\mathrm{P}$ & PM & $\mathrm{Q}$ & $\mathrm{R}$ & $\mathrm{RA}$ & $\mathrm{S}$ & TOTAL \\
\hline 1 & & & & 2 & & & & & & & & & & & & 2 \\
\hline 2 & & & & 2 & & & & & & & & & & & & 2 \\
\hline 3 & & & & & & & & & & 1 & 2 & & & & & 3 \\
\hline 4 & & & & & & & & & & & & & & & & NONE \\
\hline 5 & 1 & & & & & & & & & & 1 & & & & & 2 \\
\hline 6 & & & & & & & & & & & & & & & & NONE \\
\hline 7 & 2 & & 1 & & & & & & & & 1 & & & & & 4 \\
\hline 8 & & & & 1 & & & & & & & & & & & & 1 \\
\hline 10 & & & & & 1 & & & & & & & & & & & 1 \\
\hline 11 & 1 & & & 1 & & & & & & & & & & & & 2 \\
\hline 14 & & & & 1 & & & & & & & 1 & & & & & 2 \\
\hline 15 & 1 & & & & & & & & & & & & & & & 1 \\
\hline 17 & 4 & & & & & & & & & 2 & & & & & & 6 \\
\hline 19 & 2 & & & & & & & & & & & & & & 1 & 3 \\
\hline 21 & 1 & & & 1 & & & & & & & & & & & & 2 \\
\hline 23 & 2 & & & & & & & & & & & & & & & 2 \\
\hline 25 & 1 & & & & & & & & & & & & & & & 1 \\
\hline TOTAL & 15 & & 1 & 8 & 1 & & & & & 3 & 5 & & & & 1 & 34 \\
\hline
\end{tabular}

$A=$ Assist

$\mathrm{CF}=$ Corrective Feedback

$\mathrm{CO}=$ Called on to answer question

$\mathrm{D}=$ Discipline

$\mathrm{E}$ = Encourage to engage
EXP = Explanation

$\mathrm{H}=$ Called into Hallway

$\mathrm{H} / \mathrm{J}=$ Humor/Joking

II = Individualized Instruction

$\mathrm{P}=$ Praise
$\mathrm{PM}=$ Progress Monitoring

$\mathrm{Q}=$ Student asked question

$\mathrm{R}=$ Teacher responds to question

$\mathrm{RA}=$ Read Aloud

$\mathrm{S}=$ Social

INDICATES STUDENT w/SLN 
Table 22 Observation 3 - Frequency Data - Coalton Middle School - GENED Teacher

\begin{tabular}{|c|c|c|c|c|c|c|c|c|c|c|c|c|c|c|c|c|}
\hline $\begin{array}{l}\text { Student } \\
\text { Seat \# }\end{array}$ & $A$ & CF & $\mathrm{CO}$ & $D$ & $E$ & EXP & $\mathrm{H}$ & $\mathrm{H} / \mathrm{J}$ & II & $\mathrm{P}$ & PM & $\mathrm{Q}$ & $\mathrm{R}$ & $\mathrm{RA}$ & $\mathrm{S}$ & TOTAL \\
\hline 1 & & & & & & & & & & & 1 & & & & & 1 \\
\hline 2 & & & & 1 & & & & & & & & & & & & 1 \\
\hline 3 & & & & & & & & & & & 1 & & & & & 1 \\
\hline 4 & 1 & & & & & & & & & & 1 & & & & & 2 \\
\hline 5 & & 1 & & 7 & & & & & & & 3 & & & & & 11 \\
\hline 6 & & & & 2 & & & & & & & & & & & & 2 \\
\hline 7 & 1 & & & & & & & & & & 1 & & & & & 2 \\
\hline 8 & & & & & & & & & & & & & & & & NONE \\
\hline 10 & & & & & & & & & & & & & & & & NONE \\
\hline 11 & & & & & & & & & & & & & & & & NONE \\
\hline 14 & & & & & & & & & & & & & & & & NONE \\
\hline 15 & & & & & & & & & 1 & & 1 & & & & & 2 \\
\hline 17 & 1 & & & & & & & & 1 & & & & & & & 2 \\
\hline 19 & 4 & 1 & & & & & & & 1 & & & & & 1 & & 7 \\
\hline 21 & & & & & & & & & & & & & & & & NONE \\
\hline 23 & & & & & & & & & & & 1 & & & & & 1 \\
\hline 25 & 1 & & 2 & & & & & & & & 1 & 1 & & & 2 & 7 \\
\hline TOTAL & 8 & 2 & 2 & 10 & & & & & 3 & & 10 & 1 & & 1 & 2 & 39 \\
\hline
\end{tabular}

$A=$ Assist

$\mathrm{CF}=$ Corrective Feedback

$\mathrm{CO}=$ Called on to answer question

$\mathrm{D}=$ Discipline

$\mathrm{E}$ = Encourage to engage
EXP = Explanation

$\mathrm{H}=$ Called into Hallway

$\mathrm{H} / \mathrm{J}=$ Humor/Joking

II = Individualized Instruction

$\mathrm{P}=$ Praise
$\mathrm{PM}=$ Progress Monitoring

$\mathrm{Q}=$ Student asked question

$\mathrm{R}=$ Teacher responds to question

$\mathrm{RA}=$ Read Aloud

$\mathrm{S}=$ Social

INDICATES STUDENT W/SLN 
Table 23: Observation 4 - Frequency Data - Coalton Middle School - GENED Teacher

\begin{tabular}{|c|c|c|c|c|c|c|c|c|c|c|c|c|c|c|c|c|}
\hline $\begin{array}{l}\text { Student } \\
\text { Seat \# }\end{array}$ & $A$ & CF & $\mathrm{CO}$ & $\mathrm{D}$ & $E$ & EXP & $\mathrm{H}$ & $\mathrm{H} / \mathrm{J}$ & II & $\mathrm{P}$ & $P M$ & $\mathrm{Q}$ & $\mathrm{R}$ & $\mathrm{RA}$ & $\mathrm{S}$ & TOTAL \\
\hline 1 & & & & 2 & & & & & & & & & & & & 2 \\
\hline 2 & & & 3 & 1 & & & & & & & & & & & & 4 \\
\hline 3 & 1 & & 2 & & & & & & & & & & & & & 3 \\
\hline 4 & & & 2 & & & & & & & & & & & & & 2 \\
\hline 5 & & & & 5 & & & & & & & & & & & & 5 \\
\hline 6 & & & & 1 & & & & & & & & 1 & & & & 2 \\
\hline 7 & & & & & & & & & & & & & & & & NONE \\
\hline 8 & & & & & & & & & & & & & & & & NONE \\
\hline 10 & & & 1 & & & & & & & & & & & & & 1 \\
\hline 11 & & & 2 & 3 & & & & & & & & & & & & 5 \\
\hline 14 & & & & & & & & & & & & & & & & NONE \\
\hline 15 & 2 & & 2 & & & & & & & & & 1 & & & & 5 \\
\hline 17 & & & & & & & & & & & & 1 & & & & 1 \\
\hline 19 & & & & & & & & & & & & & & & & NONE \\
\hline 21 & & & & 1 & & & & & & & & & & & 1 & 2 \\
\hline 23 & & & 1 & & & & & & & & 1 & & & & & 2 \\
\hline 25 & & & & & & & & & & & & & & & & NONE \\
\hline TOTAL & 3 & & 13 & 13 & & & & & & & 1 & 3 & & & 1 & 34 \\
\hline
\end{tabular}

$A=$ Assist

$\mathrm{CF}=$ Corrective Feedback

$\mathrm{CO}=$ Called on to answer question

$\mathrm{D}=$ Discipline

$\mathrm{E}$ = Encourage to engage
EXP = Explanation
$\mathrm{H}=$ Called into Hallway
$\mathrm{H} / \mathrm{J}=$ Humor/Joking
II = Individualized Instruction
$\mathrm{P}=$ Praise
$\mathrm{PM}=$ Progress Monitoring
$\mathrm{Q}=$ Student asked question
$\mathrm{R}=$ Teacher responds to question
$\mathrm{RA}=$ Read Aloud
$S=$ Social

\section{INDICATES STUDENT w/SLN}

Table 24: Observation 5 - Frequency Data - Coalton Middle School - GENED Teacher 


\begin{tabular}{|c|c|c|c|c|c|c|c|c|c|c|c|c|c|c|c|c|}
\hline $\begin{array}{l}\text { Student } \\
\text { Seat \# }\end{array}$ & $A$ & CF & $\mathrm{CO}$ & $\mathrm{D}$ & $E$ & EXP & $\mathrm{H}$ & $\mathrm{H} / \mathrm{J}$ & II & $P$ & PM & Q & $\mathrm{R}$ & $\mathrm{RA}$ & $\mathrm{S}$ & TOTAL \\
\hline 1 & & & & & & & & & & & & & & & & \\
\hline 2 & & & & & & & & & & & & & & & & \\
\hline 3 & & & & & & & & & & & & & & & & \\
\hline 4 & & & & & & & & & & & & & & & & \\
\hline 5 & & & & & & & & & & & & & & & & \\
\hline 6 & & & & & & & & & & & & & & & & \\
\hline 7 & & & & \multirow{4}{*}{\multicolumn{8}{|c|}{$\begin{array}{l}\text { FIFTH OBSERVATON CANCELLED } \\
\text { UNABLE TO RESCHEDULE }\end{array}$}} & & & & & \\
\hline 8 & & & & & & & & & & & & & & & & \\
\hline 10 & & & & & & & & & & & & & & & & \\
\hline 11 & & & & & & & & & & & & & & & & \\
\hline 14 & & & & & & & & & & & & & & & & \\
\hline 15 & & & & & & & & & & & & & & & & \\
\hline 17 & & & & & & & & & & & & & & & & \\
\hline 19 & & & & & & & & & & & & & & & & \\
\hline 21 & & & & & & & & & & & & & & & & \\
\hline 23 & & & & & & & & & & & & & & & & \\
\hline 25 & & & & & & & & & & & & & & & & \\
\hline TOTAL & & & & & & & & & & & & & & & & \\
\hline
\end{tabular}
$A=$ Assist
$\mathrm{CF}=$ Corrective Feedback
$\mathrm{CO}=$ Called on to answer question
$\mathrm{D}=$ Discipline
$\mathrm{E}=$ Encourage to engage

EXP = Explanation

$\mathrm{H}=$ Called into Hallway

$\mathrm{H} / \mathrm{J}=$ Humor/Joking

II = Individualized Instruction

$\mathrm{P}=$ Praise
$\mathrm{PM}=$ Progress Monitoring

$\mathrm{Q}=$ Student asked question

$R=$ Teacher responds to question

$\mathrm{RA}=$ Read Aloud

$S=$ Social 
Table 25 summarizes the interactions of both Betty and Linda with their students. As was indicated in the Coalton case narrative, Betty, the special education teacher, was considered to be the lead teacher for the writing portion of the ELA class. This is supported by the data recorded in Tables 24 and 25 as well as the daily data recorded in the previously discussed tables.

Table 25

Number of Interactions Observed - Coalton Middle School

\begin{tabular}{|l|c|c|c|c|c|c|c|c|c|c|c|c|c|c|c|c|}
\hline & A & CF & CO & D & E & EXP & H & H/J & II & P & PM & Q & R & RA & S & TOTAL \\
\hline $\begin{array}{c}\text { SPED } \\
\text { (Betty) }\end{array}$ & 40 & 3 & 77 & 16 & 3 & & & & 3 & 7 & 8 & 6 & & 1 & 1 & $\mathbf{1 6 5}$ \\
\hline $\begin{array}{c}\text { GENED } \\
\text { (Linda) }\end{array}$ & 38 & 2 & 25 & 31 & 2 & & & & 3 & 3 & 18 & 7 & & 2 & 5 & 136 \\
\hline COMBINED & $\mathbf{7 8}$ & $\mathbf{5}$ & $\mathbf{1 0 2}$ & $\mathbf{4 7}$ & $\mathbf{5}$ & & & & $\mathbf{6}$ & $\mathbf{1 0}$ & $\mathbf{2 9}$ & $\mathbf{1 0}$ & $\mathbf{3}$ & $\mathbf{6}$ & $\mathbf{3 0 1}$ \\
\hline
\end{tabular}
A $\quad=$ Assist
CF = Corrective Feedback
II = Individual Instruction
CO = Called on to answer question
$\mathbf{P} \quad=$ Praise
D = Discipline
PM = Progress Monitoring
E = Encourage to engage
EXP = Explanation
Q = Student asked question
$\mathbf{H}=$ Called to hall
$\mathbf{R}=$ Teacher responds to question
$\mathbf{H} / \mathbf{J}=$ Humor/Joking
RA = Read aloud
$\mathrm{S}=$ Social

A closer examination of the number of interactions would appear to support the conclusion that both Linda and Betty provide assistance equally to both the general education students and the students with SLN. Additionally, both teachers had more total interactions overall with students with SLN than with the general education students. Of the 17 students in class, eight receive modifications of some type (See Appendices $\mathrm{K}$ and $\mathrm{L}$.

Given the total numbers of interactions that occurred during observations and data collection, it is apparent that both Linda and Betty are actively engaged with their 
students. This is also supported in the narrative of the Coalton case. In fact, as both teachers stipulated in their respective interviews, having two teachers in the classroom does seem to provide more opportunities for individual assistance, attention and instruction.

Table 26

Comparison of SPED Teacher's Interactions to GENED Teacher's Interactions Coalton Middle School

\begin{tabular}{|c|c|c|c|c|c|c|c|c|c|c|c|c|c|c|c|c|}
\hline & A & CF & CO & D & E & EXP & H & H/J & II & P & PM & Q & R & RA & S & TOTAL \\
\hline $\begin{array}{c}\text { SPED } \\
\text { (Betty) } \\
\text { > } \\
\text { SLN }\end{array}$ & 22 & 2 & 37 & 11 & 1 & & & & 3 & 2 & 6 & 3 & & 1 & & 88 \\
\hline $\begin{array}{c}\text { SPED } \\
\text { > } \\
\text { gened }\end{array}$ & 18 & 1 & 40 & 5 & 2 & & & & & 5 & 2 & 3 & & & 1 & 77 \\
\hline TOTAL & $\mathbf{4 0}$ & $\mathbf{3}$ & $\mathbf{7 7}$ & $\mathbf{1 6}$ & $\mathbf{3}$ & & & & $\mathbf{3}$ & $\mathbf{7}$ & $\mathbf{8}$ & $\mathbf{6}$ & & $\mathbf{1}$ & $\mathbf{1}$ & $\mathbf{1 6 5}$ \\
\hline $\begin{array}{c}\text { GENED } \\
\text { (Linda) } \\
\text { > } \\
\text { SLN }\end{array}$ & 19 & 1 & 12 & 23 & 1 & & & & 1 & 2 & 12 & 3 & & & 1 & 73 \\
\hline $\begin{array}{c}\text { GENED } \\
\text { > } \\
\text { gened }\end{array}$ & 19 & 1 & 13 & 8 & 1 & & & & 2 & 1 & 6 & 4 & & 2 & 4 & 61 \\
\hline TOTAL & $\mathbf{3 8}$ & $\mathbf{2}$ & $\mathbf{2 5}$ & $\mathbf{3 1}$ & $\mathbf{2}$ & & & & $\mathbf{3}$ & $\mathbf{3}$ & $\mathbf{1 8}$ & $\mathbf{7}$ & $\mathbf{2}$ & $\mathbf{5}$ & $\mathbf{1 3 6}$ \\
\hline
\end{tabular}
A $=$ Assist
CF = Corrective Feedback
CO = Called on to answer question
D = Discipline
E = Encourage to engage
EXP = Explanation
$\mathbf{H}=$ Called to hall
$\mathbf{H} / \mathbf{J}=$ Humor/Joking
II = Individual Instruction
$\mathbf{P} \quad=$ Praise
PM = Progress Monitoring
$\mathbf{Q}=$ Student asked question
$\mathbf{R}=$ Teacher responds to question
RA = Read aloud
$\mathrm{S}=$ Social


Great Falls Middle School

Great Falls Middle School was originally built to house Great Falls Jr. High School in 1997 but was later reconfigured as a middle school with grades 6, 7, and 8. Its design is indicative of an evolving philosophical change in education that has given way to the middle school concept. It was designed and built in such a way that, although not a perfect structure, the transition from junior high school to middle school was easier to accomplish than with much older structures. Not far from Wright Middle, Great Falls is also located in the city of Alton. Until Great Falls Elementary was built just a few years ago, Great Falls Middle sat alone in what was once an empty field. Yet the school's apparent isolation is deceiving for within a mile or so of the school lies a very small but busy city.

The school's appearance is like no other in Walter County. A portion of the front of the building is made mostly of windows instead of walls. Behind those windows are the offices of the principal and her two assistant principals. The windows look out on the bus area, the parking lot, the main entrance to the school grounds, and Great Falls Elementary School. The front entrance to the school opens immediately into the cafeteria. Just beyond the cafeteria is a wide and lengthy lobby area which is outside of the school gym. Across from the gym is the school's media center. To the left of the cafeteria is the main office, a staircase leading to the second floor, and a hallway leading to the sixth grade classrooms. Lockers line the walls on either side of the hallway. The English/Language Arts class that Naomi and Mary share is located on the left a little more than halfway down the hall. 
Naomi and Mary

Naomi has an English/Language Arts 5-12 (ELA 5-12) certification and an authorization from the Alternative Education Program to teach all subjects - all grades. She substituted for two and one-half years before becoming a fulltime teacher and has now been teaching for 10 years. Her only experiences with co-teaching prior to this year were while she taught at the county's alternative school; however, those experiences were with other content teachers and not special education teachers as partners. Naomi has only one year of co-teaching experience in an inclusive environment. She currently teaches $6^{\text {th }}$ grade English/Language Arts and has within her schedule two inclusive, co-taught ELA classes. Naomi is a "no nonsense" teacher intent on keeping an orderly and productive classroom. She has the same expectations for all her students regardless of whether they are students with special learning needs or students without identified special learning needs.

Mary has been a special education teacher for four years. The last two years she has been in co-teaching partnerships with content teachers in inclusive classrooms. Mary has a Masters' degree in special education and holds a multicategorical special education certification. She is currently working toward a certification in Business Education 5-Adult and has the option of additional endorsements in math and reading. Although she has co-taught for two years, this has been her first year with Naomi as her partner. Like some of the other special education teachers at Great Falls, Mary coteaches with more than one content teacher each day. In addition to the two classes she shares with Naomi, she co-teaches with two other content teachers: one in math and the other in another ELA classroom. 
Naomi and Mary have had significantly different experiences in their preparation for the implementation of co-teaching. Although a two-day seminar on co-teaching was provided by Walter County last year, Naomi was not in a co-teaching situation at that time and was, therefore, not permitted to attend. Consequently, she has had very little actual training in the models of co-teaching and was somewhat confused when I asked her to identify the type of co-teaching model she and Mary use. Mary, however, and her previous co-teaching partner were among those selected to attend last year's seminar. During my interview with Mary, she described that training to me:

We had a two day seminar out at the federal prison learning center. And we went with our co-teachers. The principal picked several pairs out of each grade level. We were assigned to our partners....So you went with your co-teacher and there was a two day training... it was very good. The trainer did a lot of modeling to kind of show us the proper ways to implement co-teaching. The seminars were wonderful because they laid out a foundation for you to give you something to stand on.

Although Mary enjoyed the training and admitted that she had gotten a lot from the twoday seminar, she explained that there was more that should have been addressed:

The one thing that bothered me about the seminar was they went over all the basics of co-teaching - whether you were gonna do a one teach-one assist - all the different models - but the one thing that I know they would naturally not deal with - or even talk about was - because you would assume all the people who are educated and working in the school system by this point and their age, you would assume that they would know how to work with other adults on an appropriate level, but they did not approach anything as far as professionalism.

Something about her tone piqued my curiosity so I asked her to elaborate. As she related her experiences, I understood why professionalism was such an issue for her: 
Well, the teacher I had last year - it did not work out well at all because that particular teacher was very set in exactly the way she wanted things done. And I would plan for an hour and a half a week - minimum - to figure out what I was going to do for the week and then I'd still go in and things would still be changed around without my knowing.

She talked way too fast, and she talked above the students. I would try to talk with her in planning about the need to slow down instruction in the coteaching classroom because with these kids (indicating students with special learning needs) it goes right over their heads.

Or I might stand up and I would start talking and if she didn't feel that I was doing it the way I should have been doing it, she would interrupt me and correct me - pretty much I would just stand back and just say, 'Okay, fine.' And I didn't - I would just not participate as much because I got tired of it.

In spite of the problems Mary related, none seemed to keep her from developing an appropriate, pleasant, and professional relationship with Naomi.

While Mary was struggling through her co-teaching situation the previous year, Naomi was not involved in co-teaching. As Naomi explained, an "experimental program" was in place at Great Falls Middle during that year. By virtue of the fact that she did not have students with special learning needs in her classes, she was not a part of the "experiment.":

All of the special education students were assigned to only one inclusion teacher who worked with just the special education students. We had one inclusion teacher who worked with just the special education students in their $7^{\text {th }}$ grade included ELA class. I was not the $7^{\text {th }}$ grade English teacher who worked with the special education department. The other $7^{\text {th }}$ grade teacher did that. I just did not have special ed so I did not have a coteacher.

Co-teaching at Great Falls Middle is different now. Students with special learning needs are divided among two or more grade level teachers so that there is not just one 
"inclusion class" per grade level. As a result of the change, Naomi and Mary were assigned as co-teachers for two of the $6^{\text {th }}$ grade inclusive ELA classes.

Naomi and Mary both believe they "work well together and that it's been a good arrangement" in spite of Naomi's lack of formal training in the models of co-teaching. Mary is quite willing to share what she learned at the co-teaching seminar with Naomi; in fact, she feels like it is expected of her:

I think Ms. T (principal) assumed I would be able to - since l've had the training and I'd done it before - I would help Naomi. I would say, 'here's what we can do' or ask 'what can I help you with'? I might try to give her ideas. But she's very easy to work with so it's like - nothing to it!

They agree that theirs is an effective arrangement because of the strengths they each bring to the partnership. While both teachers have equal authority in the classroom, Naomi is quick to point out that she is much more comfortable being the disciplinarian, and "Mary is better at dealing with the kids because they open up and respond to her more easily. They see me as more of an authority figure." Mary adds:

I don't have a problem in Naomi's room if I have to pipe up and say something to a student. I just never really have to because Naomi has got pretty good control. I don't usually have to say a lot; I don't have to be the disciplinarian.

Naomi sums up their partnership as each supplying what the other lacks. She stipulates what Mary provides. "[T]here are times when I feel inadequate...as advisor... as a confidant... or with technology. Mary is more comfortable with these things. I think we're a good combination together." 
Co-teaching Partnership/Roles and Responsibilities

Making a co-teaching partnership work can be a challenge under the best circumstances. Determining appropriate roles and responsibilities for each of the partners is an essential element that cannot be ignored if the partnership is to be successful. Naomi and Mary have begun to develop a very positive and effective coteaching relationship because they understand the significance of appropriately and effectively sharing the roles and responsibilities in their classroom. Naomi describes their efforts as both collaborative and cooperative:

When we are working with the lesson plans, Mary and I will get together and she'll say, 'What do you have planned for next week?' And I think our plan is more collaborative and cooperative - by this I mean I usually work with the lesson plans and Mary know the exceptionalities and the modifications that should be made of the special education students and she adapts for those students. If I am leading the instruction, then Mary will probably be at the board or going around to the students.

Our main responsibility is to help deliver instruction. We are both authority figures and we both work on grading the papers. I design the lesson plans and Mary looks over them to see what is going to work for the students that she works with and what's not going to work.

Interestingly enough, because Mary co-teaches with three different partners throughout the day, her descriptions of the roles and responsibilities she has is somewhat different. That difference, according to Mary, is due largely to the characteristics or personalities that make each of her co-teaching partners unique. Although this case focused primarily on Mary's co-teaching partnership with Naomi, the impact of her other co-teaching partnerships could not be ignored. She explained all three of her partnerships as if each was somehow connected. And she described them all from the perspective of how the two compare with the most difficult partnership: 
You have different personalities you've got to mesh with. So, it's a oneon-one thing. I have three different teachers I co-teach with in a day. And all three of them - they're all totally different in the way they co-teach - or the way they accept me into their classroom.

I have one who is very controlling - wants everything the way she says it's gonna be. I had to have a talk with her about professionalism. She did not accept it. She's also very, very young - very immature - fresh out of college. She makes it very well known that if somebody wants to go to the restroom or there's some sort of thing that requires a decision, she wants to make the final decision on everything that goes on in the class. So that is the room that I just hang back and just wander around. I am more of an assistant in there. I just wander around helping the kids who have questions.

The one class I'm in only one time a day is a math class. I absolutely love her as a co-teacher. I will interject - she doesn't care. If I say 'Ms. Suchand-such, what about... or how do you... or can you re-explain?' And she just stops and says, 'Sure.' I can tell the biggest difference in the way the kids treat me in that classroom than the way they treat me in the other one. They treat me more respectfully - like I actually have a job here.

With Naomi I have no problems. I'm not as up on writing grammar skills as she is so she gives most of the lessons. I mean I've tried to give some lessons here and there, but she knows to listen to what l'm saying because it's highly possible I'm gonna say the wrong thing or say it the wrong way. When I make a mistake, she handles it in a very professional manner. It's never a condescending 'Just forget it; let me take over' attitude.

Although Mary indicated during our interview that Naomi "usually leads since she's the core teacher for the subject," that was not the case during the classes I observed. While it was obvious that Naomi had shared in the planning and preparation for each class, Mary delivered the instruction. That is not to say that Naomi was not an active participant during class. Naomi offered an explanation:

Mary takes the lead role more when we are using technology than when we are doing just grammar or written work because that is her area of strength. 
In spite of her knowledge of and skills with technology, Mary quickly points out that grammar and writing are not her strengths. The comfort and effectiveness of their partnership is most apparent when Mary is faced with presenting content she is not sure of:

... if I'm going into some sort of subject matter, or if something comes up, I quick to say, 'Mrs. -, you might want to explain this one.' I'll stop and let her jump in because....well, the students definitely can tell I'm not the grammar teacher (laughs).

It is interesting to note that Naomi does not see this as much as a weakness as she sees it as an opportunity to make a point with their students - a teachable moment that has nothing, really, to do with the content, but everything to do with teaching students one of life's lessons. She emphatically explains that she uses such times to ensure that students understand that "we don't have to know everything. All we have to know is to realize that we don't know everything but we do know where to find the information that we need. I think that with them being able to see that we don't know everything and that we can go get it, it gives them that 'Hey, we can do this.' attitude."

The success of good partnerships lies within the individual strengths that comprise those partnerships. It is clear that both Naomi and Mary understand how to use their strengths in a manner that enhances not only their co-teaching partnership but also the learning opportunities that are available to their students.

\section{Use and Impact of Technology}

Technology is used in a variety of ways in Naomi and Mary's classroom. For instructional purposes, a laptop connected to a document camera is on a cart that is situated in the center of the classroom between the two center rows of desks. It is used 
on a daily basis in some way to assist in the delivery of the content. Students are not permitted to use the laptop, even though the activities are frequently interactive in nature. There is a computer and printer on the teacher's desk at the back of the room. It is used by the teachers for storing grades, attendance records, and other types of student records. It is also used by the teachers for research in the preparation of lessons. Typically, Mary incorporates the laptop during instruction, and Naomi uses the computer at her desk to keep grades and attendance records up to date. It is an arrangement that works for them because, as Naomi points out, "Mary is more comfortable with the technology." Mary explained how the technology is incorporated in their instruction:

If we're talking about some kind of a lesson - maybe what information she's going to be covering - or something she wants to cover, l'll be like... well, do you want me to look on the computer. I can probably find a PowerPoint, or I can probably find some interactive website because I notice that the kids like it a lot if I have something projected instead of doing just book work - or just reading and answering questions or whatever. They kind of seem to like it better if they're looking up at a screen and we're doing something on it... on the computer. They open up a little better.

Naomi added:

If the information is new information or information that we want to review... if it is covered in the literature or in our text, I try to use the text as a reference. But if it is information that is not covered as comprehensively as I would like for it to be, then we go online; we consult; we do what we need to do to find the information.

It is interesting to note that during my observations, Mary incorporated the technology to enhance the instruction that Naomi had presented during a prior class as well as her own instruction. For example, during one class, Mary used a PowerPoint $₫$ presentation to provide students with information on "Alliteration." By incorporating real 
life examples of or pictures that illustrated alliteration, it appeared that students were quickly able to grasp the concept of alliteration. Naomi explained that Mary takes the lead role when the technology is being used to deliver instruction because that is one of her strong points. She adds, "I don't have a problem with sitting back and letting her take the lead and present that because that's what she's better at than I am." On another occasion, Mary used the laptop and projector to present 'idioms'. It appeared to me, however, that this was a review of an earlier lesson:

As students begin to work on their warm-up activity, Mary gets the classroom set up for the use of the laptop. Naomi calls roll.

Announcements and the pledge interrupt the warm-up activity. Mary continues to work on setting up the laptop and projector while Naomi continues to work at the computer on her desk. She pulls up a grade book program, and it becomes apparent that she is documenting absences.

When Mary begins, she presents the material from the website on the screen. She presents to the whole group and interacts with students randomly - yet not really acknowledging specific students individually. The website is idiomsite.com. Mary goes through an alphabetized list of idioms and allows students to pick out the idioms they want to see. She opens each one and reads it aloud. Students are then asked to explain the literal meaning of each idiom and to discuss the context in which it might be used.

This continues for several minutes. The entire activity was done with the whole group. There was no explicit instruction...only the idioms and their explanations were presented and discussed. When students began to show signs of tiring of this activity, Naomi began the next phase of instruction - the illustration of idioms. There is a website entitled "Eye on Idioms" that accompanies this part of the instruction. It includes a list of idioms - each accompanied by an illustration of its meaning.

The use of technology is not confined to the classroom. Students are given

access to the computer lab on a regular basis. It is in the lab that students are permitted to visit specific internet sites designed to enhance their classroom experiences. They also use word processing to prepare final drafts of writing 
assignments in the lab that were begun in the classroom. On the final day of my observations, class was held in the computer lab. Mary seemed to feel most comfortable as she moved with confidence from one student to the next monitoring individual progress and troubleshooting when something didn't seem to work just right. By contrast, Naomi did not circulate around the room. Instead, she used the time to review student progress with individuals whose grades had dropped or who had assignments missing.

Both teachers recognize the impact the use of technology has had with their students. Mary and Naomi explained how it has helped:

Mary: They're more awake; they act more interested; they pay more attention. I try to mix it up a little bit, and it works pretty good with them. You don't want them bored; you want them to try to listen. You want them to learn.

Naomi: They are so technology savvy - with the text messaging, with the Blackberries, with the computers they have at home, the cell phones - it's just commonplace for them. Anything that they learn with the technology - I can see that this $21^{\text {st }}$ century learning is where education is going. I recognize the need for it and I think the kids just intuitively know that it's something that's going to be important to them.

Interactions with Students

Naomi and Mary's class is the first period of their day. By design, it is a few minutes longer than their other classes to allow time for the morning routines: attendance, morning announcements, and the pledge. Once the morning rituals are complete, students are expected to be ready to begin working. To that end, written in the upper left corner of the Whiteboard there is an Essential Question (EQ). Since it reflects a particular objective that will be addressed during class, it is carefully worded 
so that its answer will identify the key concepts required to successfully master the day's lesson. Typically, the EQ changes every day. Accompanying the essential question is the corresponding content standard. At the opposite end of the Whiteboard, in the upper right corner is the current date, a warm-up activity - designed to prepare students' minds for the day's topic, and the an assignment that will follow the instruction. Students are expected to begin working on the warm-up activity immediately following the pledge. There is very little interaction between the teachers and their students during this time. During the observations, Naomi and Mary use the time to prepare materials or to discuss the last minute details of the day's class.

The students' desks are arranged in traditional rows that face the Whiteboard in the front of the room. Naomi's desk is in the back of the room behind the students' desks. Along the wall to the left of Naomi's desk is a table. Two computers, a couple of stacks of books, and trays with what appeared to be graded papers in them are on the table. A tray of blank notebook paper for student use is at the end of the table. Students are frequently reminded that paper is available. Windows lined the wall to the right of Naomi's desk.

When Naomi is ready for instruction to begin, she asks that students put aside their warm-up activities. Even when Mary takes the lead role, it appeared to me that it was important to Naomi takes the opportunity to initiate the day's lesson in some way. During my observations, she reviewed previously covered material, led a quick warm-up activity, or engaged the group in some form of discussion or conversation. Following her opening activity, the day's lesson is presented. Many of the interactions that occur between Naomi and the students are intended to assist struggling students or to 
maintain a well behaved, disciplined environment, but as a group rather than individually. It is with this type of group interaction that Naomi seems most comfortable. There are few opportunities for students to act out, and Naomi likes to keep it that way. She explained how her personal life experiences have influenced her demeanor as a disciplinarian in her classroom:

I think I grew into it based on my prior teaching experience. And - even in my life experiences because I was a military wife. I was always used.... and not because I was in the military but because my husband had a position of authority in the military. I just always expected it to be done and it was.

Although Naomi is a constant presence in the classroom, it is Mary who has more individual interactions with the students. During most of my observations, once instruction was complete, the remainder of Mary's time was spent circulating the room, monitoring student progress or providing individual instruction or assistance to students who needed or wanted her help. Although Naomi also monitored students' progress, most of her interactions were with the whole group rather than with individual students. It should be noted, however, that there were occasions when Naomi did interact with individual students - especially when Mary was busy with other students or when she needed to restore the quiet, disciplined environment she required of her class. As noted in my fieldnotes, the interactions in their class followed a consistent pattern:

Naomi begins the class by reminding students about their textbook and library card requirements. She then initiated an oral review of the figurative language that had been discussed during the week. She asked for definitions of simile, metaphor, idiom and alliteration. She called on students who responded to their respective terms.

The announcements interrupted the review, but after they were done, Mary started to take care of attendance. Naomi continued the review but made her way to the desk where Mary was preparing the attendance 
report. A student approached Mary and asked for her assistance which she gave. Naomi took a seat at her desk and continued to work on the attendance report, and Mary began to move about the room assisting students. Naomi remained at her desk but often interjected comments to what Mary said to the individual students.

After students have worked on their warm-up activity for a while, Naomi moves to the front of the room to explain the day's assignment to them. She goes over the assignment and tells the students, 'We are going to be in the computer lab tomorrow. In order for you to have something to type, you will complete this assignment.'

Naomi then distributes a copy of the assignment requirements to each student. Mary immediately begins to help Student C-S4. She explains carefully and extensively each item on the page. As Mary continues to work with individual students, Naomi walks around the room monitoring but not engaging very many students.

The students seem to ask for Mary over Naomi. Naomi does not mingle with the students - although she does move about the classroom. She initiates few interactions and the students don't typically engage her. Most questions are directed, instead, to Mary who interacts with the students more freely and with more frequency. She does not stop moving around the room until the class is over.

It appears that both teachers are very comfortable with their respective styles of interactions with the students. Additionally, each recognizes the contributions of her coteaching partner:

Naomi: Mary is better at dealing with the kids. They open up and they respond to her more easily than they do with me. They're thrilled with her comments to them. With both of us being here, the students know what their individual needs are, and, based on those needs or desires, they know who to approach.

Mary: They know who they're comfortable with. The fact is, they know I don't have the content knowledge that Naomi has. Sometimes they'll look at me like, 'Gosh, Mrs. -, don't you know what you're doing?' But, you know, it's the rapport that I've built with the kids... and all this time that I've been working with them and the way that I work with them that makes them feel free enough to look at me and say something like that. You'd never hear them say that to Naomi...just because she has a different demeanor than I do with the kids. So, in my position, I build a strong 
rapport with the kids because I feel like when I've got to float around all day, I just can't do it like she does. I have to change all day long.

Naomi: I think a lot of it is our age difference. There's a twenty year difference between us. The kids relate to her more.

Mary: The kids think I'm younger than I am.

Naomi: You really look younger than you are. But, l...you know...l'm more authoritative; it's just me.

As if Mary sensed something uncomfortable or some insecurity in Naomi's tone, she very quickly responded, "Well, there's nothing wrong with it. It works." The rapport Naomi has developed with their students appears related to the open relationship Mary has developed with their students. It is as if the students' trust of Mary has brought about their trust in Naomi. And, as Mary said, from the teachers' perspective, it works.

Throughout my observations at Great Falls Middle, it became apparent that both teachers recognized the benefit their students received from the co-taught, inclusive environment. Both agree that much of the benefit comes from having two teachers in the classroom because each brings an expertise that the other lacks. As Mary explained, "Naomi decides what we're going to do, but then I try to figure out ways I can help her help the kids." Because "the number one priority is what is in the best interest of the students," Naomi has no problems with the different activities or approaches that Mary initiates. Mary explained how she and Naomi approached the diverse needs in their class:

All the kids actually benefit from what we do. They all benefit. It's just that there are some kids that are slower - who are not special ed - who need more visuals...they need something written down so they can actually look at it - something they can touch...that's why we use a lot of visuals. We do a lot of kinesthetic stuff - we try to mix it up, so I throw things in there thinking that they will help. And maybe those things will make it sink in for 
my special needs kids - and maybe they will make it sink in for some of the other kids, too.

Their purpose is clear, and they each work to ensure that their students succeed.

Frequency Data

An analysis of Tables 27-36 reveals two trends. First, it appears that many of the students go through class without ever having Mary or Naomi interact with them. Second, there are few instances of individual instruction that occur during instructional time. From the perspective of Tables 37 and 38, a third trend surfaces. Based on Naomi's total number of observed interactions, it appears that she, as the content teacher, has significantly fewer interactions with students than Mary does. Given the fact that Mary explicitly states that she is not always confident in her ELA skills, Naomi's apparent lack of involvement during instruction may be cause for concern. Yet, what I found most compelling is the number of total interactions both Naomi and Mary had with students identified as having SLN, or, more significantly, the apparent lack of interactions with students with SLN.

When this trend emerged, I returned to observation and interview notes in an effort to identify a context which would explain such startling information. First, and probably most important with regard to the apparent lack of interactions with students with SLN, during observations, I made note of student absences. For example, Student C-S3, a student with SLN, was absent two of the five days I observed (See Appendix M or $\mathrm{N}$ ). Also important to note is that of the 21 students in class, only three are identified as students with SLN. It should also be noted that when Student C-S3 returned after his absence, both Naomi and Mary assisted him with getting the work he had missed. 
Absenteeism actually seems to be something that Naomi and Mary should address. Of the 21 students in the class, only seven were in attendance all five days that I observed. 
Table 27: Observation 1 - Frequency Data - Great Falls Middle School - SPED Teacher

\begin{tabular}{|c|c|c|c|c|c|c|c|c|c|c|c|c|c|c|c|c|}
\hline $\begin{array}{l}\text { Student } \\
\text { Seat \# }\end{array}$ & $A$ & CF & $\mathrm{CO}$ & $\mathrm{D}$ & $E$ & EXP & $\mathrm{H}$ & $\mathrm{H} / \mathrm{J}$ & II & $P$ & PM & $\mathrm{Q}$ & $\mathrm{R}$ & RA & $S$ & TOTAL \\
\hline 1 & 1 & & & & & & & & & & & & & & & 1 \\
\hline 2 & & & & & & & & & & & & & & & & NONE \\
\hline 3 & & & & & & & & & & & & & & & & NONE \\
\hline 4 & & & & & & & & 1 & & & & & & & & 1 \\
\hline 5 & & & & & & & & 1 & & & & & & & & 1 \\
\hline 6 & & & & & & & & & & & & & & & & NONE \\
\hline 7 & 2 & & 1 & & & & & 1 & & & & & & & & 4 \\
\hline 9 & & & & & & & & & & & & & & & & NONE \\
\hline 10 & & & 2 & & & & & & & & & & & & & 2 \\
\hline 11 & & & & & & & & & & & & & & & & NONE \\
\hline 13 & & & & & & & & 2 & & & & & & & 3 & 5 \\
\hline 14 & & & & & & & & & & & & & & & & NONE \\
\hline 15 & & & & & & & & 1 & & & & & & & & 1 \\
\hline 16 & 1 & & & & & & & & & & & & & & 1 & 2 \\
\hline 17 & & & & & & & & & & & & & & & & NONE \\
\hline 18 & & & & & & & & & & & & & & & & NONE \\
\hline 22 & 1 & & 2 & & & & & 2 & & & & & & & 1 & 6 \\
\hline 23 & 1 & & & & & & & & & & & & & & & 1 \\
\hline 24 & & & & & & & & & & & & & & & & NONE \\
\hline 25 & 1 & & & & & & & & & & & & & & 1 & 2 \\
\hline 26 & & & & & & & & & & & & & & & & NONE \\
\hline TOTAL & 7 & & 5 & & & & & 8 & & & & & & & 6 & 26 \\
\hline \multicolumn{5}{|c|}{$\begin{array}{l}A=\text { Assist } \\
C F=\text { Corrective Feedback } \\
C O=\text { Called on to answer question } \\
D=\text { Discipline } \\
E=\text { Encourage to engage }\end{array}$} & & $\begin{aligned} E X P & = \\
H & = \\
H / J & =1 \\
I I & = \\
P & =\end{aligned}$ & $\begin{array}{l}\text { eplar } \\
\text { alled } \\
\text { mor } \\
\text { divid } \\
\text { aise }\end{array}$ & $\begin{array}{l}\text { on } \\
\text { o Hal } \\
\text { king } \\
\text { lized }\end{array}$ & & \multicolumn{7}{|c|}{$\begin{aligned} \mathrm{PM} & =\text { Progress Monitoring } \\
\mathrm{Q} & =\text { Student asked question } \\
\mathrm{R} & =\text { Teacher responds to question } \\
\mathrm{RA} & =\text { Read Aloud } \\
\mathrm{S} & =\text { Social }\end{aligned}$} \\
\hline
\end{tabular}

INDICATES STUDENT w/SLN 
Table 28: Observation 2 - Frequency Data - Great Falls Middle School - SPED Teacher

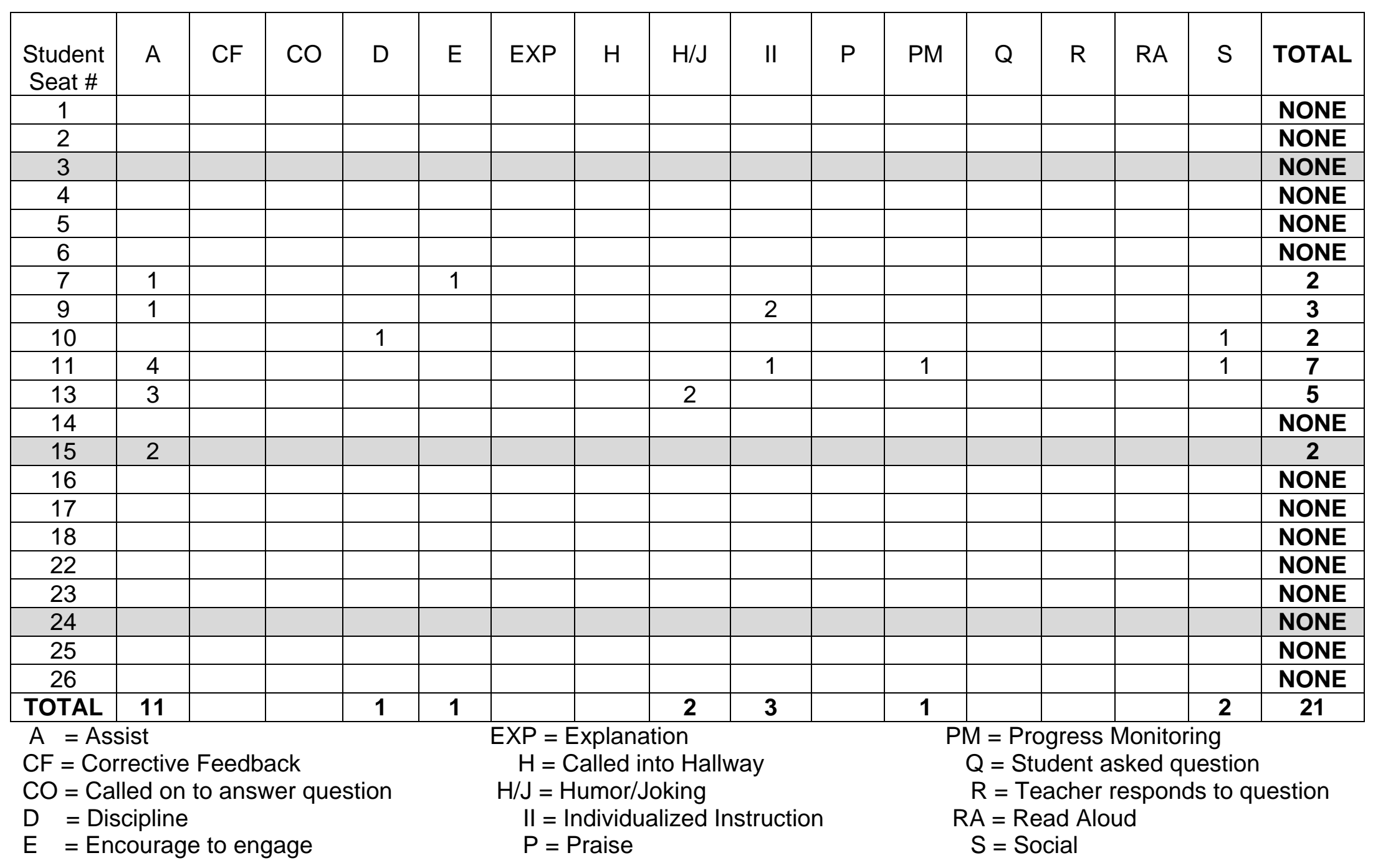

INDICATES STUDENT w/SLN 
Table 29: Observation 3 - Frequency Data - Great Falls Middle School - SPED Teacher

\begin{tabular}{|c|c|c|c|c|c|c|c|c|c|c|c|c|c|c|c|c|}
\hline $\begin{array}{l}\text { Student } \\
\text { Seat \# }\end{array}$ & $A$ & $\mathrm{CF}$ & $\mathrm{CO}$ & $\mathrm{D}$ & $E$ & EXP & $\mathrm{H}$ & $\mathrm{H} / \mathrm{J}$ & II & $P$ & PM & $\mathrm{Q}$ & $\mathrm{R}$ & $\mathrm{RA}$ & $S$ & TOTAL \\
\hline 1 & & & & & & & & & & & & & & & & NONE \\
\hline 2 & 1 & & & & & & & & & & & & & & & 1 \\
\hline 3 & & & & & & & & & & & & & & & & NONE \\
\hline 4 & 2 & & & & & & & & 1 & & & & & & & 3 \\
\hline 5 & & & & & & & & & & & & & & & & NONE \\
\hline 6 & 1 & & & & & & & 1 & & & & & & & & 2 \\
\hline 7 & 1 & & & & & & & & & & & & & & & 1 \\
\hline 9 & & & & & & & & & & & & & & & & NONE \\
\hline 10 & 3 & & & & & & & & & & & & & & & 3 \\
\hline 11 & 4 & & & & & & & & & & 1 & & & & & 5 \\
\hline 13 & 2 & & 1 & & & & & 2 & & & & & & & & 5 \\
\hline 14 & & & & & & & & & & & & & & & & NONE \\
\hline 15 & 1 & & & & & & & & & & & & & & & 1 \\
\hline 16 & & & & & & & & & & & & & & & & NONE \\
\hline 17 & & & & & & & & & & & & & & & & NONE \\
\hline 18 & 1 & & & & & & & & & & 1 & & & & & 2 \\
\hline 22 & 1 & & 1 & & & & & & & & & & & & & 2 \\
\hline 23 & & & & & & & & & & & & & & & & NONE \\
\hline 24 & & & & & & & & & & & & & & & & NONE \\
\hline 25 & 2 & & & & & & & & & & & & & & & 2 \\
\hline 26 & & & & & & & & & & & & & & & & NONE \\
\hline TOTAL & 19 & & 2 & & & & & 3 & 1 & & 2 & & & & & 27 \\
\hline $\begin{array}{l}A=A s s \\
C F=\text { Cor } \\
C O=C a \\
D=\text { Dis } \\
E \quad=E n\end{array}$ & $\begin{array}{l}\text { st } \\
\text { ectiv } \\
\text { ed ol } \\
\text { iplin } \\
\text { oura }\end{array}$ & $\begin{array}{l}\text { Feed } \\
\text { o ans } \\
\text { to er }\end{array}$ & $\begin{array}{l}\text { ck } \\
\text { er que }\end{array}$ & ion & & \multicolumn{5}{|c|}{$\begin{aligned} \text { EXP } & =\text { Explanation } \\
H & =\text { Called into Hallway } \\
H / J & =\text { Humor/Joking } \\
\text { II } & =\text { Individualized Instruction } \\
\mathrm{P} & =\text { Praise }\end{aligned}$} & \multicolumn{6}{|c|}{$\begin{aligned} Q & =\text { Student asked question } \\
R & =\text { Teacher responds to question } \\
\text { RA } & =\text { Read Aloud } \\
S & =\text { Social }\end{aligned}$} \\
\hline
\end{tabular}

INDICATES STUDENT w/SLN 
Table 30: Observation 4 - Frequency Data - Great Falls Middle School - SPED Teacher

\begin{tabular}{|c|c|c|c|c|c|c|c|c|c|c|c|c|c|c|c|c|}
\hline $\begin{array}{c}\text { Student } \\
\text { Seat \# }\end{array}$ & $A$ & CF & $\mathrm{CO}$ & $D$ & $E$ & EXP & $\mathrm{H}$ & $\mathrm{H} / \mathrm{J}$ & II & $P$ & PM & $\mathrm{Q}$ & $\mathrm{R}$ & $\mathrm{RA}$ & $\mathrm{S}$ & TOTAL \\
\hline 1 & & & & & & & & & & & & & & & & NONE \\
\hline 2 & & & & & 1 & & & & & & & & & & & 1 \\
\hline 3 & 1 & & & & & & & & & & & & & & & 1 \\
\hline 4 & & & & & 1 & & & & 1 & & & & & & & 2 \\
\hline 5 & & & & & & & & & & & & & & & & NONE \\
\hline 6 & 2 & & & & & & & & 1 & & & & & & & 3 \\
\hline 7 & 4 & & & & & & & & 1 & & & & & & & 5 \\
\hline 9 & & & & & & & & & & & & & & & & NONE \\
\hline 10 & 2 & & & & & & & & & & & & & & 1 & 3 \\
\hline 11 & 2 & & 1 & & & & & & & & & & & & & 3 \\
\hline 13 & 2 & & 2 & & & & & & & & & & & & & 4 \\
\hline 14 & & & & & & & & & & & & & & & & NONE \\
\hline 15 & & & & & & & & & & & & & & & & NONE \\
\hline 16 & 3 & & & & & & & & 3 & & 1 & & & & & 7 \\
\hline 17 & & & & & & & & & & & & & & & & NONE \\
\hline 18 & & & & & & & & & & & & & & & & NONE \\
\hline 22 & 3 & & 1 & & & & & & & & & & & & & 4 \\
\hline 23 & & & & & & & & & & & & & & & & NONE \\
\hline 24 & 1 & & 1 & & & & & & 1 & & & & & & & 3 \\
\hline 25 & 3 & & & & & & & & & & & & & & & 3 \\
\hline 26 & 1 & & & & & & & & & & & & & & & 1 \\
\hline TOTAL & 24 & & 5 & & 2 & & & & 7 & & 1 & & & & 1 & 40 \\
\hline $\begin{array}{l}A=A s \\
C F=C o \\
C O=C a \\
D=D i s \\
E=E n\end{array}$ & $\begin{array}{l}\text { ist } \\
\text { ectiv } \\
\text { ed ol } \\
\text { ciplin } \\
\text { oura }\end{array}$ & $\begin{array}{l}\text { Feed } \\
\text { o ans } \\
\text { to en }\end{array}$ & $\begin{array}{l}\text { ck } \\
\text { er que }\end{array}$ & tion & & \multicolumn{5}{|c|}{$\begin{aligned} \text { EXP } & =\text { Explanation } \\
H & =\text { Called into Hallway } \\
H / J & =\text { Humor/Joking } \\
\text { II } & =\text { Individualized Instruction } \\
\mathrm{P} & =\text { Praise }\end{aligned}$} & \multicolumn{6}{|c|}{$\begin{aligned} \text { PM } & =\text { Progress Monitoring } \\
Q & =\text { Student asked question } \\
\mathrm{R} & =\text { Teacher responds to question } \\
\mathrm{RA} & =\text { Read Aloud } \\
\mathrm{S} & =\text { Social }\end{aligned}$} \\
\hline
\end{tabular}

INDICATES STUDENT w/SLN 
Table 31: Observation 5 - Frequency Data - Great Falls Middle School - SPED Teacher

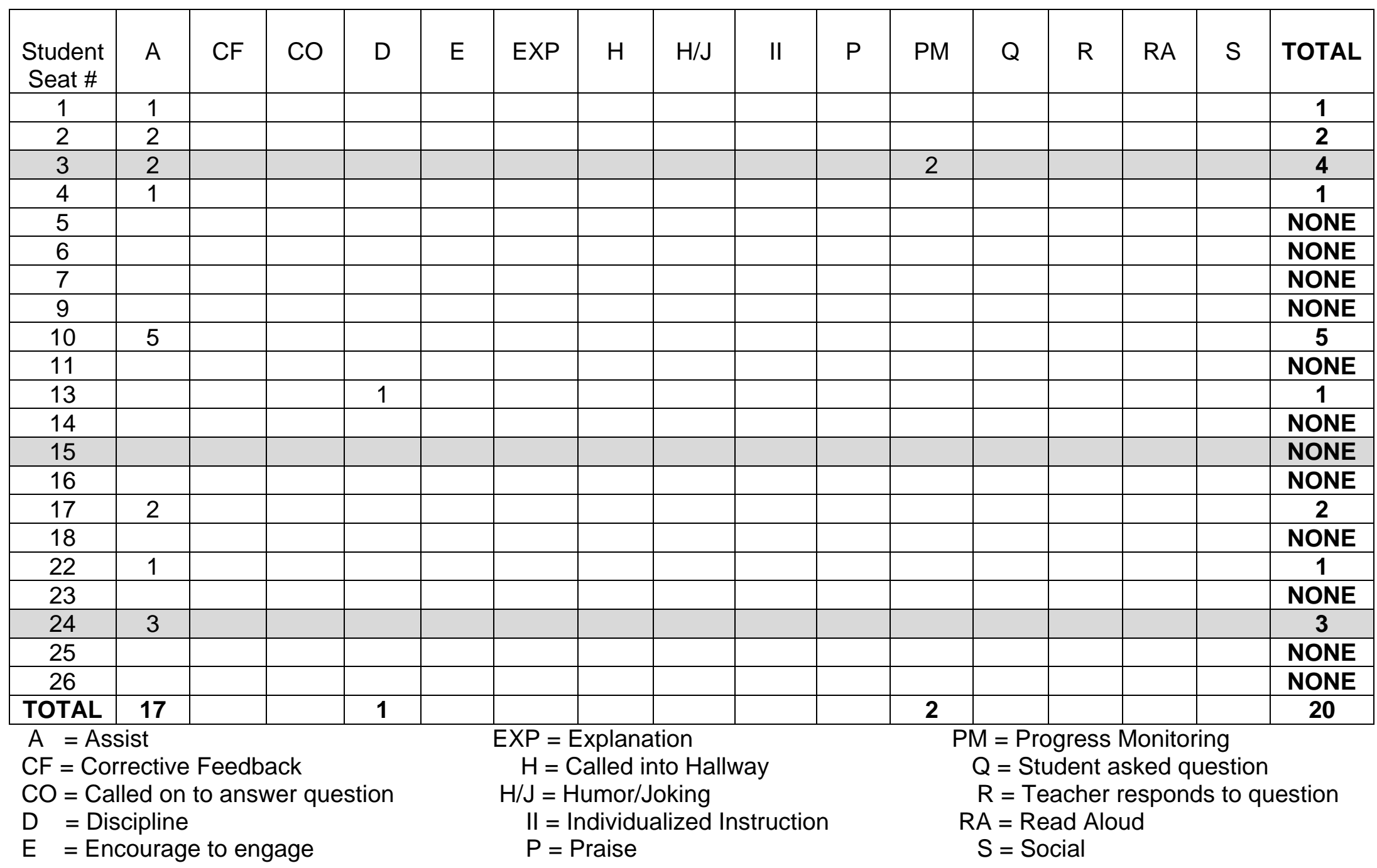

INDICATES STUDENT w/SLN 
Table 32: Observation 1 - Frequency Data - Great Falls Middle School - GENED Teacher

\begin{tabular}{|c|c|c|c|c|c|c|c|c|c|c|c|c|c|c|c|c|}
\hline $\begin{array}{c}\text { Student } \\
\text { Seat \# }\end{array}$ & $A$ & CF & $\mathrm{CO}$ & $\mathrm{D}$ & $E$ & EXP & $\mathrm{H}$ & $\mathrm{H} / \mathrm{J}$ & II & $P$ & PM & $\mathrm{Q}$ & $\mathrm{R}$ & $\mathrm{RA}$ & $S$ & TOTAL \\
\hline 1 & & & & & & & & & & & & & & & & NONE \\
\hline 2 & & & & & & & & & & & & & & & & NONE \\
\hline 3 & & & & & & & & & & & & & & & & NONE \\
\hline 4 & 2 & & 1 & & & & & 2 & & & 1 & & & & & 6 \\
\hline 5 & & & & & & & & & & & & & & & & NONE \\
\hline 6 & & & & & & & & & & & & & & & & NONE \\
\hline 7 & & & & & & & & 1 & & & & & & & & 1 \\
\hline 9 & & & & & & & & & & & & & & & & NONE \\
\hline 10 & & & 1 & 1 & & & & & & & & & & & & 2 \\
\hline 11 & & & & & & & & & & & & & & & & NONE \\
\hline 13 & 1 & & & 1 & & & & 1 & & & 1 & & & & & 4 \\
\hline 14 & & & & 1 & & & & & & & & & & & & 1 \\
\hline 15 & & & & & & & & & & & & & & & & NONE \\
\hline 16 & & & & 1 & & & & & & & & & & & & 1 \\
\hline 17 & & & & & & & & & & & & & & & & NONE \\
\hline 18 & & & & & & & & & & & & & & & & NONE \\
\hline 22 & & & 1 & & & & & & & & 1 & & & & & 2 \\
\hline 23 & & & & & & & & & & & & & & & & NONE \\
\hline 24 & & & & & & & & & & & & & & & & NONE \\
\hline 25 & 1 & & & & & & & 1 & & & & & & & 1 & 3 \\
\hline 26 & 1 & & & & & & & & & & & & & & & 1 \\
\hline TOTAL & 5 & & 3 & 4 & & & & 5 & & & 3 & & & & 1 & 21 \\
\hline $\begin{array}{l}\mathrm{A}=\mathrm{Ass} \\
\mathrm{CF}=\mathrm{Cor} \\
\mathrm{CO}=\mathrm{Cal} \\
\mathrm{D}=\mathrm{Dis} \\
\mathrm{E}=\mathrm{En}\end{array}$ & $\begin{array}{l}\text { st } \\
\text { ectiv } \\
\text { ed o } \\
\text { iplin } \\
\text { oura }\end{array}$ & o ans & $\begin{array}{l}\text { ck } \\
\text { er que }\end{array}$ & ion & \multicolumn{6}{|c|}{$\begin{aligned} \text { EXP } & =\text { Explanation } \\
H & =\text { Called into Hallway } \\
H / J & =\text { Humor/Joking } \\
I I & =\text { Individualized Instruction } \\
P & =\text { Praise }\end{aligned}$} & \multicolumn{6}{|c|}{$\begin{aligned} \mathrm{Q} & =\text { Student asked question } \\
\mathrm{R} & =\text { Teacher responds to question } \\
\mathrm{RA} & =\text { Read Aloud } \\
\mathrm{S} & =\text { Social }\end{aligned}$} \\
\hline
\end{tabular}

INDICATES STUDENT w/SLN 
Table 33: Observation 2 - Frequency Data - Great Falls Middle School - GENED Teacher

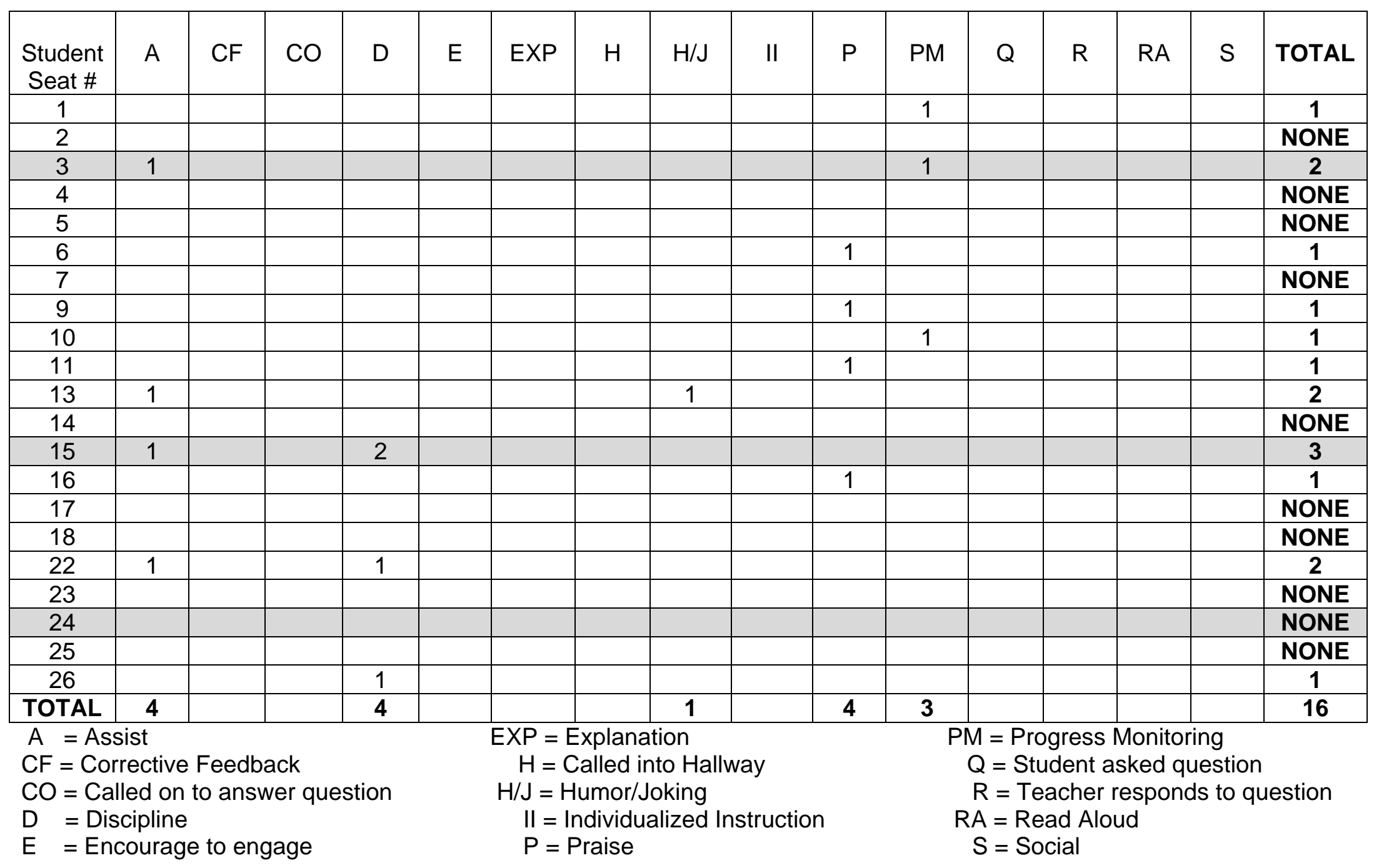

INDICATES STUDENT w/SLN 
Table 34: Observation 3 - Frequency Data - Great Falls Middle School - GENED Teacher

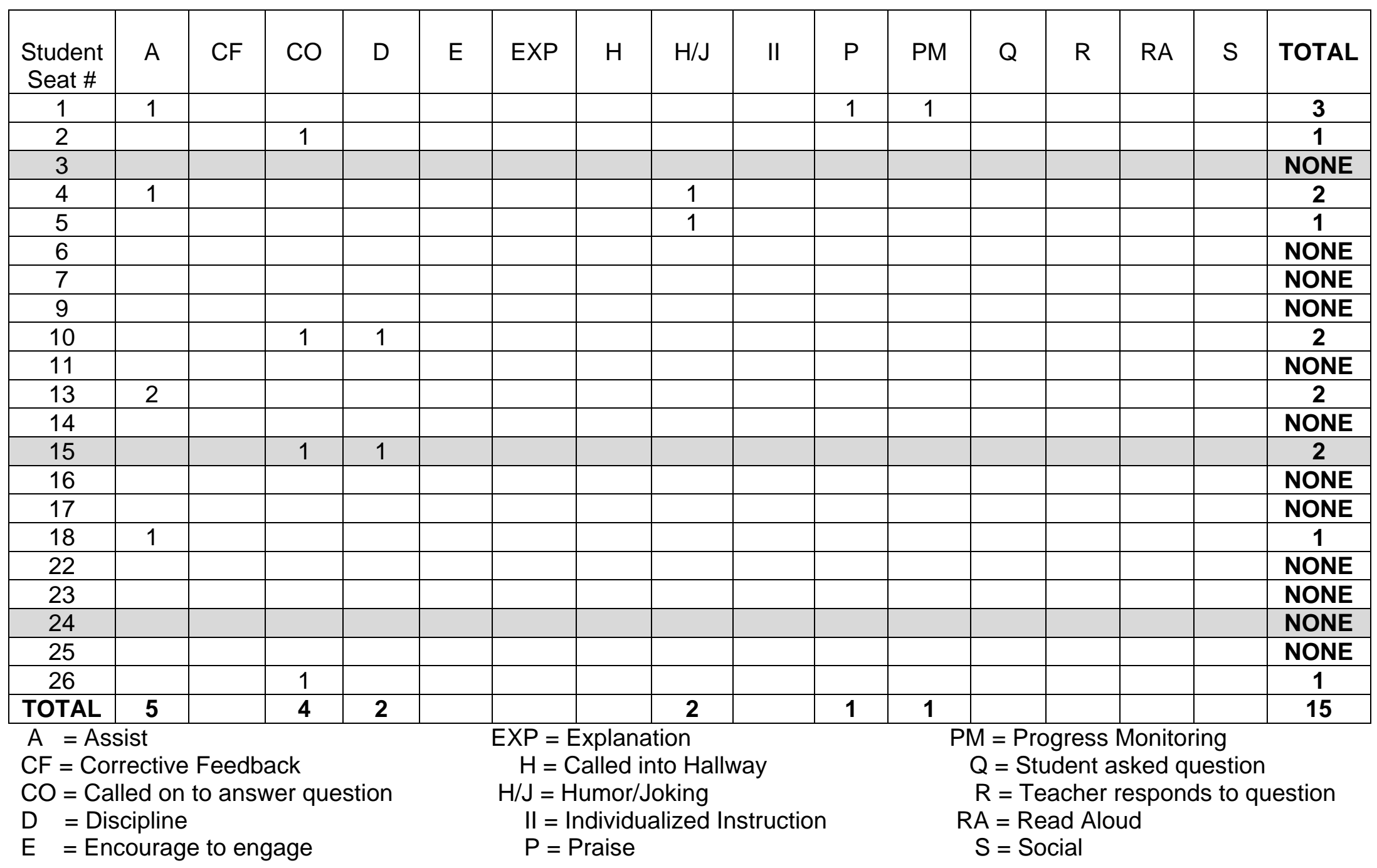

INDICATES STUDENT w/SLN 
Table 35: Observation 4 - Frequency Data - Great Falls Middle School - GENED Teacher

\begin{tabular}{|c|c|c|c|c|c|c|c|c|c|c|c|c|c|c|c|c|}
\hline $\begin{array}{c}\text { Student } \\
\text { Seat \# }\end{array}$ & $A$ & CF & $\mathrm{CO}$ & $\mathrm{D}$ & $E$ & EXP & $\mathrm{H}$ & $\mathrm{H} / \mathrm{J}$ & II & $P$ & PM & $\mathrm{Q}$ & $\mathrm{R}$ & $\mathrm{RA}$ & $S$ & TOTAL \\
\hline 1 & & & & & & & & & & & & & & & & NONE \\
\hline 2 & 1 & & & & & & & & 1 & & & & & & & 2 \\
\hline 3 & & & & & & & & & & & & & & & & NONE \\
\hline 4 & & & & & & & & & & & & & & & & NONE \\
\hline 5 & & & & & & & & & & & & & & & & NONE \\
\hline 6 & 1 & & & & & & & & & & & & & & & 1 \\
\hline 7 & 1 & & & & & & & & & & & & & & & 1 \\
\hline 9 & & & & & & & & & & & & & & & & NONE \\
\hline 10 & & & & 2 & & & & & & & & & & & & 2 \\
\hline 11 & 1 & & & & & & & & 1 & & & & 1 & & & 3 \\
\hline 13 & 3 & & & & & & & & & & & & 1 & & & 4 \\
\hline 14 & & & & & & & & & & & & & & & & NONE \\
\hline 15 & & & & & & & & & & & & & & & & NONE \\
\hline 16 & & & 1 & & & & & & 1 & & & & & & & 2 \\
\hline 17 & & & & 1 & & & & & & & & & & & & 1 \\
\hline 18 & & & & & & & & & & & & & & & & NONE \\
\hline 22 & & & & & & & & & & & & & & & & NONE \\
\hline 23 & & & & & & & & & & & & & & & & NONE \\
\hline 24 & & & & & & & & & & & & & 1 & & & 1 \\
\hline 25 & 1 & & & & & & & & 1 & & & & & & & 2 \\
\hline 26 & 1 & & 1 & 1 & & & & & & & & & 1 & & & 4 \\
\hline TOTAL & 9 & & 2 & 4 & & & & & 4 & & & & 4 & & & 23 \\
\hline \multicolumn{6}{|c|}{$\begin{array}{l}A=\text { Assist } \\
C F=\text { Corrective Feedback } \\
C O=\text { Called on to answer question } \\
D=\text { Discipline } \\
E=\text { Encourage to engage }\end{array}$} & \multicolumn{5}{|c|}{$\begin{aligned} \text { EXP } & =\text { Explanation } \\
H & =\text { Called into Hallway } \\
H / J & =\text { Humor/Joking } \\
I I & =\text { Individualized Instruction } \\
P & =\text { Praise }\end{aligned}$} & \multicolumn{6}{|c|}{$\begin{aligned} \text { PM } & =\text { Progress Monitoring } \\
\mathrm{Q} & =\text { Student asked question } \\
\mathrm{R} & =\text { Teacher responds to question } \\
\mathrm{RA} & =\text { Read Aloud } \\
\mathrm{S} & =\text { Social }\end{aligned}$} \\
\hline
\end{tabular}

INDICATES STUDENT w/SLN 
Table 36: Observation 5 - Frequency Data - Great Falls Middle School - GENED Teacher

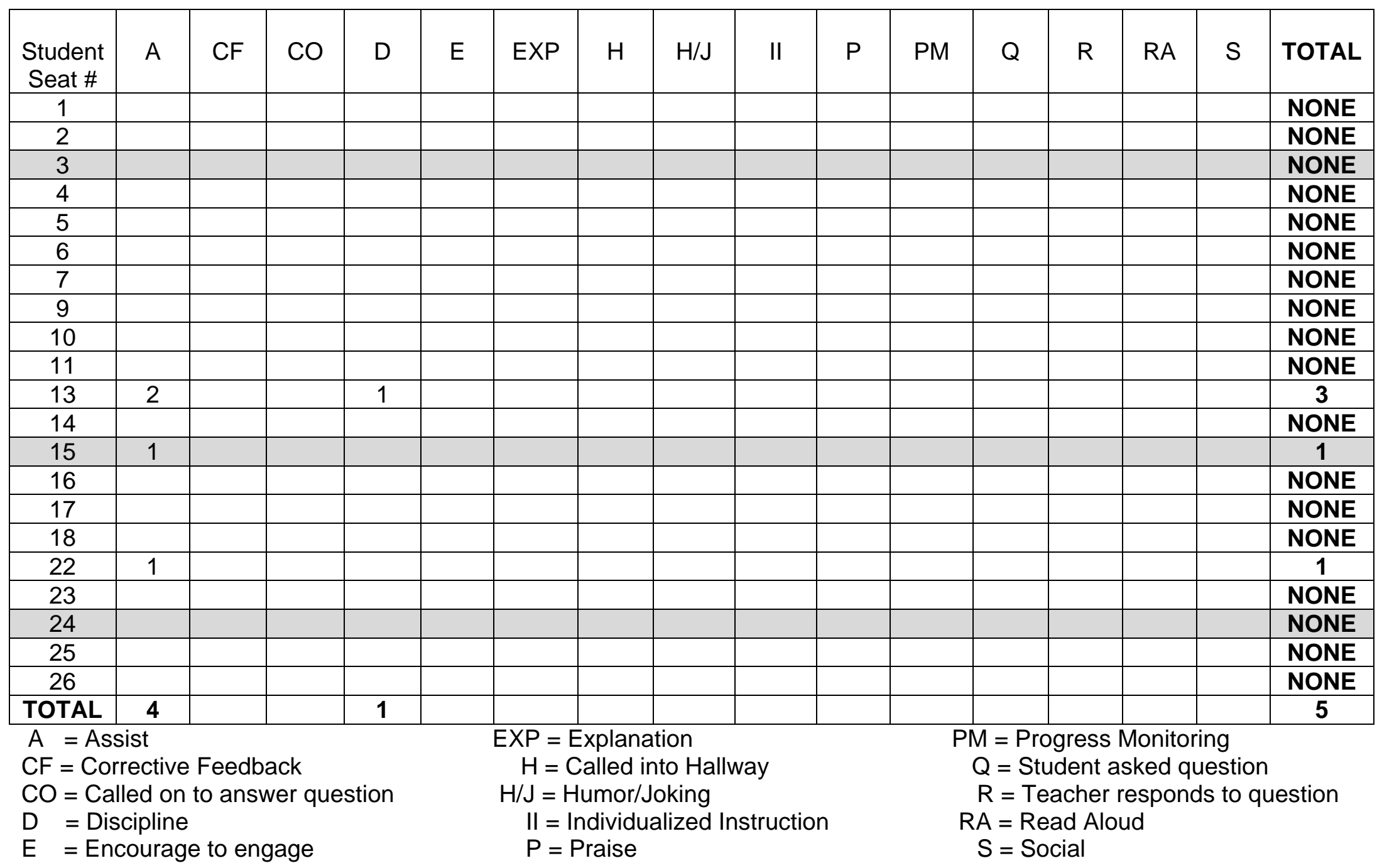

INDICATES STUDENT w/SLN 
Table 37 presents an interesting scenario in that it appears that Mary, the special education teacher, interacts with students much more than Naomi. This supports the fact that Mary generally led instruction during all observations and that she is very approachable in the classroom. It would also tend to support Naomi's description of the students' tendency to ask for Mary's assistance more than they do hers. Of particular significance, however, is the fact that only three of the 21 students are identified as students with SLN (see Appendices M and N). Therefore, what would appear, at first glance, to be a tremendous neglect of students with SLN is not necessarily the reality of their classroom interactions and practices.

Finally, implicit in the case narrative is the notion that Naomi's attitude and philosophy toward instruction could best be described as teacher-centered and teacherdirected - a more traditional practice that tends to limit teacher-to-student interactions in some cases. In fact, Naomi insists on an orderly environment. She is meticulous in her attention to routine and detail. Her students perceive her as an authority figure, which also tends to limit their interactions with her. This, in turn, could be a possible reason for such a difference between her numbers of interactions with students and Mary's number of interactions. 
Table 37

Number of Interactions Observed

Great Falls Middle School

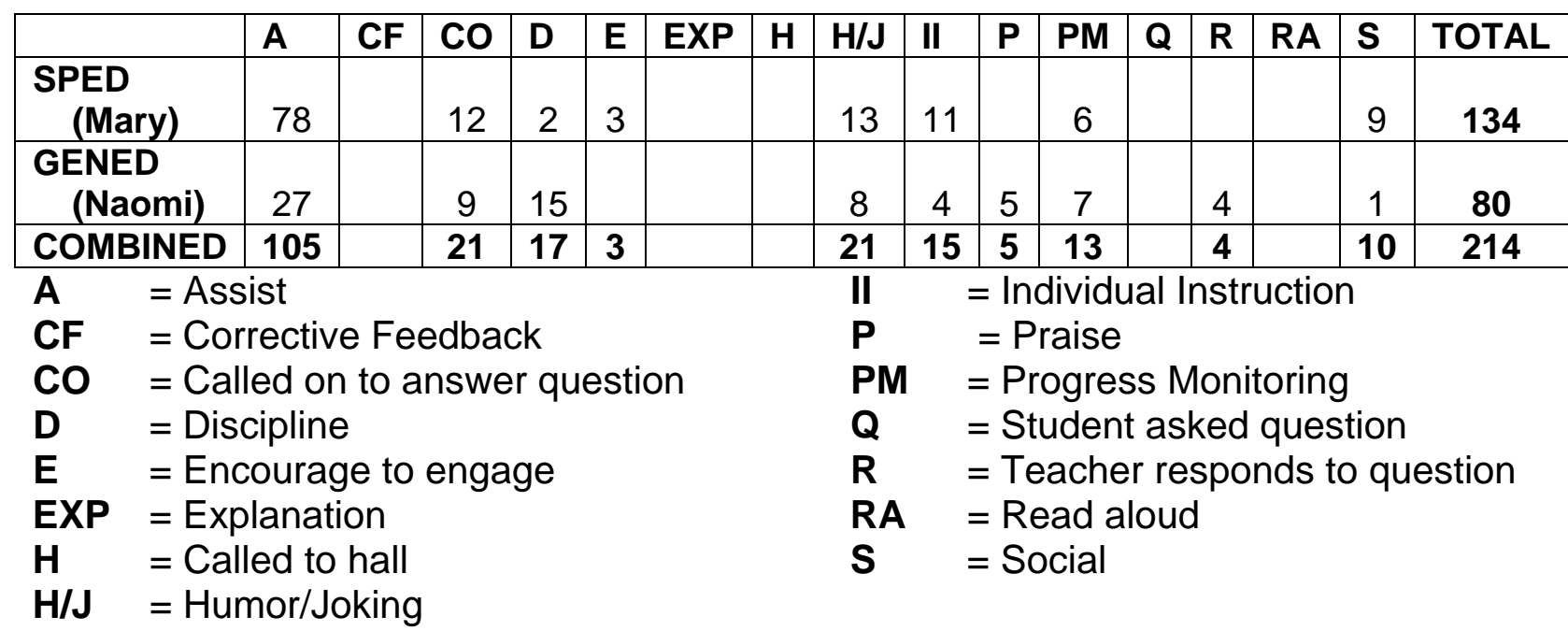

Table 38

Comparison of SPED Teacher's Interactions to GENED Teacher's Interactions Great Falls Middle School

\begin{tabular}{|c|c|c|c|c|c|c|c|c|c|c|c|c|c|c|c|c|c|}
\hline & & A & CF & $\mathrm{CO}$ & D & $E$ & EXP & H & $\mathrm{H} / \mathrm{J}$ & II & $\mathbf{P}$ & PM & $\mathbf{Q}$ & $\mathbf{R}$ & RA & $S$ & TOTAL \\
\hline & $\begin{array}{l}\text { ED } \\
\text { Iry) } \\
\\
N\end{array}$ & 10 & & 1 & & & & & 1 & 1 & & 2 & & & & & 15 \\
\hline & & 68 & & 11 & 2 & 3 & & & 12 & 10 & & 4 & & & & 9 & 119 \\
\hline & $\mathrm{AL}$ & 78 & & 12 & 2 & 3 & & & 13 & 11 & & 6 & & & & 9 & 134 \\
\hline $\begin{array}{l}\text { GE } \\
\text { (Na } \\
\mathrm{S}\end{array}$ & $\begin{array}{l}\text { JED } \\
\mathrm{mi} \text { ) } \\
\mathrm{N}\end{array}$ & 4 & & 1 & 3 & & & & & 1 & & 1 & & & & & 10 \\
\hline $\begin{array}{r}\text { GEI } \\
\text { ge }\end{array}$ & $\begin{array}{l}\text { ED > } \\
\text { led }\end{array}$ & 23 & & 8 & 12 & & & & 8 & 3 & 5 & 6 & & 4 & & 1 & 70 \\
\hline & AL & 27 & & 9 & 15 & & & & 8 & 4 & 5 & 7 & & 4 & & 1 & 80 \\
\hline $\begin{array}{l}\text { A } \\
\text { CF } \\
\text { CO } \\
\text { D } \\
\text { E } \\
\text { EXP } \\
\text { H } \\
\text { H/J }\end{array}$ & $\begin{array}{l}=\mathrm{As} \\
=\mathrm{Co} \\
=\mathrm{Ca} \\
=\mathrm{Di} \\
=\mathrm{En} \\
=\mathrm{EX} \\
=\mathrm{Ca} \\
=\mathrm{HL}\end{array}$ & $\begin{array}{l}\text { div } \\
\text { d or } \\
\text { pline } \\
\text { uras } \\
\text { anat } \\
\text { d to }\end{array}$ & $\begin{array}{l}\text { e to } \\
\text { on } \\
\text { hall } \\
\text { king }\end{array}$ & $\begin{array}{l}\text { dba } \\
\text { nswe }\end{array}$ & k $q u$ & stio & & & $\begin{array}{l}\text { II } \\
\text { P } \\
\text { PM } \\
\text { Q } \\
\text { R } \\
\text { RA } \\
\text { S }\end{array}$ & $=$ & $\begin{array}{l}=\operatorname{Inc} \\
=\mathrm{Pr} \\
=\mathrm{Pr} \\
=\mathrm{St} \\
=\mathrm{Te} \\
=\mathrm{Re} \\
=\mathrm{So}\end{array}$ & $\begin{array}{l}\text { lividu } \\
\text { aise } \\
\text { ogres } \\
\text { udent } \\
\text { ache } \\
\text { ad a } \\
\text { cial }\end{array}$ & $\begin{array}{l}\text { s M } \\
\text { ask } \\
\text { res } \\
\text { oud }\end{array}$ & $\begin{array}{l}\text { onit } \\
\text { ed } \\
\text { por }\end{array}$ & $\begin{array}{l}\text { bring } \\
\text { quest } \\
\text { ds to }\end{array}$ & ion & stion \\
\hline
\end{tabular}




\section{Wright Middle School}

Wright Middle School was built in Walter County in 1924. At that time, however, it housed Wilson High School - the home of legendary sports teams and athletes that people still talk about today. Located in the city of Alton, the school building, football field and athletic facilities are situated within one of the older, more affluent residential sections of Alton. Located in a central part of the community, it has been, and continues to be a significant part of the community in spite of the fact that Great Falls Middle is just across town.

As with other aged buildings, Wright Middle has undergone more than one transformation and programmatic reconfiguration. With the construction and subsequent opening of a new Wilson High School during the 1960s, the old school became Wright Jr. High. District students in grades 7, 8, and 9 attended there until sometime during the late 1990s when all junior high schools in Walter County were reconfigured as middle schools serving students in grades 6, 7, and 8 .

The front entrance to the school opens into a short hallway with double doors at its end that opens to the main hall. The door to the office is on the right about half way down the short hallway. Although the entrance to the main hall of the building is at the end of the entry hallway, signs posted on the outside doors direct visitors to "report immediately to the main office." Inside the newly renovated office a desk for the school's receptionist/secretary is situated behind a window that looks out on the front lawn of the school. Next to the receptionist's desk is an inner office for a second secretary. Mailboxes for the teachers and a row of chairs line the wall opposite the 
receptionist's desk. A walk-in safe and restroom are to the right of the mailboxes. Neither the principal nor the assistant principal are located in the main office. Instead, the assistant principal is located in an office a short distance down the main hall, and the principal's office is located on the second floor of the three story building. A door adjacent to the safe leads to the school's main hallway. Across the hall from the office is the school's auditorium. The stage now serves as the seating area for the cafeteria. It becomes evident upon entering the cafeteria/auditorium that this is a building designed for a different era and different purposes than those it now serves.

Only the English/Language Arts (ELA) and mathematics classes are co-taught at Wright Middle. At each grade level a special education teacher is assigned to co-teach with content teachers in these two areas. These special educators are referred to as "inclusion" teachers. They are responsible for co-teaching in two inclusive ELA classes and two inclusive mathematics classes. They are, therefore, responsible for coteaching with multiple general education teachers. In fact, in some situations, as is the case with Mr. R, the inclusion teachers have as many as four different co-teaching partners during each day.

Mr. R and Mrs. M

Mr. R has a Physical Education K-12 certification and is currently enrolled in a special education, multicategorical program in one of the state's higher education institutions. Until he completes this program, he is currently teaching on an out-of-field permit in the special education department at Wright Middle School. Mr. R is completing his sixth year of teaching. This year, however, is his first experience with 
co-teaching which he does with four different content teachers - two in mathematics and two in ELA. This case focuses on his co-teaching partnership with Mrs. $M$ in a $6^{\text {th }}$ grade mathematics class.

At the beginning of the school year, Mr. R's classes were self-contained, re-teach classes where students received mathematics and reading instruction in addition to the instruction they received in their ELA and mathematics inclusion classes. When the original $6^{\text {th }}$ grade inclusion teacher left Wright Middle, Mr. R moved into the co-teaching position - a position for which he admits he has had very little formal training. Given his lack of formal preparation in the models of co-teaching, he experienced a range of feelings about the change:

My feelings have been kind of mixed. I liked having my own room. At first it was kind of difficult going into other teachers' classrooms and just kind of gettin' the feel for what goes on and that kind of thing. Um...it has its perks, and it has its drawbacks at the same time. With the inclusion, I found that it is rewarding 'cause you get to work with more kids. With our situation, we're in full inclusion and, just my personal opinion, I don't feel like that's the right place for every student.

I asked him to explain why he felt inclusion wasn't the right place for some students, and he continued:

...some students are so far behind in that classroom with twenty to twentyfive students in it, there's not the opportunity available to pick them up without leaving everybody else behind. I mean, we're under pressure to cover content standards and without the time to, we don't have the time to cover those content standards and go back to second or third grade and cover what they've missed there.

Yet, during my observations, Mr. R. appeared to take every opportunity he could to help struggling students keep pace with their classmates. His enthusiasm effectively masked the concerns he had expressed to me. An added dimension that poses 
another challenge for Mr. R is his schedule; he does not co-teach the entire 90-minute period in Mrs. M's room. Instead, he is with another of the sixth grade teachers for the first half of the class period and with Mrs. $M$ for the second half of the class period. The 90-minute period is split by the sixth grade lunch period. Throughout each day, in addition to co-teaching in two math classes, Mr. R co-teaches in two ELA classrooms.

It is a difficult teaching assignment to explain, and it poses many challenges for Mr. R:

Mr. R: I co-teach with three other teachers besides Mrs. M. I co-teach with Mrs. $M$ and Mrs. $S_{1}$ for sixth grade math, Mrs. $S_{2}$ for sixth grade literature and Mrs. $S_{3}$ for sixth grade writing and grammar. I have several different classrooms I go to. We alternate classes every 35 minutes, so I'll go to literature for 35 minutes, then writing for 35 , back to literature, back to writing, then to Mrs. $S_{1}$ for math and then Mrs. M for math.

NB: How do you plan?

Mr. R: We have a common planning time.

NB: You have common planning with each of those individuals?

Mr. R: You kinda (laughs) you kinda get to it when you're able to get to it. All sixth grade teachers have a planning time and my planning is with those sixth grade teachers at the same time. Now, obviously I can't meet with those teachers every day, but we try to get together to say, well, this is what we'll kinda plan on doing on certain days. And then, you just have to be flexible 'cause some days you might plan on doing something and there's an assembly that you didn't know about. So you have to be flexible with that.

In spite of such a diverse teaching assignment, Mr. R underscores his commitment to flexibility and his understanding of his role in the co-teaching partnership:

You have to be flexible. Some teachers want more control of their room because they still feel like it's their room. You're coming in to help, but it's still their room. Some teachers will tell you - 'This class is both of ours, so whatever you want to do is fine.' 
Mr. R speaks of Mrs. M with a deep admiration and respect. He is very appreciative of Mrs. M's years of experience and her expertise. He seems to have no issue with not being the lead teacher; in fact, he sees his co-teaching assignment with her as an opportunity to learn from a more experienced teacher. Having only taught six years himself, Mr. R is eager to learn from each of his co-teaching partners:

[Co-teaching] has allowed me to learn from more experienced teachers. I've been in a self-contained classroom for four years and...you don't get to see what other people are doing. And one thing about being in coteaching situations...some teachers I'm currently teaching with are in the latter part of their career. They've been teaching thirty-some years. You kind of get to learn what they've learned... and see what they learn on a daily basis. So I think that has helped a lot.

Regardless of the impact his co-teaching assignments have had on him, Mr. R has a healthy and productive understanding of the attitude a co-teacher must have. "You can't be rigid going into other people's classrooms....You can't be emotional and get your feelings hurt. You just gotta realize that people are different." It is an attitude that serves him well with both his students and his co-teaching partners.

His attitude and flexibility blend well with Mrs. M who, as Mr. R describes, "keeps her classroom a tight ship." It is an accurate description of a class that is highly structured and traditional in its discipline and management. Mrs. $M$ is insistent that her class must operate in such a manner.

I'm just from the old school. I admire teachers that have all of this going on [referring to small group instruction and multiple activities occurring during instruction] and they still can stay on top of it, but just my personality, I'm basically a quiet person anyway...so I just can't take a lot of chaos because I feel like I'm not in control. I don't know what's going on, and I MUST know what's going on.... These kids come to school to be in a safe environment, and I'm responsible for their environment being safe. 
Mrs. M has an Elementary 1-9 certification and specializations in both language arts and social studies. She also has a Master's degree in middle childhood. Her current teaching assignment, however, is $6^{\text {th }}$ grade math. She has taught for 37 years; 34 years have been at the $6^{\text {th }}$ grade level. This is her second year in a co-teaching arrangement; however, she only has one, 45-minute period that she co-teaches with Mr. R. She teaches all her other math classes alone.

Mrs. $M$ is a self-proclaimed traditionalist who describes her training in coteaching as "a small, mini-training for co-teachers. It's not really in depth or anything." In fact, Mrs. M attributes most of what she has learned about co-teaching as something she has learned on her feet. It is apparent, however, that she has a clear understanding of both her highly structured nature and its impact on the co-teaching that occurs during the class time she shares with Mr. R. It is her dedication to her students and her understanding of their needs that allow her to both acknowledge and welcome Mr. R's contributions to the class:

...for one thing with that class, with me being older, I think they seem to feel that I'm sort of structured. You'll find that because I don't do crazy at all. You can't disrupt my classroom. So I think they sort of respond or feel more comfortable with Mr. R because Mr. R is just barely 30, (she laughs), IF he's 30 - and he's the basketball coach. A lot of my boys in here play basketball with him, and they know him and play around with him a lot. So I have found them to ask him questions quicker than they do with me.

The structure and discipline of her classroom is indeed what one would describe as traditional. Students are seated in rows that face the whiteboard at the front of the room. Although Mrs. M allows students to work in groups "at least a couple of times during the six weeks," there is rarely a deviation from the whole-group instructional 
format. Her text and materials are the guides and resources that she uses to ensure that instruction is both developmentally and academically appropriate. She proudly claims, "I'll tell anybody, I'm book driven." She believes that the integrity of her math classes is deeply rooted in the developmental research that is the basis of content texts, and therefore adheres to the conceptual framework of her text. Mrs. M is acutely aware of the skills and content her students must master and devotes her efforts to ensuring they have appropriate opportunities to be successful with both. She admonished teachers who are not book driven - teachers whose focus is on meeting the state content standards and objective rather than the skills and concepts students need:

I have found...teachers will take that list of CSOs and they put their whole curriculum on it and that's all they teach. If it's not a CSO, let's forget it. But it hurts the kid as he moves through the grade levels. Because, I am teaching a skill and I assume that they have some prior knowledge of it because it's in the third, fourth and fifth grade books, but they don't. They would have done much better for math had their teachers stayed book driven.

Mrs. M sets the tone for class each day. Class is just after lunch. Prior to some of my observations, I made a point of arriving at the school before the end of the lunch period so I could follow the students to their classroom. The routine was the same each day. Its structure and discipline were executed with precision. Students knew the drill well:

As we walked down the hall to the classroom, the students walked quietly and orderly. When they got to Mrs. M's room, they lined up along the wall while she unlocked her door. While they waited, there was no talking; they were silent. Mrs. M opened her door and stepped aside to allow the students to silently file into the classroom and take their seats. Each student immediately began working on something at his desk. When the last student entered the room, Mrs. M followed him, shut the door, and class was ready to begin. 
The only deviation I witnessed was the day one young man, D-S16, was stopped at the door and reprimanded for his appearance - a Mohawk haircut and something painted on his face. I assume that because nothing could be done about his hair style, Mrs. M said nothing about it; however, while I did not hear exactly what Mrs. M said to him, I understood (as did the student) that he was not going to be allowed to cause a distraction in her class by having his face painted. I heard her tell the student that she would not tolerate such. D-S16 took his seat and said nothing. It is very clear that Mrs. M does indeed "keep her classroom a tight ship;" she doesn't "do crazy." During the observations she got no argument from her students. Co-teaching Partnership/Roles and Responsibilities

Mrs. M has welcomed Mr. R's presence in her classroom. Typically, as she instructs the group, Mr. R either moves about the room making sure students are on task or he draws examples and writes information on the whiteboard, thereby providing visual aids that accompany Mrs. M's instruction. Once the instruction is complete, students are given opportunities to practice using the skills that have been introduced. As the students work, both Mr. R and Mrs. M move about the room monitoring student progress and providing individual assistance or instruction as needed. Everyone is engaged.

Mrs. M identifies the model of co-teaching that she and Mr. R use as "team teaching". While it was clear to me that Mrs. $M$ is the lead teacher, it was evident that she depends on Mr. R's contributions to help students grasp the content:

We do team teaching because we teach at the same time....I'm talking, he's talking, we talk at the same time. If I'm working on the data projector or something on the computer, then he'll go to the board. He's a better 
drawer than me-'cause we've been doing geometry and he'll draw the figures and things, or he'll put a formula up as I walk them through the formula that he has up....We're constantly talking off of each other.

Mr. R's description of his partnerships is somewhat different from Mrs. M's because he co-teaches with three other content teachers. Although this case only focused on his co-teaching partnership with Mrs. M, Mr. R's responses were generally from a perspective that included all four of his partnerships. He attributes the differences among his co-teaching partners to the fact that each teacher has his or her own unique situation:

I'm using several different models in different classrooms.... [s]everal classrooms have different opportunities for people to work together in different ways. In some classrooms they're more independent working, so the core content teacher might give the instruction and l'll go around with each individual student at a time while they're working and ask them if there are any questions or help them work out problems more individually.... One model doesn't work for everybody. I think that you have to feel your way around to see what's going to work for your situation.

Because the class is split by the students' lunch period, Mr. R does not typically find himself in the role of lead teacher. Quite often, by the time Mr. R comes to Mrs. M's room, students are practicing the skills that were presented by Mrs. M during the portion of the class before lunch. When Mr. R arrives, however, he immediately begins to move about the room to both monitor student progress and to assist Mrs. M during any additional instruction she may provide. Mrs. M explained Mr. R's involvement when he arrives for class:

... I would say I deliver most of the content, but when he's in here, we talk off of each other. He jumps right in when he comes through the door.... He knows the lessons; he knows what we're on; he knows what we're doing. He knows all the kids really well. 
While students work quietly at their desks, both teachers are available to assist students and to answer questions as they are posed. Additionally, Mr. R monitors the modifications being made for students and notifies Mrs. M when modifications may need revised or altered.

Given the fact that Mr. R teaches with four different teachers, it is apparent that collaborative planning poses a significant challenge for him. Consequently, he often finds himself assisting more than instructing students. But it works in his partnership with Mrs. M whose "old school" philosophy dictates that she is the instructional leader in her classroom. Theirs is an effective relationship built on mutual respect for each other and for the diverse skills and knowledge each has to offer. Mrs. M explained how they address the challenge of planning:

Since I have all my other math classes alone - including the first part of the class we co-teach - I would say I do most of the planning. But when he comes in for his period...sometimes he'll do a reteach sheet or find something that is easier for them to go along with what I'm doing. He does more of their modifying. On a regular basis he usually does that part and I make the lesson plans for what we are going to do that day. And then sometimes we'll talk about...technology....because he is better at technology. So we'll plan a lesson together because he knows the technology.

It is interesting to note that when both teachers were asked what, if anything they would change about co-teaching, the issue of planning was the first to come up. Both agreed that with more time to plan, more diverse instruction would be possible:

Mr. R: l'd like for there to be more time to plan to do more technology and stuff like that in our room. It seems that we have more time in our schedule than we actually do with meetings and having parents call and scheduling. Things come up, and we don't actually have the amount of planning time that it says on the schedule. 
Mrs. M: I guess that is true because we don't have enough time that we actually sit down and plan. What I would change? The planning because I enjoy having Mr. R work with the kids.

In spite of the planning issues they face, both Mrs. M and Mr. R appear to have found an effective means of making their class work.

Use and Impact of Technology

Some form of technology is used daily during instruction; however, Mrs. M admits that she is most familiar with PowerPoint ${ }^{\circ}$ and uses it more than any other program when she incorporates technology in her instruction. She is reluctant to attempt much more without relying on Mr. R and will quickly admit to her apprehension and impatience when instruction involves technology. In fact, it is this frustration and her fear of something expensive being broken rather than an inability to use the technology that causes her reluctance. Mrs. $\mathrm{M}$ elaborated on both her apprehension and impatience with technology:

I'm sort of scared of it, you know. I'm scared I'm gonna mess that computer up and that thing costs a lot of money. The data projector-the bulbs cost $\$ 700$. Why, I don't want to push the wrong button and mess the thing up, ... so I usually just pick on Mr. R. But that's even in knowing how to find different things to do with it. I mean, even the instruction what to do - how to come up with a lesson with it. Mr. R is better at that than I am...I get into those crazy things and something else will come up on the screen... and it won't work....That's the one thing I can't stand...the kids sitting there waiting for me to troubleshoot. But what are my kids doing sitting there looking at me while l'm wasting all this time. That's what I call it - wasting all this time. I want things to be rolling at all times, so that's why I have a problem with technology.

Despite her personal feelings toward technology, Mrs. M acknowledges that her students are accustomed to it and have no fear of it. She recognizes that they not only enjoy its incorporation in the class instruction but they also get more out of technology enhanced instruction than they do more traditional styles of math instruction: 
...You have to move with the type of kids - the type of learning they have been exposed to... It's just their environment. And then...you know...they have been taught now to watch television for most everything, like Sesame Street - all that was on TV, so when they're looking at it up on the screen, they actually feel that they're watching television. I mean, it's another visual screen for them. They have grown accustomed to seeing it ever since they were two years old.

She and Mr. R both acknowledge the impact the use of technology has on the students. Mrs. $M$ does not deny that the effective use of technology can be a tremendous help in keeping students appropriately and actively engaged:

...I think that's what helps them because I know they like the PowerPoint ${ }^{\circledR}$ lessons better than they do when I do it on the board. When I'm doing the lessons on the board, they seem to get more into it when I do the PowerPoint $₫$ lessons. They'll write the examples and things better for me and that's why it just got to the point I started to use the PowerPoint ${ }^{\circ}$ lessons most of the time when I do the technology.

Mr. R adds, "I think some students learn better by seeing it up on the board instead of just looking at it in their books." Occasionally, Mr. R prepares interactive activities for the students. For example, on one particular day, students were given the opportunity to use responders. Designed much like a television remote, the responder allows students to electronically respond to problems that are projected onto the Smartboard. The responders create an opportunity for all students to participate; each student is given a responder and every response is recorded. This technology also allows Mrs. M and Mr. R the capacity to both monitor student progress and to identify students' specific strengths and weaknesses, as illustrated during this observation:

Mrs. M and Mr. R entered the classroom together. Mrs. M immediately began review while Mr. R set up the computer for use with the responders. Mrs. M distributed a set of worksheets about lines, line segments, and rays. Mr. R distributed the responders and instructed students to answer question one so he could verify that all responders were working properly. 
Each student was given a copy of the worksheet. They were instructed to read the problems for themselves. After a brief pause, Mr. R began the assignment. After he read each problem aloud, he paused while students keyed in their answers individually. He then opened the answer box to reveal the answer. A grade summary for each answer submitted indicated the percentage of both incorrect and correct responses. There was no immediate, individual feedback. Instead, incorrect answers were addressed with the entire group, and correct solutions were reviewed and explained.

This activity continued until all items on the worksheet were completed. At the end of the activity, the overall scores discussed with the students. Individual students were then instructed to find the number on the screen that corresponded with the responder they held so they could locate their individual scores.

I asked the teachers to explain how the information available with such technology was used to enhance instruction. Mr. R explained that he uses the responders for spelling tests every Thursday because grading is done automatically. He added that in the math class, he and Mrs. M can "look back and see the number of students who got the question wrong" and either provide individual instruction for some or provide additional instruction for all. "If $85 \%$ of the students get it right, we can just move on." I was curious about the 15\% who didn't "get it right" so I asked what they did to address those students' needs. Mr. R responded that he and Mrs. M "can go back when we're finished and see who those people were, and then go to them individually." Mrs. M explained further:

Usually, if it's a skill that they have a lot of problems with, that's the sheet that l'll give them for extra credit because then they get to take it home. The get to keep it two or three days, and they get to have someone at their house to go over it with them. They have the opportunity to go home and have it re-taught to them by someone at home - if someone will help them. 
I was convinced that they used the technology frequently enough that it had become an effective instructional tool provided another means of both delivering instruction and monitoring individual student progress.

Interactions with Students

It was evident from the observations that each day follows the same basic routine in this classroom. However, the interactions that occur between Mrs. M and the students are somewhat different from the interactions between Mr. R and the students:

I entered the classroom with Mr. R. The students were already seated and engaged - and the tardy bell had not yet rung. Mrs. M had already placed the day's problems on the overhead screen - this day addressed types of angles. As with other days, she used a laptop and computer instead of a text to present the lesson. As I took my seat, Mrs. M began a question/answer activity. While she explained problems and their solutions, Mr. R interjected as at will. He attempted to make the information more relevant to the students by talking about angles from the perspective of snowboarding or skateboarding - two activities many of the students can relate to. Both Mrs. M and Mr. R activated prior knowledge and used multiple mnemonic devices to assist students in remembering specific information. The students were attentive and well disciplined. They worked silently and raised their hands before speaking.

Although both are available to answer questions, re-teach, or explain concepts, it is Mr. $\mathrm{R}$ that has more individual interactions with students. Mrs. M generally delivers whole group instruction and may call individual students to her desk to check their work, but her interactions are mostly with the class as a whole. Even when she moves about the room to monitor students' progress, if there are students in need of assistance or direction, Mrs. M uses the opportunities to direct or instruct all students. Analysis of fieldnotes reveals that individual student questions or errors provide teachable moments for the entire class so that all students have the opportunity to benefit from the additional instruction or direction: 
Students are as quiet inside the room as they are when they're lined up outside the classroom waiting to be let in. There are no disruptions or outbursts; students raise their hands to be called on to answer questions or to ask for help with a particular problem. There is no roaming around the room or out of seat behavior. At the hint of any deviation from the expected behavior, Mrs. M is quick to squelch it. She insists on a quiet, respectful classroom and has strong convictions about how children should behave. She demands respect and expects it - without exception. From what I observed, she gets it. The students do respect Mrs. M and work hard for her. Mrs. $M$ and Mr. $R$ interact with their students in ways that are indicative of their roles in the classroom. Mrs. M's interactions tend to be with the group as a whole during instruction, and Mr. R's interactions are more often with individuals than with the whole group. However, when Mrs. M does interact with individual students, it is still significantly different from Mr. R's interactions as Mrs. M explained:

I think he has a tendency more to help them get the answer. Where if you ask me something, then l'll refer back to an Excel we have done or an example that we have done and sort of have you to think about what it is we have already done rather than to just give you the answer. I think that's why, too, that they shy away from me.

She went on to describe her instructional interactions with her students

If you walk in and I'm doing a PowerPoint $₫$ lesson, and I'm standing here, (indicating the area around the data projector and cart) I will be putting the lesson on and I walk them through...they tell me how to work the problems before I click the button. I won't click the button for the answers until they walk me through. If I'm explaining something, Mr. R will walk in and he'll start explaining something with me. Or usually he'll go to the board. If I'm back here, (indicating the data projector), he'll go to the board; if he's back here, l'll go to the board because we use them both when we're doing the instruction. 
While Mr. R clearly understands the math content, his contributions are specifically designed to make the content more accessible to students. He provides strategies or assistance to students who are struggling and assists Mrs. M with the delivery of the content. It is interesting to note that most of his time is spent assisting the non-disabled students in class rather than the students with special learning needs. He explains:

Some special ed students won't ask for help in a co-teaching setting because they don't want other students to know that they need that help....I think we're more apt to answer questions form the regular ed students than the special ed students. Sometimes I think inclusion is intimidating for the special ed students....The special ed kids will deny the help; they don't want it. That's why l'll try to walk around and even if they're not asking for help, l'll say 'do you have any questions?' or 'If you need any help, let me know.' And l'll say that two or three times a class period.

He is very much aware of and in touch with what it will take to provide every student an opportunity to succeed - even if he does use his own version of a little "reverse psychology" from time to time. As Mrs. M and Mr. R explained, one of the girls with SLN is extremely self-conscious about being a "special education" student. Mr. R goes out of his way to make her feel comfortable receiving his help. In fact, he makes sure that she and every other student with SLN see him working with every student in the class:

I think it is intimidating for her. I try to walk around and work with everyone to let her know that l'm not just coming to the special ed kids. That's why even D-S13 - who's always finished first - l'll try at least once a class period to go over there and say something to her...just talk to her...just stop there. Nobody knows what I'm talking about...just so that I'm stopped in different places throughout the room....just to show the special ed kids, it's not just them. 
Mrs. $\mathrm{M}$ and Mr. $\mathrm{R}$ recognize the benefits of co-teaching for all students and not just for the students with special learning needs. Mrs. M explained:

It's offering that extra assistance to so many kids...not only special needs children. I mean, kids that are borderline from being special ed. We suggest that so many kids be tested; then they're tested and they keep telling us they don't qualify. Well, you have half of a room that really needs someone else to help them because they don't qualify but they certainly can't keep up with the classroom.... They get the help because even when we do group work and things, we always group them where they have someone to help them.

While Mr. R agrees that students receive much needed extra assistance, he is also quick to point out that co-teaching "can be good because you do have two different teachers with two different personalities. Sometimes students don't respond well to a certain teacher's personality. They might not respond well to me, but they might respond very well to the core teacher or the regular ed teacher or vice versa." Either way, from the teachers' perspective, the students in their classroom reap the benefits of the expertise of both teachers.

Frequency Data

After a review of the frequency data collected during observations in Mrs. M and Mr. R's classroom, several characteristics are apparent. First, Mrs. M is unquestionably the instructional leader in her classroom. As such she provides most of the content instruction to the whole group rather than to small groups or individuals. As described in the case narrative, Mrs. $\mathrm{M}$ is intent on providing her students with a highly structured environment that is both safe and respectful. Mrs. M is in control of her classroom. An analysis of Tables 39-48 would appear to indicate Mrs. M's role by virtue of the fact that she, alone, provides corrective feedback. Additionally, while Mr. R calls on students to 
participate, Mrs. M does so with considerably more frequency. Although both teachers do interact with individual students at times, the data strongly supports the idea that instruction is delivered to the whole group. The case narrative supports this as well. 
Table 39: Observation 1 - Wright Middle School - SPED Teacher

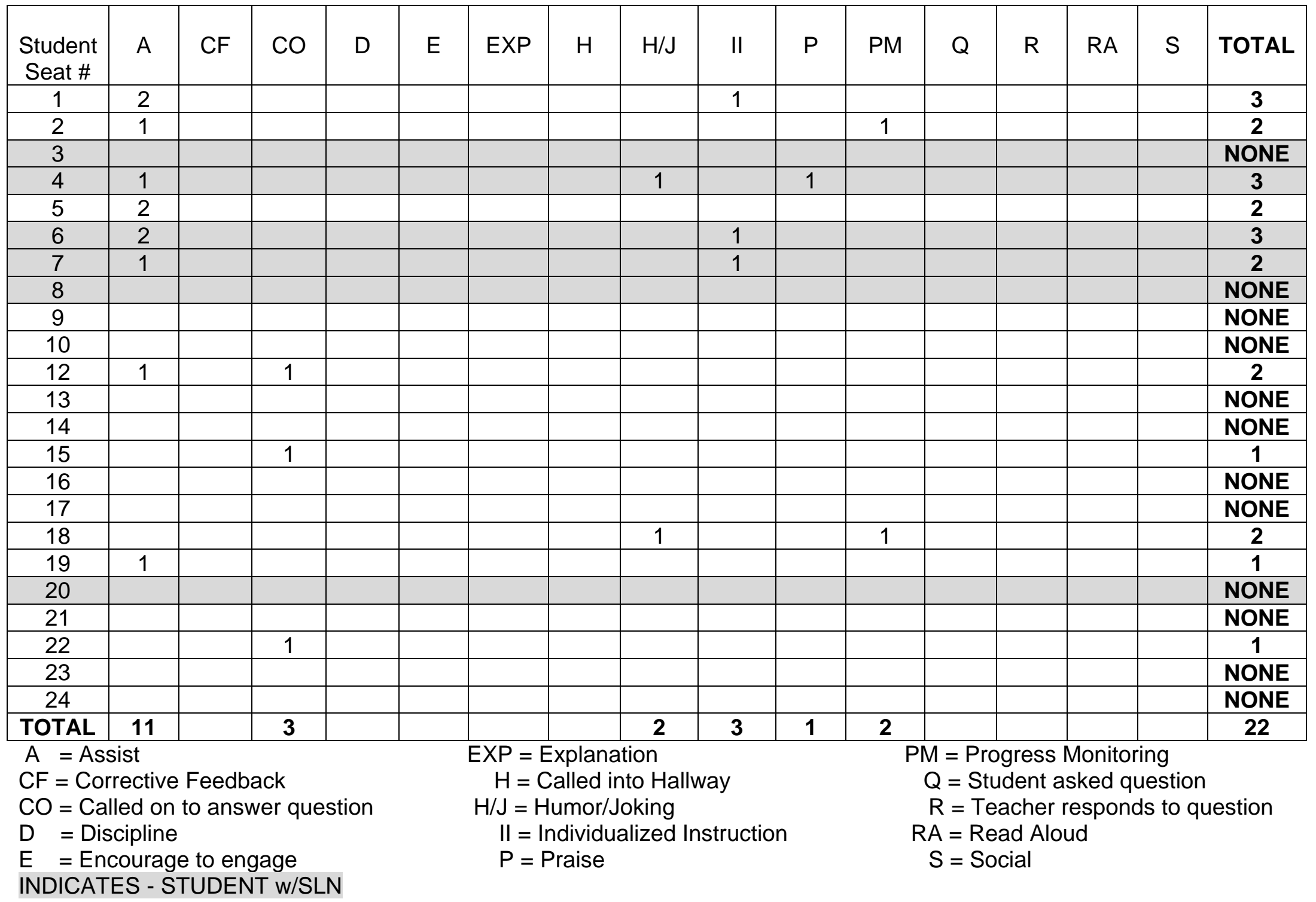


Table 40: Observation 2 - Wright Middle School - SPED Teacher

\begin{tabular}{|c|c|c|c|c|c|c|c|c|c|c|c|c|c|c|c|c|}
\hline $\begin{array}{c}\text { Student } \\
\text { Seat \# }\end{array}$ & $A$ & CF & $\mathrm{CO}$ & $\mathrm{D}$ & $E$ & EXP & $\mathrm{H}$ & $\mathrm{H} / \mathrm{J}$ & II & $\mathrm{P}$ & PM & $\mathrm{Q}$ & $\mathrm{R}$ & RA & $\mathrm{S}$ & TOTAL \\
\hline 1 & 3 & & & & & & & & 1 & & & & & & & 4 \\
\hline 2 & & & & & & & & & & & & & & & & NONE \\
\hline 3 & & & & & & & & & & & & & & & & NONE \\
\hline 4 & & & & & & & & & & & & & & & & NONE \\
\hline 5 & & & & & & & & & & & & & & & & NONE \\
\hline 6 & 2 & & & & & & & & & & & & & & & 2 \\
\hline 7 & 2 & & & & & & & & & & & & & & & 2 \\
\hline 8 & 1 & & & & & & & & & & & & & & & 1 \\
\hline 9 & & & & & & & & & & & & & & & & NONE \\
\hline 10 & & & & & & & & & & & & & & & & NONE \\
\hline 12 & 1 & & & & & & & & & & & & & & & 1 \\
\hline 13 & & & & & & & & 1 & & & & & & & & 1 \\
\hline 14 & 1 & & & & & & & & & & & & & & & 1 \\
\hline 15 & & & & & & & & & & & & & & & & NONE \\
\hline 16 & & & & & & & & & & & & & & & & NONE \\
\hline 17 & & & & & & & & & & & & & & & & NONE \\
\hline 18 & & & & & & & & & & & & & & & & NONE \\
\hline 19 & & & & & & & & & & & & & & & & NONE \\
\hline 20 & 2 & & & & & & & & & & & & & & & 2 \\
\hline 21 & & & 2 & & & & & & & & 1 & & & & & 3 \\
\hline 22 & & & & & & & & & & & & & & & & NONE \\
\hline 23 & & & & & & & & & & & & & & & & NONE \\
\hline 24 & & & & & & & & & & & & & & & & NON \\
\hline TOTAL & 12 & & 2 & & & & & 1 & 1 & & 1 & & & & & 17 \\
\hline \multicolumn{6}{|c|}{$\begin{array}{l}A=\text { Assist } \\
C F=\text { Corrective Feedback } \\
C O=\text { Called on to answer question } \\
D=\text { Discipline } \\
E \quad=\text { Encourage to engage } \\
\text { INDICATES STUDENT w/SLN }\end{array}$} & \multicolumn{6}{|c|}{$\begin{aligned} \text { EXP } & =\text { Explanation } \\
H & =\text { Called into Hallway } \\
H / J & =\text { Humor/Joking } \\
I I & =\text { Individualized Instruction } \\
P & =\text { Praise }\end{aligned}$} & $\begin{array}{l}\mathrm{U}=P \\
Q=S \\
R=1 \\
A=P \\
S=S\end{array}$ & $\begin{array}{l}\text { dent } \\
\text { che } \\
\text { ial }\end{array}$ & $\begin{array}{l}\text { lonito } \\
\text { ked o } \\
\text { spon } \\
\text { d }\end{array}$ & $\begin{array}{l}\text { ng } \\
\text { estio } \\
s \text { to }\end{array}$ & lestion \\
\hline
\end{tabular}


Table 41: Observation 3 - Wright Middle School - SPED Teacher

\begin{tabular}{|c|c|c|c|c|c|c|c|c|c|c|c|c|c|c|c|c|}
\hline $\begin{array}{l}\text { Student } \\
\text { Seat \# }\end{array}$ & $A$ & $\mathrm{CF}$ & $\mathrm{CO}$ & $\mathrm{D}$ & $E$ & EXP & $\mathrm{H}$ & $\mathrm{H} / \mathrm{J}$ & II & $P$ & $\mathrm{PM}$ & $\mathrm{Q}$ & $\mathrm{R}$ & $\mathrm{RA}$ & $S$ & TOTAL \\
\hline 1 & & & & & & & & & & & & & & & & NONE \\
\hline 2 & & & & & & & & & & & & & & & & NONE \\
\hline 3 & & & & & & & & & & & & & & & & NONE \\
\hline 4 & & & & & 1 & & & & & & & & & & & 1 \\
\hline 5 & & & & & & & & & & & & & & & & NONE \\
\hline 6 & & & & & & & & & & & & & & & & NONE \\
\hline 7 & & & & & & & & & 1 & & & & & & & 1 \\
\hline 8 & & & & & & & & & & & & & & & & NONE \\
\hline 9 & & & & & & & & & & & & & & & & NONE \\
\hline 10 & 1 & & & & & & & & & & & & & & & 1 \\
\hline 12 & & & & & & & & & & & & & & & & NONE \\
\hline 13 & & & & & & & & & & & & & & & & NONE \\
\hline 14 & & & & & & & & & & & & & & & & NONE \\
\hline 15 & & & & & & & & & & & & & & & & NONE \\
\hline 16 & & & & & & & & & & & & & & & & NONE \\
\hline 17 & & & & & & & & & & & & & & & & NONE \\
\hline 18 & & & & 1 & & & & & & & & & & & & 1 \\
\hline 19 & & & & & & & & & & & & & & & & NONE \\
\hline 20 & & & & & & & & & & & & & & & & NONE \\
\hline 21 & & & & & & & & & & & & & & & & NONE \\
\hline 22 & & & & & & & & & & & & & & & & NONE \\
\hline 23 & & & & & & & & & & & & & & & & NONE \\
\hline 24 & & & & & & & & & & & & & & & & NONE \\
\hline TOTAL & 1 & & & 1 & 1 & & & & 1 & & & & & & & 4 \\
\hline \multicolumn{6}{|c|}{$\begin{array}{l}\mathrm{A}=\text { Assist } \\
\mathrm{CF}=\text { Corrective Feedback } \\
\mathrm{CO}=\text { Called on to answer question } \\
\mathrm{D}=\text { Discipline } \\
\mathrm{E}=\text { Encourage to engage } \\
\text { INDICATES STUDENT w/SLN }\end{array}$} & \multicolumn{4}{|c|}{$\begin{aligned} \text { EXP } & =\text { Explanation } \\
H & =\text { Called into Hallway } \\
H / J & =\text { Humor/Joking } \\
I I & =\text { Individualized Instruction } \\
P & =\text { Praise }\end{aligned}$} & \multicolumn{7}{|c|}{$\begin{aligned} \text { PM } & =\text { Progress Monitoring } \\
Q & =\text { Student asked question } \\
R & =\text { Teacher responds to question } \\
\text { RA } & =\text { Read Aloud } \\
S & =\text { Social }\end{aligned}$} \\
\hline
\end{tabular}


Table 42: Observation 4 - Wright Middle School - SPED Teacher

\begin{tabular}{|c|c|c|c|c|c|c|c|c|c|c|c|c|c|c|c|c|}
\hline $\begin{array}{c}\text { Student } \\
\text { Seat \# }\end{array}$ & $A$ & CF & $\mathrm{CO}$ & $\mathrm{D}$ & $E$ & EXP & $\mathrm{H}$ & $\mathrm{H} / \mathrm{J}$ & II & $\mathrm{P}$ & PM & $\mathrm{Q}$ & $\mathrm{R}$ & $\mathrm{RA}$ & $\mathrm{S}$ & TOTAL \\
\hline 1 & 2 & & & & & & & & & & & & & & & 2 \\
\hline 2 & & & & & & & & & & & & & & & & NONE \\
\hline 3 & & & 1 & & & & & & & & & & & & & 1 \\
\hline 4 & & & & & & & & & & & & 1 & & & & 1 \\
\hline 5 & & & & & & & & & & & & & & & & NONE \\
\hline 6 & & & & & & & & & & & & & & & & NONE \\
\hline 7 & & & & & & & & & & & & & & & & NONE \\
\hline 8 & & & & & & & & & & & & & & & & NONE \\
\hline 9 & & & & & & & & & & & & & & & & NONE \\
\hline 10 & 1 & & & & & & & & & & & & & & & 1 \\
\hline 12 & 1 & & & & & & & & & & 1 & & & & & 2 \\
\hline 13 & & & & & & & & & & & & & & & & NONE \\
\hline 14 & 1 & & & & & & & & & & & & & & & 1 \\
\hline 15 & 1 & & & & & & & & & & & & & & & 1 \\
\hline 16 & & & & & & & & & & & 1 & & & & & 1 \\
\hline 17 & & & & & & & & & & & & & & & & NONE \\
\hline 18 & & & & & & & & & & & & & & & & NONE \\
\hline 19 & & & & & & & & & & & & & & & & NONE \\
\hline 20 & & & & & & & & & & & & & & & & NONE \\
\hline 21 & & & & & & & & & & & & & & & & NONE \\
\hline 22 & 2 & & & & & & & & & & & & & & & 2 \\
\hline 23 & 2 & & & & & & & & & & & & & & & 2 \\
\hline 24 & & & & & & & & & & & & & & & & NONE \\
\hline TOTAL & 10 & & 1 & & & & & & & & 2 & 1 & & & & 14 \\
\hline \multicolumn{6}{|c|}{$\begin{array}{l}\mathrm{A}=\text { Assist } \\
\mathrm{CF}=\text { Corrective Feedback } \\
\mathrm{CO}=\text { Called on to answer question } \\
D=\text { Discipline } \\
\mathrm{E}=\text { Encourage to engage } \\
\text { INDICATES STUDENT w/SLN }\end{array}$} & \multicolumn{6}{|c|}{$\begin{aligned} \text { EXP } & =\text { Explanation } \\
H & =\text { Called into Hallway } \\
H / J & =\text { Humor/Joking } \\
I I & =\text { Individualized Instruction } \\
P & =\text { Praise }\end{aligned}$} & $\begin{array}{l}=F \\
=\subseteq \\
= \\
=F \\
=S\end{array}$ & $\begin{array}{l}\text { dent } \\
\text { id Al } \\
\text { ial } \\
\text { ial }\end{array}$ & $\begin{array}{l}\text { lonito } \\
\text { ked q } \\
\text { spon } \\
\text { d }\end{array}$ & $\begin{array}{l}\mathrm{gg} \\
\text { estio } \\
\text { to }\end{array}$ & lestion \\
\hline
\end{tabular}


Table 43: Observation 5 - Wright Middle School - SPED Teacher

\begin{tabular}{|c|c|c|c|c|c|c|c|c|c|c|c|c|c|c|c|c|}
\hline $\begin{array}{c}\text { Student } \\
\text { Seat \# }\end{array}$ & $A$ & CF & $\mathrm{CO}$ & $\mathrm{D}$ & $E$ & EXP & $\mathrm{H}$ & $\mathrm{H} / \mathrm{J}$ & II & $P$ & PM & $\mathrm{Q}$ & $\mathrm{R}$ & $\mathrm{RA}$ & $\mathrm{S}$ & TOTAL \\
\hline 1 & & & & & & & & & 2 & & & & & & & 2 \\
\hline 2 & & & & & & & & & & & & & & & & NONE \\
\hline 3 & & & & & & & & & & & & & & & & NONE \\
\hline 4 & & & & & & & & & 1 & & & & & & & 1 \\
\hline 5 & & & & & & & & & & & & & & & & NONE \\
\hline 6 & & & & & & & & & & & & & & & & NONE \\
\hline 7 & & & & & & & & & & 1 & & & & & & 1 \\
\hline 8 & & & & & & & & & & & & & & & & NONE \\
\hline 9 & & & & & & & & & 1 & & & 1 & & & & 2 \\
\hline 10 & & & & & & & & & & & & & & & & NONE \\
\hline 12 & 2 & & & & & & & & 2 & & & & & & & 4 \\
\hline 13 & & & & & & & & & & & 1 & & & & & 1 \\
\hline 14 & & & & & & & & & & & & & & & & NONE \\
\hline 15 & & & & & & & & & & 1 & & 1 & & & & 2 \\
\hline 16 & & & & & & & & & & & & & & & & NONE \\
\hline 17 & & & & & & & & & & & & & & & & NONE \\
\hline 18 & & & & & & & & & & & & & & & & NONE \\
\hline 19 & & & & & & & & & & & & & & & 1 & 1 \\
\hline 20 & & & & & & & & & & & & & & & & NONE \\
\hline 21 & & & & & & & & & & & & & & & & NONE \\
\hline 22 & & & & & & & & & & & & & & & & NONE \\
\hline 23 & 1 & & & & & & & & 1 & & & & & & & 2 \\
\hline 24 & 1 & & & & & & & & 1 & & & & & & & 2 \\
\hline TOTAL & 4 & & & & & & & & 8 & 2 & 1 & 2 & & & 1 & 18 \\
\hline \multicolumn{6}{|c|}{$\begin{array}{l}A=\text { Assist } \\
C F=\text { Corrective Feedback } \\
C O=\text { Called on to answer question } \\
D=\text { Discipline } \\
E=\text { Encourage to engage }\end{array}$} & \multicolumn{5}{|c|}{$\begin{aligned} \text { EXP } & =\text { Explanation } \\
H & =\text { Called into Hallway } \\
H / J & =\text { Humor/Joking } \\
I I & =\text { Individualized Instruction } \\
\mathrm{P} & =\text { Praise }\end{aligned}$} & \multicolumn{4}{|c|}{$\begin{aligned} \text { PM } & =\text { Progress Monito } \\
\mathrm{Q} & =\text { Student asked } \mathrm{c} \\
\mathrm{R} & =\text { Teacher respon } \\
\mathrm{RA} & =\text { Read Aloud } \\
\mathrm{S} & =\text { Social }\end{aligned}$} & $\begin{array}{l}\mathrm{g} \\
\text { stio } \\
\text { to }\end{array}$ & estion \\
\hline
\end{tabular}


Table 44: Observation 1 - Wright Middle School - GENED Teacher

\begin{tabular}{|c|c|c|c|c|c|c|c|c|c|c|c|c|c|c|c|c|}
\hline $\begin{array}{c}\text { Student } \\
\text { Seat \# }\end{array}$ & $A$ & CF & $\mathrm{CO}$ & $\mathrm{D}$ & $E$ & EXP & $\mathrm{H}$ & $\mathrm{H} / \mathrm{J}$ & II & $P$ & PM & $\mathrm{Q}$ & $\mathrm{R}$ & $\mathrm{RA}$ & $\mathrm{S}$ & TOTAL \\
\hline 1 & & & 2 & & & & & & 1 & & & & & & & 3 \\
\hline 2 & 1 & & & & & & & & & & & & & & & 1 \\
\hline 3 & & & & & & & & & & & & & & & & NONE \\
\hline 4 & & & 1 & & & & & & & & & & & & & 1 \\
\hline 5 & & & 3 & & & & & & & & & & & & & 3 \\
\hline 6 & & & 2 & & & & & & & & & & & & & 2 \\
\hline 7 & & & 1 & & & & & & & & & & & & & 1 \\
\hline 8 & & & & & & & & & & & & & & & & NONE \\
\hline 9 & & & & & & & & & & & & & & & & NONE \\
\hline 10 & & & 2 & & & & & & & & & & & & & 2 \\
\hline 12 & & & 1 & & & & & & & & & & & & & 1 \\
\hline 13 & & & & & & & & & & & & & & & & NONE \\
\hline 14 & & & 2 & & & & & & & & 1 & 1 & & & & 4 \\
\hline 15 & & & & & & & & & & & 1 & & & & & 1 \\
\hline 16 & & & & & & & & & & & & & & & & NONE \\
\hline 17 & & & & & & & & & & & & & & & & NONE \\
\hline 18 & & & 3 & & & & & & & & & & & & & 3 \\
\hline 19 & & & & & & & & & & & 1 & & & & & 1 \\
\hline 20 & & & & & & & & & & & & & & & & NONE \\
\hline 21 & & & & & & & & & & & & & & & & NONE \\
\hline 22 & & & 2 & & & & & & & & & & & & & 2 \\
\hline 23 & & & 2 & & & & & & & & & & & & & 2 \\
\hline 24 & & & 1 & & & & & & & & 1 & & & & & 2 \\
\hline TOTAL & 1 & & 22 & & & & & & 1 & & 4 & 1 & & & & 29 \\
\hline \multicolumn{6}{|c|}{$\begin{array}{l}\mathrm{A}=\text { Assist } \\
\mathrm{CF}=\text { Corrective Feedback } \\
\mathrm{CO}=\text { Called on to answer question } \\
\mathrm{D}=\text { Discipline } \\
\mathrm{E}=\text { Encourage to engage } \\
\text { INDICATES STUDENT w/SLN }\end{array}$} & \multicolumn{5}{|c|}{$\begin{aligned} \text { EXP } & =\text { Explanation } \\
H & =\text { Called into Hallway } \\
H / J & =\text { Humor/Joking } \\
I I & =\text { Individualized Instruction } \\
P & =\text { Praise }\end{aligned}$} & \multicolumn{4}{|c|}{$\begin{aligned} \mathrm{PM} & =\text { Progress } \mathrm{Mo} \\
\mathrm{Q} & =\text { Student ask } \\
\mathrm{R} & =\text { Teacher res } \\
\mathrm{RA} & =\text { Read Aloud } \\
\mathrm{S} & =\text { Social }\end{aligned}$} & $\begin{array}{l}\text { g } \\
\text { stion } \\
\text { to } q\end{array}$ & estion \\
\hline
\end{tabular}


Table 45: Observation 2 - Wright Middle School - GENED Teacher

\begin{tabular}{|c|c|c|c|c|c|c|c|c|c|c|c|c|c|c|c|c|}
\hline $\begin{array}{c}\text { Student } \\
\text { Seat \# }\end{array}$ & $A$ & CF & $\mathrm{CO}$ & $\mathrm{D}$ & $E$ & EXP & $\mathrm{H}$ & $\mathrm{H} / \mathrm{J}$ & II & $\mathrm{P}$ & PM & Q & $\mathrm{R}$ & $\mathrm{RA}$ & $S$ & TOTAL \\
\hline 1 & 4 & & 1 & & & & & & & & 1 & & & & & 6 \\
\hline 2 & & & 2 & & & & & & & & & & & & & 2 \\
\hline 3 & & & & & & & & & & & & & & & & NONE \\
\hline 4 & & & 3 & & & & & & & & & & & & & 3 \\
\hline 5 & & & & & & & & & & & & & & & & NONE \\
\hline 6 & 1 & & 1 & & & & & & & & & & & & & 2 \\
\hline 7 & & & 2 & & & & & & & & & & & & & 2 \\
\hline 8 & & & & & & & & & & & & & & & & NONE \\
\hline 9 & & & 1 & & & & & & & & & & & & & 1 \\
\hline 10 & & & 1 & & & & & & & & & & & & & 1 \\
\hline 12 & & & 2 & & & & & & & & & & & & & 2 \\
\hline 13 & & & 2 & & & & & & & & & & & & & 2 \\
\hline 14 & & & 2 & & & & & & & & & & & & & 2 \\
\hline 15 & & & 1 & & & & & & & & & & & & & 1 \\
\hline 16 & & & & & & & & & & & & & & & & NONE \\
\hline 17 & & & 3 & & & & & & & & & & & & & 3 \\
\hline 18 & & & 1 & & & & & & & & & & & & & 1 \\
\hline 19 & 2 & & 1 & & & & & & & & & & & & & 3 \\
\hline 20 & & & 2 & & & & & & & & & & & & & 2 \\
\hline 21 & & & 2 & & & & & & & & & & & & & 2 \\
\hline 22 & 1 & & 1 & & & & & & & & & & & & & 2 \\
\hline 23 & & & 1 & & & & & & & & & & & & & 1 \\
\hline 24 & & & & & & & & & & & & & & & & NONE \\
\hline TOTAL & 8 & & 29 & & & & & & & & 1 & & & & & 38 \\
\hline \multicolumn{6}{|c|}{$\begin{array}{l}A=\text { Assist } \\
C F=\text { Corrective Feedback } \\
C O=\text { Called on to answer question } \\
D=\text { Discipline } \\
E=\text { Encourage to engage }\end{array}$} & \multicolumn{6}{|c|}{$\begin{aligned} \text { EXP } & =\text { Explanation } \\
H & =\text { Called into Hallway } \\
H / J & =\text { Humor/Joking } \\
I I & =\text { Individualized Instruction } \\
P & =\text { Praise }\end{aligned}$} & $\begin{array}{l}1=P \\
V=S \\
R=T \\
A=R \\
S=S\end{array}$ & $\begin{array}{l}\text { ress } \\
\text { lent } \\
\text { cher } \\
\text { d Alc } \\
\text { ial }\end{array}$ & $\begin{array}{l}\text { lonito } \\
\text { ked q } \\
\text { spon } \\
\text { d }\end{array}$ & $\begin{array}{l}\mathrm{g} \\
\text { stior } \\
\text { to } q\end{array}$ & estion \\
\hline
\end{tabular}


Table 46: Observation 3 - Wright Middle School - GENED Teacher

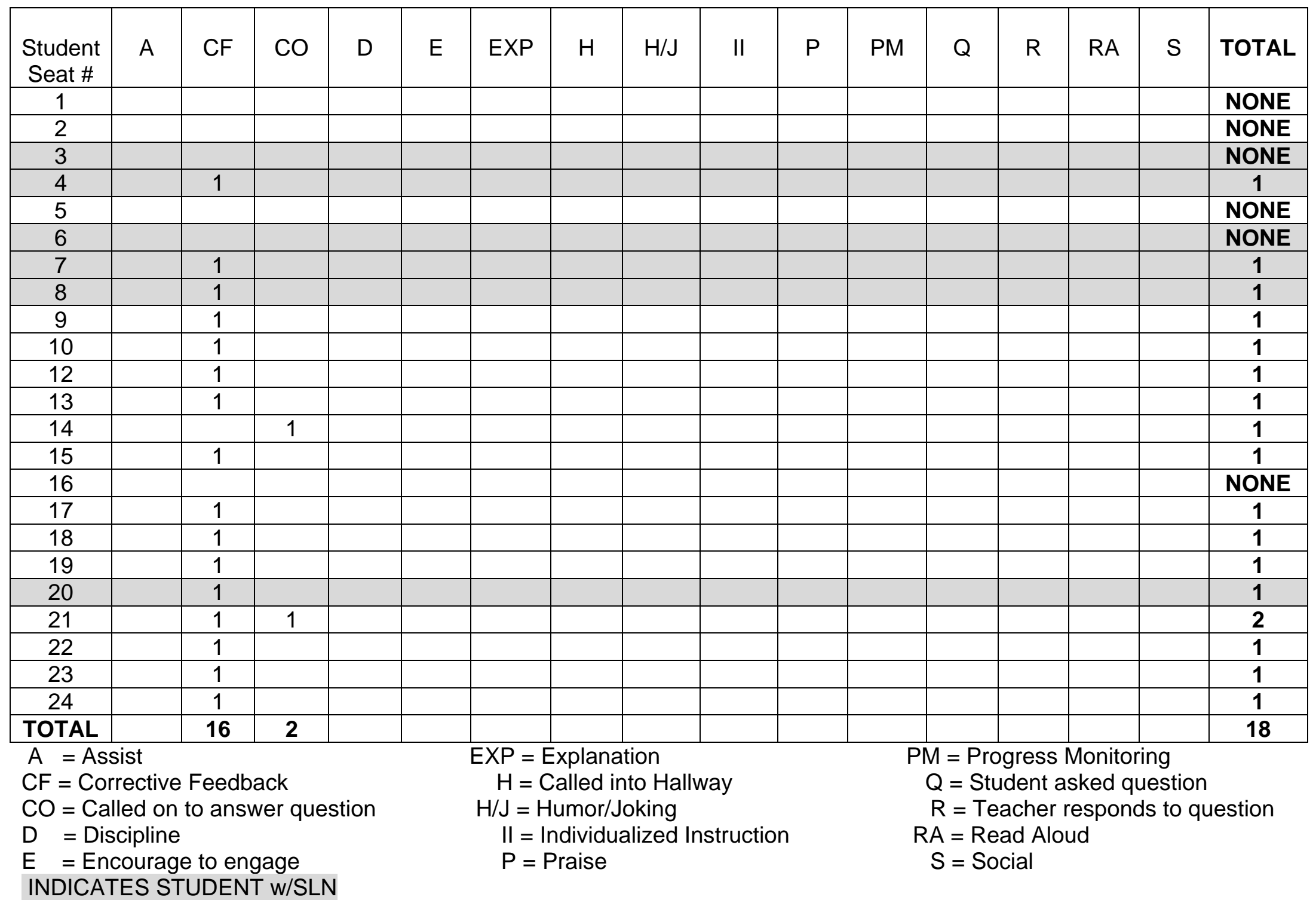


Table 47: Observation 4 - Wright Middle School - GENED Teacher

\begin{tabular}{|c|c|c|c|c|c|c|c|c|c|c|c|c|c|c|c|c|}
\hline $\begin{array}{c}\text { Student } \\
\text { Seat \# }\end{array}$ & $A$ & CF & $\mathrm{CO}$ & $\mathrm{D}$ & $E$ & EXP & $\mathrm{H}$ & $\mathrm{H} / \mathrm{J}$ & II & $P$ & PM & $\mathrm{Q}$ & $\mathrm{R}$ & $\mathrm{RA}$ & $\mathrm{S}$ & TOTAL \\
\hline 1 & 3 & & & & & & & & & & 1 & & & & & 4 \\
\hline 2 & 1 & & 1 & & & & & & & & & & & & & 2 \\
\hline 3 & & & & & & & & & & & & & & & & NONE \\
\hline 4 & & & & & & & & & & & & & & & & NONE \\
\hline 5 & & & & & & & & & & & & & & & & NONE \\
\hline 6 & & & & & & & & & & & 1 & & & & & 1 \\
\hline 7 & 1 & & & & & & & & & & & & & & & 1 \\
\hline 8 & & & & & & & & & & & & & & & & NONE \\
\hline 9 & & & & & & & & & & & & & & & & NONE \\
\hline 10 & & & & & & & & & & & & & & & & NONE \\
\hline 12 & 1 & & & & & & & & & & & & & & & 1 \\
\hline 13 & & & & & & & & & & & & & & & & NONE \\
\hline 14 & 1 & & 1 & & & & & & & & & & & & & 2 \\
\hline 15 & 1 & & & & & & & & & & & & & & & 1 \\
\hline 16 & & & & & & & & & & & & & & & & NONE \\
\hline 17 & 1 & 1 & & & & & & & & & & & & & & 2 \\
\hline 18 & & & & & & & & & & & & & & & & NONE \\
\hline 19 & & & & & & & & & & & & & & & & NONE \\
\hline 20 & 1 & & & & & & & & & & 1 & & & & & 2 \\
\hline 21 & & & & & & & & & & & & & & & & NONE \\
\hline 22 & & & & & & & & & & & & & & & & NONE \\
\hline 23 & & & & & & & & & & & & & & & & NONE \\
\hline 24 & 1 & & & & 1 & & & & & & & & & & & 2 \\
\hline TOTAL & 11 & 1 & 2 & & 1 & & & & & & 3 & & & & & 18 \\
\hline \multicolumn{6}{|c|}{$\begin{array}{l}A=\text { Assist } \\
C F=\text { Corrective Feedback } \\
C O=\text { Called on to answer question } \\
D=\text { Discipline } \\
E \quad=\text { Encourage to engage } \\
\text { INDICATES STUDENT w/SLN }\end{array}$} & \multicolumn{6}{|c|}{$\begin{aligned} \text { EXP } & =\text { Explanation } \\
H & =\text { Called into Hallway } \\
H / J & =\text { Humor/Joking } \\
I I & =\text { Individualized Instruction } \\
P & =\text { Praise }\end{aligned}$} & $\begin{array}{l}\mathrm{V}=P \\
Q=S \\
R=T \\
A=R \\
S=S\end{array}$ & $\begin{array}{l}\text { dent } \\
\text { che } \\
\text { id Al } \\
\text { ial }\end{array}$ & $\begin{array}{l}\text { Monito } \\
\text { ked o } \\
\text { espon } \\
\text { d }\end{array}$ & $\begin{array}{l}\text { ig } \\
\text { estio } \\
\text { to } 0\end{array}$ & lestion \\
\hline
\end{tabular}


Table 48: Observation 5 - Wright Middle School - GENED Teacher

\begin{tabular}{|c|c|c|c|c|c|c|c|c|c|c|c|c|c|c|c|c|}
\hline $\begin{array}{c}\text { Student } \\
\text { Seat \# }\end{array}$ & $A$ & CF & $\mathrm{CO}$ & $\mathrm{D}$ & $E$ & EXP & $\mathrm{H}$ & $\mathrm{H} / \mathrm{J}$ & II & $\mathrm{P}$ & PM & $\mathrm{Q}$ & $\mathrm{R}$ & $\mathrm{RA}$ & $\mathrm{S}$ & TOTAL \\
\hline 1 & & 1 & & & 2 & & & & & & & & & & & 3 \\
\hline 2 & & & & & & & & & & & & & & & & NONE \\
\hline 3 & & & & & & & & & & & & & & & & NONE \\
\hline 4 & & & & & & & & & & & & & & & & NONE \\
\hline 5 & & & & & & & & & & & & & & & & NONE \\
\hline 6 & & & & & & & & & & & & & & & & NONE \\
\hline 7 & & & & & & & & & & & & & & & & NONE \\
\hline 8 & & & & & & & & & & & & 1 & & & & 1 \\
\hline 9 & & & & & & & & & & & & & & & & NONE \\
\hline 10 & & & & & & & & & & & & & & & & NONE \\
\hline 12 & & & & & & & & & & & & & & & & NONE \\
\hline 13 & & & & & & & & & & & & 1 & & & & 1 \\
\hline 14 & & & & & & & & & & & & & & & & NONE \\
\hline 15 & & & & & & & & & & & & & & & & NONE \\
\hline 16 & & & & & & & & & & & & & & & & NONE \\
\hline 17 & & & & & & & & & & & & & & & & NONE \\
\hline 18 & & & & & & & & & & & & & & & & NONE \\
\hline 19 & & & & & & & & & & & & & & & & NONE \\
\hline 20 & & & & & & & & & & & & & & & & NONE \\
\hline 21 & & & & & & & & & & & & & & & & NONE \\
\hline 22 & & & & & & & & & & & & & & & & NONE \\
\hline 23 & & & & & & & & & & & & & & & & NONE \\
\hline 24 & & & & & & & & & & & & & & & & NONE \\
\hline TOTAL & & 1 & & & 2 & & & & & & & 2 & & & & 5 \\
\hline \multicolumn{6}{|c|}{$\begin{array}{l}A=\text { Assist } \\
C F=\text { Corrective Feedback } \\
C O=\text { Called on to answer question } \\
D=\text { Discipline } \\
E=\text { Encouraqe to enqaae }\end{array}$} & \multicolumn{5}{|c|}{$\begin{aligned} \text { EXP } & =\text { Explanation } \\
H & =\text { Called into Hallway } \\
H / J & =\text { Humor/Joking } \\
\text { II } & =\text { Individualized Instruction } \\
\text { P } & =\text { Praise }\end{aligned}$} & \multicolumn{6}{|c|}{$\begin{aligned} \mathrm{PM} & =\text { Progress } \mathrm{Mo} \\
\mathrm{Q} & =\text { Student ask } \\
\mathrm{R} & =\text { Teacher res } \\
\mathrm{RA} & =\text { Read Aloud } \\
\mathrm{S} & =\text { Social }\end{aligned}$} \\
\hline
\end{tabular}


Just over $25 \%$ of the 23 students (See Appendices O and P) in Mrs. M and Mr. R's class are identified as students with special learning needs. While, Table 49 summarizes the interactions of both teachers, there are three types of interactions that are of particular significance. First, the number of instances when Mr. R assisted students is double those of Mrs. M. Equally significant is the fact that Mrs. M was observed providing individual instruction only once during the entire observation period. Supportive of the fact that Mrs. M is the lead teacher in the classroom, the number of times she called on individuals to answer questions makes up almost half of her total interactions with students. This would also appear to support Mrs. M's traditional teaching style. Given context of the data collected during individual classes, the summary data is supportive of daily practices.

As shown in Table 50, Mr. R's total interactions with general education students is more than twice his total interactions with students with special learning needs. There is an even greater discrepancy, almost four times as many, between Mrs. M's interactions with general education students and her interactions with students with special learning needs. It is interesting to note, however, that both teachers recognized, as related in the Wright case narrative, that students with special learning needs quite often prefer to have fewer contacts with teachers because they do not want their nondisabled peers to know they are identified as students with SLN. 
Table 49

Number of Interactions Observed

Wright Middle School

\begin{tabular}{|l|l|c|c|c|c|c|c|c|c|c|c|c|c|c|c|c|}
\hline & A & CF & CO & D & E & EXP & H & H/J & II & P & PM & Q & R & RA & S & TOTAL \\
\hline SPED & 38 & & 6 & 1 & 1 & & & 3 & 13 & 3 & 6 & 3 & & & 1 & $\mathbf{7 5}$ \\
\hline GENED & 20 & 18 & 55 & & 3 & & & & 1 & & 8 & 3 & & & & $\mathbf{1 0 8}$ \\
\hline COMBINED & $\mathbf{5 8}$ & $\mathbf{1 8}$ & $\mathbf{6 1}$ & $\mathbf{1}$ & $\mathbf{4}$ & & & $\mathbf{3}$ & $\mathbf{1 4}$ & $\mathbf{3}$ & $\mathbf{1 4}$ & $\mathbf{6}$ & & & $\mathbf{1}$ & $\mathbf{1 8 3}$ \\
\hline
\end{tabular}
A = Assist
$\mathrm{CF}=$ Corrective Feedback
II = Individual Instruction
CO = Called on to answer question
$\mathbf{P} \quad=$ Praise
D = Discipline
PM = Progress Monitoring
E = Encourage to engage
Q = Student asked question
EXP = Explanation
$\mathbf{R}=$ Teacher responds to question
$\mathbf{H}=$ Called to hall
RA = Read aloud
$\mathbf{H} / \mathbf{J}=$ Humor/Joking
S = Social

Table 50

Comparison of SPED Teacher's Interactions to GENED Teacher's Interactions Wright Middle School

\begin{tabular}{|c|c|c|c|c|c|c|c|c|c|c|c|c|c|c|c|c|}
\hline & A & CF & CO & D & E & EXP & H & H/J & II & P & PM & Q & R & RA & S & TOTAL \\
\hline $\begin{array}{c}\text { SPED > } \\
\text { SLN }\end{array}$ & 11 & & 1 & & 1 & & & 1 & 4 & 2 & & 1 & & & & $\mathbf{2 1}$ \\
\hline $\begin{array}{c}\text { SPED } \\
\text { > } \\
\text { gened }\end{array}$ & 27 & & 5 & 1 & & & & 2 & 9 & 1 & 6 & 2 & & & 1 & $\mathbf{5 4}$ \\
\hline TOTAL & $\mathbf{3 8}$ & & $\mathbf{6}$ & $\mathbf{1}$ & $\mathbf{1}$ & & & $\mathbf{3}$ & $\mathbf{1 3}$ & $\mathbf{3}$ & $\mathbf{6}$ & $\mathbf{3}$ & & & $\mathbf{1}$ & $\mathbf{7 5}$ \\
\hline $\begin{array}{c}\text { GENED } \\
\text { > } \\
\text { SLN }\end{array}$ & 3 & 4 & 12 & & & & & & & & 2 & 1 & & & & $\mathbf{2 2}$ \\
\hline $\begin{array}{c}\text { GENED > } \\
\text { gened }\end{array}$ & 17 & 14 & 43 & & 3 & & & & 1 & & 6 & 2 & & & & $\mathbf{8 6}$ \\
\hline TOTAL & $\mathbf{2 0}$ & $\mathbf{1 8}$ & $\mathbf{5 6}$ & & $\mathbf{3}$ & & & & $\mathbf{1}$ & $\mathbf{8}$ & $\mathbf{3}$ & & & $\mathbf{1 0 8}$ \\
\hline
\end{tabular}
A $\quad$ Assist
CF = Corrective Feedback
CO = Called on to answer question
D = Discipline
E = Encourage to engage
EXP = Explanation
$\mathbf{H} \quad$ = Called to hall
$\mathbf{H} / \mathbf{J}=$ Humor/Joking

II = Individual Instruction

$\mathbf{P} \quad=$ Praise

PM = Progress Monitoring

$\mathbf{Q}=$ Student asked question

$\mathbf{R}=$ Teacher responds to question

RA = Read aloud

$\mathrm{S}=$ Social 


\section{Cross-Case Analysis}

This study was focused on two research questions. To begin to understand what

impact teachers' interactions have during instruction in co-taught inclusive classrooms, it is imperative that the perspectives of the co-teachers themselves be explored and then analyzed for similarities across cases. To that end, the first research question seeks to explore the perspectives of co-teaching from the lived experiences of the coteachers themselves.

Participants' Perspectives of Co-teaching - Research Question 1 Caryn and Micah

Both Caryn and Micah have had considerable experience in co-teaching arrangements. Caryn has been in co-teaching situations for the past six years, and Micah has been in a co-teaching arrangement the entire seven years of his teaching career. What makes his partnerships so unique is the fact that he has actually assumed the role of the general education, content teacher in a co-teaching partnership with a special educator, and he has been the special education teacher in a co-teaching partnership with a content teacher. While the opportunity to teach from both perspectives is not an option for every teacher, it has allowed Micah to develop a deeper understanding of his students and their specific, individual needs. His compassion and understanding are evident when he speaks of his experiences:

I look at those low MI kids - at them coming in here and seeing the material - knowing pretty well they probably won't get it all, and they probably won't make mastery on the test, but it might be the difference between working at McDonald's or not working....Show them. Show them and give them a chance. And then every second they're in here, they're working on important skills.... It's the picture that we've forgotten in public 
schools. We're not cranking out widgets. And it's not just special needs kids; it's everyone. I think that a lot of the regular ed kids benefit from having the other kids in here too.

Caryn's experiences with co-teaching partnerships have been somewhat different from Micah's. Her training in co-teaching has come mostly from her experiences within the classroom. Her perspective, therefore, is that of a content teacher, trained as a general educator. Yet, because she has been in multiple coteaching partnerships, she fully understands the versatility and flexibility a content teacher must possess in order to be effective with students who struggle. She states:

I'm trained to teach your average kid. I've worked a lot with special needs kids over the years, so I have some experience to deal with it, but I couldn't imagine trying to teach - there is a special way to teach those kids. There are techniques and ways to teach it to them and to deal with their disabilities in a way that's best for them.

Although not trained as a special educator, Caryn possesses a compassion and understanding of her students that is very similar to Micah's. She understands the sense of community that is represented in the classroom and is quick to point out that society is, in reality, inclusive; it does not generally offer opportunities in exclusion. In Caryn's view, neither does the classroom. Her belief that all students can be benefit from the inclusive environment is evident when she states, "... and most of them...even the lowest one that we have, he can do more than he would do if he went down the hall."

Perhaps because they have been in co-teaching partnerships for the past several years, both Caryn and Micah appear to equate co-teaching with inclusion. Both believe that the co-taught environment has benefits for all students, but, as Caryn stipulated, the benefits can only be realized if co-teachers understand that "it's supposed to be a 
shared teaching experience. It's not supposed to be my classroom, and he's intruding....He's always going to be better at something I'm not, and I'm always going to be a little better at something that he's not, and it'll balance itself out somewhere."

The impact of their knowledge of each other, their knowledge of teaching, and their knowledge of students has provided them insights which promote their successful instruction of all their students. Both Caryn and Micah are blatantly student-centered a perspective not always evident in many teachers. Although they have only been coteaching partners for two years, they share a common perspective and attitude toward teaching that serves their students well.

Linda and Betty

Linda has been teaching for seven years. The past two years have been in a coteaching partnership with Betty. As is often typical of school administrators, Linda and Betty's partnership was determined without their knowledge or input. Linda explains:

"I felt uncomfortable because I hadn't ever worked with inclusion before last year. And I was like...'I'm going to do WHAT?"'

Although Linda's initial reactions to being assigned a co-teaching partner have been replaced with some measure of acceptance and even enthusiasm at time, it is apparent that her perspectives are based in those of a content-oriented teacher. Much of Linda's teaching is from a perspective of frustration and a belief that neither she nor Betty can provide all that their students may require:

We have some that are reading on a first or second grade level. We have some that are on an actual $6^{\text {th }}$ grade level. And there is such a gap between that that we can't step down to that second grade level because of the other kids in the class. But yet, these kids cannot function on a $6^{\text {th }}$ grade level. There are a few that no matter how hard we try, no matter 
what the different types of lessons we do, I still don't think they're getting it.

Betty has taught for 27 years; four of those have been in co-teaching partnerships. This is her second year with Linda. Although they appear to have a good working relationship, Betty will quickly explain the unfortunate, bad experience she had with her previous partner. Her story, coupled with a deeply rooted conviction that too many students are inappropriately included in their content ELA class, tend to shape a perspective of co-teaching that is somewhat negative. It appears to be difficult for Betty to acknowledge a positive impact of co-teaching and inclusion except to agree, however reluctantly, that co-teaching can be beneficial to all students. In fact, her apparent bitterness is recognizable when she explains that students with SLN were "thrown out of self-contained classes all at once and dumped into general education classes without appropriate transitioning or preparation for such a placement."

The frustration that was so obvious in Betty's comments during interviews has a significant impact on her perspective. Evidence of that impact can be detected in the explanations she provides for a lack of student progress either socially or academically and in her justifications for her efforts to return students to self-contained environments.

Betty makes no effort to hide or even tone down her discontent with coteaching and inclusion. Yet she has developed a rapport with Linda that separates Linda from issues Betty has with co-teaching. In reality, however, Betty's discontent is shared by Linda. It was never apparent if Betty's perspective was strong enough to cause Linda to assume the same beliefs or if 
Linda's own perspectives were somehow strengthened by Betty's. What is apparent, though, is that in spite of such beliefs, Linda and Betty seem to have found ways to survive in their classroom and to even enjoy a level of success with their students.

Naomi and Mary

Naomi has been teaching for ten years; only one has been in a co-teaching situation. Because most of her teaching experiences have been in an alternative school setting, it would seem logical to assume that she understands the full nature of teaching students based on their unique, individual needs. But that is not the case. In fact, Naomi is very proud of the fact that she has the same expectations for all her students regardless of whether they are students with special learning needs or students without identified special learning needs. Her perspective is traditional in nature in that she believes that all students should be taught in the same way and that classrooms should be orderly and structured. It is that perspective that causes her to remain somewhat aloof from her students, opting instead to provide whole group rather than individual instruction and to assume a "no nonsense" approach to her dealings with students .

Mary has been teaching for four years; the last two years were co-teaching partnerships. While she admits that her previous co-teaching partnership was not a pleasant experience, she is very quick to point out that her partnership with Naomi is an effective one. Mary believes that students must be taught as individuals with specific and often unique learning needs. It is obvious that their perspectives are significantly different, yet they seem to have been able to find common ground from which they can meet the needs of their students. 
Mrs. M and Mr. R

This is Mr. R's sixth year of teaching, but he has been in a co-teaching partnership just short of one full semester. Until the beginning of the current semester, he taught only in a self-contained classroom. Because he has had such limited experience with both co-teaching and inclusive classrooms, the change has evoked mixed feeling for him. On the one hand, he enjoyed having his won classroom; on the other hand, he finds inclusion and co-teaching rewarding because "you get to work with more kids."

From Mr. R's perspective, co-teaching is a difficult teaching assignment because he actually has multiple teaching partners. Although Mr. R appeared very comfortable with Mrs. M during my observations of their classroom, it was during his interview and conversations with me that he expressed the complexities of working with multip0le partners. On one such occasion he explained:

You just kinda have to be flexible. One model doesn't work for everybody. I think you kinda have to feel your way around to see what's gonna work for your situation.

In spite of the difficulties he encounters, Mr. R understands the need to be flexible and respectful of his co-teaching partners - two qualities that appear to reiterate the newness of his position. While it is evident that Mr. R is diligent in his teaching and knowledge of his students, it is equally clear that he is significantly influenced by the expertise of his co-teaching partners. No where is this more evident than with Mrs. M. What is not readily evident is whether or not Mr. R has co-taught enough to have developed his own perspective. It appears, however, that he has adopted some of the views of his co-teaching partners - particularly those of Mrs. M, yet without observations 
of Mr. R with his other co-teaching partners, it is impossible to make such an assumption.

In contrast, there is no doubt that Mrs. M has developed her own perspective of both co-teaching and inclusion. She is, by her own admission, "old school, textbook driven, and in control." Although she is not opposed to the use of new technologies or innovative ideas, she is insistent on a highly structured and disciplined classroom environment that is more teacher-centered. That is not to imply that Mrs. M is not aware of students' needs. On the contrary, she is acutely aware of the skills and content knowledge students need to succeed, and she holds them all to the high standards and expectations that should get them there. Yet it is her strong content orientation and high expectations for all students that dictate that she is the instructional leader in a strictly run classroom where few if any deviations from the structured environment are tolerated. While her perspective is deeply rooted in a more traditional philosophy of teaching, it would appear that she is very comfortable in her co-teaching partnership with Mr. R - especially since his instructional efforts are typically spent addressing the individual needs of students who struggle.

\section{Cross-case Summary - Research Question 1}

Each of the teacher participants has had his own unique experiences as a coteacher. For example, Micah has had the unique experience of having been a coteacher from the perspective of both content and special education. Prior to his current special education co-teaching assignment with Caryn, Micah taught as a content teacher with a special education teacher. Each of the teachers is also aware of the responsibilities required of them in order for their respective partnerships to have a 
positive impact on their students. Additionally, each of the participants recognizes there are limitations in co-taught, inclusive environments that support the continued need for self-contained classrooms. Interestingly enough, in spite of past challenges with coteaching partnerships, all of the participants believe that all students can benefit from co-teaching to some degree.

Several themes common among the four co-teacher pairs emerged from the comparative analysis of the cases. First, although teachers believed that co-teaching was an effective means of delivering instruction in inclusive classrooms, they all also believed not all students with SLN should be placed in inclusive environments. All teachers in this study agreed there is a need for a continuum of services that includes more restrictive environments for some students. Second, the four content teachers, without exception, believe that having a special education teacher as a partner has made them more effective - a particularly significant finding given legislative mandates requiring that special education teachers must have a content certification to be considered "highly qualified" to teach students with SLN. While there is no such mandate requiring content teachers to have additional certifications to be considered "highly qualified," it would seem that the teachers in this study understand the subtle differences between content teachers and special education teachers. Additionally, special educators also have unique opportunities to learn from their content partners who often have the experience they lack. Such was the case, for example, with Mr. R and Mrs. M.

Although not initially a focus of this study, the use of technology during instruction emerged as a significant instructional and behavior management tool in each of the four 
classes. All teachers in this study, regardless of their co-teaching role and respective technology knowledge or skill levels, recognized the positive impact and advantages that technology brings to their classrooms. A sense of cooperation and collaboration between the co-teaching pairs was most evident when the use of technology was considered. Perhaps their co-teaching partnerships created an environment where risk taking is perceived as being safe. Perhaps it was the assurance that each teacher could rely on his or her partner for the benefit of the students when integrating technology into their teaching and students' learning experiences that allowed the effective use of technology.

A final theme that emerged from this study is the ongoing need for appropriate training for both teachers and administrators. Most of the challenges that were disclosed during interviews with the teachers were challenges created by administrators who tried to implement school wide co-teaching models without having participated in appropriate training or preparation to lead to such an initiative. Additionally, the teacher participants in this study each expressed some frustration with the type of training and professional development provided by their respective counties. Most of the teachers in the study expressed some degree of satisfaction with the training provided by their respective counties; however, some quickly explained that they actually learned to coteach "on their feet." While most would agree that there is little more valuable than experience, each of the teachers in this study would strongly recommend that teachers new to co-teaching need appropriate training and preparation. 
Types, Frequencies, and Patterns of Interactions - Research Question 2

The second research question focused on the interactions that occurred between the co-teachers and the students in their respective classrooms. There were three components to the question. The question asked, [w]hat types of interactions can be observed during co-taught, inclusive classrooms? With what frequency does each type occur; and are there identifiable patterns of interactions that occur? The data for this part of the study was collected during observations of the classes during instructional time. Several of the types of interactions identified were evident in each of the four classrooms. Additionally, all teachers were actively engaged with their students either in a whole group situation or, if need be, in one-on-one situations. The extent of those interactions, however, varied among teachers.

\section{Caryn and Micah}

From the time class begins until its dismissal, Caryn and Micah are engaged with their students in a variety of ways. There is instruction, modeling, individual assistance, whole group assistance, humor - in a work, there is communication. Both teachers posses an understanding of their students that goes beyond the classroom walls. It is that understanding that affords them a rapport with their students that allows their classroom community to work comfortably and productively. Instruction and reinforcement are provided by both teachers.

Although Caryn, as the content specialist, usually lead instruction, Micah is still quite actively involved during instruction by interjecting his own instruction from the perspective of a learning strategist. After key concepts are presented, both Caryn and Micah move about the room providing individual assistance to all students who are 
struggling. Caryn's assistance is typically just enough to keep students on the right track. Because she does not usually linger with any one student, she is able to observe more students. Micah, however, frequently provides individualized assistance that is much more detailed and specific. In fact, he often re-teachers difficult concepts while working one-on-one with students who are struggling. Although he often spends a considerable amount of time at the desks of individual students and is unable to engage every student, Micah still manages to find ways to acknowledge every student in some way. Both teachers monitor the progress of their students so that every student in class has some type of interaction with either Caryn or Micah each day; no one is excluded. It is something rather unique to observe.

\section{Linda and Betty}

Negative perspectives do not appear to impact the types and frequencies of interactions that occur in Linda and Betty's classroom. On the contrary, both teachers have managed to develop a positive rapport and working relationship with their students. Although Linda is actually the content specialist, it is Betty who assumes the role of lead teacher during the instruction of writing and grammar. As Betty presents each concept, Linda moves about the room to monitor student progress. Since much of the work the students complete is in the form of worksheets that are completed by the class as a whole, students are kept at the same pace thereby minimizing the possibility of students working too far ahead of the group.

Students are seated in a manner which easily allows Linda to be able to sit beside struggling students to offer appropriate levels of individualized assistance. Following the presentation of concepts, both Betty and Linda move about the room to 
assist students and to answer questions. Because both teachers are excited about the incorporation of technology in their classroom, the overhead or Whiteboard is frequently used as a means of allowing students to share their work with their classmates. Both teachers recognize the significance of allowing students opportunities to become familiar with new technologies.

\section{Naomi and Mary}

While both Naomi and Mary have equal authority in their classroom, it is apparent that Naomi is much more comfortable in the role of a traditional English teacher whose students are well disciplined and whose class is highly structured and teacher-centered. Naomi enjoys her role as the disciplinarian and content specialist. Mary, however, provides the buffer that is needed in such a strict classroom environment. Even though Naomi tends to avoid individual interactions with her students, she recognizes the rapport that Mary shares with them.

During my observations in their classroom, Mary provided most of the group instruction while Naomi tended to classroom management tasks (i.e., attendance, preparing make-up work, grades, etc.). Student desks, arranged in traditional rows, allow opportunities for both teachers to move about the room in their attempts to monitor student progress, but it is Naomi who is most engaging with individual students. Most of the interactions that occur between Naomi and the students are intended to either assist them with a particular problem or to correct inappropriate behaviors in an effort to maintain the disciplined environment she demands. 
Mrs. M and Mr. R

The interactions that occur in Mrs. M's and Mr. R's classroom are what one might expect in a highly structured, traditional classroom. As the content specialist (mathematics) in the room, Mrs. M assumes the role of instructional leader. As such, she presents all content instruction and makes assignments. During instruction, there is little interaction between Mrs. M and individual students. In fact, most of her interactions are with the whole group. Mrs. M's interactions with individual students generally occur if Mr. R is already working with another student.

While Mrs. M provides instruction, Mr. R attempts to provide assistance to the whole group by writing key concepts on the board or by providing visuals to enhance student comprehension. After Mrs. M completes a lesson, she and Mr. R move about the room to provide assistance; however, it appears that Mr. R provides more individual assistance to students who struggle. Mrs. M monitors what is occurring in what appears to be an effort to remain aware and in control of the classroom. Typically Mrs. M encourages students to work independently to find solutions to problems so that they can learn to think for themselves. In contrast, Mr. R works along side students often prompting them as he works through problems with them until an appropriate solution is found. Although Mrs. M is concerned that her students acquire the necessary skills for success in math, her traditional philosophy seems to compel her to limit both modifications for and interactions with individual students. Consequently, modifications that are provided for students with special learning needs (SLN) are the same for all students with SLN and limited to: shortened assignments, modified tests, multiplication strips that accompany tests, and frequent study guides. 
Because there is much content to cover, Mrs. M does not spend much time working in groups or "talking like you would if you was in a social studies class. I don't do a lot of interaction with them." In fact, it would appear that the interactions are left for Mr. R to accomplish. With a philosophy that is significantly different from Mrs. M, Mr. R seems to relate well with students. This is no accident because it is apparent he works hard to build a rapport with the students. He understands that quite often students "like somebody to take an interest in them instead of just what the math problem is about." His involvement extends beyond the classroom into athletics which allow him additional insights to some of the students he encounters.

While it appears that Mrs. M and Mr. R share little in common with regard to their teaching styles and beliefs about how students learn, the reality is that their common desire to ensure that students succeed transcends the boundaries of their stark differences. They each understand and respect the strengths and weaknesses of their partner and appear to have found ways to make their co-teaching partnership work.

Cross-case Summary - Research Question 2

Teacher interactions occur in contexts that are always changing. The most frequent interactions among the teachers in this study were those that occurred in the context of assisting students who struggled with assignments or content specific concepts. The degree of difficulty students experienced dictated the degree of assistance the teachers provided. Students who needed more than redirection or minimal corrective feedback were provided with individual instruction at their seats. Additionally, teachers' interactions with students were often contingent on the roles 
each had in their respective classrooms, their sense of the strengths of their partners, and their understanding of the unique learning needs of their students.

Areas where teacher perspectives begin to differ usually become evident in their diverse teaching styles and the philosophical beliefs they have. In this study, two of the teachers, Naomi and Mrs. M openly expressed their desire to maintain their traditional styles and expectations. Both appeared more comfortable when their students were working quietly and independently at their seats. Although both were actively engaged in monitoring student progress, they rarely interacted with individual students. Both teachers also expressed their apprehensions regarding their use of technology in the classroom. In spite of their reluctance to personally use the technologies available in their respective classrooms, both agreed that because students live in a technological society they must have opportunities to use technology effectively in their classrooms. The other six teachers agreed. 


\section{Chapter 5}

\section{Results}

The purpose of this study was to examine co-teaching through an analysis of the perspectives of teachers engaged in co-teaching partnerships and observable interactions of those teachers as they implemented co-teaching in their classrooms. Interviews were conducted with individual teachers and with co-teaching pair of teachers to document and describe co-teacher perspectives. Multiple classroom observations were conducted in participants' classrooms to document the types and frequencies of teacher-students interactions that occur during instruction in co-taught classrooms. Co-teaching pairs from four middle schools in southern West Virginia were selected as participants. Participants ranged in teaching experience and co-teaching experience from very experienced to novice. Content areas included math and English/Language Arts. All classrooms were categorized as inclusive. Following teacher interviews and classroom observations, multiple themes regarding both inclusion and co-teaching emerged from the interview and observation data. The most significant themes provide a framework for a final discussion of the outcomes of this study.

The Research Questions and Emergent Themes

This study focused on two research questions.

1. What are the perspectives of co-teaching that teachers identify from their experiences? 
2. What types of interactions can be observed during co-taught, inclusive classrooms? With what frequency does each type occur? Are there identifiable patterns that occur?

The first research question dealt with teachers' general perspectives of their coteaching experiences and the impact of co-teaching on their roles and responsibilities, their teaching practice, and their students.

Teachers' experiences with co-teaching. The teachers reported a variety of experiences; some were extremely positive, some were somewhat negative. Unfortunately, some participants had been placed in extremely challenging situations that made effective co-teaching difficult. From their perspectives at least two factors were critical to the success of co-teaching: the structural arrangements of co-teaching partnerships and professional development. All could agree, however, that co-teaching would be much more effective if assignments were carefully considered and if both teachers and administrators were appropriately trained in its implementation.

Effective co-teaching partnerships are like any other relationship. Teaching partnerships require that each partner is compatible with the other and is flexible enough to work together to establish an effective relationship in inclusive classroom environment. Each must bring his or her expertise to the partnership and be willing to acknowledge any weaknesses that exist. Caryn from Chicory Middle described it best when she said, "it's supposed to be a shared teaching experience. It's not my classroom and he's intruding...He's supposed to be as much of this class as I am." The development of co-teaching partnerships can be achieved when teachers are provided 
with reasonably appropriate classroom settings and scheduling that includes sufficient planning time for partners to plan together. Once teachers are committed to working as a co-teaching teaming, on-going, supportive training should follow.

Seven of the eight teachers have had some training in models of co-teaching, yet none expressed a level of satisfaction with their training that made them comfortable in their knowledge and skill in the implementation of co-teaching. In fact, all eight have learned to co-teach as they co-taught - what the teachers repeatedly referred to as "on their feet." Although not explicitly identified by teachers in the study, implicit in their remarks is the fact that many building administrators have had even less training than teachers have had. Consequently, students may be inappropriately placed in co-taught classrooms with two teachers who are very apt to have been assigned as partners. Much of the concern expressed by the teacher participants regarding their administrators was specific to the appropriate implementation of co-teaching in their respective schools, the administrators' inadequate understanding of the planning needs of co-teachers, and the often minimal support teachers received from their building administrators.

With the exception of Micah and Caryn from Chicory Middle, teachers seemed somewhat concerned that their administrators did not understand the needs of coteachers. Additionally, teachers did not seem to feel there was sufficient knowledge about co-teaching among their respective administrative staff. Micah and Caryn, however, had the full support and assistance of their building administrators. In retrospect, I am convinced that, compared to the other co-teacher pairs in this study, Micah and Caryn were the most confident in their partnership. It may be that their 
confidence and enthusiasm was derived from other sources, but knowing they have the full support of a principal who works hard to make their partnership work effectively was a potentially supportive factor.

Co-teacher partnerships. Two key elements of co-teaching were mentioned repeatedly in my discussions with the teachers. First, how co-teaching partnerships are determined must be carefully examined. With the exception of Mr. R, each of the coteaching pairs in this study had been assigned by the building administrators. Mr. R became Mrs. M's partner by virtue of a lateral job move at Wright Middle. Although each of the co-teaching pairs in this study worked well together, best practice stipulates that teachers are allowed to both volunteer and choose their co-teaching partners (Walther-Thomas, et al., 2000).

The issue of planning. Second, because scheduling is a difficult task under the best circumstances, it becomes an even greater issue when administrators attempt to schedule time for co-teachers to share their planning time. Without a specific time to plan together, teachers are forced to "plan on the run" as Mary and Naomi do when they come together - often just before one class ends and another begins, or to plan alone, as Mrs. M and Mr. R do. While each of the teachers in the study has found a way of planning that works for them, every one of them considered co-planning a necessary part of co-teaching that is repeatedly neglected. It is important to note that both these elements identified by the teachers in this study are also found in current literature. Characteristics essential to the success of any co-teaching model include: common planning time, teachers' willingness to engage in co-teaching models, co-teaching 
partners that volunteer to co-teach and are not assigned administratively, and a balanced, heterogeneous group of students (Walther-Thomas, Bryant, \& Land, 1996) .

One of the most compelling issues that emerged from this study is the fact that while there is a significant research base to support the use of co-teaching as an effective instructional model in inclusive classroom environments, it would appear that there has been nothing done to improve the implementation of such a model. Teachers are still learning "on their feet", administrators still assign teachers their partners, and the scheduling of adequate co-planning time is often nonexistent. Left to their own devices and without training, teachers frequently revert to teaching methods that are less risky and more traditional by nature. In other words, classroom environments become much more teacher-centered and /or content oriented and much less studentcentered.

Co-teaching is not for everyone. Co-teaching is not for all teachers; it is not for all students. Although all students may benefit to some degree from co-teaching, not all students with SLN should be placed in inclusive environments. As was reported in the Coalton case, Betty and Linda are adamantly opposed to placing students in inclusive classrooms just for the sake of having them there. Betty insists that many of the students now being taught in their general education, content classrooms would be more appropriately served if they were placed in the self-contained special education classroom where they can receive more individual attention. Her administration, however, does not agree. And, based on my last conversations with both Betty and Linda, that is not something they see as being changed in the future. 
Mr. R, from Wright Middle, emphasized the fact that students with SLN are often uncomfortable in inclusive classrooms. In fact, he spoke to me about one student in particular who did not want to be acknowledged by Mr. R for fear that the other students in class would decide that she was, indeed a student with SLN. It is a dilemma that Mr. $\mathrm{R}$ takes very seriously. He goes to great lengths to ensure that he is seen working with the general education students as well as the students with SLN. He reports, however, that even this tactic is not always successful. The negative effects of labeling are well documented, and co-teaching may contribute to these phenomena for SLN students.

The use of technology. The use of technology is a powerful tool for instruction. When this study was designed, technology was not one of the factors to be examined. However, every lesson I observed, in every classroom, was presented using some form of technology. As Mrs. M explained, "it's what the students know." The technology observed in this study isn't just computers in the classrooms. In these inclusive classrooms, the use of technology ranges from the use of laptops and data projectors used to project portions of lessons onto the Whiteboard to the use of PowerPoint $\AA$ presentations designed and used to introduce students to new content or ideas. Every teacher in this study identified the multiple benefits of having technology in their classrooms to enhance instruction and engage students.

Implications for the Field

While the majority of the findings from this study serve to reinforce previous research on co-teaching, there are still several implications for the field of education that can be can be realized from this multi-case study. 
Teacher Preparation. First, teacher preparation programs should note the growing popularity of the co-teaching model as an effective delivery model for inclusive classroom environments. Once noted, programs should be developed whereby both pre-service and in-service teachers can establish relationships that allow for the development of appropriate skills necessary for co-teaching partnerships. While "learning on your feet" is something that all teachers must experience, professional development opportunities should be provided to remove some of the uncertainty that seems to accompany the implementation of co-teaching models.

Sustained, Embedded, Professional Development. In their article about teachers' feelings of preparedness, Boyer and Mainzer (2003) related the fact that general educators' confidence in serving students with special learning needs was found to be dependent upon the general educators' relationships with special education teachers. Co-teaching provides natural classroom opportunities for sustained professional development that does more than simply provide information. Sustained professional development opportunities, in turn, would allow for the meaningful development of relationships between teachers that would bring multiple opportunities for effective instruction to their classrooms. Additionally, co-teaching could provide mentoring opportunities for both pre-service and new, in-service teachers. In each case in this study, teachers described how they learned from one another and improved their teaching as a result of these powerful learning opportunities. Current trends in professional development point to the effectiveness of mentoring and coaching. Teacher inquiry is another aspect of professional development that is currently receiving attention as a strategy for teachers to identify areas of their practice that need 
improvement and to systematically implement change. Co-teaching partnerships provide a strong foundation for initiating these models of professional development. Cotaught classrooms eliminate the barrier of isolation and provide opportunities for purposeful collaboration and professional development.

Multiple Models. From the perspective of the interactions that occurred during observed classes, it is apparent that the "one teach, one assist" model was the most frequently used model among the teachers in this study. While there were occasions when teachers switched roles in the classroom, for the most part there was clear evidence that only one teacher assumed the lead role. It is entirely possible that, because of the lack of training in the models of co-teaching, teachers may have been unaware of other models that could be implemented.

Enhancing Student Learning. Analysis of the interactions between co-teaching partners and their students also revealed patterns of behavior that have significant implications for the learning experiences of students. First, because co-teaching occurs in inclusive classrooms, it should be designed in such a way that both general education students and students with SLN will benefit from instruction. Given the difficulty many students encounter with science or social studies, learning opportunities beyond mathematics and English/Language Arts could be provided. Second, if teachers are to be regarded as equals in co-taught classrooms, then both teachers should engage students in a variety of ways. 


\section{Future Research}

Findings from this study are limited by the number of participants included in the sample and the targeted location of the research sites. To extend the results of this research, I would suggest the following.

Multiple Perspectives. This study focused exclusively on the perspectives of coteachers. Other perspectives that are critical to the success of co-teaching include school administrators, the other teachers working with students with SLN, and the students themselves. Future research should expand the sampling criteria to include the perspectives of these other participants in the context of co-teaching.

Consider Achievement. While student achievement was used to help describe the contexts for this study, this data was not analyzed to describe the effects of coteaching. Future research should more systematically rely on standardized measures of student achievement to establish the impact of co-teaching on student learning. Opportunities for future research should include an investigation of the impact coteaching models have on the achievement levels of the students with and without SLN. Given the influence of NCLB and IDEA on services for students with SLN and the general curriculum, achievement could be a central feature of future research.

Archive Observations. The observations in this study were all conducted by one researcher and the analysis and categorization of interactions was conducted through the perspective of that one researcher. To ensure the accuracy of each of the written case studies prepared, teacher participants were asked to review their respective case studies and to offer comment or correction as deemed appropriate. Without exception, 
teacher participants agreed that their respective case studies accurately captured and reported what had occurred during observations. In an effort to broaden the analysis of future observational data, observations could be videotaped and used to elicit data from the co-teachers. The opportunity to examine classroom interactions with the participants would enrich the analysis and the findings of the study.

Focus on Professional Development. Designing evaluation research that makes the connection between the training offered to teachers as they assume their roles and responsibilities as co-teachers and the effectiveness of the implementation of coteaching would also make a valuable contribution to the field of practice.

Expand the Geographic Location. Co-teaching is not a practice restricted to schools in southern West Virginia. Examining co-teaching practices and the perspectives of co-teachers in other areas in West Virginia as well as in other states could provide a broader understanding of co-teaching from a cultural perspective.

\section{Conclusion}

Teaching is a lifelong commitment to change. While the challenges of coteaching are very similar to the challenges of co-teaching identified in the past decade, it appeared to me that the teacher participants were willing to implement co-teaching models in spite of the challenges they faced. Each found a way to plan when there was no planning time assigned; each worked to ensure that classroom activities were not inadvertently exclusive of any student in the room; and each had an admiration and respect for his or her partner that is not always something a casual observer may have the opportunity to see. Finally, as I observed the diverse teaching styles and 
personalities of the participants in their classrooms, I recognized that in spite of their differences, each was willing to work with their respective partners to ensure that their students were successful. At the end of the day, that's all that really matters. 


\section{References}

Bauwens, J., \& Hourcade, J. J. (1995). Cooperative teaching: Rebuilding the school house for all students. Austin, TX: Pro-Ed.

Bauwens, J., Hourcade, J. J., \& Friend, M. (1989). Cooperative teaching: A model for general and special education integration. Remedial and Special Education, 10(2), 17-22.

Beckman, P. (2001). Access to the general education curriculum for students with disabilities. Arlington, VA: ERIC Clearinghouse on Disabilities \& Gifted Education. (ERIC Identifier: ED458735).

Berg, B. L. (2004). Qualitative research methods for the social sciences. (5 $5^{\text {th }}$ ed.). Boston: Allyn \& Bacon.

Bogdan, R., \& Biklen, S. (2007). Qualitative research for education: An introduction to theories and methods. Boston: Allyn \& Bacon.

Bouck, E. C. (2007). Co-teaching...not just a textbook term: Implications for practice. Preventing School Failure, 51(2), 46-51.

Boyer, S. J. (1996). The effectiveness of a collaborative cooperative teaching instructional model (Doctoral dissertation, University of Georgia, 1996). Dissertation Abstracts International, 57, 2753. 
Boyer, L., \& Mainzer, R. W. (2003). Who's teaching students with disabilities? A profile of characteristics, licensure status, and feeling of preparedness. Teaching Exceptional Children, 35(6), 8-11.

Choate, D. H. (1997). Special education at the crossroads: A study of Floyd County's collaborative instruction program (Doctoral dissertation, The University of Alabama, 1997). Dissertations Abstract International, 58, 2158.

Cohen, E. G. (1973). Open-space schools: The opportunity to become ambitious. Sociology of Education, 46, 143-161.

Compton, M., Stratton, A., Maier, A., Meyers, C., Scott, H., \& Tomlinson, T. (1998). It takes two: Co-teaching for deaf and hard of hearing students in rural schools. In: Coming together: Preparing for rural special education in the $21^{\text {st }}$ century. Conference Proceedings of the American Council on Rural Special Education $18^{\text {th }}$, Charleston, SC, March 25-28, 1998).

Council for Exceptional Children. (2003). No Child Left Behind Act of 2001: Reauthorization of the Elementary and Secondary Education Act (A Technical Assistance Resource) April 2003. Retrieved September 26, 2007, from http://www.cec.sped.org/pp/overviewNCLB.pdf

Denzin, N., \& Lincoln, Y. (2003). Strategies for qualitative inquiry. Thousand Oaks, CA: Sage.

Dettmer, P., Thurston, L. P., \& Dyck, N. (2005). Consultation, collaboration, and teamwork for students with special needs ( $5^{\text {th }}$ ed.). Boston: Allyn \& Bacon. 
Dieker, L. (1998). Rationale for co-teaching. Social Studies Review, 37(2), 62-65.

Dieker, L. (2001). What are the characteristics of "effective" middle and high school cotaught teams for students with disabilities? Preventing School Failure 46(1), 14.

Friend, M., \& Bursuck, W. D. (2005). Including students with special needs: A practical guide for classroom teachers ( $4^{\text {th }}$ ed.). Boston: Allyn \& Bacon.

Friend, M., \& Cook, L. (1996). Interactions: Collaboration skills for school professionals ( $2^{\text {nd }}$ ed.). New York: Longman.

Gans, H.J. (1982). The participant observer as a human being: Observations on the personal aspects of fieldwork. In R. G. Burgess (ed.), Field research: A sourcebook and field manual. London: Allen \& Unwin. In S.B. Merriam, Qualitative research and case study applications in education. San Francisco: Jossey-Bass.

Garver, A., \& Papanla, A. (1982). Team teaching: It works for the student. Academic Therapy, 18(2), 191-196.

Gerber, P. J., \& Popp, P. A. (1999). Consumer perspectives on the collaborative teaching model: Views of students with and without LD and their parents. Remedial and Special Education, 20(5), 288-296.

Hamel, J., Dufour, S., \& Fortin, D. (1993). Case study methods. Qualitative Research Methods Series, Vol. 32. Newbury Park, CA: Sage. In M. Q. Patton, Qualitative Research \& Evaluation Methods. ( $3^{\text {rd }}$ ed.). Thousand Oaks: Sage Publications. 
Harbort, G., Gunter, P. L., Hull, K., Brown, Q., Venn, M. L., Wiley, L. P., \& Wiley, E. W. (2007). Behaviors of teachers in co-taught classes in a secondary school. Teacher Education and Special Education, 30(1), 13-23.

Hardy, S. D. (2001). A qualitative study of the instructional behaviors and practices of a dyad of educators in self-contained and inclusive co-taught secondary biology classrooms during a nine-week science instruction grading period. (Doctoral dissertation, George Mason University, 2001). Dissertation Abstracts International, 61, 4731.

Hoover, J. J., \& Patton, J. R. (2004). Differentiating standards-based education for students with diverse needs. Remedial and Special Education, 25(2), 74-78.

Keefe, E. B., \& Moore, V. (2004). The challenge of co-teaching in inclusive classrooms at the high school level: What the teachers told us. American Secondary Education, 32(3), 77-88.

Kidder, L. H. (1981). Selltiz, Wrightsman \& Cook's research methods in social relations. ( $4^{\text {th }}$ ed.) Austin, TX: Holt, Rinehart and Winston In S. B. Merriam, Qualitative Research and Case Study Applications in Education. San Francisco: Jossey-Bass.

LeCompte, M. D., \& Preissle, J. (1993). Ethnography and qualitative design in educational research. ( $2^{\text {nd }}$ ed.). Orlando, Fla.: Academic Press.

Luckner, J. (1999). An examination of two co-teaching classrooms. American Annals of the Deaf, 144(1), 24-34. 
Magiera, K., Smith, C., Zigmond, N., \& Gebauer, K. (2005). Benefits of co-teaching in secondary mathematics classes. Teaching Exceptional Children 37(3), 20-24.

Marston, D. (1996). A comparison of inclusion only, pull-out only, and combined service models for students with mild disabilities. The Journal of Special Education, $30(2), 121-132$.

Mahoney, M. (1997). Small victories in an inclusive classroom. Educational Leadership, 54(7), 59-62.

Mastropieri, M. A., \& Scruggs, T. E. (2001). Promoting inclusion in secondary classrooms. Learning Disability Quarterly, 24, 265-274.

Mastropieri, M. A., Scruggs, T. E., Graetz, J., Norland, J., Gardizi, W., \& McDuffie, K. (2005). Case studies in co-teaching in the content areas: Successes, failures, and challenges. Intervention in School and Clinic, 40(5), 260-270.

Merriam, S. B. (1995). What can you tell from an $\mathrm{N}$ of 1?: Issues of validity and reliability in qualitative research. PAACE Journal of Lifelong Learning, 4, 51-60.

Merriam, S. B. (1998). Qualitative research and case study applications in education. San Francisco: Jossey-Bass.

Merriam, S. B. (2001). Qualitative research and case study applications in education. San Francisco: Jossey-Bass.

Miller, A., Valasky, W., \& Molloy, P. (1998). Learning together: The evolution of an inclusive class. Active Learner: A Foxfire Journal for Teachers, 3(2), 14-16. 
Morocco, C. C., \& Aguilar, C. M. (2001). Co-teaching for content understanding: A schoolwide model. Journal of Educational and Psychological Consultation, 13(4), 315-347.

Murray, C. (2004). Clarifying collaborative roles in urban high schools. Teaching Exceptional Children, 36(5), 44-51.

Patton, M. Q. (2002). Qualitative research \& evaluation methods. ( $3^{\text {rd }}$ ed.). Thousand Oaks: Sage Publications.

Polloway, E. A., Patton, J. R., \& Serna, L. (2005). Strategies for teaching learners with special needs $\left(8^{\text {th }}\right.$ ed.). Upper Saddle River, NJ: Pearson.

Pugach, M. C., \& Warger, C. L. (2001). Curriculum matters: Raising expectations for students with disabilities. Remedial and Special Education, 22(4), 194-196.

Rea, P. J., McLaughlin, V. L., \& Walther-Thomas, C. (2002). Outcomes for students with learning disabilities in inclusive and pullout programs. Exceptional Children, 68(2), 203-222.

Rice, D., \& Zigmond, N. (1999). Co-teaching in secondary schools: Teacher reports of developments in Australian and American classrooms. Resources in Education. (ERIC Document Reproduction Service NO. ED 432558).

Scruggs, T. E., Mastropieri, M. A., \& McDuffie, K. A. (2007). Co-teaching in inclusive classrooms: A metasynthesis of qualitative research. Exceptional Children, 73(4), 392-416. 
Seidman, I. (1998). Interviewing as qualitative research: A guide for researchers in education and the social sciences. ( $2^{\text {nd }}$ ed.). New York: Teachers College Press.

Stake, R. E. (1995). The art of case study research. Thousand Oaks: Sage Publications.

The National Center on Educational Restructuring and Inclusion Study. (1995). National study on inclusion: Overview and summary report. New York: City University of New York.

Thurlow, M .L. (2000). Standards-based reform and students with disabilities. Focus on Exceptional Children, 33(3), 1-16.

Thurlow, M. \& Ysseldyke, J. (1997). Large-scale assessment participation and reporting issues: Implications for local decisions. Diagnostique, 22, 225-236. In R. L. Taylor, L. R. Smiley, \& S. B. Richards, Exceptional Students: Preparing Teachers for the $21^{\text {st }}$ Century. Boston: McGraw-Hill.

Trent, S. (1998). False starts and other dilemmas of a secondary general education collaborative teacher: A case study. Journal of Learning Disabilities, 31, 503513.

United States Department of Education Fact Sheet. (2004). New No Child Left Behind flexibility: Highly Qualified Teachers. Retrieved October 3, 2006, from http://www.ed.gov/teachers/nclbguide/improve-quality.html 
Vaughn, S., Elbaum, B. E., Schumm, J. S., \& Hughes, M. T. (1998). Social outcomes for students with and without learning disabilities in inclusive classrooms. Journal of Learning Disabilities, 31(5), 428-436.

Walther-Thomas, C. (1997). Co-teaching experiences: The benefits and problems that teachers and principals report over time. Journal of Learning Disabilities, 30(4), 395-407.

Walther-Thomas, C., Bryant, M., \& Land, S. (1996). Planning for effective co-teaching: The key to successful inclusion. Remedial and Special Education, 17, 255-265.

Walther-Thomas, C., Korinek, L., McLaughlin, V., \& Williams, B.T. (2000). Collaboration for inclusive education: Developing successful programs. Boston: Allyn \& Bacon.

Weiss, M. (2004). Co-teaching as science in the schoolhouse: More questions than answers. Journal of Learning Disabilities, 37, 218-223.

Weiss, M., \& Brigham, F. (2000). Coteaching and the model of shared responsibility: What does the research support? In Thomas Scruggs, Margo Mastropieri, and Kimberly McDuffie, Coteaching in inclusive classrooms: A metasynthesis of qualitative research. Exceptional Children 73(4), pp. 392-416.

Weiss, M., \& Lloyd, J. (2002). Congruence between roles and actions of secondary special educators in co-taught and special education settings. Journal of Special Education 36(2), 58-68. 
Welch, M. (2000). Descriptive analysis of team teaching in two elementary classrooms: A formative experimental approach. Remedial and Special Education, 21, 366376.

WVEIS Data on Demand. Retrieved September 26, 2007 from http://wveis.k12.wv.us/nclb/pub

Wills, M. C. (1986). Educating children with learning problems: A shared responsibility. Exceptional Children, 52, 411-416.

Wolcott, H. (2001). Writing up qualitative research. Thousand Oaks, CA: Sage.

Yin, R. K. (1994). Case study research: Design and methods. ( $2^{\text {nd }}$ ed.). Thousand Oaks: Sage Publications.

Yin, R. K. (2003). Case study research: Design and methods. ( $3^{\text {rd }}$ ed.). Thousand Oaks: Sage Publications.

Zigmond, N., \& Magiera, K. (2001). Current practice alerts: A focus on co-teaching: Use with caution. Alerts, 6, 1-4. 
Appendix A

Graphic Representation of Procedures

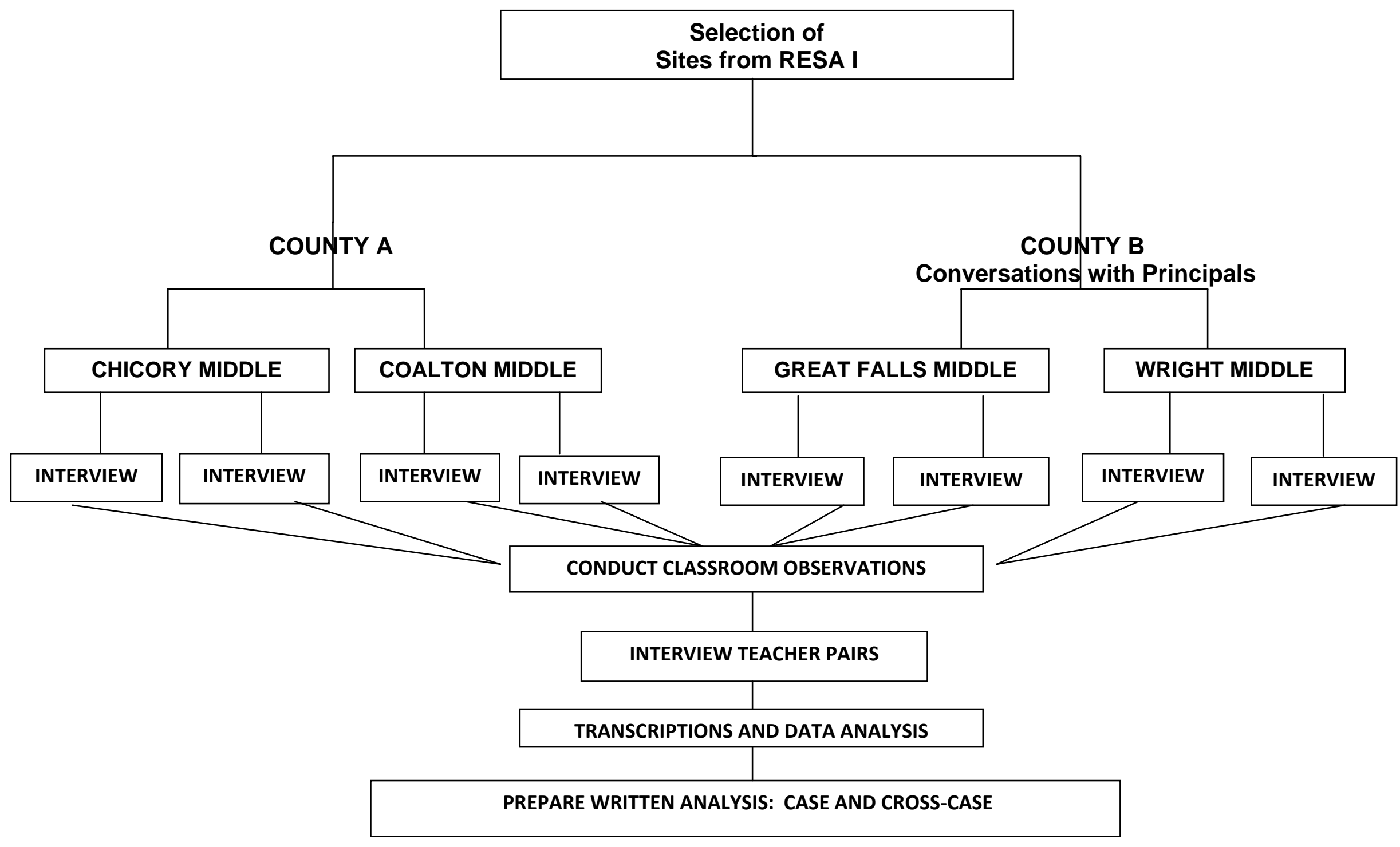


APPENDIX B

STATISTICAL COMPARISON OF RACE, SES, AND SPED DISTRIBUTION FY 2006-07

\begin{tabular}{|c|c|c|c|c|c|c|c|c|c|c|}
\hline \multirow[t]{2}{*}{ SCHOOL } & \multirow{2}{*}{$\begin{array}{l}\text { ENROLLMENT } \\
\text { TOTAL }\end{array}$} & \multirow[t]{2}{*}{ WHITE } & \multirow[t]{2}{*}{ BLACK } & \multirow[t]{2}{*}{ OTHER } & \multirow[t]{2}{*}{ LOW SES } & \multirow[t]{2}{*}{ SPED } & \multicolumn{2}{|c|}{ AYP } & \multicolumn{2}{|c|}{ SPED AYP } \\
\hline & & & & & & & MATH & RDNG & MATH & RDNG \\
\hline \multicolumn{11}{|l|}{ County A } \\
\hline $\begin{array}{l}\text { School } 1 \\
\text { (A1) }\end{array}$ & 576 & $\begin{array}{l}435 \\
76 \%\end{array}$ & $\begin{array}{l}134 \\
23 \%\end{array}$ & $\begin{array}{c}* \\
\text { Reported } 7 \\
1 \%\end{array}$ & $\begin{array}{l}403 \\
70 \%\end{array}$ & $\begin{array}{c}97 \\
17 \%\end{array}$ & $Y$ & $Y$ & $Y$ & $Y$ \\
\hline $\begin{array}{c}\text { School } 2 \\
\text { (A2) }\end{array}$ & 627 & $\begin{array}{l}572 \\
92 \%\end{array}$ & $\begin{array}{l}47 \\
7 \%\end{array}$ & $\begin{array}{c}* \\
\text { Calculated } 8 \\
1 \% \\
\end{array}$ & $\begin{array}{l}348 \\
56 \%\end{array}$ & $\begin{array}{c}95 \\
15 \%\end{array}$ & $Y$ & $Y$ & $\mathrm{~N}$ & $\mathrm{~N}$ \\
\hline \multicolumn{11}{|l|}{ County B } \\
\hline $\begin{array}{l}\text { School } 1 \\
\text { (B1) }\end{array}$ & 674 & $\begin{array}{l}493 \\
73 \% \\
\end{array}$ & $\begin{array}{l}165 \\
24 \% \\
\end{array}$ & $\begin{array}{l}16 \\
2 \% \\
\end{array}$ & $\begin{array}{l}409 \\
61 \% \\
\end{array}$ & $\begin{array}{l}141 \\
21 \% \\
\end{array}$ & $Y$ & $Y$ & $Y$ & $Y$ \\
\hline $\begin{array}{c}\text { School } 2 \\
\text { (B2) }\end{array}$ & 513 & $\begin{array}{l}504 \\
98 \%\end{array}$ & $*$ & $*$ & $\begin{array}{l}313 \\
61 \%\end{array}$ & $\begin{array}{c}92 \\
18 \%\end{array}$ & $Y$ & $Y$ & $Y$ & $Y$ \\
\hline $\begin{array}{c}\text { School } 3 \\
\text { (B3) }\end{array}$ & 415 & $\begin{array}{l}307 \\
74 \% \\
\end{array}$ & $\begin{array}{l}101 \\
24 \% \\
\end{array}$ & $\begin{array}{c}* \\
\text { Calculated } 7 \\
2 \% \\
\end{array}$ & $\begin{array}{l}224 \\
54 \%\end{array}$ & $\begin{array}{c}76 \\
18 \%\end{array}$ & $Y$ & $Y$ & $Y$ & $Y$ \\
\hline $\begin{array}{c}\text { School } 4 \\
\text { (B4) }\end{array}$ & 592 & $\begin{array}{l}577 \\
97 \%\end{array}$ & $\begin{array}{c}* \\
\text { Reported } 6 \\
1 \%\end{array}$ & $\begin{array}{c}* \\
\text { Reported } 9 \\
2 \%\end{array}$ & $\begin{array}{l}244 \\
41 \%\end{array}$ & $\begin{array}{l}122 \\
21 \%\end{array}$ & $Y$ & $Y$ & $Y$ & $Y$ \\
\hline $\begin{array}{c}\text { School } 5 \\
\text { (B5) }\end{array}$ & 403 & $\begin{array}{l}399 \\
99 \%\end{array}$ & $\begin{array}{c}* \\
\text { Reported } 4 \\
1 \% \\
\end{array}$ & $\mathrm{~N} / \mathrm{A}$ & $\begin{array}{l}231 \\
57 \%\end{array}$ & $\begin{array}{c}61 \\
15 \%\end{array}$ & $Y$ & $Y$ & $Y$ & $Y$ \\
\hline
\end{tabular}




\section{Appendix C}

Interview Protocol 1

Date: 1

School: A B C

D Teacher: SPED GENED

Greetings! Thank you for participating in this research study. The purpose of the study is to examine the frequency and types of interactions that occur between co-teachers and their students during inclusive classroom instruction.

This study is being conducted in partial fulfillment of my doctoral program at West Virginia University. I would like to digitally record this interview in order to accurately represent what you say. May I have your permission to record this interview?

Before we begin I want to make sure you understand the following:

- Your responses will be kept confidential; at no time will your name be revealed during reporting.

- Your name will not be attached to either the audio or notes from this interview, or to transcribed data.

- Your participation is entirely voluntary; you can choose to stop the interview at any time, and you do not have to answer every question.

- Your job status will not be affected by your refusal to participate or to withdraw from the study.

- At the end of this study, digital recordings of your interview will be deleted from all computer and recorder files.

- West Virginia University's Institutional Review Board's acknowledgement of this study is on file.

- Should you wish to have additional information regarding the study or the results of the study, please email either Dr. Jacqueline Webb-Dempsey at Jaci.Webb-Dempsey@mail.wvu.edu or Nancy G. Burton at nburton@mix.wvu.edu

Thank you again for your willingness to participate in this study. 


\section{Background Information}

1. What certification(s) do you hold?

2. How long have you been teaching...total years? How long have you been in a co-teaching situation?

3. Tell me about how you learned about co-teaching. How did you get started with co-teaching?

4. How did you and become co-teaching partners?

\section{The Co-taught Classroom}

5. Given the descriptions of the models of co-teaching, which model would you identify as being the one most closely indicative of what occurs in your current co-taught classroom?

a. FOLLOW UP: Why did you pick that model?

6. What are your roles and responsibilities as a co-teacher?

7. What does instruction look like in your classroom?

8. How often does whole-group instruction take place? Small-group instruction? 
9. Describe the types of interactions you have with students?

10. What impact do you think co-teaching has had on student achievement or student learning?

11. What impact has co-teaching had on you as an educator? 


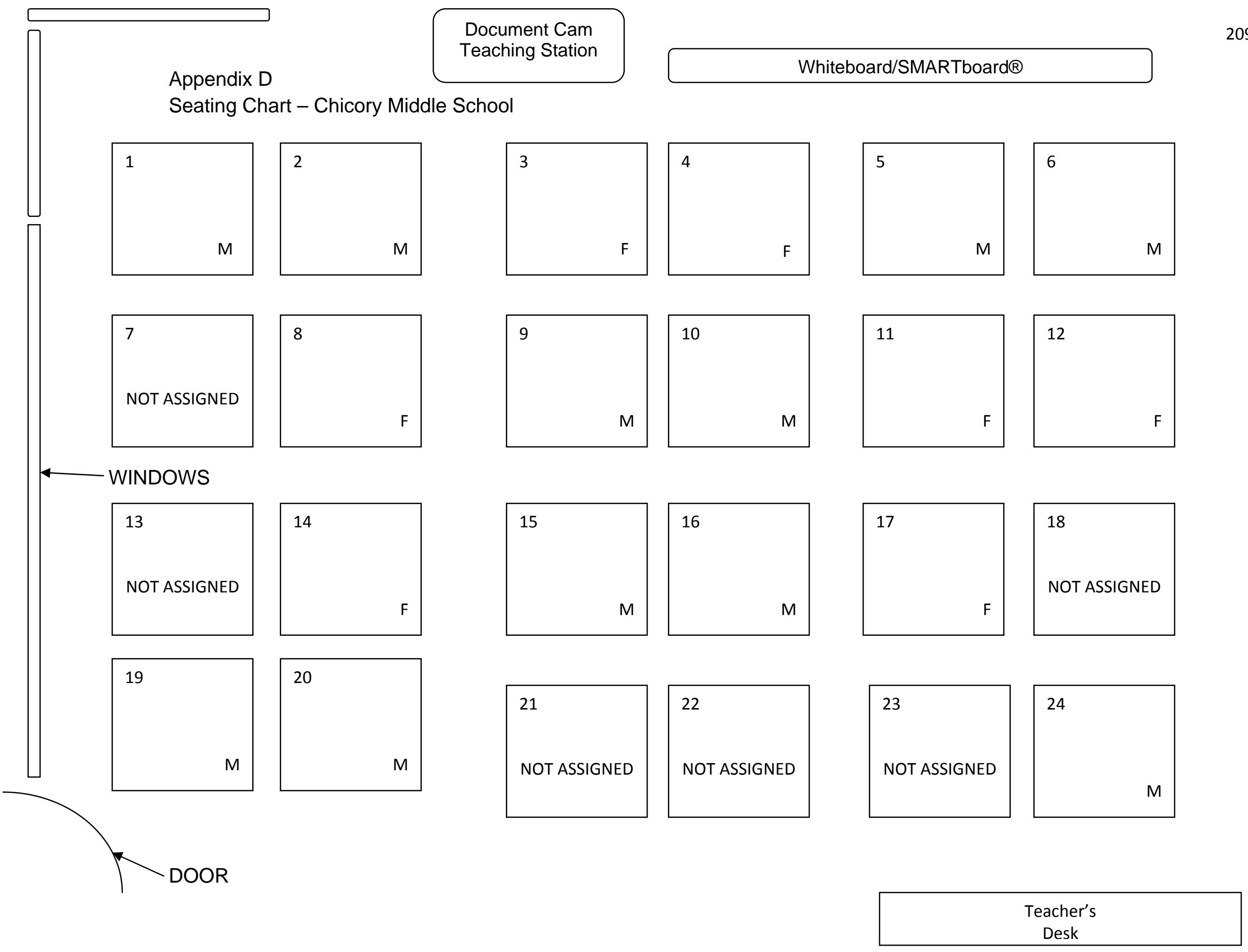


Appendix E

Seating Chart - Coalton Middle School
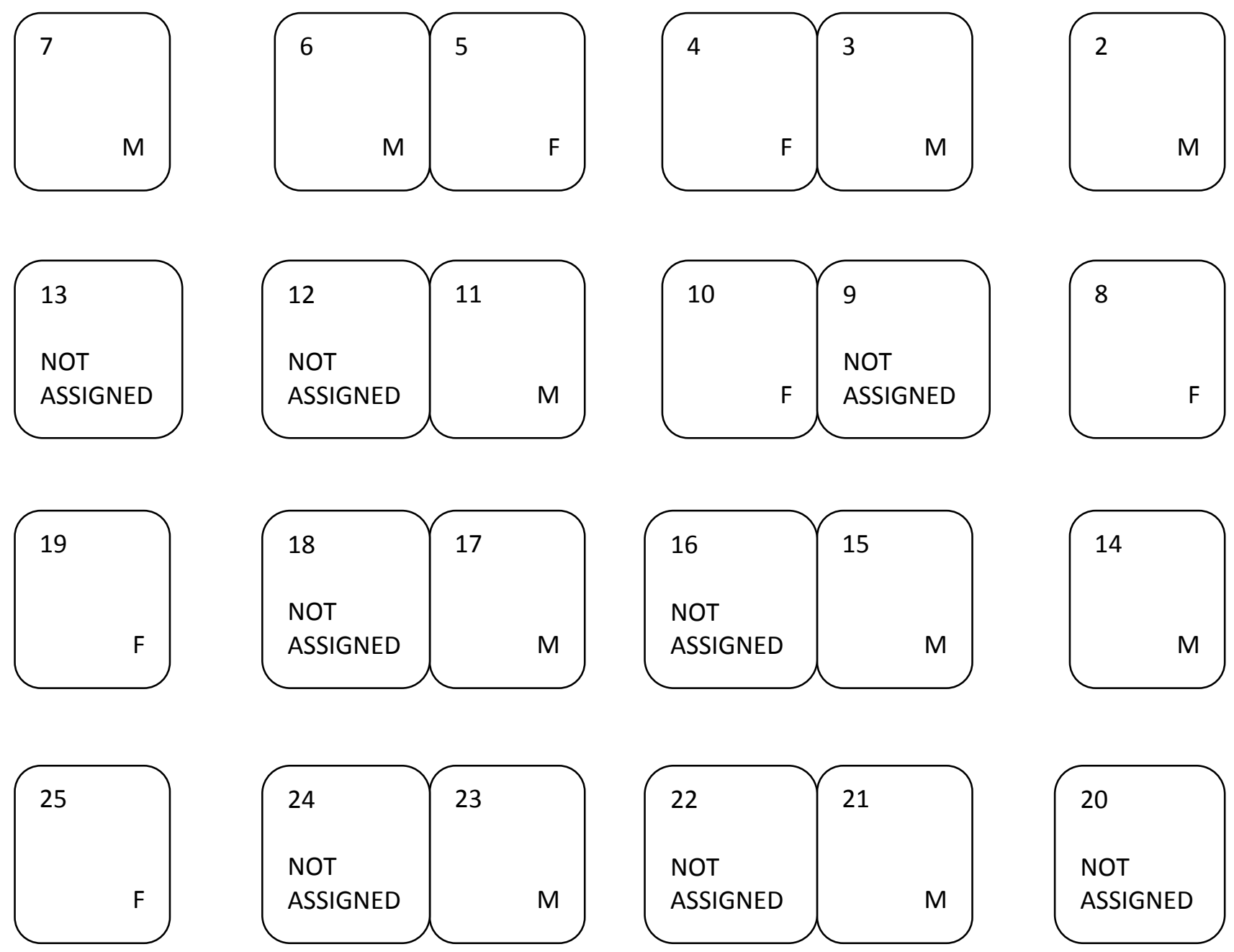

20
NOT
ASSIGNED

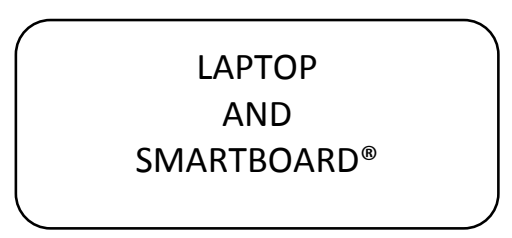




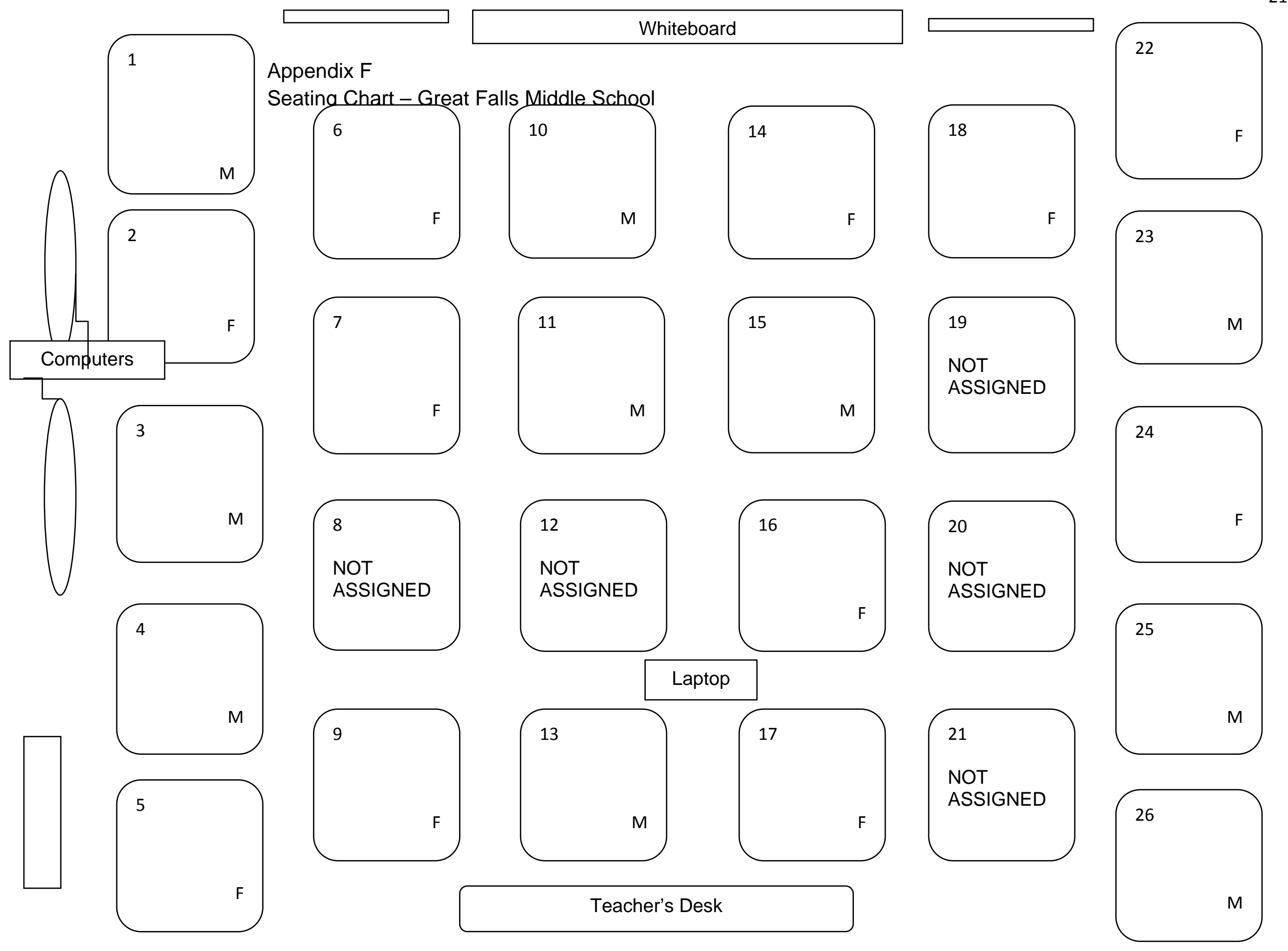



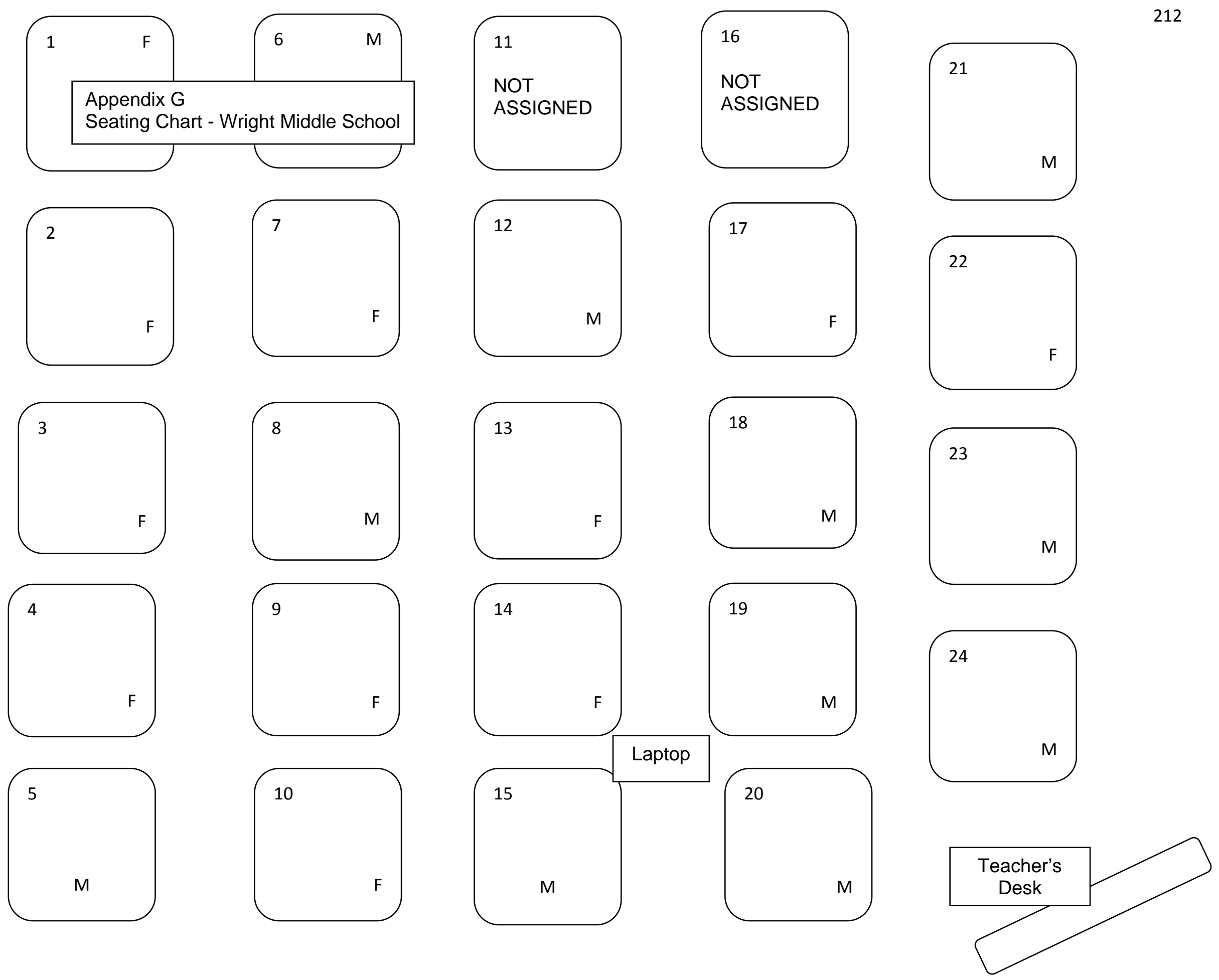
Appendix $\mathrm{H}$

Interview Protocol 2

Second Interview

Date: ___ ___ School: A B C D Teacher: SPED GENED

Greetings! Thank you for participating in this research study. The purpose of the study is to examine the frequency and types of interactions that occur between co-teachers and their students during inclusive classroom instruction.

This study is being conducted in partial fulfillment of my doctoral program at West Virginia University. I would like to digitally record this interview in order to accurately represent what you say. May I have your permission to record this interview?

Before we begin I want to make sure you understand the following:

- Your responses will be kept confidential; at no time will your name be revealed during reporting.

- Your name will not be attached to either the audio or notes from this interview, or to transcribed data.

- Your participation is entirely voluntary; you can choose to stop the interview at any time, and you do not have to answer every question.

- Your job status will not be affected by your refusal to participate or to withdraw from the study.

- At the end of this study, digital recordings of your interview will be deleted from all computer and recorder files.

- West Virginia University's Institutional Review Board's acknowledgement of this study is on file.

- Should you wish to have additional information regarding the study or the results of the study, please email either Dr. Jacqueline Webb-Dempsey at Jaci.Webb-Dempsey@mail.wvu.edu or Nancy G. Burton at nburton@mix.wvu.edu

Thank you again for your willingness to participate in this study. 


\section{Planning and Use of Technology}

1. Explain how you plan for each class. How do you determine who leads instruction?

2. How do you determine when and how you will incorporate the use of technology?

3. How does the use of technology enhance your co-teaching/instruction?

4. What impact has the use of technology had on student learning/achievement during your co-taught class?

\section{Beliefs about Co-teaching}

5. If you could change anything about co-teaching, what would it be? Why?

6. Describe what you believe to be the benefits of co-teaching?

7. What would you identify as the disadvantages of co-teaching? Why?

8. With what aspects of co-teaching are you most comfortable? Least comfortable? 


\section{Impact on Students}

9. Describe a time when you believe co-teaching actually had a positive impact on a student or students.

10. Describe a time when you believe co-teaching actually had a negative impact on a student or students.

11. What impact do you believe co-teaching has on students with special learning needs?

12. What impact do you believe co-teaching has on non-disabled students?

\section{Questions Directly Related to Observations (directed to all participant pairs)}

13. Do you recall any particular incident with a student or students that you would like to elaborate on?

14. Do you recall any particular incident with each other that you would like to elaborate on? 
APPENDIX I

GENERAL EDUCATION TEACHER'S INTERACTIONS WITH INDIVIDUAL STUDENTS CHICORY MIDDLE SCHOOL

\begin{tabular}{|c|c|c|c|c|c|c|c|c|c|c|c|c|c|c|c|c|c|}
\hline $\begin{array}{c}\text { Student/ } \\
\text { Seat \# }\end{array}$ & $\begin{array}{c}\text { Absent } \\
\mathrm{x} / 5\end{array}$ & $A$ & $\mathrm{CF}$ & $\mathrm{CO}$ & $D$ & $E$ & EXP & $\mathrm{H}$ & $\mathrm{H} / \mathrm{J}$ & $\begin{array}{l}\text { IND } \\
\text { INST }\end{array}$ & $P$ & PM & $Q$ & $\mathrm{R}$ & $\mathrm{RA}$ & $S$ & TOTAL \\
\hline 1 & & 5 & 2 & 2 & & & & 1 & & & 1 & & & & & & 11 \\
\hline 2 & & 2 & & 6 & & & & 1 & & & & & & 1 & & & 10 \\
\hline 3 & & 2 & 3 & 4 & 2 & & & & & & & 1 & & & & & 12 \\
\hline 4 & $2 / 5$ & 5 & & 5 & & & & 1 & & & 3 & 0 & & & & & 14 \\
\hline 5 & & 1 & 1 & 2 & & & & & & 1 & & & & & & & 5 \\
\hline 6 & $1 / 5$ & 2 & 2 & & 1 & & & & & & & 1 & & & & & 6 \\
\hline 8 & & & & 1 & & & & & & & & & & 1 & & & 2 \\
\hline 9 & & 6 & 1 & 5 & 5 & & & & & 1 & 1 & 1 & & & & & 20 \\
\hline 10 & $2 / 5$ & 1 & 2 & 1 & 1 & 1 & & & & & & 1 & & & & & 7 \\
\hline 11 & $2 / 5$ & 2 & 2 & 3 & & & & & & & 1 & 2 & & & & & 10 \\
\hline 12 & & & 2 & 1 & & 1 & & & & & & & & & & & 4 \\
\hline 14 & $1 / 5$ & 1 & & 2 & & 1 & & & & & & & & & & & 4 \\
\hline 15 & & 3 & 2 & 5 & & & & & & & & & & & & & 10 \\
\hline 16 & & 2 & 2 & 3 & & & 1 & & 2 & & & 2 & & & & 1 & 13 \\
\hline 17 & $2 / 5$ & 1 & & 1 & & & & & & 1 & & 3 & & & & & 6 \\
\hline 19 & & 15 & & & & & & & 1 & 6 & 2 & 1 & & & & & 25 \\
\hline 20 & & 3 & & 2 & 3 & & & 4 & & & 2 & 2 & & & & & 16 \\
\hline 24 & $1 / 5$ & 2 & & & 5 & 2 & & 1 & & 1 & & 2 & & & & & 13 \\
\hline TOTAL & & 53 & 19 & 43 & 17 & 5 & 1 & 8 & 3 & 10 & 10 & 16 & & 2 & & 1 & 188 \\
\hline$\%$ & & $28 \%$ & $10 \%$ & $23 \%$ & $9 \%$ & $3.5 \%$ & $.5 \%$ & $4 \%$ & $2 \%$ & $5 \%$ & $5 \%$ & $8.5 \%$ & & $1 \%$ & & $.5 \%$ & \\
\hline
\end{tabular}

\section{$A=$ Assist}

$\mathrm{CF}=$ Corrective Feedback

$E=E n c o u r a g e$ to engage

$\mathrm{CO}=$ Called on to answer question

$\mathrm{D}=$ Discipline
EXP = Explanation by teacher

$\mathrm{H}=$ Called into hallway
$\mathrm{H} / \mathrm{J}=$ Humor/Joking

II = Individual Instruction

$\mathrm{P}=$ Praise

$\mathrm{PM}=$ Progress Monitoring
$Q=$ Question asked by teacher

$R=$ Responds to question

$\mathrm{R} / \mathrm{A}=$ Read Aloud

$\mathrm{S}=$ Social 
APPENDIX J

SPECIAL EDUCATION TEACHER'S INTERACTIONS WITH INDIVIDUAL STUDENT CHICORY MIDDLE SCHOOL

\begin{tabular}{|c|c|c|c|c|c|c|c|c|c|c|c|c|c|c|c|c|c|}
\hline $\begin{array}{c}\text { Student/ } \\
\text { Seat \# }\end{array}$ & $\begin{array}{c}\text { Absent } \\
x / 5\end{array}$ & A & $\mathrm{CF}$ & $\mathrm{CO}$ & $\mathrm{D}$ & $E$ & EXP & $\mathrm{H}$ & $\mathrm{H} / \mathrm{J}$ & $\begin{array}{l}\text { IND } \\
\text { INS }\end{array}$ & $P$ & PM & $\mathrm{Q}$ & $\mathrm{R}$ & $\mathrm{RA}$ & $\mathrm{S}$ & TOTAL \\
\hline 1 & & 3 & & & & & & & & & & & & & & & 3 \\
\hline 2 & & & & & & & & & & & & & 1 & & & & 1 \\
\hline 3 & & 2 & 2 & & & & & & & 2 & & & & & & & 6 \\
\hline 4 & $2 / 5$ & & & & & & & & & & & & & & & & \\
\hline 5 & & 2 & & & & & & & & 1 & 1 & & & & & 1 & 5 \\
\hline 8 & & & & & & & & & & & & & & & & 1 & 1 \\
\hline 9 & & & & 1 & 2 & & & & & & & & & & & & 3 \\
\hline 10 & $2 / 5$ & 1 & & & & & & & & & & 1 & & & & & 2 \\
\hline 11 & $2 / 5$ & 1 & & & & & & & & & & & & & & & 1 \\
\hline 12 & & 2 & & 1 & & & & & & & 1 & & & & & & 4 \\
\hline 14 & $1 / 5$ & 3 & 2 & & & & & & & & & & & & & & 5 \\
\hline \multicolumn{18}{|l|}{15} \\
\hline 17 & $2 / 5$ & 2 & & & & & & & & & & & & & & 1 & 3 \\
\hline 19 & & 7 & & & & & & & 1 & 3 & 1 & & & & & & 12 \\
\hline 20 & & 3 & 1 & & 1 & & & 3 & & 1 & 1 & 1 & 2 & & & 1 & 14 \\
\hline 24 & $1 / 5$ & 3 & & & 2 & & & & & 8 & & 1 & & & & 1 & 15 \\
\hline TOTAL & & 34 & 5 & 2 & 5 & & 1 & 3 & 2 & 17 & 6 & 3 & 3 & & & 6 & 87 \\
\hline$\%$ & & $40 \%$ & $6 \%$ & $2 \%$ & $6 \%$ & & $1 \%$ & $3 \%$ & $2 \%$ & $20 \%$ & $7 \%$ & $3 \%$ & $3 \%$ & & & $7 \%$ & \\
\hline
\end{tabular}

\section{$A=$ Assist}

$\mathrm{CF}=$ Corrective Feedback

$E=E$ courage to engage

$\mathrm{CO}=$ Called on to answer question

$\mathrm{D}=$ Discipline
EXP = Explanation by teacher

$\mathrm{H}=$ Called into hallway
$\mathrm{H} / \mathrm{J}=$ Humor/Joking

II = Individual Instruction

$\mathrm{P}=$ Praise

$\mathrm{PM}=$ Progress Monitoring
$Q=$ Question asked by teacher

$\mathrm{R}=$ Responds to question

$\mathrm{R} / \mathrm{A}=$ Read Aloud

$\mathrm{S}=$ Social 
APPENDIX K

GENERAL EDUCATION TEACHER'S INTERACTIONS WITH INDIVIDUAL STUDENTS

COALTON MIDDLE SCHOOL

\begin{tabular}{|c|c|c|c|c|c|c|c|c|c|c|c|c|c|c|c|c|c|}
\hline $\begin{array}{c}\text { Student/ } \\
\text { Seat \# }\end{array}$ & $\begin{array}{c}\text { Absent } \\
x / 4\end{array}$ & $A$ & $\mathrm{CF}$ & $\mathrm{CO}$ & $D$ & $E$ & EXP & $\mathrm{H}$ & $\mathrm{H} / \mathrm{J}$ & $\begin{array}{l}\text { IND } \\
\text { INST } \\
\end{array}$ & $P$ & PM & $Q$ & $\mathrm{R}$ & RA & $S$ & TOTAL \\
\hline 1 & & 1 & & & 4 & & & & & & & 1 & & & & 1 & 7 \\
\hline 3 & $1 / 4$ & 1 & & 2 & & & & & & & 1 & 3 & & & & & 7 \\
\hline 4 & & 1 & & 2 & & & & & & & & 1 & & & & & 4 \\
\hline 5 & & 2 & 1 & & 12 & & & & & & & 4 & 1 & & & & 20 \\
\hline 7 & & 5 & & 1 & & & & & & & & 2 & & & & & 8 \\
\hline 8 & & & & 3 & 1 & & & & & & & & & & & & 4 \\
\hline 10 & & & & 1 & & 1 & & & & & & & & & & & 2 \\
\hline 11 & & 1 & & 2 & 4 & 1 & & & & & & & & & & & 8 \\
\hline 14 & & 1 & & 1 & 1 & & & & & & & 1 & & & & & 4 \\
\hline 15 & & 4 & & 4 & & & & & & 1 & & 1 & 1 & & & & 11 \\
\hline $17 * *$ & & 5 & & 2 & & & & & & 1 & 2 & 1 & 2 & & & & 13 \\
\hline 21 & & 1 & & & 2 & & & & & & & & & & & 1 & 4 \\
\hline 23 & & 2 & & 1 & & & & & & & & 2 & & & & & 5 \\
\hline 25 & & 4 & & 2 & & & & & & & & 1 & 1 & & 1 & 2 & 11 \\
\hline TOTAL & & 38 & 2 & 25 & 31 & 2 & & & & 3 & 3 & 18 & 7 & & 2 & 5 & 136 \\
\hline$\%$ & & $28 \%$ & $1.5 \%$ & $18.5 \%$ & $23 \%$ & $1.5 \%$ & & & & $2 \%$ & $2 \%$ & $13 \%$ & $5 \%$ & & $1.5 \%$ & $4 \%$ & \\
\hline
\end{tabular}

$A=$ Assist

$\mathrm{CF}=$ Corrective Feedback

$E=$ Encourage to engage

$\mathrm{CO}=$ Called on to answer question

$\mathrm{D}=$ Discipline
$\mathrm{H} / \mathrm{J}=$ Humor/Joking

II = Individual Instruction

$\mathrm{P}=$ Praise

$\mathrm{PM}=$ Progress Monitoring
$Q=$ Question asked by teacher $\mathrm{R}=$ Responds to question

$\mathrm{R} / \mathrm{A}=$ Read Aloud

$\mathrm{S}=$ Social

\section{INDICATES STUDENT w/SLN INCLUDES 504* AND ESL*}


APPENDIX L

SPECIAL EDUCATION TEACHER'S INTERACTIONS WITH INDIVIDUAL STUDENTS

COALTON MIDDLE SCHOOL

\begin{tabular}{|c|c|c|c|c|c|c|c|c|c|c|c|c|c|c|c|c|c|}
\hline $\begin{array}{c}\text { Student/ } \\
\text { Seat \# }\end{array}$ & $\begin{array}{c}\text { Absent } \\
x / 4\end{array}$ & $A$ & $\mathrm{CF}$ & $\mathrm{CO}$ & D & $\mathrm{E}$ & EXP & $\mathrm{H}$ & $\mathrm{H} / \mathrm{J}$ & $\begin{array}{l}\text { IND } \\
\text { INST }\end{array}$ & $\mathrm{P}$ & PM & $Q$ & $\mathrm{R}$ & RA & $S$ & TOTAL \\
\hline 1 & & 5 & & 4 & 2 & & & & & & 1 & & & & & & 12 \\
\hline $2 *$ & & 3 & & 6 & 1 & 1 & & & & & 1 & & 1 & & & & 13 \\
\hline 3 & $1 / 4$ & & & 4 & & & & & & & 1 & & & & & & 5 \\
\hline 4 & & & & 3 & & & & & & & & & 1 & & & & 4 \\
\hline 5 & & 4 & 1 & & 4 & & & & & & & 3 & 1 & & & & 13 \\
\hline 7 & & 4 & & 4 & & & & & & & & 1 & & & & & 9 \\
\hline 8 & & & & 4 & & & & & & & & & & & & & 4 \\
\hline 10 & & 1 & 1 & 2 & & & & & & & & & & & & & 4 \\
\hline 11 & & & & 7 & 2 & & & & & & & 1 & & & & & 10 \\
\hline 14 & & & & 2 & & & & & & & & & & & & & 2 \\
\hline 15 & & 1 & & 4 & & & & & & & & & 1 & & & & 6 \\
\hline $17 * *$ & & 10 & 1 & 9 & & & & & & 3 & 1 & 1 & & & 1 & & 26 \\
\hline 21 & & 1 & & 3 & 4 & & & & & & & 1 & & & & & 9 \\
\hline 23 & & & & 4 & & & & & & & & & & & & & 4 \\
\hline 25 & & 3 & & 8 & 3 & 2 & & & & & & & & & & & 16 \\
\hline TOTAL & & 40 & 3 & 77 & 16 & 3 & & & & 3 & 7 & 8 & 6 & & 1 & 1 & 165 \\
\hline$\%$ & & $24 \%$ & $2 \%$ & $46 \%$ & $10 \%$ & $2 \%$ & & & & $2 \%$ & $4 \%$ & $5 \%$ & $4 \%$ & & $.5 \%$ & $.5 \%$ & \\
\hline
\end{tabular}

$A=$ Assist

$\mathrm{CF}=$ Corrective Feedback

$E=$ Encourage to engage

$\mathrm{CO}=$ Called on to answer question

$\mathrm{D}=$ Discipline

EXP = Explanation by teacher

$\mathrm{H}=$ Called into hallway
$\mathrm{H} / \mathrm{J}=$ Humor/Joking

II = Individual Instruction

$\mathrm{P}=$ Praise

$\mathrm{PM}=$ Progress Monitoring
$Q=$ Question asked by teacher $\mathrm{R}=$ Responds to question

$\mathrm{R} / \mathrm{A}=$ Read Aloud

$\mathrm{S}=$ Social

\section{INDICATES STUDENT W/SLN INCLUDES 504* AND ESL**}


APPENDIX M

GENERAL EDUCATION TEACHER'S INTERACTIONS WITH INDIVIDUAL STUDENTS GREAT FALLS MIDDLE SCHOOL

\begin{tabular}{|c|c|c|c|c|c|c|c|c|c|c|c|c|c|c|c|c|c|}
\hline $\begin{array}{c}\text { Student/ } \\
\text { Seat \# }\end{array}$ & $\begin{array}{c}\text { Absent } \\
x / 5\end{array}$ & A & $\mathrm{CF}$ & $\mathrm{CO}$ & $D$ & $\mathrm{E}$ & EXP & $\mathrm{H}$ & $\mathrm{H} / \mathrm{J}$ & $\begin{array}{l}\text { IND } \\
\text { INST }\end{array}$ & $P$ & PM & $Q$ & $\mathrm{R}$ & RA & $S$ & TOTAL \\
\hline 1 & & 1 & & & & & & & & & 1 & 2 & & & & & 4 \\
\hline 2 & & 1 & & 1 & & & & & & 1 & & & & & & & 3 \\
\hline 3 & $2 / 5$ & 1 & & & & & & & & & & 1 & & & & & 2 \\
\hline 4 & $1 / 5$ & 3 & & 1 & & & & & 3 & & & 1 & & & & & 8 \\
\hline 5 & $1 / 5$ & & & & & & & & 1 & & & & & & & & 1 \\
\hline 7 & $1 / 5$ & 1 & & & & & & & 1 & & & & & & & & 2 \\
\hline 9 & $1 / 5$ & & & & & & & & & & 1 & & & & & & 1 \\
\hline 10 & & & & 2 & 4 & & & & & & & 1 & & & & & 7 \\
\hline 11 & $2 / 5$ & 1 & & & & & & & & 1 & 1 & & & 1 & & & 4 \\
\hline 13 & & 9 & & & 2 & & & & 2 & & & 1 & & 1 & & & 15 \\
\hline 14 & $4 / 5$ & & & & 1 & & & & & & & & & & & & 1 \\
\hline 15 & & 2 & & 1 & 3 & & & & & & & & & & & & 6 \\
\hline 17 & $2 / 5$ & & & & 1 & & & & & & & & & & & & 1 \\
\hline 18 & $2 / 5$ & 1 & & & & & & & & & & & & & & & 1 \\
\hline 22 & & 2 & & 1 & 1 & & & & & & & 1 & & & & & 5 \\
\hline 23 & $4 / 5$ & & & & & & & & & & & & & & & & \\
\hline 24 & & & & & & & & & & & & & & 1 & & & 1 \\
\hline 25 & $2 / 5$ & 2 & & & & & & & 1 & 1 & & & & & & 1 & 5 \\
\hline 26 & $2 / 5$ & 2 & & 2 & 2 & & & & & & & & & 1 & & & 7 \\
\hline TOTAL & & 27 & & 9 & 15 & & & & 8 & 4 & 5 & 7 & & 4 & & 1 & 80 \\
\hline$\%$ & & $34 \%$ & & $11 \%$ & $19 \%$ & & & & $10 \%$ & $5 \%$ & $6 \%$ & $9 \%$ & & $5 \%$ & & $1 \%$ & \\
\hline
\end{tabular}

$A=$ Assist

$\mathrm{CF}=$ Corrective Feedback

$E=$ Encourage to engage

EXP $=$ Explanation by teacher

$\mathrm{CO}=$ Called on to answer question

$\mathrm{D}=$ Discipline
$\mathrm{H} / \mathrm{J}=$ Humor/Joking

II = Individual Instruction

$\mathrm{P}=$ Praise

$\mathrm{PM}=$ Progress Monitoring
$Q=$ Question asked by teacher

$\mathrm{R}=$ Responds to question

$\mathrm{R} / \mathrm{A}=$ Read Aloud

$\mathrm{S}=$ Social 
APPENDIX N

SPECIAL EDUCATION TEACHER'S INTERACTIONS WITH INDIVIDUAL STUDENTS GREAT FALLS MIDDLE SCHOOL

\begin{tabular}{|c|c|c|c|c|c|c|c|c|c|c|c|c|c|c|c|c|c|}
\hline $\begin{array}{c}\text { Student/ } \\
\text { Seat \# }\end{array}$ & $\begin{array}{c}\text { Absent } \\
x / 5\end{array}$ & $A$ & $\mathrm{CF}$ & $\mathrm{CO}$ & D & $E$ & EXP & $\mathrm{H}$ & $\mathrm{H} / \mathrm{J}$ & $\begin{array}{l}\text { IND } \\
\text { INST }\end{array}$ & $P$ & PM & $Q$ & $\mathrm{R}$ & RA & $S$ & TOTAL \\
\hline 1 & & 2 & & & & & & & & & & & & & & & 2 \\
\hline 2 & & 3 & & & & 1 & & & & & & & & & & & 4 \\
\hline 3 & $2 / 5$ & 3 & & & & & & & & & & 2 & & & & & 5 \\
\hline 4 & $1 / 5$ & 3 & & & & 1 & & & 1 & 2 & & & & & & & 7 \\
\hline 5 & $1 / 5$ & & & & & & & & 1 & & & & & & & & 1 \\
\hline 6 & $2 / 5$ & 3 & & & & & & & 1 & 1 & & & & & & & 5 \\
\hline 7 & $1 / 5$ & 8 & & 1 & & 1 & & & 1 & 1 & & & & & & & 12 \\
\hline 9 & $1 / 5$ & 1 & & & & & & & & 2 & & & & & & & 3 \\
\hline 10 & & 10 & & 2 & 1 & & & & & & & & & & & 2 & 15 \\
\hline 11 & $2 / 5$ & 10 & & 1 & & & & & & 1 & & 2 & & & & 1 & 15 \\
\hline 13 & & 7 & & 3 & 1 & & & & 6 & & & & & & & 3 & 20 \\
\hline 14 & $4 / 5$ & & & & & & & & & & & & & & & & \\
\hline 15 & & 3 & & & & & & & 1 & & & & & & & & 4 \\
\hline 16 & $1 / 5$ & 4 & & & & & & & & 3 & & 1 & & & & 1 & 9 \\
\hline 17 & $2 / 5$ & 2 & & & & & & & & & & & & & & & 2 \\
\hline 18 & $2 / 5$ & 1 & & & & & & & & & & 1 & & & & & 2 \\
\hline 22 & & 6 & & 4 & & & & & 2 & & & & & & & 1 & 13 \\
\hline 23 & $4 / 5$ & 1 & & & & & & & & & & & & & & & 1 \\
\hline 24 & & 4 & & 1 & & & & & & 1 & & & & & & & 6 \\
\hline 25 & $2 / 5$ & 6 & & & & & & & & & & & & & & 1 & 7 \\
\hline 26 & $2 / 5$ & 1 & & & & & & & & & & & & & & & 1 \\
\hline TOTAL & & 78 & & 12 & 2 & 3 & & & 13 & 11 & & 6 & & & & 9 & 134 \\
\hline$\%$ & & $58 \%$ & & $9 \%$ & $1 \%$ & $2 \%$ & & & $10 \%$ & $8 \%$ & & $5 \%$ & & & & $7 \%$ & \\
\hline
\end{tabular}

$A=$ Assist

$E=$ Encourage to engage

$\mathrm{CF}=$ Corrective Feedback $\quad \mathrm{EXP}=$ Explanation by teacher

$\mathrm{CO}=$ Called on to answer question

$\mathrm{D}=$ Discipline
$\mathrm{H} / \mathrm{J}=$ Humor/Joking

II = Individual Instruction

$\mathrm{P}=$ Praise

$\mathrm{PM}=$ Progress Monitoring
$Q=$ Question asked by teacher $R=$ Responds to question

$\mathrm{R} / \mathrm{A}=$ Read Aloud

$\mathrm{S}=$ Social
INDICATES STUDENT w/SLN 
APPENDIX O

GENERAL EDUCATION TEACHER'S INTERACTIONS WITH INDIVIDUAL STUDENTS WRIGHT MIDDLE SCHOOL

\begin{tabular}{|c|c|c|c|c|c|c|c|c|c|c|c|c|c|c|c|c|c|}
\hline $\begin{array}{l}\text { Student/ } \\
\text { Seat \# }\end{array}$ & $\begin{array}{c}\text { Absent } \\
x / 5\end{array}$ & $A$ & $\mathrm{CF}$ & $\mathrm{CO}$ & $\mathrm{D}$ & $E$ & EXP & $\mathrm{H}$ & $\mathrm{H} / \mathrm{J}$ & II & $\mathrm{P}$ & PM & $Q$ & $\mathrm{R}$ & RA & $S$ & TOTAL \\
\hline 1 & & 7 & 1 & 3 & & 2 & & & & 1 & & 2 & & & & & 16 \\
\hline 2 & $1 / 5$ & 2 & & 3 & & & & & & & & & & & & & 5 \\
\hline 3 & $2 / 5$ & & & & & & & & & & & & & & & & \\
\hline 4 & & & 1 & 4 & & & & & & & & & & & & & 5 \\
\hline 5 & $3 / 5$ & & & 3 & & & & & & & & & & & & & 3 \\
\hline 6 & $1 / 5$ & 1 & & 3 & & & & & & & & 1 & & & & & 5 \\
\hline 7 & & 1 & 1 & 3 & & & & & & & & & & & & & 5 \\
\hline 8 & $1 / 5$ & & 1 & & & & & & & & & & 1 & & & & 2 \\
\hline 9 & & & 1 & 1 & & & & & & & & & & & & & 2 \\
\hline 10 & $1 / 5$ & & 1 & 3 & & & & & & & & & & & & & 4 \\
\hline 12 & & 1 & 1 & 3 & & & & & & & & & & & & & 5 \\
\hline 13 & $1 / 5$ & & 1 & 2 & & & & & & & & & 1 & & & & 4 \\
\hline 14 & $1 / 5$ & 1 & & 6 & & & & & & & & 1 & 1 & & & & 9 \\
\hline 15 & & 1 & 1 & 1 & & & & & & & & 1 & & & & & 4 \\
\hline 16 & & & & & & & & & & & & & & & & & \\
\hline 17 & $3 / 5$ & 1 & 2 & 3 & & & & & & & & & & & & & 6 \\
\hline 18 & & & 1 & 4 & & & & & & & & & & & & & 5 \\
\hline 19 & & 2 & 1 & 1 & & & & & & & & 1 & & & & & 5 \\
\hline 20 & $1 / 5$ & 1 & 1 & 2 & & & & & & & & 1 & & & & & 5 \\
\hline 21 & $1 / 5$ & & 1 & 3 & & & & & & & & & & & & & 4 \\
\hline 22 & & 1 & 1 & 3 & & & & & & & & & & & & & 5 \\
\hline 23 & & & 1 & 3 & & & & & & & & & & & & & 4 \\
\hline 24 & $1 / 5$ & 1 & 1 & 1 & & 1 & & & & & & 1 & & & & & 5 \\
\hline TOTAL & & 20 & 18 & 55 & & 3 & & & & 1 & & 8 & 37 & & & & 108 \\
\hline$\%$ & & $18 \%$ & $17 \%$ & $51 \%$ & & $3 \%$ & & & & $1 \%$ & & $5 \%$ & $3 \%$ & & & & \\
\hline
\end{tabular}

$A=$ Assist

$\mathrm{CF}=$ Corrective Feedback

$E=E n c o u r a g e$ to engage

$\mathrm{CO}=$ Called on to answer question

$\mathrm{D}=$ Discipline
EXP $=$ Explanation by teacher
$\mathrm{H}=$ Called into hallway
$\mathrm{H} / \mathrm{J}=$ Humor/Joking

$\mathrm{II}=$ Individual Instruction

$\mathrm{P}=$ Praise

$\mathrm{PM}=$ Progress Monitoring
$Q=$ Question asked by teacher

$\mathrm{R}=$ Responds to question

$\mathrm{R} / \mathrm{A}=$ Read Aloud

$\mathrm{S}=$ Social

INDICATES STUDENT w/SLN 
APPENDIX P

SPECIAL EDUCATION TEACHER'S INTERACTIONS WITH INDIVIDUAL

WRIGHT MIDDLE SCHOOL

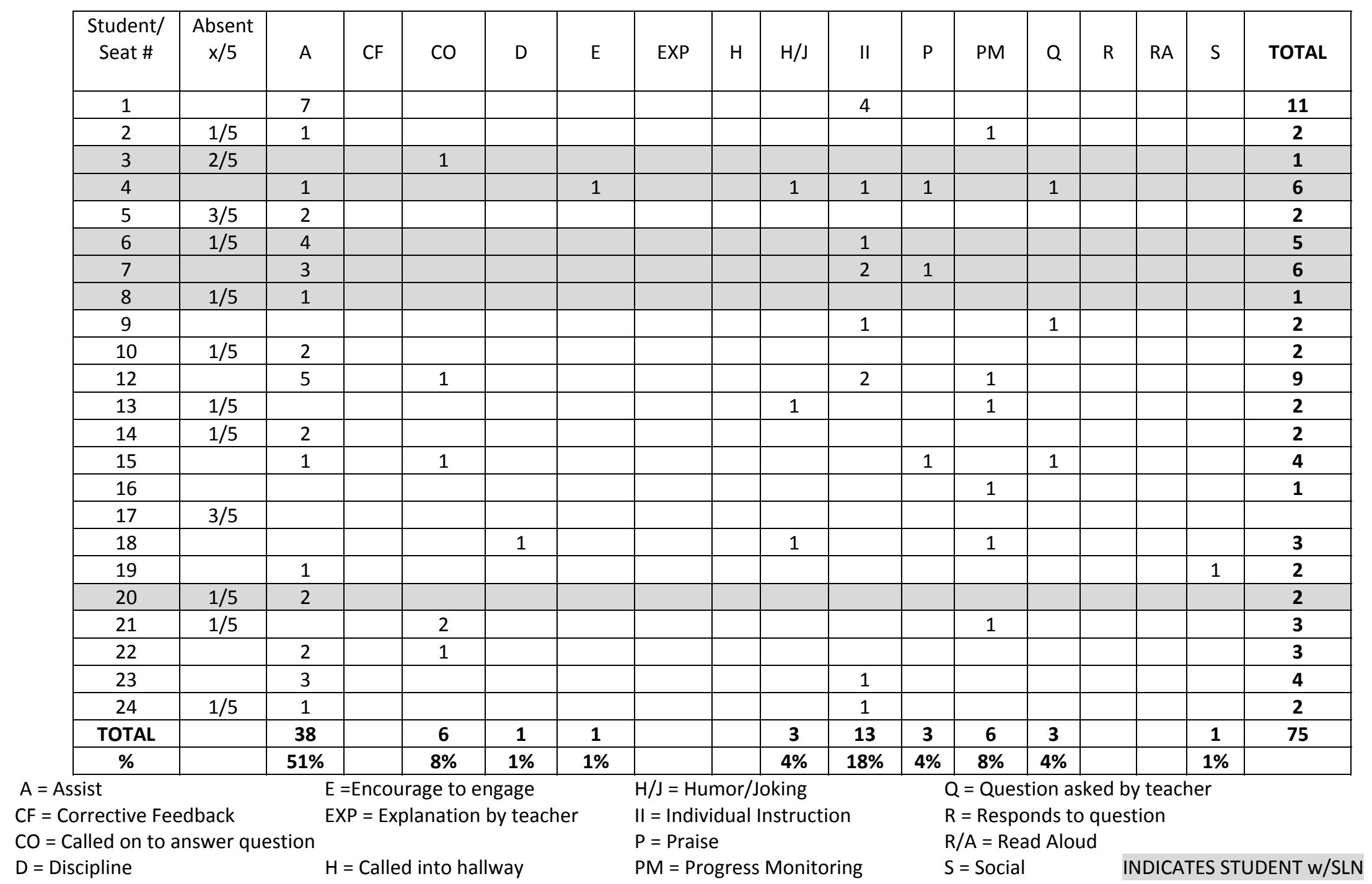

